\title{
THE ALPHA-MODIFIED \\ QUASI-SECOND ORDER \\ NEWTON-RAPHSON METHOD \\ FOR LOAD FLOW SOLUTIONS \\ IN RECTANGULAR FORM
}

\section{CENTRE FOR NEWFOUNDLAND STUDIES}

\section{TOTAL OF 10 PAGES ONLY MAY BE XEROXED}

(Without Author's Permission)

\section{OLIVER KEITH WELLON}



? 
THE ALPHA-MODIFIED QUASI-SECOND

ORDER NEWTON-RAPHSON METHOD FOR

LOAD FLOW SOLUTIONS IN RECTANGULAR

FORM

by

C 01 iver Keith Wellon, B. Eng.

A Thesis submitted in partial fulfillment of the requirements for the degree of Master of Engineering

Faculty of Engineering and Applied Science Memorial University of Newfoundland April, 1979

St. John's. Newfoundl and. 


\section{$\underline{\text { ABSTRACT }}$}

In this thesis a new class of methods for solving power system load flows is developed, which is called the alpha-modified quasi-second order Newton-Raphson (alpha - M.Q.S.O.N.R.) class.

The theory is derived from the Taylor expansion for multivariable functions and is developed using rectangular coordinates. The first part of the theory is actually the Newton-Raphson algorithm. This is expanded by including the second order terms from the Taylor expansion to produce a quasi-second order Newton-Rahpson solution method. The theory is then further modified to yield the more general alpha-modified me thod.

Extensive testing is performed using the new method for seven different power systems. The same systems are rerun with the Newton-Raphson so that a comparison can be made and the new method's relative merit judged. The rate of convergence is studied, as well as the mismatch values which occur during the load flows. This is done for many different values of alpha and for the different systems. The results are analysed and discussed in detail with the main result being that the alpha M.Q.S.O.N.R. method tested, with alpha equal to zero, is superior to the Newton-Raphson . 


\section{AC KNOWLEDGEMENTS}

The basic idea for this thesis was originally introduced to the author by his supervisor, Dr. Mohamed El-Hawary. The genuine interest he displayed and the help he gave throughout the author's research was an invaluable aid in bringing this work to a successful conclusion, and is greatly appreciated.

Another person deserving mention is Gary Somerton, programer analysist with the Newfoundland and Labrador Computer Services. His expertise led the author out of the dark on a number of occasions.

The author is extremely thankful for the financial support of the National Research Council of Canada, of Memorial University of Newfoundland in providing the Hatcher Memorial Scholarship and of the Engineering Department in providing teaching assistantships. Without this, the strain of financial burden would have indeed been great.

The author's gratitude is extended to his wife, Glenda, who not only gave her moral support, but also tangible support in tabulating the results and proofreading.

Because there is quite a large number of equations in this thes is, the author was finding it extremely difficult to locate someone willing to type the manuscript. He is thankful to Karen Murphy who did attempt the job, but was unable to do more than one chapter. However, rescue did come at the last minute when four typists within the Engineering Department offered to share the typing load. This touching gesture has earned the author's eternal gratitude for the work performed by Brenda Walsh, Edwina Newhook, Pat Gibson, and Janet Coffen. 
TABLE OF CONTENTS

PAGE NO.

\begin{tabular}{|c|c|c|}
\hline & ABSTRACT & $\mathrm{i} i$ \\
\hline & ACKNOWLEDGEMENTS & $\mathrm{i} i \mathrm{i}$ \\
\hline & LIST OF TABLES & $v i \mathrm{i}$ \\
\hline & LIST OF FIGURES & $i x$ \\
\hline & LIST OF SYMBOLS & $x i$ \\
\hline CHAPTER I & INTRODUCTION & 1 \\
\hline \multirow[t]{5}{*}{1.1} & Background & 1 \\
\hline & 1.1.1 Definition of Load Flow & 1 \\
\hline & 1.1.2 Uses for Load Flow Calculations & 1 \\
\hline & 1.1.3 A Brief History of Load Flow & 2 \\
\hline & 1.1.4 Impetus for this Thes is & 3 \\
\hline 1.2 & Scope of this Thes is & 4 \\
\hline CHAPTER II & SOME BASIC DEVELOPMENTS & 6 \\
\hline 2.1 & Introduction & 6 \\
\hline 2.2 & \multicolumn{2}{|l|}{ Introduction to the Newton-Raphson } \\
\hline & Me thod & 6 \\
\hline 2.3 & Modeling of the Power System & 7 \\
\hline 2.4 & \multicolumn{2}{|l|}{ Formulation of the Static Load Flow } \\
\hline & Equations & 12 \\
\hline & 2.4 .1 Introduction & 12 \\
\hline & \multicolumn{2}{|l|}{$\begin{array}{l}\text { 2.4.2 Derivation of the Load Bus } \\
\text { Equations }\end{array}$} \\
\hline & \multicolumn{2}{|l|}{$\begin{array}{l}\text { 2.4.3 Derivation of the Voltage Controlled } \\
\text { Bus Equations }\end{array}$} \\
\hline & 2.4.4 The Slack Bus & 15 \\
\hline & 2.4 .5 Summary & 16 \\
\hline
\end{tabular}


2.5 Formulation of the Newton-Raphson

Method in Rectangular Coordinates $\quad 16$

2.5.1 Solution Criteria 16

2.5.2 Formulation for the Load Buses 17

2.5.3 Formulation for the Voltage Controlled Buses

2.5.4 Step by Step Procedure

20

CHAPTER III DERIVATION OF SOME ALPHA-MODIFIED

QUASI-SECOND ORDER NEWTON-RAPHSON

METHODS 23

3.1 Introduction 23

3.2 Description of the Method 23

3.3 Formulation of the Quasi-Second Order

Newton-Raphson Method in Rectangular Form 24

3.3.1 Derivation of the Active Power

Second Order Correction Factors 24

3.3.2 Derivation of the Reactive Power Second Order Correction Factors 30

3.3.3 Derivation of the Voltage Magnitude Second Order Correction Factors

3.3.4 Step by Step Procedure 36

3.4 Formulation of the Alpha-Modified Quasi-

Second Order Newton-Raphson Method 38

3.4.1 Introduction 38

3.4.2 Alpha - M.Q.S.O.N.R. Method Number One 


$$
\text { 3.4.3 Alpha - M.Q.S.O.N.R. Me thod }
$$
Number Two

3.4.4 Alpha - M.Q.S.O.N.R. Me thod Numbers Three and Four

CHAPTER IV APPLICATION AND ANALYSIS OF THE

ALPHA-MODIFIED QUASI-SECOND ORDER

NEWTON-RAPHSON METHOD FOR SOLVING LOAD

FLOW PROBLEMS

4.1 Sparsity

4.2 The Computer Program 52

4.2.1 General 52

4.2.2 Definition of One-Half Iteration 55

4.2.3 program Limitations 56

4.3 The Test Systems 57

4.3.1 5-Bus Power Sys tem 57

4.3.2 23-Bus Power System 57

4.3.3 IEEE 57-Bus Test System 57

4.3.4 IEEE 118-Bus Test System 58

4.3.5 Other Test Systems 58

$\begin{array}{llr}4.4 & \text { Results } & 59\end{array}$

4.4.1 General 59

4.4.2 Iterations to Convergence 59

4.4.3 Bus Mismatches during Load Flows 70

4.4.4 Importance of the initial Values for Bus Voltages $\quad 78$ 
PAGE NO.

CHAPTER V CONCLUDING REMARKS

5.1 Conclusions

84

$5.2 \quad$ Future Work

85

BIBL IOGRAPHY AND REFERENCES

88

$\begin{array}{lll}\text { APPENDIX A JACOBIAN ELEMENTS } & 97\end{array}$

$\begin{array}{lll}\text { APPENDIX B HESSIAN ELEMENTS } & 100\end{array}$

$\begin{array}{lll}\text { APPENDIX C SUBROUTINE SPECIFICATION SHEETS } & 106\end{array}$

APPENDIX D COMPUTER PROGRAM VARIABLE

$\begin{array}{ll}\text { NAMES AND DIMENSIONS } & 121\end{array}$

$\begin{array}{lll}\text { APPENDIXE PROGRAM LISTING } & 131\end{array}$

$\begin{array}{lll}\text { APPENDIX F } & 167\end{array}$

APPENDIX G MAXIMUM MISMATCHES DURING LOAD FLOWS 191 


\section{LIST OF TABLES}

TABLE

TITLE

PAGE NO.

4.1 Number of Iterations to Convergence for

Various Alpha Values and Various Systems

80

G.1 Maximum Per Unit Mismatches after each

Iteration for the 5-Bus System

192

G.2 Maximum Per Unit Mismatches after each

Iteration for the 23-Bus System

195

G.3 Maximum Per Unit Mismatches after each

Iteration for the IEEE 57-Bus System

199

G.4 Maximum Per Unit Mismatches after each

Iteration for the IEEE 118-Bus System

205

G.5 Maximum Per Unit Mismatches after each

Iteration for the 5-Bus (No. V.C.B.) System

G.6 Maximum Per Unit Mismatches after each

Iteration for the 57-Bus (No. V.C.B.) System

G.7 Maximum Per Unit Mismatches after each

Iteration for the 118-Bus (No.V.C.B.)

Sys tem

G.8 Maximum Per Unit Mismatches after each

Iteration for the 118-Bus System with

Initial Voltage Angles not Equal to Slack

Bus Voltage Angle. 


\section{LIST OF FIGURES}

FIGURE

2.1

2.2

2.3 Equivalent Model of the Line with the Transformer of Figure 2.2

PAGE NO.

8

General Flow Chart for the Alpha - M.Q.S.O.N.R. Me thod and 0.001 p.u.

4.3 Number of I terations to Convergence for the 23Bus System with Tolerances of $0.0001 \mathrm{p} . \mathrm{u}$. and 0.001 p.u.

4.4 Number of Iterations to Convergence for the IEEE 57-Bus System with Tolerances of 0.0001 p.u. and 0.001 p.u.

4.5 Number of Iterations to Convergence for the IEEE 118-Bus System with Tolerances of 0.0001 p.u. and 0.001 p.u.

4.6 Number of Iterations to Convergence for the 5-Bus (No. V.C.B.) System with Tolerances of 0.0001 p.u. and 0.001 p.u.

4.7 Number of Iterations to Convergence for the 57-Bus (No. V.C.B.) System with Tolerances of 0.0001 p.u. and 0.001 p.u.

4.8 Number of Iterations to Convergence for the 118-Bus System (No. V.C.B.) with Tolerances of 0.0001 p.u. and 0.001 p.u.

4.9 Number of Iterations to Convergence for the 118-Bus System with Bus Angles Initially set to 0.0 Degrees (The Slace Bus has a Voltage Angle of 30.0 Degrees)

4.10 Convergence Patterns of Load Flows of the 5-Bus System

4.11 Convergence Patterns of Load Flows of the 23-Bus System 
4.12 Convergence Patterns of Load Flows of the IEEE 57-Bus System

4.13 Convergence Patterns of Load Flows of the IEEE 118-Bus System

4.14 Convergence Patterns of Load Flows of the 5-Bus (No. V.C.B.) System

4.15 Convergence Patterns of Load Flows of the 57-Bus (No. V.C.B.) System

4.16 Convergence Patterns of Load Flow of the 118-Bus (No. V.C.B.) System 


\section{LIST OF SYMBOLS}

${ }_{p q}$

$e_{p}$

$\Delta e_{i}$

$\Delta \mathrm{e}_{\mathrm{i}}^{\mathrm{i}}$

$f_{p}$

$\Delta \mathrm{f}_{\mathrm{i}}$

$\Delta \bar{F}_{i}{ }^{\prime}$

fi

$G_{p q}$

$\mathrm{H}_{\mathrm{i}}$

$I_{p}$

$1 \mathrm{p} *$

J

M.Q.S.O.N.R.

N.R.

n

no V.C.B.

$P_{p}$

Psched
Active portion of the sum of the admittances connected to bus $p$ between it and bus $q$, on a single line representation of the power system.

Active portion of the complex bus voltage of bus $p$.

Voltage correction for the active portion of the vol tage at bus i.

Updated voltage correction for the active portion as calculated using the second order correction factors.

Reactive portion of the complex bus voltage of bus $p$.

Voltage correction for the reactive portion.

Updated voltage correction for the reactive portion.

The set of simultaneous load flow equations for the Taylor expansion.

Reactive portion of the sum of the admittances connected to bus $p$ between it and bus $q$, on a single line representation of the power system.

Hessian matrix of second order derivatives.

Sum of currents flowing into bus $p$.

Con jugate of $\mathrm{I}_{\mathrm{p}}$.

Jacobian matrix of first order derivatives

Modified quasi-second order Newton-Raphson .

Newton-Raphson .

Number of buses in system.

There are no. voltage controlled buses other than the slack bus.

Total injected active power into bus $p$.

Scheduled active power at bus $p$. 


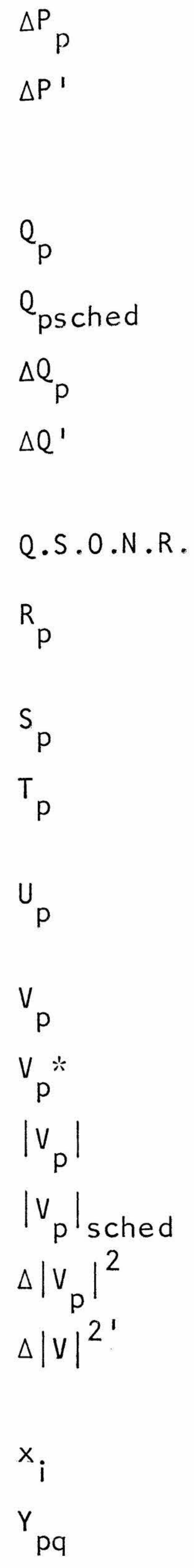

$\alpha$
Active power mismatch for bus $p$.

Updated active power bus mismatch matrix as calculated using the second order correction factors.

Total calculated reactive power at bus $p$.

Scheduled reactive power at bus $p$.

Reactive power mismatch for bus $p$.

Updated reactive power bus mismatch matrix as calculated with the second order correction factor.

Quasi-second order Newton-Raphson.

Active power second order correction factor for bus $p$.

Total calculated complex power at bus $p$.

Reactive power second order correction factor for bus $p$.

Square of voltage magnitude second order correction factor for bus $p$.

Voltage at bus $p$.

Conjugate of $\mathrm{V}_{\mathrm{p}}$.

Magnitude of $\mathrm{V}_{\mathrm{p}}$.

Scheduled voltage magnitude for bus $p$.

Square of voltage magnitude mismatch for bus $p$.

Updated square of voltage matnitude matrix as calculated using second order ocrrection factors.

Variables in Taylor expansion.

Complex sum of all admittances connected to bus $p$ of a line between it and bus $q$, on a single line representation of the power system. This is also the $\mathrm{p}-\mathrm{q}$ th element of the bus admittance matrix.

Alpha, the variable whose value determines what portion of the second order correction factors are applied to the updating of the bus mismatches and what portion applied to the updating of the Jacobian submatrices diagonal elements. 
$\Delta \mathrm{i}, \Delta \mathrm{x}_{\mathrm{i}}$ $\underline{\Delta}^{\top}$

$\xi$
Variable corrections of the Taylor expansion. Transpose of the variable correction matrix.

Tolerance required in order that convergence criterion be met. 


\section{CHAPTER I}

INTRODUCTION

\subsection{Background}

1.1.1 Definition of Load Flow

Load flow (or power flow) is the most frequently performed of routine digital-computer power network calculations. A load flow program is used to determine the powerflow, both real and imaginary, over transmission 1 ines and the corresponding bus voltages across the system. This calculation is a steady state solution or snapshot of the system under one specific condition and configuration. A configuration describes the system connections, such as the particular lines connected and generating stations on line. The system conditions describe the magnitude of load and the generation schedule to meet the load. Simply put, load flow is therefore defined as the solution for the static operating condition of an electric power transmission system.

\subsubsection{Uses for Load Flow Calculations}

Load flow calculations are performed in power system planning, operational planning, and operation control. It is necessary to use them to see the effects on the whole system of, and help determine, network changes involving:

1. plant site selection

2. plant size and number of units

3. operation of plant (i.e., base load or peak)

4. routing of new transmission lines

5. location, and voltage level, of new area interconnections 
6. bulk power transfer capability

7. size and location of capacitors and reactors for reactive compensation

8. contingency evaluation due to temporary loss of generation and/or transmission circuits

Over the past decade, load flow calculations have also been utilized more and more in optimization and stability studies in electric power systems.

\subsubsection{A Brief History of Load Flow}

Twenty-Five years ago all electrical networks were solved either by hand or by a network analyser. The analyser was simply an electrical analogue device which scaled down the electrical quantities of a system. It is now obsolete as a tool for routine studies of power systems and is relegated to the worthwhile role of an educational tool.

This rapid demise of the "analogue calculator" started in 1956 when the first truly successful (i.e., practical) automatic digital simultaneous quadratic equations solution method was developed by Ward and Hale [71]. Their method was an approximation to the Newton iterative technique using rectangular form which allowed it to be run on the small-memory computer by neglecting the off-diagonal elements of the Jacobian submatrices and also by using the admittance matrix formulation. Using this as a basis, the programs, which immediately followed, implemented the Gauss-Seidel algorithm, introduced by Glimn and Stagg [33], and were accepted by the power industry. Other methods were also proposed such as Jordan's relaxation method [39] and zero mismatch methods, but Gauss-Seidel's became the industry standard. 
Unfortunately, Gauss-Siedel requires a large number of iterations to obtain a solution and this number increases with system size. Also, the algorithm is such, that any adjustments made in an iteration take several more iterations to propagate their effect throughout the system. This sometimes leads to convergence problems.

In the early 1960's the Bonneville Power Administration (B.P.A.) was engaged in research involving the Newton-Raphson method, which had been shown to have very powerful convergence properties [72], [73], [74], but poor computational efficiency. In 1963, Sato and Tinney of B.P.A. publicly introduced the concept of optimally ordered elimination for the solution of large, general, sparse networks, and showed such methods were very efficient for solving large power system problems [53]. The mathematics behind the concept are concisely summarized in [63] and [65]. This constituted a major break-through in power system network computation, with the original application being to dramatically improve the computing speed and storage requirements of the Newton-Raphson method [64]. As a result, this method is now widely regarded as the preeminent general-purpose load flow approach, and has been adopted by much of the power industry.

\subsubsection{Impetus for This Thesis}

With the stimulus of increasing problem:sizes, on-line applications, system optimization, and the fact that there is no "best" method for all systems, the development of faster and more efficient algorithms for solving load flows continues to be the object of many research efforts. Recently Sachdev and Medicherla introduced the second order Newton- 
Raphson (S.O.N.R.) method for load flow solutions [46]. It was applied in polar form. In discussing that paper, El-Hawary and Vetter [29] suggest that employing the rectangular form may enhance convergence. This seems like a reasonable assumption. For quadratic functions, as the load flow equations are, the derivatives of order higher than two are zero. Thus, a second order Taylor expansion-based iteration, such as NewtonRaphson, will converge in one iteration in the single variable problem. The load flow problem is a multi-variable problem that normally requires more than one iteration to solve the nonlinear equations. The use of the polar form introduces trignometric functions, but with the rectangular form, terms beyond second order are zero, thus making the second order scheme exact, and likely superior.

\subsection{Scope of the Thesis}

In this thesis. a quasi-second order Newton-Raphson (Q.S.O.N.R.) load flow method in retangular coordinates, as suggested in [29], is developed. This then forms the basis for the formulation of the alphamodified quassi-second order Newton-Raphson (alpha-M.Q.S.O.N.R.) method.

Chapter II provides the theory upon which this thesis is based. First, the load flow problem is formulated in rectangular coordinates. Then, starting with the Taylor expansion for multivariable functions, the Newton-Raphson technique is evolved.

The derivation of the Q.S.O.N.R. is detailed in section 3.3. This is followed by the formulation of a number of alpha-modified second order schemes in section 3.4. The alpha - M.Q.S.O.N.R. method number one, der- 
ived in subsection 3.4 .2 , is the algorithm upon which most of the testing was performed.

Chapter IV details the application of this method to solving load flows for a number of test systems, which are described in section 4.3 . The next section presents and analyses the results obtained.

The last chapter summarizes the conclusions reached as a result of the testing, and suggests some areas in which further efforts could be applied. Seven appendices are included. These describe many aspects related to the development reported in the text. Among these are descriptions of test systems, derivative evaluations, program listings to mention a few. 


\section{CHAPTER II.}

\section{SOME BASIC DEVELOPMENTS}

\subsection{Introduction}

In this chapter, some background theory is developed which will form the basis for work reported in this thesis. The following section briefly introduces the theory of the Newton-Raphson technique which is the foundation for the methods developed in chapter 3 . Section 2.3 illustrates how a general power system is represented so that its parameters and variables can be used in the load flow solution methods effectively. Section 2.4 sets up the problem by formulating the static load flow equations of the system modeled in the previous section. The last section then derives the Newton-Raphson method in rectangular coordinates to the load flow equations.

\subsection{Introduction to the Newton-Raphson Method}

It is well known that the Newton-Raphson method is based on a Taylor expansion of multi-variable functions, where only the first order terms are considered. For a system of nonlinear equations, $f_{\mathfrak{i}}$, the Taylor expansion is,

$$
\begin{aligned}
f_{i}\left(x_{1}+\Delta_{1}, x_{2}+\Delta_{2}, \ldots\right) & =f_{i}\left(x_{1}, x_{2}, \ldots\right)+\frac{1}{1 !} \sum_{j=1}^{n} \Delta_{j} \frac{\partial f_{i}}{\partial x_{j}} \\
& +\frac{1}{2 !} \sum_{j=1}^{n} \sum_{k=1}^{n} \Delta_{j} \Delta_{k} \frac{\partial^{2} f_{i}}{\partial x_{j} \partial x_{k}} \\
& +\frac{1}{3 !} \sum_{j=1}^{n} \sum_{k=1}^{n} \sum_{\ell=1}^{n} \Delta_{j} \Delta_{k} \Delta_{\ell} \frac{\partial^{3} f_{i}}{\partial x_{j} \partial x_{k} \frac{1}{\partial x_{l}}} \\
& +. . \quad, \quad i=\ell, \ldots n
\end{aligned}
$$


The Newton-Raphson method uses only the first order approximation of the above expression, which leaves

$$
f_{i}\left(x_{1}+\Delta_{1}, x_{2}+\Delta_{2}, \ldots\right)-f_{i}\left(x_{1}, x_{2}, \ldots\right)=\sum_{j=1}^{n} \Delta_{j} \frac{\partial f_{i}}{\partial x_{j}}, i=1, \ldots, n
$$

In vector form this can be written as,

$$
\underline{\Delta f}=\underline{J} \underline{\Delta}
$$

and manipulated to obtain

$$
\underline{\Delta}=\underline{\mathrm{J}}^{-1} \underline{\Delta f}
$$

with which we can solve for the increments, $\Delta_{i}$. Here, $\underline{J}$ denotes the Jacobian matrix of first order partial derivatives. In the last section of this chapter, this method is employed in solving the static load flow equations for a general power system.

\subsection{Modeling of the power system}

Before developing the static load flow equations and the solution methods of concern, modeling of the power system must be discussed.

A balanced three-phase power system is assumed, and the transmission system is represented by its positive-phase-sequence network of 1 inear lumped series and shunt branches. Figure 2.1 represents a simple 3-bus system and illustrates the main types of buses as well as the main parameters and variables associated with each 1 ine and bus.

The symbols used in figure 2.1 are defined as follows:

$$
\begin{array}{ll}
S_{p}=P_{p}+j Q_{p} & \text { Power generation or power demand at bus } p \\
v_{p}=v_{p} L \theta_{p} & \text { Voltage at bus } p \text { (polar coordinates) } \\
z_{p q}=R_{p q}+j X_{p q} & \text { Series impedance of the transmission line between } \\
& \text { bus } p \text { and bus } q \\
x_{p o} & \text { Shunt reactors and or static capacitors at bus } p
\end{array}
$$




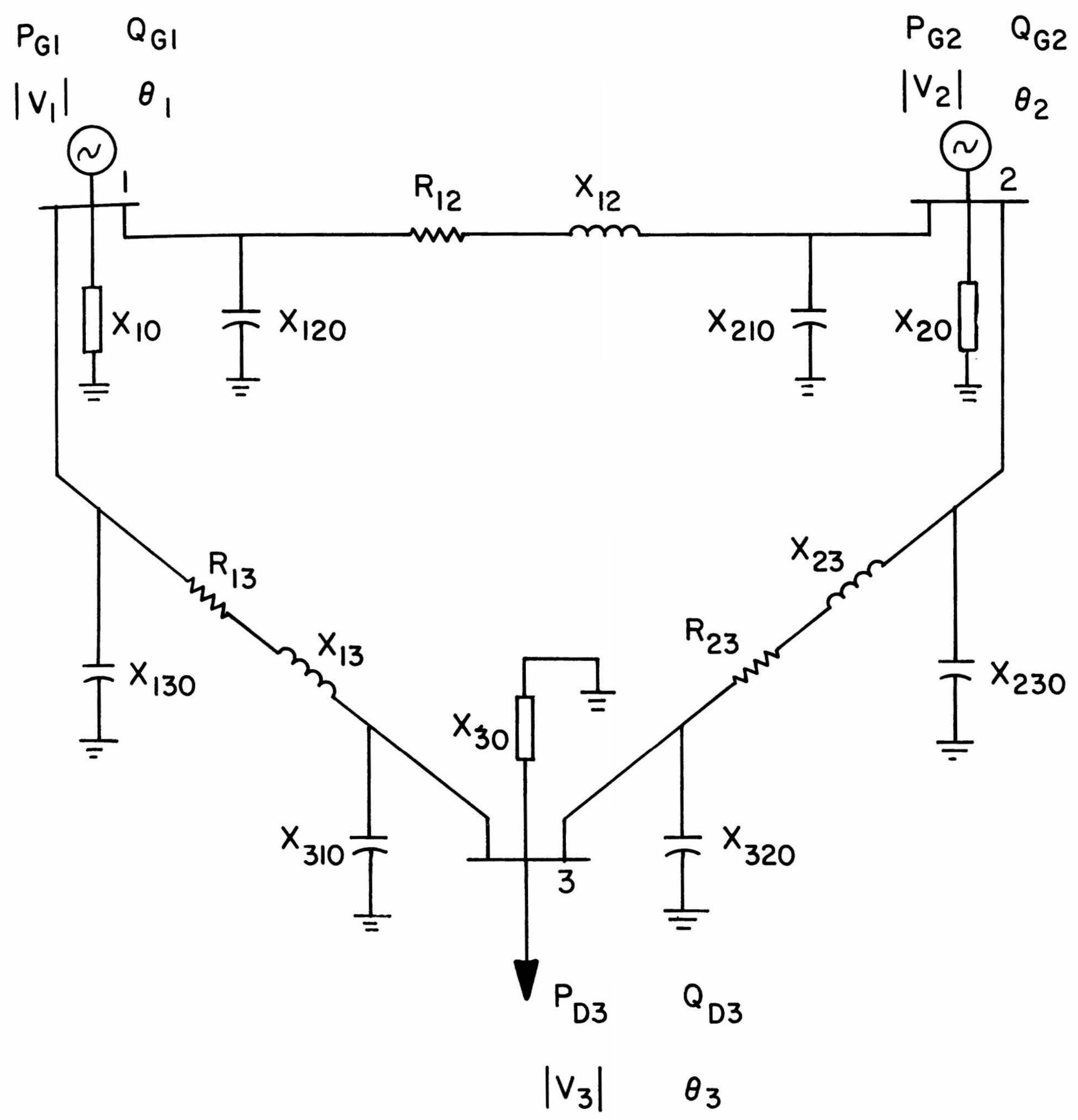

FIGURE 2.1 MODEL OF A 3-BUS POWER SYSTEM 
$x_{p q o}, x_{q p o}$

Transmission line shunt reactance. In a normal line, $\mathrm{x}_{\mathrm{pqo}}=\mathrm{x}_{\mathrm{qpo}}$ and their sum is the total $\mathrm{line}$ shunt reactance. $x_{\text {pqo }} \neq x_{\text {qpo }}$ if there is a tap setting transformer in tandem with the line.

Buses are categorized into three main types for load flow solution purposes:

(i) A load bus, such as bus 3 , has the total injected power, P, and the reactive power, $Q$, specified, while the voltage magnitude and angle are the unknowns to be solved for.

(ii) A voltage regulated bus (a generator bus), such as bus 1 or bus 2 , is one at which the total injected active power, P, is specified, and the voltage magnitude is maintained at a specified value by the reactive power injection, $Q$. Therefore $Q$ and the voltage angle, $\theta$, must be solved for.

(iii) The slack (or swing) bus. One of the generator buses, such as bus 1 , is taken as the slack bus. Because total line losses are not known before a load flow study, one bus must have the active and reactive power unspecified so that it can pick up "the slack"--the difference between the total injected power of all the other buses and the requirements of the system loads. The slack bus voltage angle is assigned as the system phase reference and is considered a known quantity. Being a voltage controlled bus, the voltage magnitude is also set and known.

If a line has a fixed tap setting transformer as shown in figure 2.2, the transmission line variables are manipulated in order to obtain 


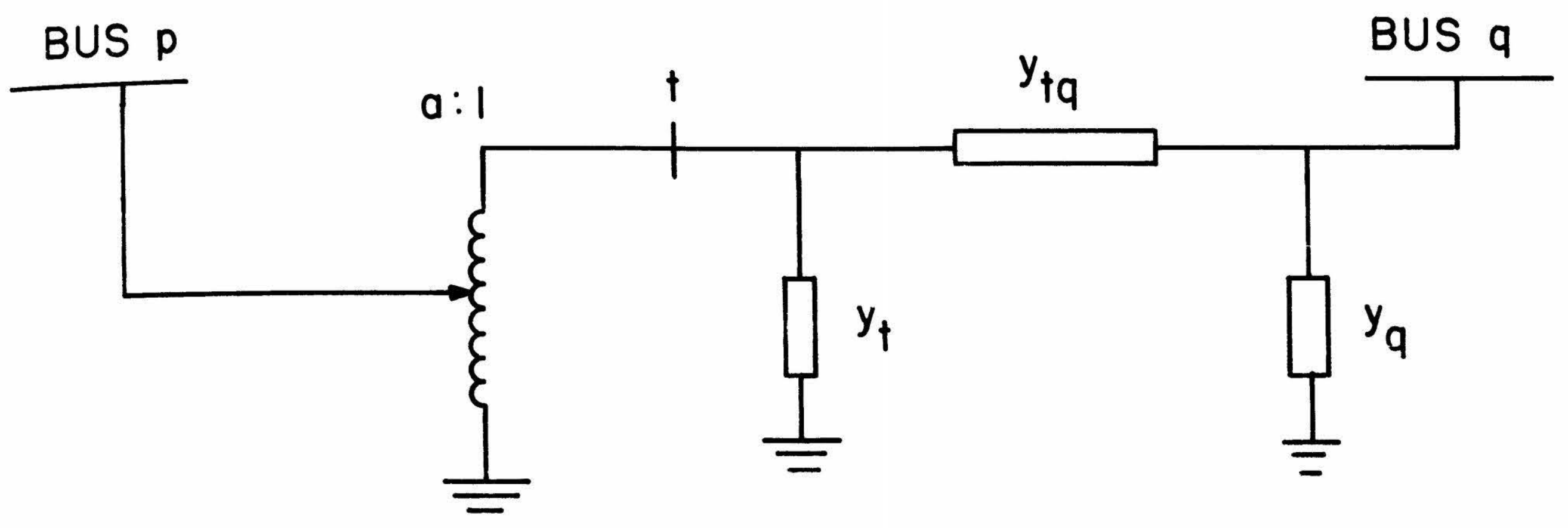

FIGURE 2.2. FIXED TAP SETTING TRANSFORMER IN TANDEM WITH A LINE.

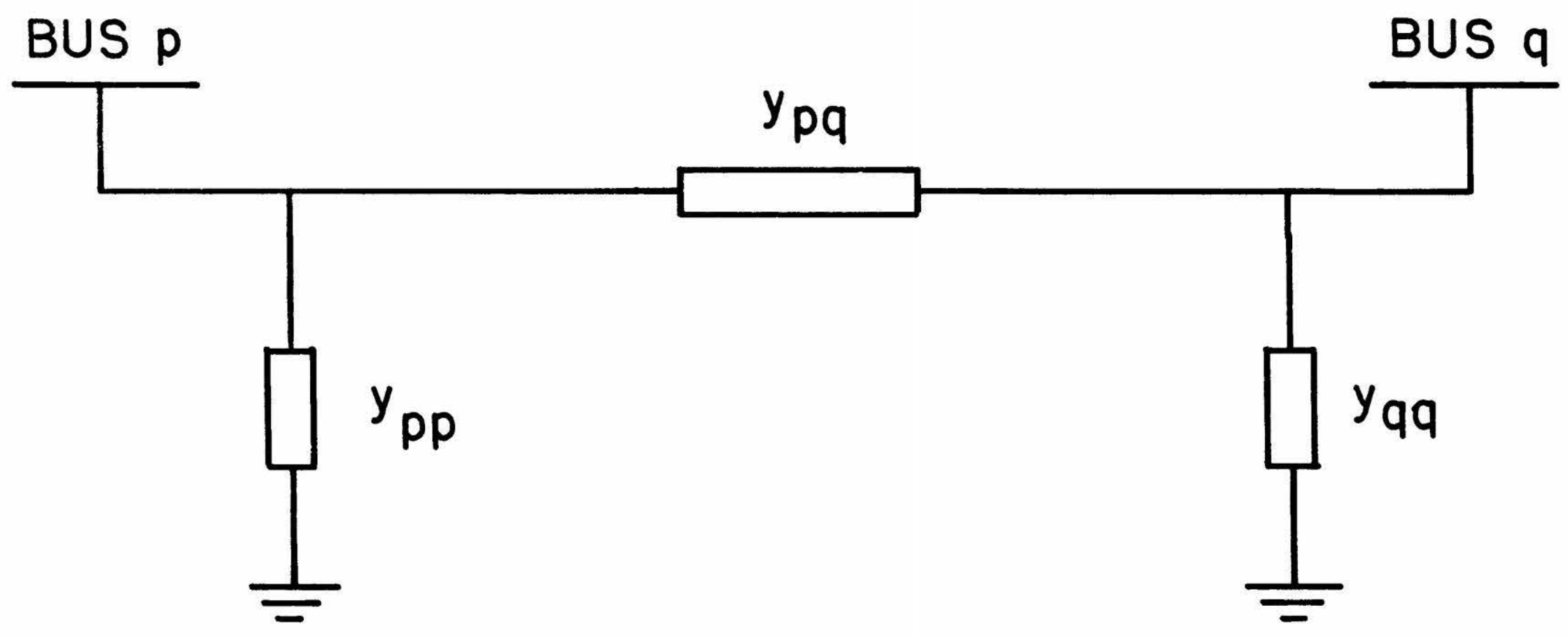

FIGURE 2.3 EQUIVALENT MODEL OF THE LINE WITH THE TRANSFORMER OF FIGURE 2.2. 
the equivalent model of figure 2.3 so that it will be compatible with the load flow solution procedure. The manipulation is performed in the following way.

The transformer performance expressed using the transmission form of the two-port network presentation is

$$
\left[\begin{array}{c}
e_{p} \\
i_{p}
\end{array}\right]=\left[\begin{array}{cc}
a & 0 \\
0 & 1 / a
\end{array}\right]\left[\begin{array}{l}
e_{t} \\
i_{t}
\end{array}\right]
$$

This describes the relationship between the nodal voltages and currents at node $p$ in terms of those at node $t$ on the line side of the transformer.

For the transmission line the following relationship holds:

$$
\left[\begin{array}{c}
e_{t} \\
i_{t}
\end{array}\right]=\left[\begin{array}{cc}
{\left[1+\left(y_{q} / y_{t q}\right)\right]} & \left(-1 / y_{t q}\right) \\
{\left[y_{t}+y_{q}+\left(\frac{y_{t} y_{q}}{y_{t q}}\right)\right]} & {\left[-\left(1+\frac{y_{t}}{y_{t q}}\right)\right]}
\end{array}\right]\left[\begin{array}{c}
e_{q} \\
i_{q}
\end{array}\right]
$$

Substituting equation (2.5) into equation (2.4) yields

$$
\left[\begin{array}{l}
e_{p} \\
i_{p}
\end{array}\right]=\left[\begin{array}{ll}
a\left[1+\left(y_{q} / y_{t q}\right)\right] & \left(-a / y_{t q}\right) \\
\frac{1}{a}\left[y_{t}+y_{q}+\left(\frac{y_{t} y_{q}}{y_{t q}}\right)\right. & -\frac{1}{a}\left(1+\frac{y_{t}}{y_{t q}}\right)
\end{array}\right]\left[\begin{array}{c}
e_{q} \\
i_{q}
\end{array}\right]
$$

In order for the transformer and 1 ine of figure 2.2 to be replaced with the equivalent $\pi$ networks of figure 2.3 , equation (2.6) must be equivalent to the transmission relationship of figure 2.3 , which is,

$$
\left[\begin{array}{l}
e_{p} \\
i_{p}
\end{array}\right]=\left[\begin{array}{cc}
\left(1+\frac{y_{q q}}{y_{p q}}\right. & \left(-1 / y_{p q}\right) \\
y_{p p}+y_{q q}+\left(\frac{y_{p p} y_{q q}}{y_{p q}}\right) & -\left(1+\frac{y_{p p}}{y_{p q}}\right)
\end{array}\right]\left[\begin{array}{c}
e_{q} \\
i_{q}
\end{array}\right]
$$

Equating the two relationships for the elements $(1,2)$ leads to

$$
-1 / y_{p q}=-a / y_{t q}
$$


which reduces to

$$
y_{p q}=y_{t q} / a
$$

Also we have for the $(1,1)$ elements:

$$
1+\left(\mathrm{y}_{\mathrm{qq}} / \mathrm{y}_{\mathrm{pq}}\right)=\mathrm{a}\left[1+\left(\mathrm{y}_{\mathrm{q}} / \mathrm{y}_{\mathrm{tq}}\right)\right]
$$

which reduces to,

$$
y_{q q}=y_{t q}+y_{q}-y_{p q}
$$

The equality of the $(2,2)$ elements results in

$$
1+\left(\mathrm{y}_{\mathrm{pp} / \mathrm{y}_{\mathrm{pq}}}\right)=\frac{1}{\mathrm{a}} \cdot\left(1+\mathrm{y}_{\mathrm{t} / \mathrm{y}_{\mathrm{tq}}}\right)
$$

which reduces to

$$
y_{p p}=\frac{y_{t}}{a}+\left(\frac{1}{a}-1\right) y_{p q}
$$

With equations (2.8), (2.9), and (2.10) the transmission line with a transformer of figure 2.2 is transformed to the "standard line" representation of figure 2.3 whose parameters can now be used in the formulation of the static load flow equations.

\subsection{Formulation of the Static Load Flow Equations}

\subsubsection{Introduction}

Nodal analysis is almost universally preferred in the formulation of the load flow problem for analysis. This is because of the simplicity of data preparation and the ease with which the bus admittance matrix can be formed and modified for network changes in subsequent cases. It is centered around the nodal equation,

$$
\underline{I}=\underline{Y} \cdot \underline{E}
$$

where the vector 1 is the set of currents flowing into each bus and the vector $\underline{E}$ is the set of bus voltages, and the vector $\underline{Y}$ is the bus 
admittance matrix.

\subsubsection{Derivation of Load Bus Equations}

The power at bus $p$ is defined as

$$
S_{p}=v_{p} I_{p}^{*}
$$

Also,

$$
S_{p}=P_{p}+j Q_{p}
$$

Therefore,

$$
P_{p}+j Q_{p}=V_{p} I_{p}^{*}
$$

Taking the conjugate of both sides of $(2.14)$, so that $I_{p}$ can be evaluated more conveniently, results in,

$$
P_{p}-j Q_{p}=V_{p}^{*} I_{p}
$$

Referring to figure 2.1 it can be easily seen that, applying ohm's law, the total current flowing from a bus $p$, would be,

$$
I_{p}=v_{p}\left(y_{p o}\right)+\sum_{\substack{q=1 \\ q \neq p}}^{m}\left(v_{p}-v_{q}\right) y_{p q}
$$

where,

$$
v_{p} \triangleq \text { voltage at bus } p
$$

$v_{q} \triangleq$ voltage at a bus, $q$, which is connected to bus $p$

$\mathrm{m} \triangleq$ number of buses connected to bus $\mathrm{p}$

$\mathrm{y}_{\mathrm{pq}} \triangleq$ the series admittance of the line connecting bus $p$ and bus $q$

$y_{p o} \triangleq$ the sum of all the shunt admittances to ground connected to bus $p$, including that of bus shunt reactors and/or static capacitors and that portion of the line shunt 
admittance delegated to the leg of the r-equivalent model of the line which is closest to bus $p$.

Equation (2.16) can be reduced to

$$
I_{p}=v_{p} Y_{p p}-\sum_{\substack{q=1 \\ q \neq p}}^{m}+v_{q} y_{p q}
$$

where $Y_{p p}$ is the sum of all admittances connected to bus $p$.

$$
y_{p p}=y_{p o}+\sum_{\substack{q=1 \\ q \neq p}}^{m} y_{p q}
$$

Letting $Y_{p q}=-y_{p q}$, the general form will be

$$
I_{p}=\sum_{q=1}^{n} V_{q} Y_{p q}
$$

where $\mathrm{n}$ is the number of buses in the system. Note that for any bus $q$ not connected to bus $p$, the term $Y_{p q}$ is zero.

Substituting this result into equation (2.15) gives,

$$
P_{p}-j Q_{p}=V_{p}^{*} \sum_{q=1}^{n} V_{q} Y_{p q}
$$

Equation (2.18) defines the load flow problem to be solved. The real and reactive portions of the power are separated to form a set of $2 \mathrm{n}$ equations. The method that will be used for solving these requires the use of rectangular coordinates. Thus, with

$$
v_{p}=e_{p}+j f p
$$

and

$$
Y_{p q}=G_{p q}-j B_{p q}
$$

The expressions in rectangular coordinates are substituted into equation (2.18) to give,

$$
p_{p}-j Q_{p}=\left(e_{p}-j f_{p}\right) \sum_{q=1}^{n}\left[\left(e_{q}+j f_{q}\right)\left(G_{p q}-j B_{p q}\right)\right]
$$




$$
=\left(e_{p}-j f_{p}\right) \sum_{q=1}^{n}\left[\left(e_{q} G_{p q}+f_{q} B_{p q}\right)+j\left(f_{q} G_{p q}-e_{q} B{ }_{p q}\right)\right]
$$

Separating the real and imaginary parts gives,

$$
\begin{aligned}
& P_{p}=e_{p}\left[\sum_{q=1}^{n}\left(e_{q} G_{p q}+f_{q} B_{p q}\right)\right]+f_{p}\left[\sum_{q=1}^{n}\left(f_{q} G_{p q}-e_{q} B_{p q}\right)\right] \\
& Q_{p}=f_{p}\left[\sum_{q=1}^{n}\left(e_{q} G_{p q}+f_{q} B_{p q}\right)\right]-e_{p}\left[\sum_{q=1}^{n}\left(f_{q} G_{p q}-e_{q} B_{p q}\right)\right]
\end{aligned}
$$

Simplified, the static load flow equations in rectangular coordinate form are,

$$
\begin{aligned}
& P_{p}=\sum_{q=1}^{n}\left[e_{p}\left(e_{q} G_{p q}+f_{q} B_{p q}\right)+f_{p}\left(f_{q} G_{p q}-e_{q} B_{p q}\right)\right] \\
& Q_{p}=\sum_{q=1}^{n}\left[f_{p}\left(e_{q} G_{p q}+f_{q} B p q\right)-e_{p}\left(f_{q} G_{p q}-e_{q} B_{p q}\right)\right]
\end{aligned}
$$

\subsubsection{Derivation of the Voltage Controlled Bus Equations}

Equations $(2.21)$ and $(2.22)$ specify the static operating state at the load buses. However, at a voltage controlled bus, the specified variables are active power and voltage magnitude. The two equations governing such a bus are equation (2.21) and

$$
\left|v_{p}\right|^{2}=e_{p}^{2}+f_{p}^{2}
$$

\subsubsection{The Slack Bus}

At the slack bus the voltage magnitude and angle are specified. The active and reactive powers are determined at the conclusion of a load flow solution, since the purpose of the slack bus is to provide the additional power to supply the transmission losses which are not known initially. As a result there are no equations to be formally solved iteratively for this bus. 


\section{4 .5 Summary}

The load flow problem for an n-node power system consists of a set of $2(n-1)$ nonlinear simultaneous algebraic equations to be satisfied.

At a load bus, $p$,

$$
\begin{aligned}
& P_{p}=\sum_{q=1}^{n} e_{p}\left(e_{q} G_{p q}+f_{q} B_{p q}\right)+f_{p}\left(f_{q} G_{p q}-e_{q} B_{p q}\right) \\
& Q_{p}=\sum_{q=1}^{n} f_{p}\left(e_{q} G_{p q}+f_{q} B_{p q}\right)-e_{p}\left(f_{q} G_{p q}-e_{q} B_{p q}\right)
\end{aligned}
$$

At a voltage controlled bus, $r$,

$$
\begin{aligned}
& P_{r}=\sum_{q=1}^{n} e_{r}\left(e_{q} G_{r q}+f_{q} B_{r q}\right)+f_{r}\left(f_{q} G_{r q}-e_{q}{ }^{B} r\right) \\
& \left|V_{r}\right|^{2}=e_{r}{ }^{2}+f_{r}{ }^{2}
\end{aligned}
$$

\subsection{Formulation of the Newton-Raphson Method in Rectangular Form}

\section{$\underline{2.5 .1}$ Solution Criteria}

The equations defining the static operating state of the power system, derived in the previous section, must be satisfied for an exact load flow solution. The criteria for solution will be set up as,

$$
\begin{aligned}
& \left|\Delta P_{p}\right|=\left|P_{\text {psched }}-P_{\text {pcal }}\right| \leq \xi \\
& \left|\Delta Q_{p}\right|=\left|Q_{\text {psched }}-Q_{\text {pcal }}\right| \leq \xi
\end{aligned}
$$

for load buses and

$$
\begin{aligned}
& \left|\Delta P_{p}\right|=\left|P_{\text {psched }}-P_{\text {pcal }}\right| \leq \xi \\
& \left.|\Delta| v_{p}\right|^{2}|=|\left|v_{p}\right|_{\text {sched }}^{2}-\left|v_{p}\right|_{\text {cal }}^{2} \mid \leq \xi
\end{aligned}
$$

for voltage controlled buses, where $P_{\text {psched }}$, $Q_{\text {psched }}$, and $\left|V_{p}\right|_{\text {sched }}$ are the scheduled variables; $P_{c a l}, Q_{c a l}$, and $\left|V_{p}\right|_{\text {cal }}^{2}$ are the variable values as calculated by equations (2.21), (2.22), and (2.23), respectively; 
$\Delta P_{p}, \Delta Q_{p}$, and $\Delta\left|V_{p}\right|^{2}$ are called the bus mismatches; and $\xi$ is the tolerance within which the bus mismatches must fall to constitute a solution--normally of the order .01 to $10 \mathrm{MW}$. or MVar or $(\mathrm{kv})^{2}$.

\subsubsection{Formulation For the Load Buses}

The Newton-Raphson (N.R.) method requires that a set of linear equations be formed expressing the relationship between the changes in the active and reactive powers and the bus voltage components during the iterative solution procedure. This is achieved using the Taylor expansion. For the system of nonlinear, multivariable equations, $f_{i}$, the Taylor expansion is

$$
\begin{aligned}
f_{i}\left(x_{1}+\Delta_{1}, x_{2}+\Delta_{2}, \ldots\right) & =f_{i}\left(x_{1}, x_{2}, \ldots\right) \\
& +\frac{1}{1 !} \sum_{j=1}^{n} \Delta_{j} \frac{\partial f_{i}}{\partial x_{j}} \\
& +\frac{1}{2 !} \sum_{j=1}^{n} \sum_{k=1}^{n} \Delta_{j} \Delta_{k} \frac{\partial^{2} f_{i}}{\partial x_{j} \partial x_{k}} \\
& +\frac{1}{3 !} \sum_{j=1}^{n} \sum_{k=1}^{n} \sum_{i=1}^{n} \Delta_{j} \Delta_{k} \Delta_{l} \frac{\partial^{3} f_{i}}{\partial x_{j} \partial x_{k} \partial x_{l}} \\
& +. . \quad, i=1,2, \ldots n
\end{aligned}
$$

The N.R. method is based on taking the first order approximation of expression (2.1), which is the first two terms

$$
\begin{gathered}
f_{i}\left(x_{1}+\Delta_{1}, x_{2}+\Delta_{2}, \ldots\right)=f_{i}\left(x_{1}, x_{2}, \ldots\right)+\sum_{j=1}^{n} \Delta_{j} \frac{\partial f_{i}}{\partial x_{j}} \\
i=1, \ldots, n
\end{gathered}
$$

Rearranging (2.27) to get it in the form of the mismatch criteria relationships of section 2.5 .1 , 


$$
f_{i}\left(x_{1}+\Delta_{1}, x_{2}+\Delta_{2}, \ldots\right)-f_{i}\left(x_{1}, x_{2}, \ldots\right)=\sum_{j=1}^{n} j \frac{\partial f_{i}}{\partial x_{j}}
$$

or

$$
\Delta f_{i}=\sum_{j=1}^{n} \Delta_{j} \frac{\partial f_{i}}{\partial x_{j}}
$$

Applying this to the load flow equations, the function, $f_{i}$, becomes that of the active bus power $P_{p}$, or the reactive bus power $Q_{p}$, both being functions of the voltages of the system's buses. Thus,

$$
\begin{aligned}
& P_{p}\left(v_{1}+\Delta v_{1}, v_{2}+\Delta v_{2}, \ldots\right)-P_{p}\left(v_{1}, v_{2}, \ldots\right)=\sum_{i=1}^{n}\left(\frac{\partial p_{p}}{\partial v_{i}} \Delta v_{i}\right) \\
& Q_{p}\left(v_{1}+\Delta v_{1}, v_{2}+\Delta v_{2}, \ldots\right)-Q_{p}\left(v_{1}, v_{2}, \ldots\right)=\sum_{i=1}^{n}\left(\frac{\partial Q_{p}}{\partial v_{i}} v_{i}\right)
\end{aligned}
$$

If,

$$
\begin{aligned}
& \Delta P_{p}=P_{p}\left(v_{1}+\Delta v_{1}, v_{2}+\Delta v_{2}, \ldots\right)-P_{p}\left(v_{1}, v_{2}, \ldots\right) \\
& \Delta Q_{p}=Q_{p}\left(v_{1}+\Delta v_{1}, v_{2}+\Delta v_{2}, \ldots\right)-Q_{p}\left(v_{1}, v_{2}, \ldots\right)
\end{aligned}
$$

and

$$
v_{i}=e_{i}+j f_{i}
$$

then,

$$
\begin{aligned}
& \Delta P_{p}=\left.\sum_{i=1}^{n}\left(\frac{\partial P_{p}}{\partial e_{i}} \Delta e_{i}\right)+\sum_{i=1}^{n} \frac{\partial P_{p}}{\partial f_{i}} \Delta f_{i}\right) \\
&\left.\Delta Q_{p}=\sum_{i=1}^{n}\left(\frac{\partial Q_{p}}{\partial e_{i}} \Delta e_{i}\right)+\sum_{i=1}^{n} \frac{\partial Q_{p}}{\partial f_{i}} \Delta f_{i}\right)
\end{aligned}
$$

(2.31) and (2.32) is the needed set of linear equations expressing the relationship between the changes in active and reactive powers and the components of the bus voltages. In matrix form, for an n-bus system 
(the nth bus being the slack bus),

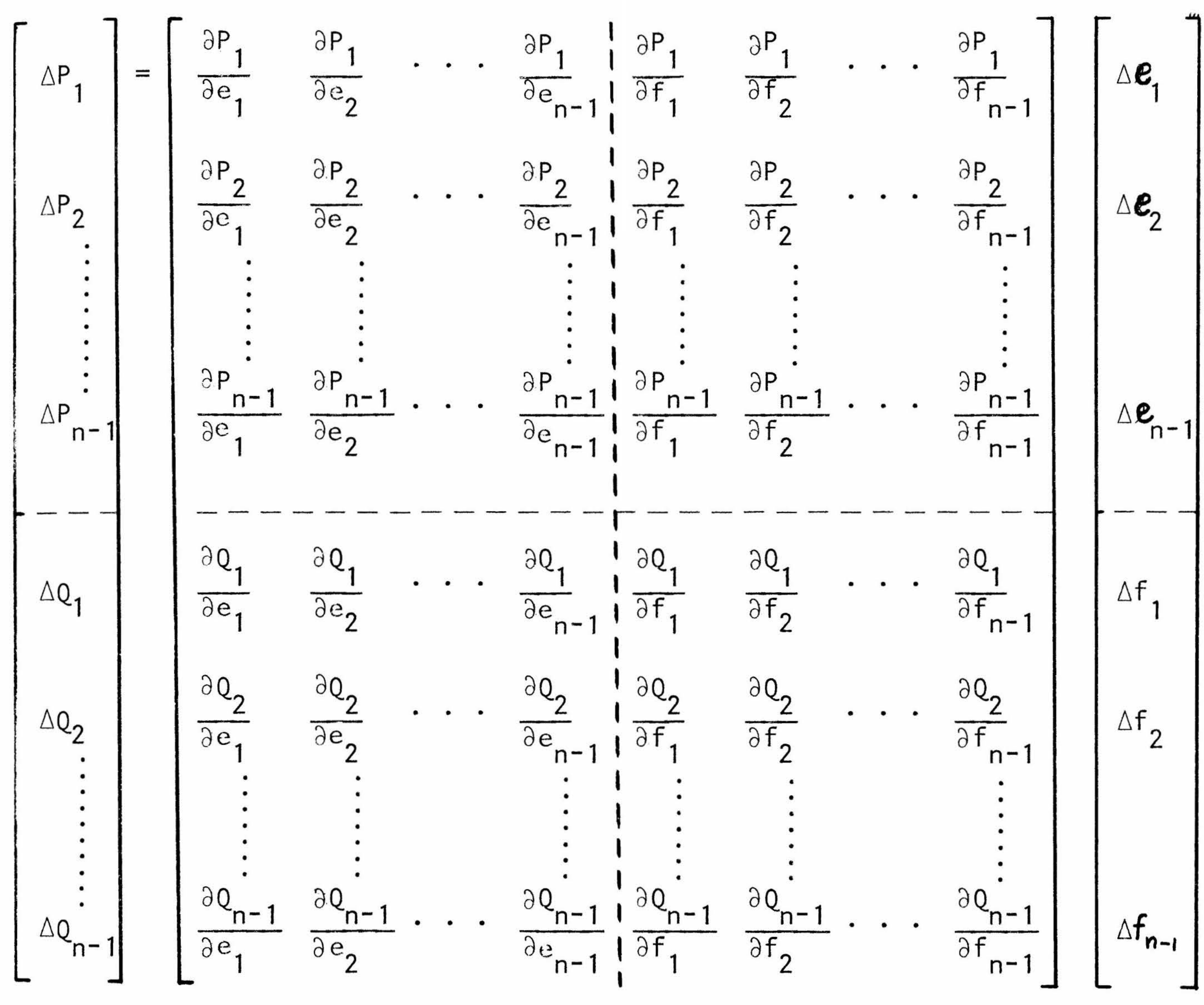

The coefficient matrix of first order partial derivatives is called the Jacobian matrix. In compact form, we have,

$$
\left[\begin{array}{c}
\Delta \mathrm{P} \\
\hdashline \Delta \mathrm{Q}
\end{array}\right]=\left[\begin{array}{c:c}
\mathrm{J}_{1} & \mathrm{~J}_{2} \\
\hdashline \mathrm{J}_{3} & \mathrm{~J}_{4}
\end{array}\right]\left[\begin{array}{c}
\Delta \mathrm{e} \\
\hdashline \Delta \mathrm{f}
\end{array}\right]
$$

The elements of the Jacobian are derived in Appendix A.

\subsubsection{Formulation for the Voltage Controlled Buses}

In section 2.4 .3 it was noted that the equations governing the voltage controlled buses were, 


$$
P_{p}=\sum_{q=1}^{n}\left[e_{p}\left(e_{q} G_{p q}+f_{q} B_{p q}\right)+f_{p}\left(f_{q} G_{p q}-e_{q p q}^{B}\right)\right]
$$

and

$$
\left|v_{p}\right|^{2}=e_{p}^{2}+f_{p}^{2}
$$

In the previous section the linear relationship for $\Delta P$ in terms of $\Delta e$ and $\Delta f$ was found. In the same way, using the Taylor expansion as a basis, the linear relationship for $\Delta|v|^{2}$ is

$$
\Delta\left|v_{p}\right|^{2}=\sum_{i=1}^{n}\left(\frac{\partial\left|v_{p}\right|^{2}}{\partial e_{i}} \Delta e_{i}\right)+\sum_{i=1}^{n}\left(\frac{\partial\left|v_{p}\right|^{2}}{\partial f_{i}} \Delta f_{i}\right)
$$

This leads us to the complete linear relationships for the system of $\mathrm{n}$ buses of which there are $\mathrm{m}$ voltage controlled buses (one of which is the slack bus). This is given by (2.36). In compact form, $(2.36$ is represented as

$$
\left[\begin{array}{c}
\Delta P \\
\Delta Q \\
\hdashline \Delta|V|^{2}
\end{array}\right]=\left[\begin{array}{c:c}
\mathrm{J}_{1} & \mathrm{~J}_{2} \\
\hdashline \mathrm{J}_{3} & \mathrm{~J}_{4} \\
\hdashline \mathrm{J}_{5} & \mathrm{~J}_{6}
\end{array}\right] \quad\left[\begin{array}{c}
\Delta \mathrm{e} \\
\hdashline \\
\Delta \mathrm{f}
\end{array}\right]
$$

where $\mathrm{J}_{1}, \mathrm{~J}_{2}, \mathrm{~J}_{3}$, and $\mathrm{J}_{4}$ are the same as in equation (2.34). The Jacobian elements for $\mathrm{J}_{5}$ and $\mathrm{J}_{6}$ are derived in Appendix $A$, along with those of $\mathrm{J}_{1}, \mathrm{~J}_{2}, \mathrm{~J}_{3}$, and $\mathrm{J}_{4}$.

\section{5 .4 Step by Step Procedure}

Having obtained the relationship (2.37), the basic step by step procedure of the N.R. method can be listed, briefly as follows:

1) Form the bus admittance matrix, [Y]

2) Initialize the bus voltage components, $e_{i}$ and $f_{i}$

3) Calculate $P_{i}, Q_{i}$, and $\left|V_{j}\right|^{2}$ using equations (2.21), (2.22), and (2.23), respectively. 

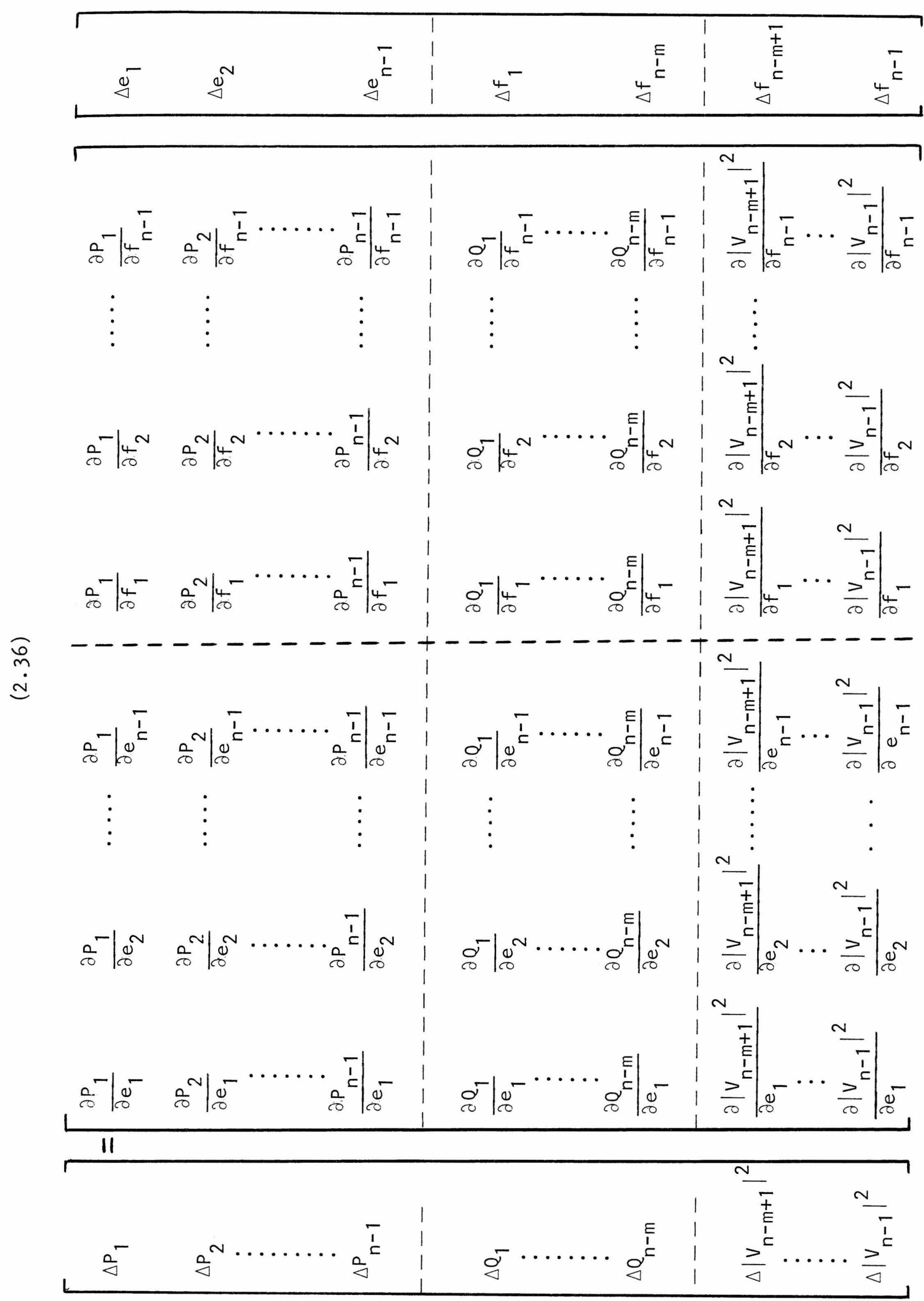
4) Calculate $\Delta P_{i}, \Delta Q_{i}$ and $\Delta\left|V_{j}\right|^{2}$ with

$$
\begin{aligned}
& \Delta P_{i}=P_{i \text { sched }}-P_{i} \\
& \Delta Q_{i}=Q_{i \text { sched }}-Q_{i} \\
& \Delta\left|v_{j}\right|^{2}=\left|v_{\text {jsched }}\right|^{2}-\left|v_{j}\right|^{2}
\end{aligned}
$$

5) Check to see if $\Delta P_{i}, \Delta Q_{i}$, and $\Delta\left|V_{j}\right|^{2}$ are within the specified tolerance, $\xi$. If so, solution has been achieved. If not, continue.

6) Calculate the Jacobian matrix elements

7) Solve the set of equations (2.36) for $\Delta e_{i}$ and $\Delta f_{i}$. That is, compute

$$
\left[\begin{array}{c}
\Delta \mathrm{e} \\
-\mathrm{f}
\end{array}\right]=\left[\begin{array}{c:c}
\mathrm{J}_{1} & \mathrm{~J}_{2} \\
\hdashline \mathrm{J}_{3} & \mathrm{~J}_{4} \\
\hdashline \mathrm{J}_{5} & \mathrm{~J}_{6}
\end{array}\right]^{-1}\left[\begin{array}{c}
\Delta \mathrm{P} \\
\hdashline \Delta \mathrm{Q} \\
\hdashline|\mathrm{V}|^{2}
\end{array}\right]
$$

8) Update $e_{i}$ and $f_{i}$,

$$
\begin{aligned}
& e_{i}{ }^{(k+1)}=e_{i}{ }^{(k)}+\Delta e_{i}{ }^{(k)} \\
& f_{i}{ }^{(k+1)}=f_{i}{ }^{(k)}+\Delta f_{i}{ }^{(k)}
\end{aligned}
$$

9) Go to step 3 . 


\section{CHAPTER III}

\section{DERIVATION OF SOME ALPHA-MODIFIED QUASI- \\ SECOND ORDER NEWTON RAPHSON METHODS}

\subsection{Introduction}

In the previous chapter theory was developed upon which the work reported in this thesis is based. Section 3.2 briefly illustrates how the Newton-Raphson method is extended to obtain a second order NewtonRaphson technique (S.O.N.R.) and then an alpha-modified second order Newton Raphson procedure for solving a set of nonlinear simultaneous equations. Section 3.3 extends the Newton-Raphson derivation outlined in the previous chapter, by detailing the derivation of the S.O.N.R. and its application to the load flow problem. This is what we can call a Quasi-Second Order Newton Raphson (Q.S.O.N.R.) method in retangular form. Section 3.4 builds upon this by developing a number of alphamodified quasi-second order Newton-Raphson (M.Q.S.O.N.R.) methods, one of which is programmed and tested on a number of power systems, the results of which are presented and analysed in chapter 4 .

\subsection{Description of the method}

A second order Newton-Raphson is an obvious extension of the Newton-Raphson method. It is obtained by simply taking the second order terms of the Taylor expansion, for a multivariable function, into account. This results in

$$
f_{i}\left(x_{1}+\Delta_{1}, x_{2}+\Delta_{2}, \ldots\right)=f_{i}\left(x_{1}, x_{2}, \ldots\right)+\sum_{j=1}^{n} \Delta_{j} \frac{\partial f_{i}}{\partial x_{j}}
$$




$$
+\frac{1}{2} \sum_{j=1}^{n} \sum_{k=1}^{n} \Delta_{j} \Delta_{k} \frac{\partial^{2} f}{\partial x_{j} \partial x_{k}}
$$

we now have to solve a system of second-order equations in the increments $\Delta$. Unless $n=1$, this will not have an explicit solution. The above expression can be written in vector form as,

$$
\Delta f_{i}=\nabla f_{i}^{\top} \cdot \Delta+\frac{1}{2} \Delta \Delta^{\top} \underline{H}_{i} \Delta
$$

Here $\Delta f_{i}$ is the gradient of $f_{i}$, and $H_{i}$ is the Hessian, which is the matrix of second-order derivatives.

Many alternative forms exist for implementing the above relationship. In the next section, the Q.S.O.N.R. method is presented and, in section 3.4, the alpha-modified algorithms are derived. The basic idea of an alpha-modified method can be shown by rewriting equation (3.2) in the following form,

$$
\left.\Delta f_{i}-\alpha_{i}\left[\frac{1}{2} \underline{\Delta}^{\top} \underline{H}_{i} \Delta\right]=\underline{\left[\nabla f_{i}\right.}+\left(1-\alpha_{i}\right)\left(\frac{1}{2} \underline{\Delta}^{\top} \underline{H_{i}}\right)\right] \underline{\Delta}
$$

This is in fact the basis for the M.Q.S.O.N.R. method number one which is derived and applied to the load flow problem in subsection 3.4.2.

\subsection{Formulation of the Quasi-Second Order Newton-Raphson method in}

Rectangular Form

3.3.1 Derivation of the active power second order correction factors

With the Newton Raphson method, only the first order terms of the Taylor expansion are used [equation (2.27)] . Now the second order terms will be ultilized. This results in,

$$
\begin{aligned}
f_{i}\left(x_{1}+\Delta_{1}, x_{2}+\Delta_{2}, \ldots\right) & -f_{i}\left(x_{1}, x_{2}, \ldots\right)=\sum_{j=1}^{n}\left(-\frac{\partial f}{\partial x_{j}} \Delta_{j}\right) \\
& +\sum_{j=1}^{n-1} \sum_{k=j+1}^{n}\left(\Delta_{j} \Delta_{k} \frac{\partial^{2} f_{i}}{\partial x_{j} \partial x_{k}}\right)
\end{aligned}
$$




$$
+\frac{1}{2} \sum_{j=1}^{n}\left(\Delta_{j}^{2} \frac{\partial^{2} f_{i}}{\partial x_{j}^{2}}\right)
$$

Equation (3.4) is of the form,

$$
\Delta f_{i}=D_{1}+D_{2}+D_{3}
$$

where, $D_{1}$ represents the first order terms and $D_{2}$ and $D_{3}$ represent the second order terms.

To obtain the active power correction factors we write

$$
\Delta P_{i}=D_{1 p}+D_{2 p}+D_{3 p}
$$

this relates the change in active powers with the change in the bus voltages, $\Delta e_{i}$ and $\Delta f_{i}$.

The first order terms are the same as those derived in Section 2.5 . For the active power component, they are,

$$
\begin{aligned}
D_{1 p} & \sum_{\substack{q=1 \\
q \neq p}}^{n-1} \frac{\partial P}{\partial e_{q}}\left(\Delta e_{q}\right)+\frac{\partial p}{\partial e_{p}}\left(\Delta e_{p}\right) \\
& +\sum_{\substack{q=1 \\
q \neq p}}^{n-1} \frac{\partial p}{\partial f}\left(\Delta f_{q}\right)+\frac{\partial p}{\partial f_{p}}\left(\Delta f_{p}\right)
\end{aligned}
$$

The second order terms are $D_{2 p}$ and $D_{3 p}$.

$$
\begin{aligned}
D_{2 p} & =\frac{1}{2} \sum_{\substack{q=1 \\
q \neq p}}^{n-1} \frac{\partial^{2} p_{p}}{\partial e_{q}^{2}}\left(\Delta e_{q}\right)^{2}+\frac{1}{2} \sum_{\substack{q=1 \\
1 \neq p}}^{n-1} \frac{\partial_{q}^{2} p_{p}^{2}}{\partial f_{q}^{2}}\left(\Delta f_{q}\right)^{2} \\
+ & \frac{1}{2} \frac{\partial^{2} p_{p}}{\partial e_{p}^{2}}\left(\Delta e_{p}\right)^{2}+\frac{1}{2} \frac{\partial^{2} p_{p}}{\partial f_{p}^{2}}(\Delta f p)^{2}
\end{aligned}
$$

, which reduces to 


$$
D_{2 p}=\frac{1}{2} \frac{\partial^{2} p}{\partial e_{p}{ }^{2}}\left(\Delta e_{p}\right)^{2}+\frac{1}{2} \frac{\partial^{2} p}{\partial f_{p}^{2}}\left(\Delta f_{p}\right)^{2}
$$

Evaluating the second order terms gives

$$
D_{2 p}=G_{p p}\left(\Delta e_{p}\right)^{2}+G_{p p}\left(\Delta f_{p}\right)^{2}
$$

All the second order partial derivatives (Hessian terms) are derived in Appendix B.

Now for the rest of the second order terms, $D_{3 p}$

$$
D_{3 p}=A_{p}+B_{p}+C_{p}
$$

where

$$
\begin{aligned}
& A_{p}=\sum_{q=1}^{n-1} \sum_{r=1}^{n-1} \frac{\partial^{2} p_{p}}{\partial e_{q} \partial f_{r}}\left(\Delta e_{q}\right)\left(\Delta f_{r}\right) \\
& B_{p}=\sum_{q=1}^{n-2} \sum_{r=q+1}^{n-1} \frac{\partial^{2} p_{p}}{\partial e_{q} \partial e_{r}}\left(\Delta e_{q}\right)\left(\Delta e_{r}\right) \\
& C_{p}=\sum_{q=1}^{n-2} n-1 \quad \sum_{n=q+1} \frac{\partial^{2} p_{p}}{\partial f_{q} \partial f_{r}}\left(\Delta f_{q}\right)\left(\Delta f_{r}\right)
\end{aligned}
$$

Now, expand and reduce the above terms. Starting with,

$$
A_{p}=\sum_{q=1}^{n-1} \sum_{r=1}^{n-1} \frac{\partial^{2} p_{p}}{\partial e_{q} \partial f_{r}}\left(\Delta f_{r}\right) \quad\left(\Delta e_{q}\right)
$$

This is equivalent to

$$
\begin{aligned}
A_{p} & =\sum_{\substack{q=1 \\
q \neq p}}^{n-1} \Delta e_{q}\left[\sum_{r=1}^{n-1} \frac{\partial^{2} p}{\partial e_{q} \partial f_{r}} \Delta f_{r}\right] \\
& +\Delta e_{p}^{n-1} \sum_{r=1} \frac{{ }^{2} p_{p}}{\partial e_{p}^{\partial f_{r}}} \Delta f_{r}
\end{aligned}
$$

Expanding, 
27

$$
\begin{aligned}
& A_{p}=\sum_{\substack{q=1 \\
q \neq p}}^{n-1} \Delta e_{q}\left[\sum_{\substack{r=1 \\
r \neq p}}^{n-1} \frac{\partial^{2} p}{\partial e_{q} \partial f_{r}} \Delta f_{r}\right]+\sum_{\substack{q=1 \\
q \neq p}}^{n-1} \Delta e_{q} \Delta f \frac{\partial^{2} p}{\partial e_{q} \partial f_{p}} \\
& +\Delta e_{p} \sum_{r=1}^{n-1} \frac{\partial^{2} p}{\partial e_{p} \partial f_{r}} \Delta f_{r}+\Delta e_{p} \Delta f_{p} \frac{\partial^{2} p}{\partial e_{p} \partial f_{p}} \\
& r \neq p
\end{aligned}
$$

This reduces to,

$$
A_{p}=\sum_{\substack{q=1 \\ q \neq p}}^{n-1} \Delta e_{p} \Delta f_{p}\left(-B_{p q}\right)+\Delta e_{p} \sum_{\substack{r=1 \\ r \neq p}}^{n-1} B_{p r} \Delta f_{r}
$$

In more compact form, the above expression is,

$$
A_{p}=\sum_{\substack{r=1 \\ r \neq p}}^{n-1} B_{p r}\left[\Delta e_{p} \Delta f_{r}-\Delta f_{p} \Delta e_{r}\right]
$$

Next, the term,

$$
B_{p}=\sum_{q=1}^{n-2} \sum_{r=q+1}^{n-1} \frac{\partial^{2} p}{\partial e_{q} \partial e_{r}}\left(\Delta e_{q}\right)\left(\Delta e_{r}\right)
$$

This term can be expanded in the following way:

$$
\begin{aligned}
B_{p} & =\sum_{q=1}^{p-1} \sum_{\substack{r=q+1 \\
r \neq p}}^{n-1} \frac{\partial^{2} p_{p}}{\partial e_{q} \partial e_{r}}\left(\Delta e_{q}\right)\left(\Delta e_{r}\right)+\sum_{q=1}^{p-1} \frac{\partial^{2} p_{p}}{\partial e_{q} \partial e_{p}}\left(\Delta e_{q}\right)\left(\Delta e_{p}\right) \\
+ & \sum_{q=p+1}^{n-2} \sum_{r=q+1}^{n-1} \frac{\partial^{2} p}{\partial e_{q} \partial e_{r}}\left(\Delta e_{q}\right)\left(\Delta e_{r}\right)+\sum_{r=p+1}^{n-1} \frac{\partial^{2} p_{p}}{\partial e_{p} \partial e_{r}}\left(\Delta e_{p}\right)\left(\Delta e_{r}\right)
\end{aligned}
$$

As a result of the following relationship,

$$
\frac{\partial^{2} p}{\partial e_{q} \partial e_{r}}=0 \text { for } r \neq p \text { or } q \neq p
$$

the expression for $B_{p}$ reduces to, 


$$
B_{p}=\sum_{q=1}^{p-1} \frac{\partial^{2} p}{\partial e_{q} \partial e_{p}}\left(\Delta e_{q}\right)\left(\Delta e_{p}\right)+\sum_{r=p+1}^{n-1} \frac{\partial^{2} p}{\partial e_{p} \partial e_{r}}\left(\Delta e_{p}\right)\left(\Delta e_{r}\right)
$$

Substituting the values of the Hessian terms yields,

$$
B_{p}=\Delta e_{p}^{p-1} \sum_{q=1}^{p} G_{p q} \Delta e_{q}+\Delta e_{p}^{n-1} \sum_{r=p+1}^{n} G_{p r} \Delta e_{r}
$$

which is,

$$
B_{p}=\Delta e_{p} \sum_{\substack{r=1 \\ r \neq p}}^{n-1} G_{p r} \Delta e_{r}
$$

Now for the last part of equation (3.9) which is

$$
\begin{aligned}
& c_{p}=\sum_{q=1}^{n-2} \sum_{r=q+1}^{n-1} \frac{\partial^{2} p}{\partial f_{q} \partial f_{p}}\left(\Delta f_{q}\right)\left(\Delta f_{r}\right)
\end{aligned}
$$

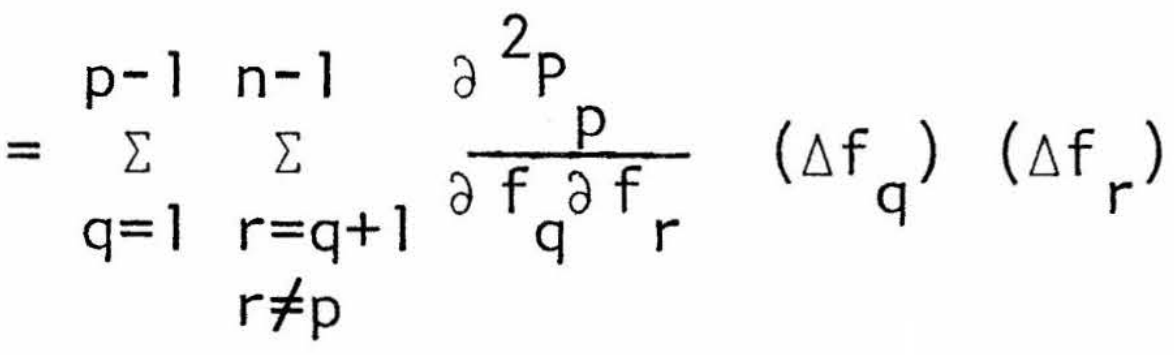

$$
\begin{aligned}
& +\sum_{q=1}^{p-1} \frac{\partial^{2} p}{\partial f_{q} \partial f_{p}}\left(\Delta f_{q}\right)\left(\Delta f_{p}\right) \\
& =\sum_{q=p+1}^{n-2} \sum_{r=q+1}^{n-1} \frac{\partial^{2} p}{\partial f_{q} \partial f_{r}}\left(\Delta f_{q}\right)\left(\Delta f_{r}\right) \\
& +\sum_{r=p+1}^{n-1} \frac{\partial^{2} p_{p}}{\partial f_{p}^{\partial f_{r}}}\left(\Delta f_{p}\right)\left(\Delta f_{r}\right)
\end{aligned}
$$

Since

$$
\frac{\partial^{2} p}{\partial f_{q} \partial f_{r}}=0 \text { for } r \neq p \text { or } q \neq p
$$

the expression for $C_{p}$ reduces to, 


$$
\begin{aligned}
& C_{p}=\sum_{q=1}^{p-1} \frac{\partial^{2} p_{p}}{\partial f_{q} \partial f_{p}}\left(\Delta f_{q}\right)\left(\Delta f_{p}\right) \\
&+\sum_{r=p+1}^{n-1} \frac{\partial^{2} p}{\partial f_{p} \partial f_{r}}\left(\Delta f_{p}\right)\left(\Delta f_{r}\right)
\end{aligned}
$$

Substituting the values of the Hessian terms yields

$$
C_{p}=\Delta f_{p} \underset{q=1}{p-1} G_{p q} \Delta f q+\Delta f_{p} \underset{r=p+1}{n-1} G_{p r} \Delta f_{r}
$$

which, in more compact form, is

$$
\begin{aligned}
& c_{p}=\Delta f_{p} \underset{r=1}{n-1} G_{p r} \Delta f_{r} \\
& r \neq p
\end{aligned}
$$

Thus, equation (3.9) is reduced, using (3.10), (3.11), and (3.12), to

$$
\begin{aligned}
& D_{3 p}=\Delta e_{p} \sum_{\substack{r=1 \\
r \neq p}}^{n-1}\left[B_{p r} \Delta f_{r}+G_{p r} \Delta e_{r}\right] \\
&+\Delta f_{p} \sum_{\substack{r=1 \\
r \neq p}}^{n-1}\left[G_{p r} \Delta f_{r}-B_{p r} \Delta e_{r}\right]
\end{aligned}
$$

Combining equations (3.8) and (3.13) yields the second order terms of the Taylor expansion in the form,

$$
\begin{aligned}
R_{p} & =D_{2 p}+D_{3 p}=\Delta e_{p} \underset{r=1}{n-1}\left[B_{p r} \Delta f_{r}+G_{p r} \Delta e_{r}\right] \\
& +\Delta f_{p} \sum_{r=1}^{n-1}\left[G_{p r} \Delta f_{r}-B_{p r} \Delta e_{r}\right]
\end{aligned}
$$

which are the active power second order correction factors. 
3.3.2 Derivation of the reactive power second order correction factors

From equation (3.4), we write,

$$
\Delta Q_{i}=D_{1 Q}+D_{2 Q}+D_{3 Q}
$$

The first order terms are,

$$
\begin{aligned}
D_{1 Q} & =\sum_{\substack{q=1 \\
q \neq p}}^{n-1} \frac{\partial Q_{p}}{\partial e_{q}} \Delta e_{q}+\frac{\partial Q_{p}}{\partial e_{p}} \quad\left(\Delta e_{p}\right) \\
& +\sum_{\substack{q=1 \\
q \neq p}}^{n-1} \frac{\partial Q_{p}}{\partial f_{q}}\left(\Delta f_{q}\right)+\frac{\partial Q_{p}}{\partial f_{p}}\left(\Delta f_{p}\right)
\end{aligned}
$$

The second order terms, $D_{2 Q}$ and $D_{3 Q}$, are

$$
\begin{aligned}
D_{2 Q} & =\frac{1}{2} \sum_{\substack{q=1 \\
q \neq p}}^{n-1} \frac{\partial^{2} Q_{p}}{\partial e^{2} q}\left(\Delta e_{q}\right)^{2}+\frac{1}{2} \sum_{\substack{q=1 \\
q \neq p}}^{n-1} \frac{\partial^{2} Q_{p}}{\partial f^{2} q}\left(\Delta f_{q}\right)^{2} \\
& +\frac{1}{2} \frac{\partial^{2} Q_{p}}{\partial e^{2} p}\left(\Delta e_{p}\right)^{2}+\frac{1}{2} \frac{\partial^{2} Q_{p}}{\partial f_{p}^{2}}\left(\Delta f_{p}\right)^{2}
\end{aligned}
$$

which reduces to

$$
D_{2 Q}=\frac{1}{2} \frac{\partial^{2} Q_{p}}{\partial e^{2} p}\left(\Delta e_{p}\right)^{2}+\frac{1}{2} \frac{\partial^{2} Q_{p}}{\partial f^{2} p}\left(\Delta f_{p}\right)^{2}
$$

which, in turn, is

$$
D_{2 Q}=B_{p p}\left(\Delta e_{p}\right)^{2}+B_{p p}\left(\Delta f_{p}\right)^{2}
$$

As well,

$$
D_{3 Q}=A_{Q}+B_{Q}+C_{Q}
$$

where, 


$$
\begin{aligned}
& A_{Q}=\sum_{q=1}^{n-1} \sum_{r=1}^{n-1} \frac{\partial^{2} Q_{p}}{\partial e_{q} \partial f_{r}}\left(\Delta e_{q}\right)\left(\Delta f_{r}\right) \\
& B_{Q}=\sum_{q=1}^{n-2} \sum_{r=q+1}^{n-1} \frac{\partial^{2} Q_{p}}{\partial e_{q} \partial e_{r}}\left(\Delta e_{q}\right)\left(\Delta e_{r}\right) \\
& C_{Q}=\sum_{q=1}^{n-2} \sum_{r=q+1}^{n-1} \frac{\partial^{2} Q_{p}}{\partial f_{q} \partial f_{r}}\left(\Delta f_{q}\right)\left(\Delta f_{r}\right)
\end{aligned}
$$

First, expanding $A_{Q}$,

$$
\begin{aligned}
A_{Q} & =\sum_{\substack{q=1 \\
q \neq p}}^{n-1} \Delta e_{q}\left[\sum_{r=1}^{n-1} \frac{\partial^{2} Q_{p}}{\partial e_{q}^{\partial f_{r}}} \Delta f_{r}\right] \\
& +\Delta e_{p} \sum_{r=1}^{n-1} \frac{\partial^{2} Q_{p}}{\partial e_{p} \partial f_{r}} \Delta f_{r}
\end{aligned}
$$

Expanding again yields,

$$
\begin{aligned}
A_{Q} & \sum_{\substack{q=1 \\
q \neq p}}^{n-1} \Delta e_{q} \sum_{\substack{r=1 \\
r \neq p}}^{n-1} \frac{\partial^{2} Q_{p}}{\partial e_{p} \partial f_{r}} \Delta f_{r}+\sum_{\substack{q=1 \\
q \neq p}}^{n-1} \Delta e_{q} \Delta f_{p} \frac{\partial^{2} Q_{p}}{\partial e_{q} \partial f_{p}} \\
& +\Delta e_{p}^{\substack{r=1 \\
r \neq p}} \sum_{p}^{n-1} \frac{\partial^{2} Q_{p}}{\partial e_{p} \partial f_{r}} \Delta f_{r}+\Delta e_{p} \Delta f_{p} \frac{\partial^{2} Q_{p}}{\partial e_{p} \partial f_{p}}
\end{aligned}
$$

Substituting the values of the Hessian terms reduces the above expression to,

$$
A_{Q}=\Delta f_{p} \sum_{\substack{q=1 \\ q \neq p}}^{n-1} G_{p q} \Delta e_{q}+\Delta e_{p} \sum_{\substack{r=1 \\ r \neq p}}^{n-1}-G_{p r} \Delta f_{r}
$$

which is, in a more compact form,

$$
A_{Q}=\sum_{\substack{r=1 \\ r \neq p}}^{n-1} G_{p r}\left[\Delta f_{p} \Delta e_{r}-\Delta e_{p} \Delta f_{r}\right]
$$


Now for the next term,

$$
B_{Q}=\sum_{q=1}^{n-2} \sum_{r=q+1}^{n-1} \frac{\partial^{2} Q_{p}}{\partial e_{q} \partial e_{r}}\left(\Delta e_{q}\right)\left(\Delta e_{r}\right)
$$

Expanding,

$$
\begin{aligned}
& B_{Q}=\sum_{\substack { q=1 \\
\begin{subarray}{c}{r=q+1 \\
r \neq p{ q = 1 \\
\begin{subarray} { c } { r = q + 1 \\
r \neq p } }\end{subarray}}^{n-1} \frac{\partial^{2} Q_{p}}{\partial e_{q} \partial e_{r}}\left(\Delta e_{q}\right)\left(\Delta e_{r}\right) \\
& +\sum_{q=1}^{p-1} \frac{\partial^{2} Q_{p}}{\partial e_{q} \partial e_{p}}\left(\Delta e_{q}\right)\left(\Delta e_{p}\right) \\
& +\sum_{q=p+1}^{n-2} \sum_{r=q+1}^{n-1} \frac{\partial^{2} Q_{p}}{\partial e_{q} \partial e_{r}}\left(\Delta e_{q}\right)\left(\Delta e_{r}\right) \\
& +\sum_{r=p+1}^{n-1} \frac{\partial^{2} Q_{p}}{\partial e_{p} \partial e_{r}}\left(\Delta e_{p}\right)\left(\Delta e_{r}\right)
\end{aligned}
$$

Since

$$
\frac{\partial^{2} Q_{p}}{\partial e_{q} \partial e_{r}}=0 \text { for } r \neq p \text { or } q \neq p
$$

we have,

$$
\begin{aligned}
B_{Q} & =\sum_{q=1}^{p-1} \frac{\partial^{2} Q_{p}}{\partial e_{q} \partial e_{p}}\left(\Delta e_{q}\right)\left(\Delta e_{p}\right) \\
& +\sum_{r=p+1}^{n-1} \frac{\partial^{2} Q_{p}}{\partial e_{p} \partial e_{r}}\left(\Delta e_{p}\right)\left(\Delta e_{r}\right)
\end{aligned}
$$

Substituting in the values of the Hessian terms yields,

$$
B_{Q}=\Delta e_{p} \sum_{q=1}^{p-1} B_{p q} \Delta e_{q}+\Delta e_{p} \sum_{r=p+1}^{n-1} B_{p r} \Delta e_{r}
$$

and in compact form

$$
B_{Q}=\Delta e_{p} \sum_{\substack{r=1 \\ r \neq p}}^{n-1} B_{p r} \Delta e_{r}
$$


33

Finally,

$$
C_{Q}=\sum_{q=1}^{n-2} \sum_{r=q+1}^{n-1} \frac{\partial^{2} Q_{p}}{\partial f_{q} \partial f_{r}}\left(\Delta f_{q}\right)\left(\Delta f_{r}\right)
$$

Expanding,

$$
\begin{aligned}
C_{Q}=\sum_{\substack { q=1 \\
\begin{subarray}{c}{r=q+1 \\
r \neq p{ q = 1 \\
\begin{subarray} { c } { r = q + 1 \\
r \neq p } }\end{subarray}}^{n-1} \frac{\partial^{2} Q_{p}}{\partial f_{q} \partial f_{r}}\left(\Delta f_{q}\right)\left(\Delta f_{r}\right) \\
+\sum_{q=1}^{p-1} \frac{\partial^{2} Q_{p}}{\partial f_{q} f_{p}}\left(\Delta f_{q}\right)\left(\Delta f_{p}\right) \\
+\sum_{\substack{n-2 \\
q=p+1}}^{n-1} \sum_{\substack{n+1 \\
n-1}} \frac{\partial^{2} Q_{p}}{\partial f_{q} \partial f_{r}}\left(\Delta f_{q}\right)\left(\Delta f_{r}\right) \\
+\underset{r=p+1}{\partial f_{p} \partial f_{r}}\left(\Delta f_{p}\right)\left(\Delta f_{r}\right)
\end{aligned}
$$

Since

$$
\frac{\partial^{2} Q_{p}}{\partial f_{q} \partial f_{r}}=0 \text { for } r \neq p \text { or } q \neq p
$$

the above is essentially,

$$
\begin{aligned}
C_{Q} & =\sum_{q=1}^{p-1} \frac{\partial^{2} Q_{p}}{\partial f_{q} \partial f_{p}}\left(\Delta f_{q}\right)\left(\Delta f_{p}\right) \\
+ & \sum_{r=p+1}^{n-1} \frac{\partial^{2} Q_{p}}{\partial f_{p} \partial f_{r}}\left(\Delta f_{p}\right)\left(\Delta f_{r}\right)
\end{aligned}
$$

Using the derivative expressions we then have

$$
C_{Q}=\Delta f_{p} \sum_{q=1}^{p-1} B_{p q} \Delta f_{q}+\Delta f_{p} \sum_{r=p+1}^{n-1} B_{p r} \Delta f_{r}
$$

More compactly,

$$
C_{Q}=\Delta f_{p} \sum_{\substack{r=1 \\ r \neq p}}^{n-1} B_{p r} \Delta f_{r}
$$


Thus, equation (3.18) is reduced, using (3.19), (3.20) and (3.21), to

$$
\begin{aligned}
D_{3 Q} & =\Delta f_{p} \sum_{\substack{r=1 \\
r \neq p}}^{n-1}\left(G_{p r} \Delta e_{r}+B_{p r} \Delta f_{r}\right) \\
& +\Delta e_{p} \sum_{r \neq p}^{n-1}\left[B_{p r} \Delta e_{r}-G_{p r} \Delta f_{r}\right]
\end{aligned}
$$

Combining equation (3.17) with equation (3.22) yields the second order terms of the Taylor expansion in the form,

$$
\begin{aligned}
T_{p}=D_{2 Q}+D_{3 Q} & =\Delta f_{p} \sum_{r=1}^{n-1}\left[G_{p r} \Delta e_{r}+B_{p r} \Delta f_{r}\right] \\
& +\Delta e_{p} \underset{r=1}{n-1}\left[B_{p r} \Delta e_{r}-G_{p r} \Delta f_{r}\right]
\end{aligned}
$$

which are the reactive power second order correction factors.

\subsubsection{Derivation of the voltage magnitude second order correction factors}

Again, for voltage controlled buses a relationship is needed that relates the change in the bus voltage magnitudes with the changes in the components of the bus voltages, $\Delta \mathrm{e}_{\mathbf{i}}$ and $\Delta \mathrm{f}_{\mathrm{i}}$. Here we desire the relationship to include second order terms. This is a very simple derivation to perform. From the Taylor expansion it can be written that,

$$
\begin{aligned}
\Delta\left|v_{i}\right|^{2} & =\sum_{j=1}^{n} \frac{\partial\left|v_{i}\right|^{2}}{\partial e_{j}} \Delta e_{j}+\sum_{j=1}^{n} \frac{\partial\left|v_{i}\right|^{2}}{\partial f_{j}} \Delta f_{j} \\
& +\frac{1}{2} \sum_{j=1}^{n} \sum_{k=1}^{n} \Delta e_{j} \Delta f_{k} \frac{\partial^{2}\left|v_{i}\right|^{2}}{\partial e_{j} \partial f_{k}}
\end{aligned}
$$




$$
\begin{aligned}
& +\frac{1}{2} \sum_{j=1}^{n} \sum_{k=1}^{n} \Delta f_{j} \Delta e_{k} \frac{\partial^{2}\left|v_{i}\right|^{2}}{\partial f_{j} \partial e_{k}} \\
& +\sum_{j=1}^{n-1} \sum_{k=j+1}^{n} \Delta e_{j} \Delta e_{k} \frac{\partial^{2}\left|v_{i}\right|^{2}}{\partial e_{j} \partial e_{k}} \\
& +\sum_{j=1}^{n-1} \sum_{k=j+1}^{n} \Delta f_{j} \Delta f_{k} \frac{\partial^{2}\left|v_{i}\right|^{2}}{\partial f_{j} \partial f_{k}}
\end{aligned}
$$

Since the relationship for $\left|v_{i}\right|^{2}$ is simply,

$$
\left|v_{i}\right|^{2}=e_{i}^{2}+f_{i}^{2}
$$

the first and second order partial derivatives of $\left|v_{i}\right|^{2}$ will be derived here. Doing this will show how easily (3.24) may then be reduced.

$$
\begin{aligned}
& \frac{\partial\left|v_{i}\right|^{2}}{\partial e_{j}}=2 e_{j} \quad, \quad j=i \\
& \frac{\partial\left|v_{i}\right|^{2}}{\partial f_{j}}=2 f j, \quad j=i \\
& \frac{\partial^{2}\left|v_{i}\right|^{2}}{\partial e_{j} \partial f_{k}}=0 \quad, \quad \text { for all j and } k \\
& \frac{\partial^{2}\left|v_{i}\right|^{2}}{\partial f_{j} \partial e_{k}}=0 \quad, \quad \text { for all j and } k \\
& \frac{\partial^{2}\left|v_{i}\right|^{2}}{\partial e_{j} \partial e_{k}}=2 \quad, \quad j=k=i \\
& \frac{\partial^{2}\left|v_{i}\right|^{2}}{\partial f_{j} \partial f_{k}}=2 \quad, \quad j=k=i \\
& =0 \text {, otherwise }
\end{aligned}
$$


With these derivations, (3.24) is quickly reduced to,

$$
\Delta\left|v_{i}\right|=2 e_{i} \Delta e_{i}+2 f_{i} \Delta f_{i}+\Delta e_{i}^{2}+\Delta f_{i}^{2}
$$

with the second order factors being

$$
u_{i}=\Delta e_{i}^{2}+\Delta f_{i}^{2}
$$

\subsubsection{Step by step procedure for the Quasi-second order} Newton-Raphson method

Having derived the second order correction factors in equations (3.14), (3.23), and (3.26) for $\Delta P_{i}, \Delta Q_{i}$, and $\Delta\left|V_{i}\right|^{2}$ respectively, the basic step by step procedure of the Q.S.O.N.R. is now listed, briefly, as follows:

1) Form the bus admittance matrix, $[\mathrm{Y}]$

2) Initialize the bus voltages components, $e_{i}$ and $f_{i}$

3) Calculate $P_{i}, Q_{i}$, and $\left|V_{j}\right|^{2}$ using equations $(2.21),(2.22)$ and (2.23), respectively

4) Calculate the power and voltage magnitudes mismatches, $\Delta \mathrm{P}_{i}$, $\Delta Q_{i}$, and $\Delta\left|v_{j}\right|^{2}$, with,

$$
\begin{aligned}
& \Delta P_{i}=P_{i S C H E D}-P_{i} \\
& \Delta Q_{i}=Q_{i S C H E D}-Q_{i} \\
& \Delta\left|v_{j}\right|^{2}=\left|v_{j S C H E D}\right|^{2}-\left|v_{j}\right|^{2}
\end{aligned}
$$

5) Check to see if $\Delta P_{i}, \Delta Q_{i}$, and $\Delta\left|V_{j}\right|^{2}$ are within the specified tolerance, $\xi$. If so, solution is achieved. If not, continue to step 6 . 
6) Calculate the Jacobian matrix elements

7) Solve the set of equations (2.36) for $\Delta e_{i}$ and $\Delta f_{i}$. That is, compute

$$
\left[\begin{array}{c}
\Delta \mathrm{e} \\
\hdashline \mathrm{f}
\end{array}\right]=\left[\begin{array}{c:c}
\mathrm{J}_{1} & \mathrm{~J}_{2} \\
\hdashline-1 & -\mathrm{J}_{-} \\
\mathrm{J}_{3} & \mathrm{~J}_{4} \\
\hdashline \mathrm{J}_{5} & \mathrm{~J}_{6}
\end{array}\right]^{-1}\left[\begin{array}{l}
\Delta \mathrm{P} \\
-\Delta \mathrm{Q} \\
\hdashline \Delta|\mathrm{V}|^{2}
\end{array}\right]
$$

8) Check to see if a solution has been achieved. If so, procedure stops, only needing to go through one half of the present iteration. If not, continue.

9) Calculate the second order correction factors, $R_{p}, T_{p}$, and $U_{i}$ with equations (3.14), (3.23), and (3.26) respectively, using the values of $\Delta e_{j}$ and $\Delta f_{j}$ obtained in step (7)

10) Update the power and voltage magnitude mismatches by subtracting the correction factors of step (9) from the original mismatches of step (4)

$$
\begin{gathered}
\Delta P_{p}^{\prime}=\Delta P_{p}-R_{p} \\
\Delta Q_{p}^{\prime}=\Delta Q_{p}-T_{p} \\
\Delta\left|v_{i}\right|^{2^{\prime}}=\Delta\left|v_{i}\right|^{2}-u_{i}
\end{gathered}
$$

11) With the new mismatch values from step (10), solve (3.36) for new values of $\Delta e_{i}$ and $\Delta f_{i}$. The same Jacobian found in step (6) and used in step (7) is again used here.

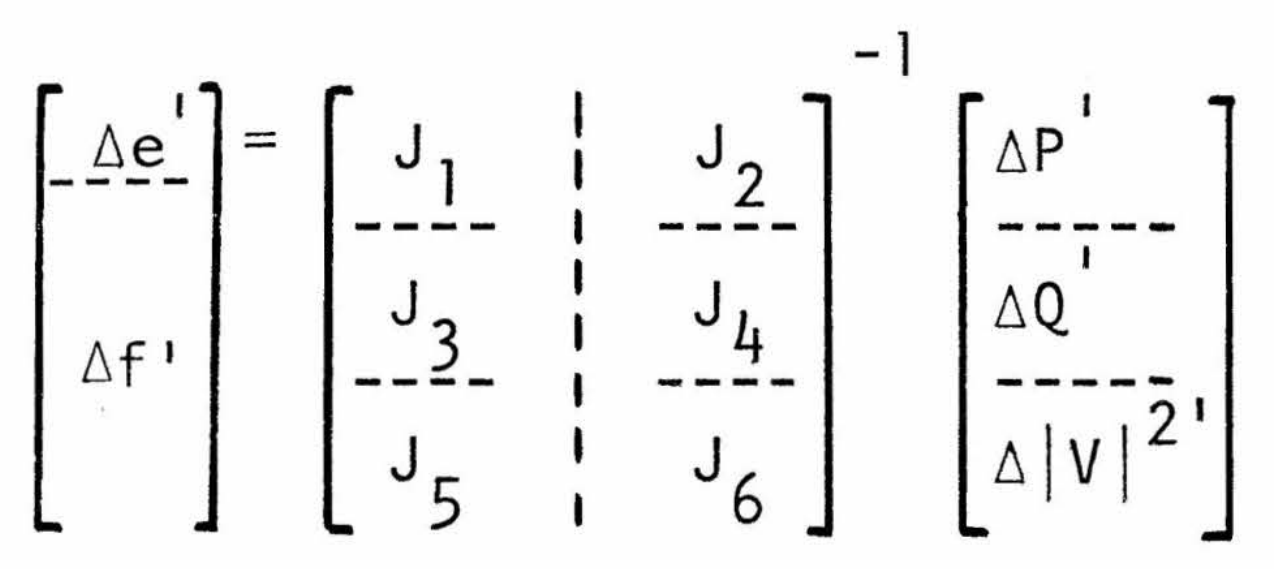


12) With the values of the voltage changes found in step (11), update the bus voltages.

$$
\begin{aligned}
& e_{i}{ }^{(k+1)}=e_{i}{ }^{(k)}+\Delta e_{i}{ }^{\prime(k)} \\
& f_{i}{ }^{(k+1)}=f_{i}{ }^{(k)}+\Delta f_{i}{ }^{\prime}(k)
\end{aligned}
$$

13) Go to step (3).

It is worth noting here that steps (1) to (7), which constitutes one half iteration of the Q.S.O.N.R., is, in fact, the Newton-Raphson method (when combined with steps (12) and (13)).

\subsection{Alpha-Modified Quasi-Second Order Newton-Raphson Method}

\subsubsection{Introduction}

The most direct way of incorporating the second order correction factors, derived in subsections $3.3 .1,3.3 .2$, and 3.6.3, into a load flow procedure is with the Q.S.O.N.R. method described in section 3.3.4. Now, in this section, four alternative means of applying the factors are presented. The first two of these alternatives will each be shown to be simply a special case of a general alpha-modified technique. The other two will be immediately written in general alpha-modified forms. In each of the first two general techniques, the Q.S.O.N.R. is also shown to be a special case.

The first alpha-modified method was studied, applied, and analysed in detail. The results are presented and discussed in Chapter 4. 
The other three alpha-modified methods were not persued beyond the formulation stage, even though they are fairly straightforward, due to time limitations.

\subsubsection{M.Q.S.O.N.R. method number 1}

First, we will rewrite the linear relationships which includes the second order terms and which are solved in the Q.S.O.N.R. for the voltage changes [step (11) of Q.S.O.N.R.].

From the N.R. procedure, we have

$$
\begin{gathered}
\Delta P_{p}=N R C P \\
\Delta Q_{p}=N R C Q \\
\Delta\left|v_{p}\right|^{2}=N R C V
\end{gathered}
$$

where,

$$
\begin{aligned}
& \text { NRCP }=\sum_{i=1}^{n-1} \frac{\partial P_{p}}{\partial e_{i}} \Delta e_{i}+\sum_{i=1}^{n-1} \frac{\partial P_{p}}{\partial f_{i}} \Delta f_{i} \\
& \text { NRCQ }=\sum_{i=1}^{n-1} \frac{\partial Q_{p}}{\partial e_{i}} \Delta e_{i}+\sum_{i=1}^{n-1} \frac{\partial Q_{p}}{\partial f_{i}} \Delta f_{i} \\
& \text { NRCV }=\sum_{i=1}^{n-1} \frac{\partial\left|V_{p}\right|^{2}}{\partial e_{i}} \Delta e_{i}+\sum_{i=1}^{n-1} \frac{\partial\left|v_{p}\right|^{2}}{\partial f_{i}} \Delta f_{i}
\end{aligned}
$$

Also,

$$
\begin{aligned}
& \Delta P_{p}=P_{\text {pSCHED }}-P_{p} \\
& \Delta Q_{p}=Q_{p S C H E D}-Q_{p} \\
& \Delta\left|v_{p}\right|^{2}=\left|v_{p S C H E D}\right|^{2}-\left|v_{p}\right|^{2}
\end{aligned}
$$


The second order correction factors are,

$$
\begin{aligned}
& R_{p}=\Delta e_{p}(C R 1)+\Delta f_{p}(C R 2) \\
& T_{p}=\Delta f_{p}(C R 1)-\Delta e_{p}(C R 2) \\
& U_{p}=\Delta e_{p}\left(\Delta e_{p}\right)+\Delta f_{p}\left(\Delta f_{p}\right)
\end{aligned}
$$

where,

$$
\begin{aligned}
& C R 1=\sum_{r=1}^{n-1}\left(B_{p r} \Delta f_{r}+G_{p r} \Delta e_{r}\right) \\
& C R 2=\sum_{r=1}^{n-1}\left(G_{p r} \Delta f_{r}-B_{p r} \Delta e_{r}\right)
\end{aligned}
$$

Based on the Taylor expansion, the mismatch relationships with the correction factors added become

$$
\begin{aligned}
& \Delta P_{p}=N R C P+R_{p} \\
& \Delta Q_{p}=N R C Q+T_{p} \\
& \Delta\left|V_{p}\right|^{2}=N R C V+U_{p}
\end{aligned}
$$

In the S.O.N.R. method, $R_{p}, T_{p}$, and $U_{p}$ are calculated using the $\Delta e_{i}$ and $\Delta f_{i}$ as determined from the N.R. portion of the procedure. The factors are then incorporated in the following way [step (10) of Q.S.O.N.R.]:

$$
\begin{aligned}
& \Delta P_{p}^{\prime}=N R C P \\
& \Delta Q_{p}{ }^{\prime}=N R C Q \\
& \Delta\left|v_{p}\right|^{2}=N R C V
\end{aligned}
$$


where,

$$
\begin{aligned}
& \Delta P_{p}^{\prime}=\Delta P_{p}-R_{p} \\
& \Delta Q_{p}^{\prime}=\Delta Q_{p}-T_{p} \\
& \Delta\left|V_{p}\right|^{2^{\prime}}=\Delta\left|V_{p}\right|^{2}-U_{p}
\end{aligned}
$$

Equations (3.35), (3.36), and (3.37) are then solved for new values of voltage changes, $\Delta e_{i}{ }^{\prime}$ and $\Delta f_{i}{ }^{\prime}$.

The M.Q.S.O.N.R. method is the same as the Q.S.O.N.R. method until the point where the second order correction factors are calculated. Rather than calculate those factors entirely, we now calculate only CRI and CR2 with equations (3.27) and (3.28), using $\Delta \mathrm{e}_{\mathbf{i}}$ and $\Delta \mathbf{f}_{\mathbf{i}}$ as calculated with the N.R. relationship [step (7) of Q.S.O.N.R.].

We can see how the correction factors will be used by writing out and expanding equations (3.29), (3.30) and (3.31), as follows,

$$
\begin{aligned}
& \Delta P_{p}=\sum_{\substack{i=1 \\
i \neq p}}^{n-1} \frac{\partial P}{\partial e_{i}} \Delta e_{i}{ }^{\prime}+\sum_{\substack{i=1 \\
i \neq p}}^{n-1} \frac{\partial P}{\partial f_{i}} \Delta e_{i}{ }^{\prime}+\left(\frac{\partial P}{\partial e_{p}}+C R l\right) \Delta e_{p}^{\prime} \\
& +\left(\frac{\partial P}{\partial f_{p}}+C R 2\right) \Delta f_{p}^{\prime} \\
& \Delta Q_{p}=\sum_{\substack{i=1 \\
i \neq p}}^{n-1} \frac{\partial Q_{p}}{\partial e_{i}} \Delta e_{i}{ }^{\prime}+\sum_{\substack{i=1 \\
i \neq p}}^{n-1} \frac{\partial Q_{p}}{\partial e_{i}} \Delta e_{i}{ }^{\prime}+\left(\frac{\partial Q_{p}}{\partial e_{p}}-C R 2\right) \Delta e_{p}{ }^{\prime} \\
& +\left(\frac{\partial Q_{p}}{\partial f_{p}}+C R l\right) \Delta f_{p}^{\prime}
\end{aligned}
$$




$$
\begin{aligned}
\Delta\left|v_{p}\right|^{2} & =\sum_{\substack{i=1 \\
i \neq p}}^{n-1} \frac{\partial\left|v_{p}\right|^{2}}{\partial e_{i}} \Delta e_{i}{ }^{\prime}+\sum_{\substack{i=1 \\
i \neq p}}^{n-1} \frac{\partial\left|v_{p}\right|^{2}}{\partial f_{i}} \Delta f_{i} \\
& +\left(\frac{\partial\left|v_{p}\right|^{2}}{\partial e_{p}}+\Delta e_{p}\right) \Delta e_{p}^{\prime}+\left(\frac{\partial\left|v_{p}\right|^{2}}{\partial f_{i}}+\Delta f_{p}\right) \Delta f_{p}^{\prime}
\end{aligned}
$$

Equations $(3.38),(3.39)$, and $(3.40)$ are solved in the given forms with the second order correction factors modifying only the diagonal elements of $\mathrm{J}_{1}, \mathrm{~J}_{2}, \mathrm{~J}_{3}, \mathrm{~J}_{4}, \mathrm{~J}_{5}$, and $\mathrm{J}_{6}$,

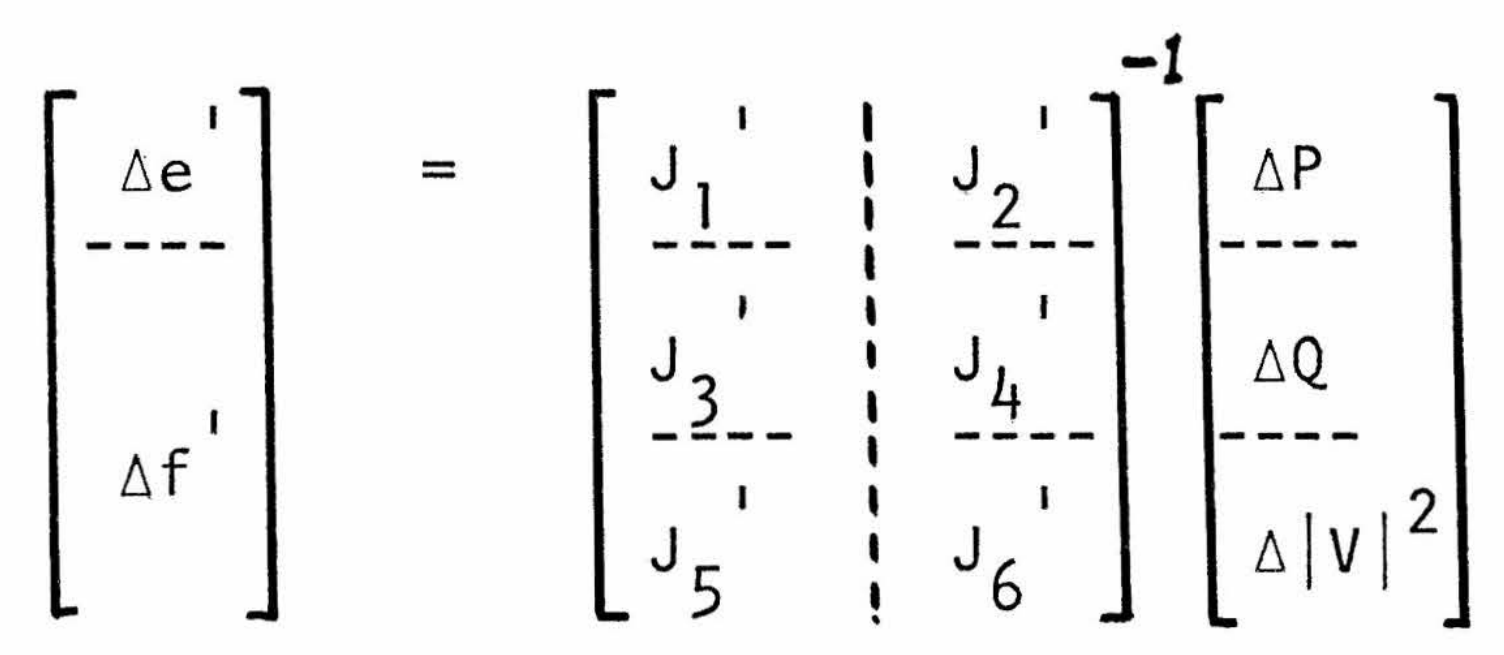

The load flow procedure then continues on, as before [step (12) of Q.S.O.N.R.]. The main changes from the Q.S.O.N.R. occur in steps (9), (10), and (11).

It is easily shown that the Q.S.O.N.R. and the M.Q.S.O.N.R., number one, are specific cases of a general scheme, if we write equations (3.38), (3.39), and (3.40) in the following forms,

$$
\begin{aligned}
\Delta P_{p}-\alpha_{p}\left[\left(\Delta e_{p}\right) C R 1\right. & \left.+\Delta f_{p}(C R 2)\right]=\sum_{i=1}^{n-1} \frac{\partial P_{p}}{\partial e_{i}} \Delta e_{i}^{\prime} \\
& +\sum_{i=1}^{n-1} \frac{\partial P_{p}}{\partial f} \Delta f_{i}^{\prime} \\
& +\left(1-\alpha_{p}\right)\left[C R 1\left(\Delta e_{p}^{\prime}\right)+C R 2\left(\Delta f_{p}^{\prime}\right)\right]
\end{aligned}
$$




$$
\begin{aligned}
\Delta Q_{p}-\alpha_{p}\left[\left(\Delta f_{p}\right) C R 1\right. & \left.-\left(\Delta e_{p}\right) C R 2\right]=\sum_{i=1}^{n-1} \frac{\partial Q_{p}}{\partial e_{i}} \Delta e_{i}{ }^{\prime} \\
& +\sum_{i=1}^{n-1} \frac{\partial Q_{p}}{\partial f_{i}} \Delta f_{i}^{\prime} \\
& +\left(1-\alpha_{p}\right)\left[C R 1\left(\Delta f_{p}^{\prime}\right)-\operatorname{CR2}\left(\Delta e_{p}^{\prime}\right)\right]
\end{aligned}
$$

$$
\begin{aligned}
\Delta\left|v_{p}\right|^{2}-\alpha_{p}\left[\left(\Delta e_{p}\right)^{2}\right. & \left.+\left(\Delta e_{f}\right)^{2}\right]=\sum_{i=1}^{n-1} \frac{\partial\left|v_{p}\right|^{2}}{\partial e_{i}} \Delta e_{i}^{\prime} \\
& +\sum_{i=1}^{n-1} \frac{\partial\left|v_{p}\right|^{2}}{\partial f_{i}} \Delta_{i}^{\prime} \\
& +\left(1-\alpha_{p}\right)\left[\Delta e_{p}\left(\Delta e_{p}^{\prime}\right)+\Delta f_{p}\left(\Delta f_{p}^{\prime}\right)\right]
\end{aligned}
$$

If we set alpha equal to 1 , then these equations reduce to the equations employed in step (11) of the Q.S.O.N.R. method. If alpha is set to 0 , then $(3.42),(3.43)$, and (3.44) reduce to equations (3.38), (3.39), and (3.40) which constitute the modified Q.S.O.N.R. method presented in this subsection. This is the alpha-modified Q.S.O.N.R. which was programmed and tested. The programming is such, that, given the proper flagging, a particular power system under consideration can be solved by N.R., Q.S.O.N.R. (i.e., M.Q.S.O.N.R. with $\alpha_{p}=1$ ) or M.Q.S.O.N.R. with any other alpha value that is desired.

\subsubsection{M.Q.S.O.N.R. method number 2}

As stated in the introduction to this section, the three alphamodified second order methods described in this and the next subsections 
were not programmed. However they represent major variants of the alphamodified idea and, as such, should be presented.

As with the M.Q.S.O.N.R. method number 1 , the load flow solution procedure for this method is the same as the Q.S.O.N.R. until we come to the point where the second order correction factors are calculated. Instead of calculating at this point, the correction factor expressions of equations (3.14), (3.23), and (3.26) are incorporated into mismatch equations $(2.31),(2.32)$, and $(2.35)$ to arrive at the forms,

$$
\begin{aligned}
\Delta P_{p} & =\sum_{i=1}^{n-1} \frac{\partial P_{p}}{\partial e_{i}} \Delta e_{i}{ }^{\prime}+\sum_{i=1}^{n-1} \frac{\partial P_{p}}{\partial f_{i}} \Delta f_{i}^{\prime} \\
& +\sum_{i=1}^{n-1}\left(G_{p i} \Delta e_{p}-B_{p i} \Delta f_{p}\right) \Delta e_{i}^{\prime}{ }^{\prime} \\
& +\sum_{i=1}^{n-1}\left(B_{p i} \Delta e_{p}+G_{p i} \Delta f_{p}\right) \Delta f_{i}^{\prime}
\end{aligned}
$$

which reduces to

$$
\begin{aligned}
\Delta P_{p} & =\sum_{i=1}^{n-1}\left(\frac{\partial P_{p}}{\partial e_{i}}+G_{p i} \Delta e_{p}-B_{p i} \Delta f_{p}\right) \Delta e_{i}^{\prime} \\
& +\sum_{i=1}^{n-1}\left(\frac{\partial P_{p}}{\partial f_{i}}+B_{p i} \Delta e_{p}+G_{p i} \Delta f_{p}\right) \Delta f_{i}^{\prime}
\end{aligned}
$$

Similarly,

$$
\begin{aligned}
\Delta Q_{p} & =\sum_{i=1}^{n-1}\left(\frac{\partial Q_{p}}{\partial e_{i}}+G_{p i} \Delta f_{p}+B_{p i} \Delta e_{p}\right) \Delta e_{i}{ }^{\prime} \\
& +\sum_{i=1}^{n-1}\left(\frac{\partial Q_{p}}{\partial f_{i}}+B_{p i} \Delta f_{p}-G_{p i} \Delta e_{p}\right) \Delta f_{i}^{\prime}
\end{aligned}
$$

and, 


$$
\begin{aligned}
\Delta\left|v_{p}\right|^{2} & =\sum_{i=1}^{n-1} \frac{\partial\left|v_{p}\right|^{2}}{\partial e_{i}} \Delta e_{i}{ }^{\prime}+\sum_{i=1}^{n-1} \frac{\partial\left|v_{p}\right|^{2}}{\partial f_{i}} \Delta f_{i}{ }^{\prime} \\
& +\left(\Delta e_{p}\right) \Delta e_{p}{ }^{\prime}+\left(\Delta f_{p}\right) \Delta f_{p}{ }^{\prime}
\end{aligned}
$$

From $(3.45),(3.46)$, and (3.47) we can see that every non-zero Jacobian element will be modified. These equations are used in this form to solve,

$$
\left[\begin{array}{l}
\Delta e^{\prime} \\
\hdashline f^{\prime}
\end{array}\right]=\left[\begin{array}{l:l}
J_{1}^{\prime} & J_{2}^{\prime} \\
\hdashline J^{i} & -J^{\prime}- \\
-J_{5}- & J_{4}-1 \\
J_{5} & J_{6}-
\end{array}\right]^{-1}\left[\begin{array}{c}
\Delta P \\
-\Delta Q \\
-\Delta|V|^{2}
\end{array}\right]
$$

From here the procedure continues on as with the Q.S.O.N.R.

In a general alpha-modified form the mismatch equations can be written as

$$
\begin{aligned}
\Delta P_{p} & -\alpha_{p} \sum_{i=1}^{n-1}\left[\left(G_{p i} \Delta e_{p}-B_{p i} \Delta f_{p}\right) \Delta e_{i}+\left(B_{p i} \Delta e_{p}+G_{p i} \Delta f_{p}\right) \Delta f_{i}\right] \\
& =\sum_{i=1}^{n-1}\left[\frac{\partial P}{\partial e_{i}}+(1-\alpha)\left(G_{p i} \Delta e_{p}-B_{p i} \Delta f_{p}\right) \Delta e_{i}{ }^{\prime}\right] \\
& =\sum_{i=1}^{n-1}\left[\frac{\partial P}{\partial f}+(1-\alpha)\left(B_{p i} \Delta e_{p}+G_{p i} \Delta f_{p}\right) \Delta f_{i}{ }^{\prime}\right] \\
\Delta Q_{p} & -\alpha_{p} \sum_{i=1}^{n-1}\left[\left(G_{p i} \Delta f_{p}+B_{p i} \Delta e_{p}\right) \Delta e_{i}+\left(B_{p i} \Delta f_{p}-G_{p i} \Delta e_{p}\right) \Delta f_{i}\right] \\
= & \sum_{i=1}^{n-1}\left[\frac{\partial Q_{p}}{\partial e_{i}}+(1-\alpha)\left(G_{p i} \Delta f_{p}+B_{p i} \Delta e_{p}\right) \Delta e_{i}{ }^{\prime}\right]
\end{aligned}
$$




$$
\begin{aligned}
+\sum_{i=1}^{n-1}\left[\frac{\partial Q_{p}}{\partial f_{i}}+(1-\alpha)\right. & \left.\left(B_{p i} \Delta f_{p}-G_{p i} \Delta e_{p}\right) \Delta f_{i}^{\prime}\right] \\
\Delta\left|v_{p}\right|^{2}-\alpha_{p}\left(\Delta e_{p}^{2}+\Delta e_{f}^{2}\right) & =\sum_{i=1}^{n-1} \frac{\partial\left|v_{p}\right|^{2}}{\partial e_{i}} \Delta e_{i}{ }^{\prime}+\sum_{i=1}^{n-1} \frac{\partial\left|v_{p}\right|^{2}}{\partial f_{i}} \Delta f_{i}{ }^{\prime} \\
& +(1-\alpha)\left(\Delta e_{p}\right) \Delta e_{p}^{\prime} \\
& +(1-\alpha)\left(\Delta f_{p}\right) \Delta f_{p}^{\prime}
\end{aligned}
$$

By setting alpha equal to one we obtain the equations for the Q.S.O.N.R. method. With alpha equal to 0 we get the specific case, illustrated earlier in this subsection, of all the Jacobian elements being altered while the mismatch values, $\Delta P_{p}, \Delta Q_{p}$, and $\Delta\left|V_{p}\right|^{2}$, remain unaltered.

Thus, we have M.Q.S.O.N.R. number 2 method for solving a load flow problem.

\section{4 .4 M.Q.S.O.N.R. methods numbers 3 and 4}

These two methods change the basic Q.S.O.N.R. method a little more drastically than the first two alpha-modified methods. However, they are, in fact, variants of those two methods since they use the same "second order" mismatch relationships.

Basically, the change from the previous two procedures is the elimination, except during the first iteration, of the Newton-Raphson voltage correction calculations [step (7) of Q.S.O.N.R.] which constitutes the first half iteration.

All the derivations needed for these two new methods have been evaluated previously. Therefore the proposed procedures for both can be 
presented now, and are as follows, (unless noted, each step is for both methods).

1) Form the bus admittance matrix, [Y]

2) Initialize the bus voltage, $\mathrm{e}_{\mathrm{i}}+\mathrm{jf}_{\mathrm{i}}$

3) Calculate $P_{p}, Q_{p},\left|V_{p}\right|^{2}$ with equation (2.21), (2.22), and (2.23)

4) Calculate the bus mismatches with

$$
\begin{aligned}
& \Delta P_{p}=P_{p s c h e d}-P_{p}-\alpha_{p} \sum_{i=1}^{n-1}\left[\Delta e_{p}\left(B_{p i} \Delta f_{i}+G_{p i} \Delta e_{i}\right)\right. \\
& \left.\quad+\Delta f_{p}\left(G_{p i} \Delta f_{i}-B_{p i} \Delta e_{i}\right)\right] \\
& \Delta Q_{p}=Q_{p s c h e d}-Q_{p}-\alpha_{p} \sum_{i=1}^{n-1}\left[\Delta f_{p}\left(B_{p i} \Delta f_{i}+G_{p i} \Delta e_{i}\right)\right. \\
& \left.\quad-\Delta e_{p}\left(G_{p i} \Delta f i-B_{p i} \Delta e_{i}\right)\right] \\
& \Delta\left|V_{p}\right|^{2}=\left|v_{p s c h e d}\right|^{2}-\left|v_{p}\right|^{2}-\alpha_{p}\left[\left(\Delta e_{p}\right)^{2}+\left(\Delta f_{p}\right)^{2}\right]
\end{aligned}
$$

Note that during the first iteration, $\Delta e_{i}$ and $\Delta f_{i}$ will be zero, which will make the "alpha terms" of the above relationship, zero.

5) Check to see if the power and voltage magnitude mismatches, calculated in step (4), are within the specified tolerance. If so, solution reached. If not, continue. 
48

6) Calculate the "modified Jacobian" elements. For M.Q.S.O.N.R. number three, we take the expression from equations (3.42), (3.43), and $(3.44)$, resulting in elements for $\mathrm{J}$, given by

$$
\begin{aligned}
J_{1}(p, i) & =\frac{\partial P}{\partial e_{i}} & , \quad i \neq p \\
& =\frac{\partial P}{\partial e_{i}}+\left(1-\alpha_{p}\right) C R I & , \quad i=p
\end{aligned}
$$

for $\mathrm{J}_{2}$ :

$$
\begin{aligned}
J_{2}(p, i) & =\frac{\partial p}{\partial f_{i}} & , \quad i \neq p \\
& =\frac{\partial P_{p}}{\partial f_{i}}+\left(1-\alpha_{p}\right) C R 2 & , \quad i=p
\end{aligned}
$$

for $\mathrm{J}_{3}$ :

$$
\begin{aligned}
J_{3}(p, i) & =\frac{\partial Q_{p}}{\partial e_{i}} & , \quad i \neq p \\
& =\frac{\partial Q_{p}}{\partial e_{i}}-\left(1-\alpha_{p}\right) C R 2 & , \quad i=p
\end{aligned}
$$

for $\mathrm{J}_{4}$ :

$$
\begin{aligned}
J_{4}(p, i) & =\frac{\partial Q_{p}}{\partial f_{i}} & , \quad i \neq p \\
& =\frac{\partial Q_{p}}{\partial f_{i}}+\left(1-\alpha_{p}\right) C R I & , \quad i=p
\end{aligned}
$$

for $\mathrm{J}_{5}$ :

$$
\begin{aligned}
J_{5}(p, i) & =\frac{\partial\left|v_{p}\right|^{2}}{\partial e_{i}}=0 & , \quad i \neq p \\
& =\frac{\partial\left|v_{p}\right|^{2}}{\partial e_{i}}+\left(1-\alpha_{p}\right)\left(\Delta e_{p}\right), & i=p
\end{aligned}
$$


49

for $\mathrm{J}_{6}$ :

$$
\begin{aligned}
J_{6}(p, i) & =\frac{\partial\left|v_{p}\right|^{2}}{\partial f_{i}}=0 & , \quad i \neq p \\
& =\frac{\partial\left|v_{p}\right|^{2}}{\partial f_{i}}+\left(1-\alpha_{p}\right)\left(\Delta f_{p}\right) & , \quad i=p
\end{aligned}
$$

For the M.Q.S.O.N.R. number four, we utilize the expressions from equations (3.48), (3.49), and (3.50), resulting in the elements being for $\mathrm{J}_{1}$ :

$$
J_{1}(p, i)=\frac{\partial P_{p}}{\partial e_{i}}+\left(1-\alpha_{p}\right)\left(G_{p i} \Delta e_{p}-B_{p i} \Delta f_{p}\right)
$$

for $\mathrm{J}_{2}$ :

$$
J_{2}(p, i)=\frac{\partial P}{\partial f_{i}}+\left(1-\alpha_{p}\right)\left(B_{p i} \Delta e_{p}+G_{p i} \Delta f_{p}\right)
$$

for $\mathrm{J}_{3}$ :

$$
J_{3}(p, i)=\frac{\partial Q_{p}}{\partial e_{i}}+\left(1-\alpha_{p}\right)\left(G_{p i} \Delta f_{p}+B_{p i} \Delta e_{p}\right)
$$

for $\mathrm{J}_{4}$ :

$$
J_{4}(p, i)=\frac{\partial Q_{p}}{\partial f_{i}}+\left(1-\alpha_{p}\right)\left(B_{p i} \Delta f_{p}-G_{p i} \Delta e_{p}\right)
$$

for $\mathrm{J}_{5}$ :

$$
J_{5}(p, i)=\frac{\partial\left|v_{p}\right|^{2}}{\partial e_{i}}+\left(1-\alpha_{p}\right)\left(\Delta e_{p}\right)
$$

for $J_{6}$ :

$$
J_{6}(p, i)=\frac{\partial\left|v_{p}\right|^{2}}{\partial f_{i}}+\left(1-\alpha_{p}\right)\left(\Delta f_{p}\right)
$$


note that, for both methods, during the first iteration $\Delta \mathbf{e}_{\mathbf{i}}$ and $\Delta f_{i}$ are both zero. This leaves the coefficient matrix composed of true Jacobian elements.

7) With the mismatch values found in step (4) and the modified Jacobian elements found in step (6), solve the following set of simultaneous equations for the voltage corrections

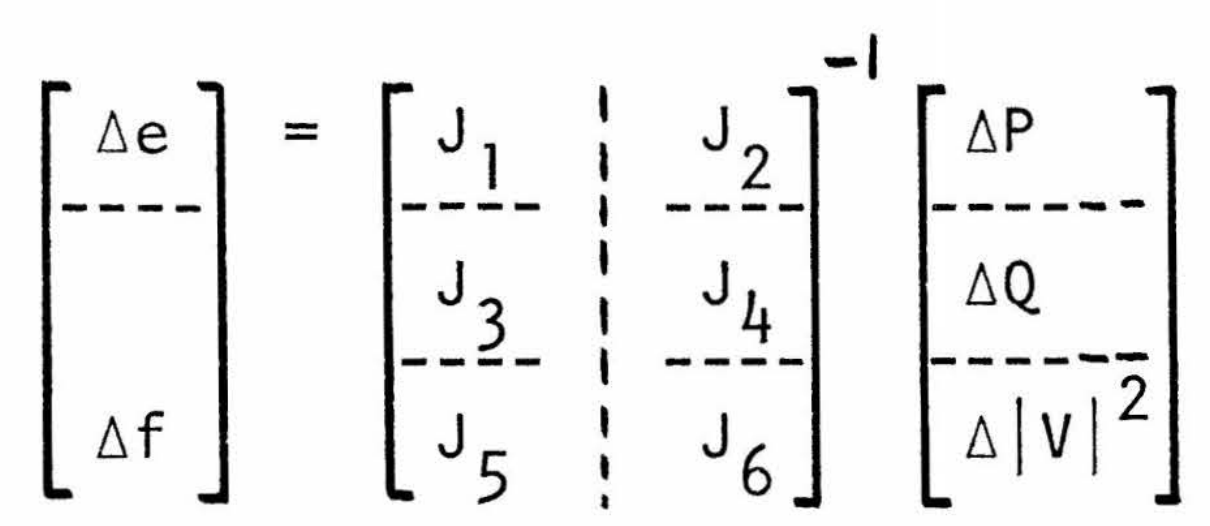

8) Update the bus voltages of the $k^{\text {th }}$ iteration,

$$
\begin{aligned}
& e_{i}^{(K+1)}=e_{i}^{(K)}+\Delta e_{i}^{(K)} \\
& f_{i}^{(K+1)}=f_{i}^{(K)}+\Delta f_{i}^{(K)}
\end{aligned}
$$

9) Go to step (3).

With the alpha-M.Q.S.O.N.R. methods number 3 and number 4 , the main advantage over the other second order methods presented previously is the elimination of the need to solve a second set of simultaneous equations during a single iteration. As a result the storage requirements should be slightly less and the computer CPU time per iteration will be substantially reduced. And, since the second order correction factors are employed, it would appear that the rate of convergence to the load flow solution would be very similar. Certainly these two methods are worth investigating and will be mentioned again in the concluding chapter. 


\author{
CHAPTER IV \\ APPLICATION AND ANALYSIS OF THE \\ ALPHA-MODIFIED QUASI SECOND ORDER \\ NEWTON-RAPHSON METHOD FOR SOLVING LOAD FLOW PROBLEMS
}

\title{
4.1 Sparsity
}

As stated in the introductory chapter, the powerful convergence properties of the Newton-Raphson technique in solving load flows can only be utilized competitively through the use of sparsity programming. For the author's programs, a package of subroutines for the solution of sparse sets of linear equations obtained from the Atomic Energy Research Establishment (U.K.) in Harwell, England [14] was adopted. These basicaly employ Gaussian elimination and aim at maintaining both stability and sparseness. It also has the feature which, after an equation set has been solved once, allows further systems with the same coefficient matrix, or one having the same sparsity pattern, to be solved more economically. Load flow solutions do, of course, benefit immensely from this feature. Only slight modifications were required to make these subroutines compatible with the program as it stood at the stage of incorporating sparsity techniques, and wi th the computer system being used. The subroutine specification sheets are given in Appendix $C$, while their listings are in appendix E, along with the main body of the program.

Incorporating the sparsity subroutine required major modifications to the program. Maximizing overall efficiency and compatibility dictated inclusion of programming modifications to (1) reorder the lines and their 
associated data into an optimum format, (2) decompose the bus admittance matrix into sparse vectors, (3) construct the Jacobian matrix sparsely, and (4) change almost all of the remaining program which worked on these sparse matrices. However, after all was said and done the benefits were immediately seen. The load flow, with the largest system being tested (IEEE 118-Bus, which is not really that big), had a reduction of $75 \%$ in core requirements and a $63 \%$ saving in CPU time, for an overall cost reduction of $91 \%$ : This improved even more as the program continued to be made more efficient. Of course, with systems of about 25 buses or less, the sparsity programming caused an increase in CPU time and storage requirements.

\subsection{The Computer Program}

\subsubsection{General}

The program was written in the FORTRAN IV language and was run on an IBM $370 / 158$ model II with SVS operating system owned by Newfoundland and Labrador Computer Services.

It should be noted here that the program, as it presently exists, is an experimental testing program, rather than one for production runs. As such, it does not yet contain the capability to handle many of the special features of a "real-life" power system, such as under load tap changing, phase shifting transformers, and tie line control.

Figure 4.1 gives the general flow chart which illustrates, in a basic manner, how the alpha-modified quasi second order Newton-Raphson procedure is programmed. It also shows that an ordinary Newton-Raphson 


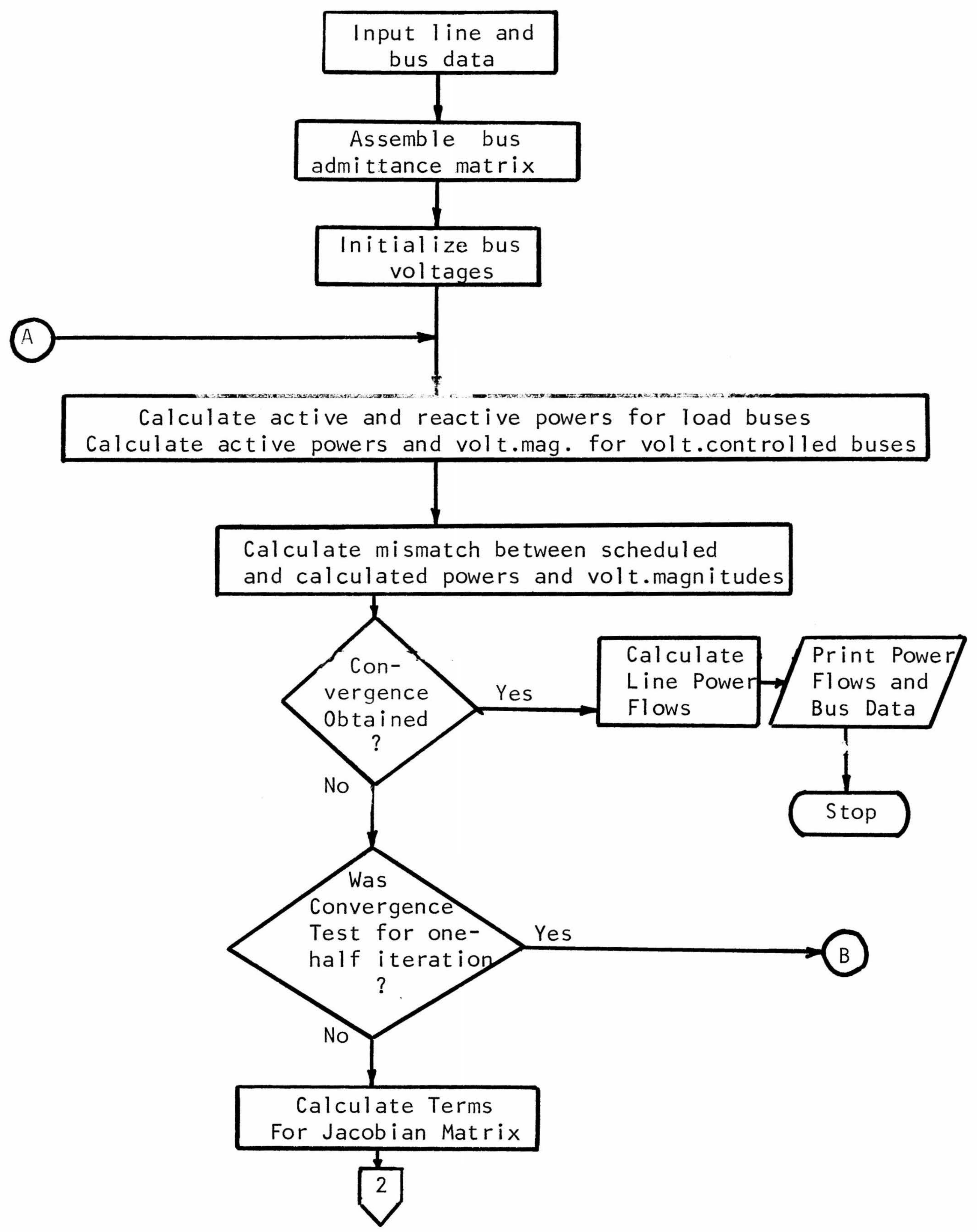

Figure 4.1: General flow chart for the alpha-modified quasisecond order Newton Raphson method. 


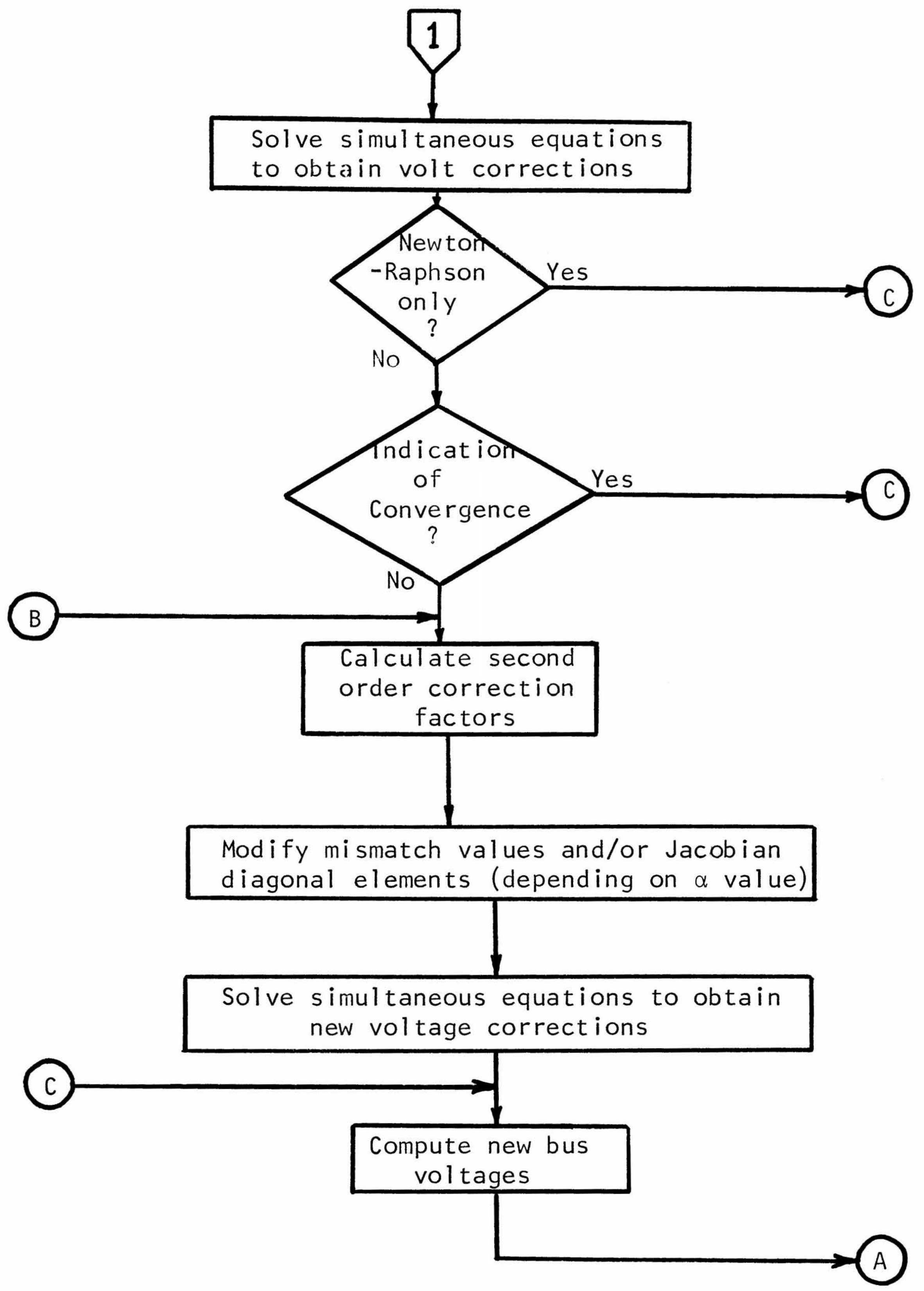


solution procedure is able to be performed. In fact, one of the advantages of second order type extensions of the Newton-Raphson method is that a subroutine with the additional programming can be simply added to existing production programs with only a few minor changes necessary.

Apendix $D$ contains the documentation defining the computer variable names, as well as how they should be dimensioned. The complete program listing is contained in appendix E.

\subsubsection{Definition of One-Half Iteration}

As will be seen in the results, we use the term a half iteration. This will be fully explained here. The second order load flow technique entails twice solving a set of simultaneous equations for bus voltage corrections. Once, with the power and voltage magnitude mismatches calculated with first order correction terms and later, with second order correction factors as well. It is possible, however, that on the last iteration needed for convergence, the convergence criterion could be met with the "first order" voltage corrections. It may not be necessary to continue on and obtain an updated set of voltage corrections.

Therefore, before attempting to solve the second set of equations, there is a check to see if this step can be skipped. One way this could have been implimented would have been to calculate, at this point, new voltages using the "first order" voltage corrections, new bus powers and voltage magnitudes with these new voltages, and new mismatches. Then, perform the convergence test to see if these mismatches are within 
the specified tolerance. However, doing this during every iteration would possibly involve as much or more computation time than if there was no attempt to eliminate the last half of the last iteration.

A much simpler way of determining the necessity for the last half iteration is utilized. With the "first order" voltage corrections, the second order power and voltage magnitude correction factors are calculated. If these factors are all less than the given tolerance, then the new mismatches would be all much the same as the previous mismatches used in the calculation to obtain the "first order" voltage corrections. In most cases, this would lead to the updated voltage corrections being much the same as the non-updated values, which is a fairly good indication that convergence has been reached.

So, if all the factors are lower than the tolerance, new voltages are calculated, then new bus variables and mismatches, followed by the convergence test. In the majority of cases, when this occurs, it has been found that convergence has indeed been obtained. If, as is sometimes the case, it has not, then the program returns to the original departure point and continues on with the second half of the iteration.

\subsubsection{Program Limitations}

The computer program is set up to perform a load flow study of a straightforward normal power system with no extras. It can handle load buses and generator, or voltage controlled, buses with static capacitors or shunt reactors; lines with series impedence and line charging susceptances; transformers with off-nominal turns ratios.

It is not limited as to system size, though with each system a new 
set of dimension cards must be typed (the sizes of which are given in appendix D). There can be any number of buses, lines, transformers, shunt reactors or capacitors.

Buses must be numbered consecutively, starting at one. The voltage controlled buses have to have the higher numbers, with the slack (or swing) bus having the highest. The lines and their associated parameters are reordered by the program.

\subsection{Test Systems}

\subsubsection{5-Bus Power System}

The 5-bus system is given in [55], and is the smallest system tested. It consists of three load buses, two voltage controlled buses, one of which acts as the slack bus, and seven lines. The system data consists of (1) the scheduled generation and loads and assumed bus voltages, (2) line impedances and line charging susceptances, and (3) Regulated bus data. The other systems also have transformer data and static capacitor or shunt reactor data. The data for all the test systems is in appendix $F$.

\subsubsection{3-Bus Power System}

The 23-bus system is based on the one used in [11] for testing a solution method for minimum loss and economic dispatch problems. In our case, all buses but one (the slack bus) are treated as load buses. There are thirty lines whose data, along with the bus information, is presented in appendix F, tables F. 4 and F.5.

\subsubsection{IEEE 57-Bus Test System}

This was originally a part of the American Electric Power Corporation's 
1962 system made available to the electric utility industry as a standard test case for evaluating various analytical methods and computer programs for the solution of power networks. It eventually became one of the standard IEEE test systems. It consists of fifty load buses, seven voltage controlled buses, eighty lines, seventeen transformers with offnominal turns ratios, and three static capacitors. All the data is contained in appendix F, tables F.6 to F. 10 .

\subsubsection{IEEE 118-Bus Test System}

This system came to be a standard test case in the same manner as the previous one. It is made up of sixty-four load buses, fifty-four voltage regulated buses, one hundred and eighty-six lines, nine transformers with off-nominal turns ratios, and fourteen static capactors and shunt reactors. All this data is in appendix $F$, along with the data for the other systems, tables F.1l to F.15.

\subsubsection{Other Test Systems}

The other three systems used for testing are simply the 5, 57, and 118 bus systems with only one voltage controlled bus each (the slack buses), with their solution bus powers being used as scheduled bus loads . This was done as a convenient way to obtain some new test systems. And, indeed they are new with different convergence patterns and different solutions than the systems from which they are derived. The data for these systems, bus power, assumed voltage, line, transformer and static capacitor and reactor information is the same as for the original systems. They are referred to as the 5-bus (no.V.C.B.), the 57-bus (No. V.C.B.) and the 118-bus (No. V.C.B.) systems, with V.C.B. standing for Voltage Controlled Buses. 


\section{4 Results}

\subsubsection{General}

The developed load flow technique has been extensively tested using the seven power systems described in the previous section. These systems cover a wide range in terms of size-5 to 118 buses - and the larger systems with only one voltage controlled bus provide an extra challenge in that in such cases, convergence is usually more difficult to achieve.

Many variations of the alpha-M.Q.S.O.N.R. method were tried such as adding second order corrections only in the first iteration or applying them only to load buses. However, it was found that the best overall results occur with the straight forward application of the method. The improvement is in terms of convergence rate and computation time. Thus, this variant will be the main focus of attention in this section.

The results of studies for all the test systems are presented graphically and discussed in detail. For comparison purposes, all system load flows were also solved with the Newton-Raphson method.

\subsubsection{Iterations to Convergence}

From the description of Chapter 3 treating the alpha-modified Q.S.O.N.R., it can be seen that any value of alpha can be chosen and used. It would appear from the theory that the choice of alpha will be important. Its value determines what proportion of the second order correction factors is subtracted from the bus mismatches and what portion is added to the Jacobian elements in the setting up of the simultaneous set of equations to be solved for the updated voltage corrections. 
Therefore, we are interested in studying what effect if any, do different values of alpha have. After this is done we determine which is the best alpha to use. With this best alpha, we can then see how the alphaM.Q.S.O.N.R. method stacks up against the Newton-Raphson method.

The above was accomplished by taking each of the test systems and computing load flows with many different alpha values (ranging from -2.0 to +2.0 in increments of 0.1$)$ as well as with the Newton-Raphson method. The results of all this testing are tabulated in table 4.1, which gives the number of iterations to convergence for each alpha value for all the systems. Convergence was achieved when the maximum bus mismatches after an iteration (or half an iteration) were below the given tolerance. These results have been plotted for each system in figures 4.2 to 4.9 as graphs of iterations to convergence versus alpha values for tolerances of 0.0001 and 0.001 p.u. On the far right hand side of each graph there are two dots which tell the number of iterations required for the two tolerances for the Newton-Raphson (N. -R.) method.

Some general observations about the alpha-M.Q.S.O.N.R. method are immediately evident from the graphs. With all the systems, except the 118-Bus systems, and with every value of alpha, the number of iterations required for the smaller tolerance is either the same or only one-half an iteration more. This indicates that the method could best prove its worth against other techniques when low mismatch tolerances are specified. With the 118-Bus systems, 0.0001 p.u. is about the lowest mismatch value that can be achieved. This makes it more difficult to reach convergence, which shows up on the graphs as a fairly erratic plot (figure 4.5), or as no con- 


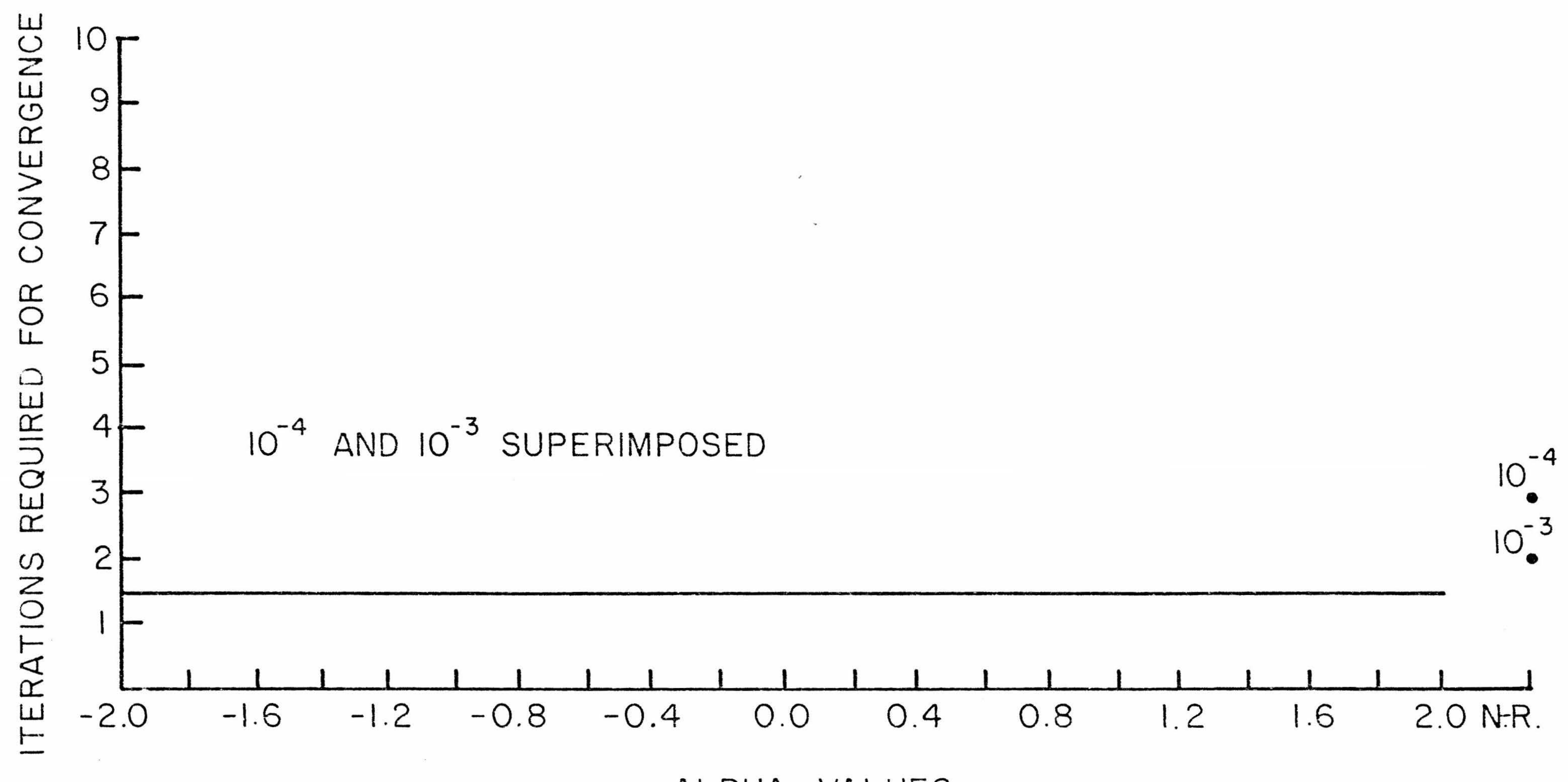

ALPHA VALUES

Figure 4.2: Number of Iterations to Convergence For the 5-Bus System with Tolerances of $10^{-4}$ p.u. and $10^{-3}$ p.u. 


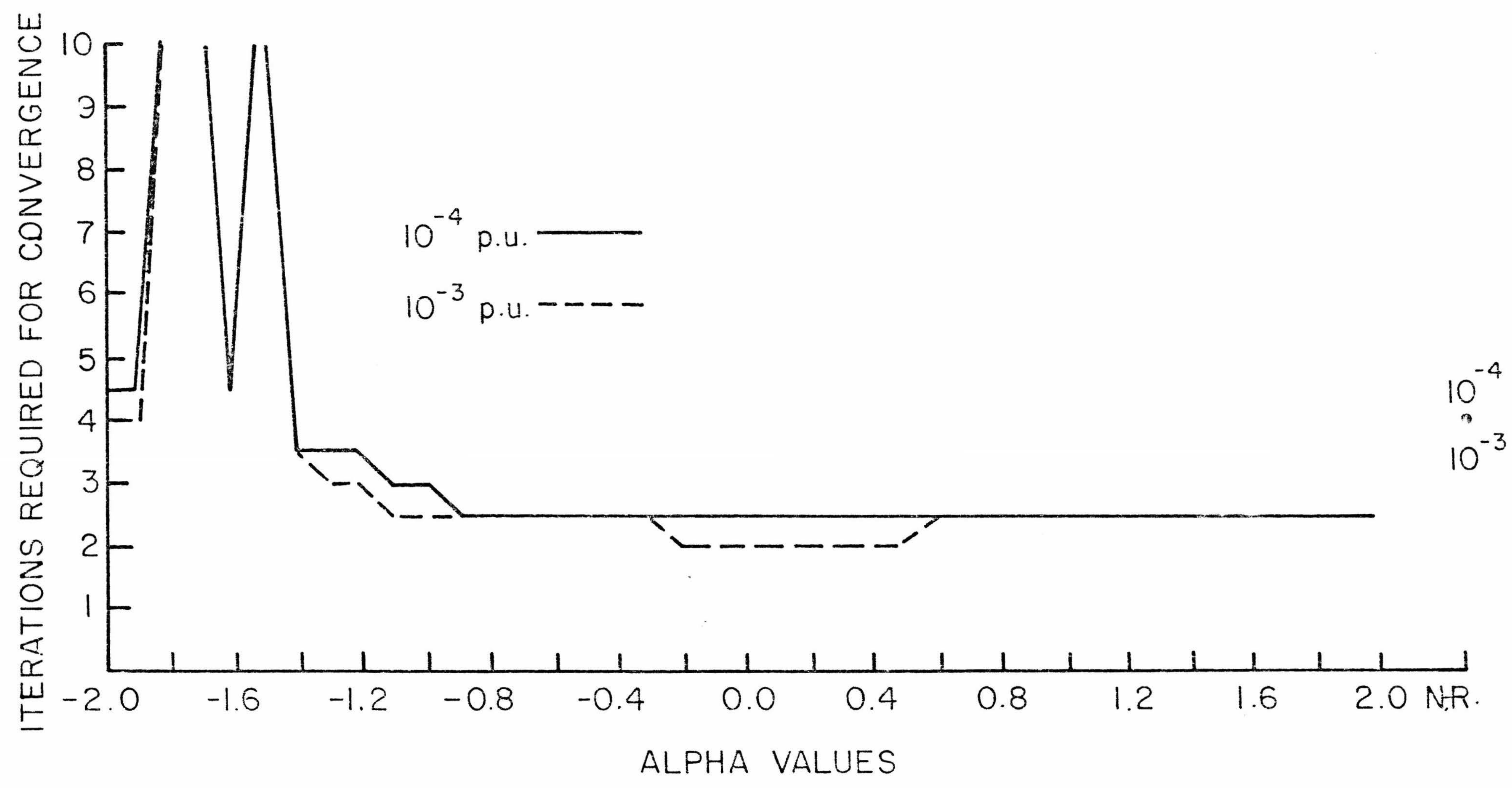

Figure 4.3: Number of Iterations to Convergence for the 23-Bus Systen with Tolerances of $10^{-4}$ p.u. and $10^{-3}$ p.u. 


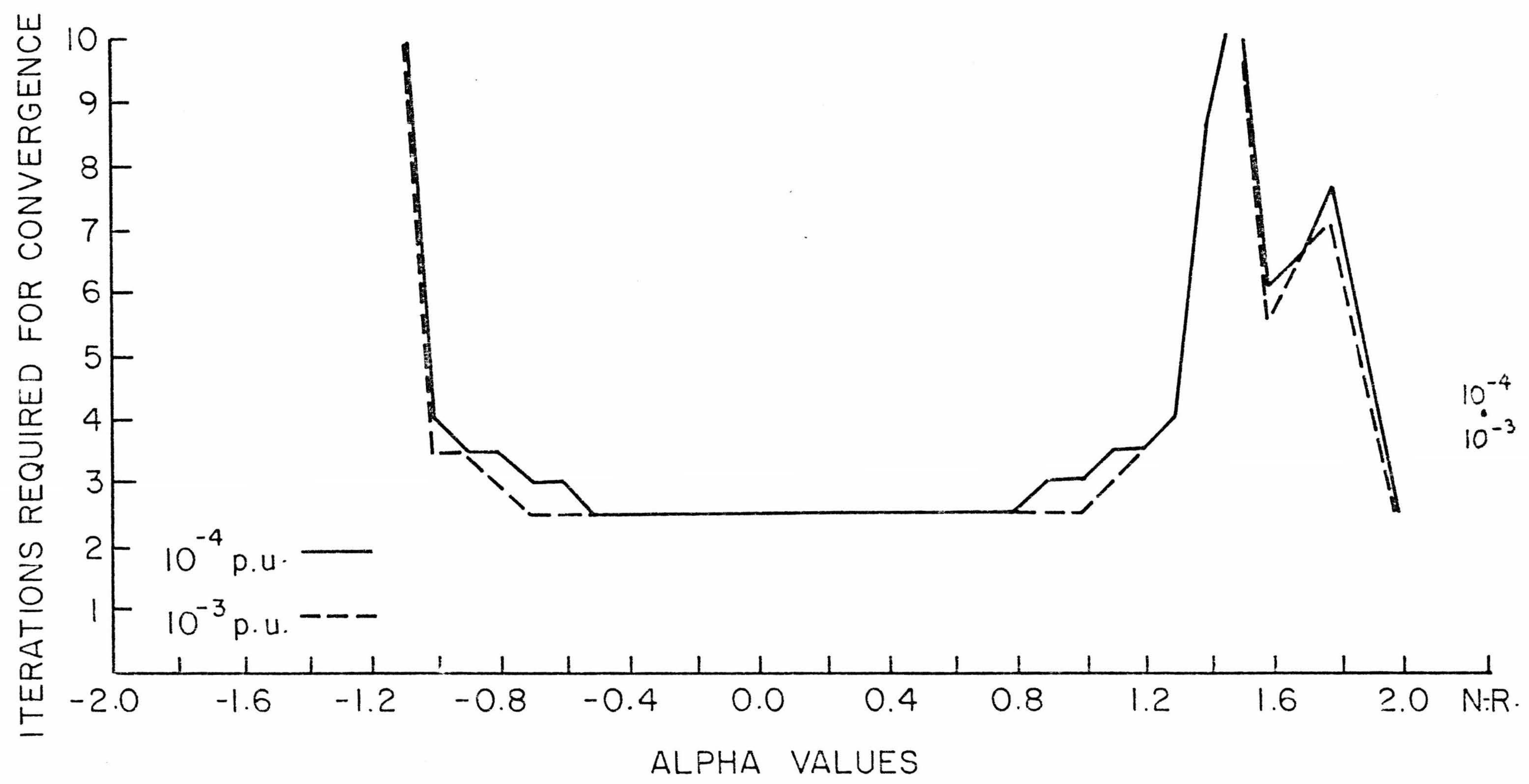

Figure 4.4: Number of Iterations to Convergence for the IEEE 57-Bus System with Tolerances of $10^{-4}$ p.u. and $10^{-3}$ p.u. 


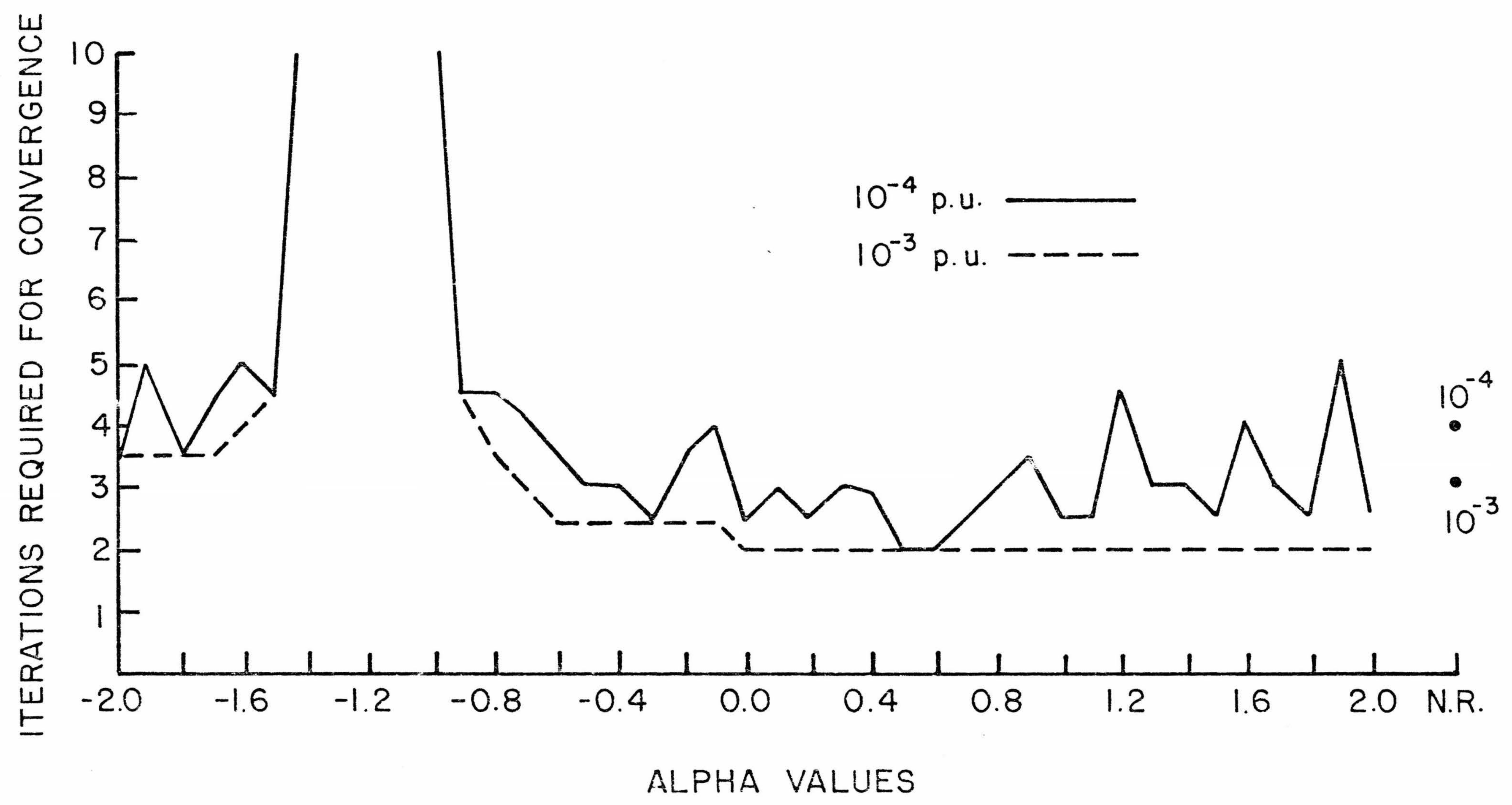

Figure 4.5: Number of Iterations to Convergence for the IEEE 18-Bus System with $V_{\text {start }}=130^{\circ}$ 


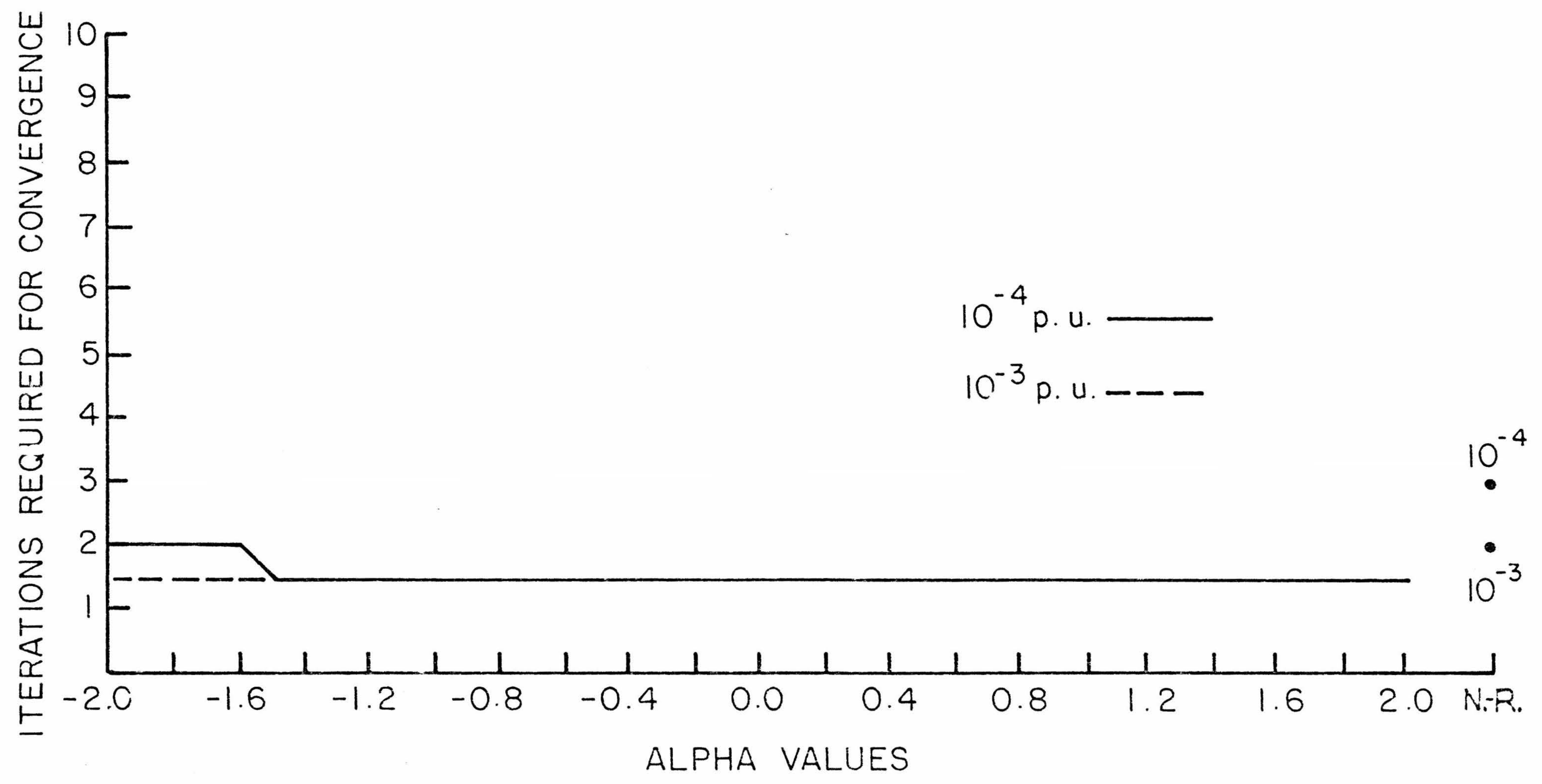

Figure 4.6: Number of Iterations to Convergence for the 5-Bus (No V.C.B.) System? with Tolerances of $10^{-4}$ p.u. and $10^{-3}$ p.u. 


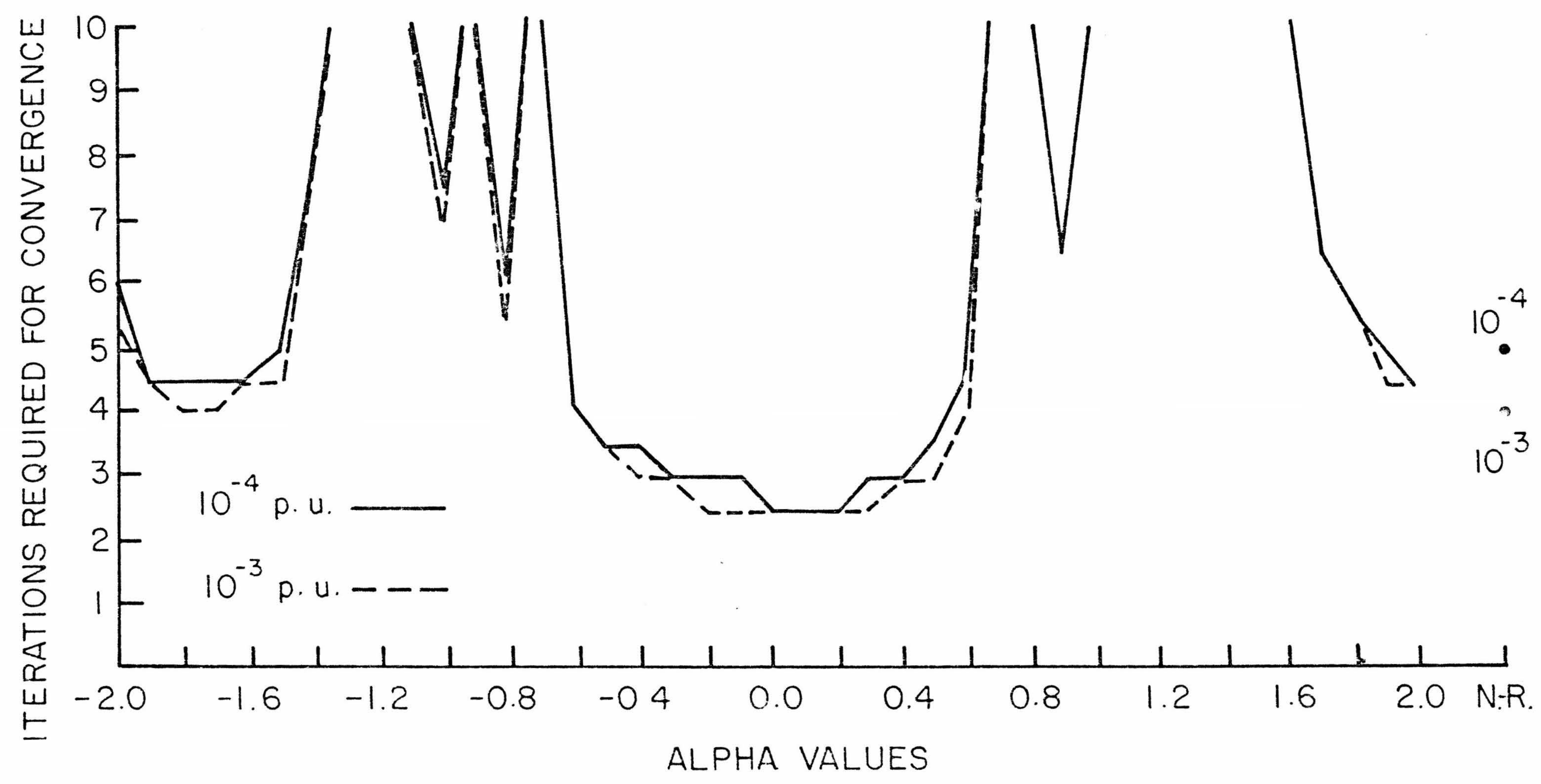

Figure 4.7: Number of Iterations to Convergence for the 57-Bus (No V.C.B.) System with Tolerances of $10^{-4} \mathrm{pus}$ and $10^{-3} \mathrm{p.u}$. 


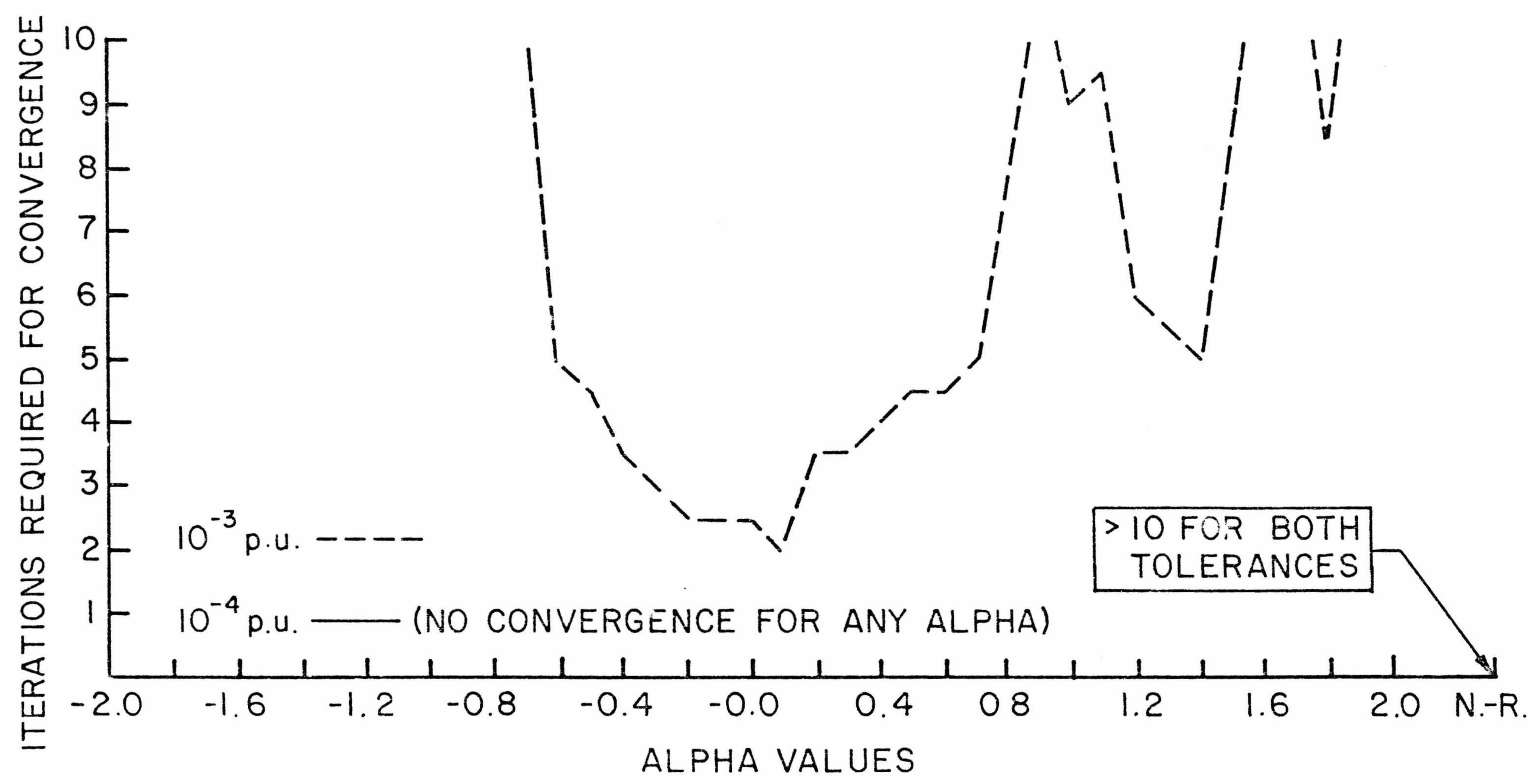

Figure 4.8: Number of 1.terations to Convergence for the 118-Bus (No. V.C.B.) System with Tolerances of $10^{-4}$ p.u. and $10^{-3}$ p.u. 


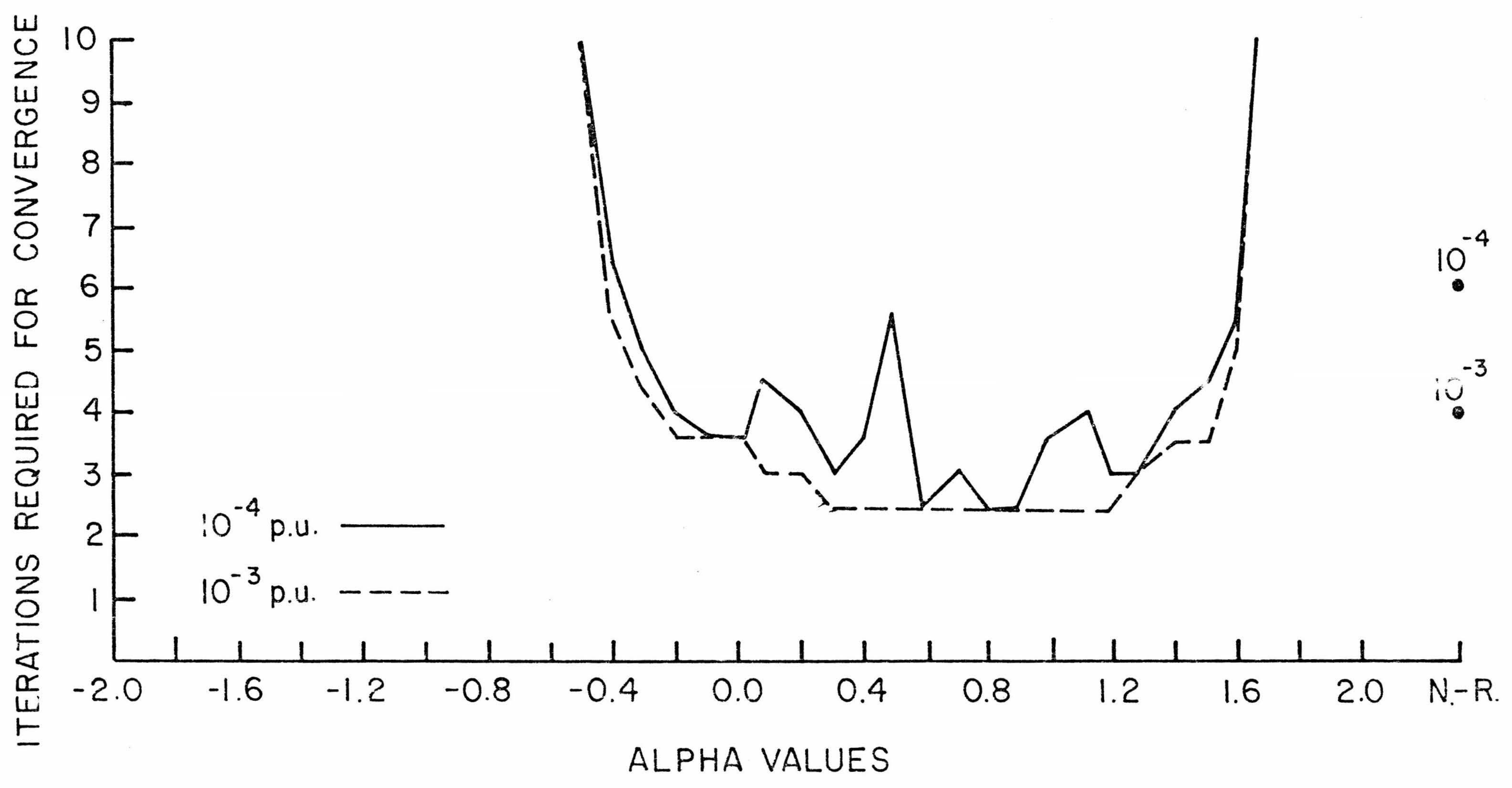

Figure 4.9: Number of Iterations to Convergence for the 118-Bus System with Initial Bus Angles Set to 0.0 Degrees. 
vergence at all (figure 4.8). This is in contrast to the well-behaved plots for the 0.001 p.u. tolerance in the same graphs.

In all cases, except for the 5 bus system, larger negative values of alpha generally result in a higher number of iterations required for convergence at best or no convergence at all (that is, at least not within 10 iterations). Except for the three smallest systems the same is true for larger positive values of alpha. But, when the value of alpha approaches zero, the method is consistently successful in bringing the load flow to a quick and successful solution.

The results lead us to the conclusion that the best convergence properties will in all likelihood occur when the alpha value is zero. This is reasonable since alpha having the value of zero causes the full second order correction factors to be added to the diagonal elements of the Jacobian submatrices and no portion subtracted from the bus mismatches. In effect, this results in the second order factors being calculated partly using the updated voltage corrections which are being solved for, thus moving those updated values further towards the correct figures. This can be seen by looking at equations (3.42), (3.43), and (3.44).

An additional advantage of alpha being equal to zero is that, because it is only necessary to modify the Jacobian, diagonal elements, there is less computational effort required than with other alpha values (except for alpha equal to one, where only the bus mismatches are modified).

Now, having determined that zero is the best value which alpha can have, the method with this alpha value must be compared with the NewtonRaphson in order to judge its merit. The number of iterations required 
for two tolerances with the Newton-Raphson procedure is shown on the right hand side of the figures 4.2 to 4.5 . In every case, but one, the alpha M.Q.S.O.N.R. load flow converges in half, or one-half more than half, the number of iterations of the Newton-Raphson load flow. The only exception is the 118-bus (No V.C.B.) system for which the Newton-Raphson fails to converge while the new method converges in 2.5 iterations for a tolerance of 0.001 p.u.

The first half of an alpha-M.Q.S.O.N.R. iteration is the same as one N.-R. iteration. The second half iteration requires very little extra storage and less C.P.U. time than the first half (or one N.-R. iteration). This is so because bus mismatches calculated in the first half only require a simple modification in the second half. Also, the Jacobian elements calculated in the first half are used again in the second half, with only the diagonal elements undergoing a computationally simple modification. As a result, all the load flows converge, not only at a much faster rate, but also in less time than the Newton-Raphson load flows and with almost the same storage requirements.

\subsubsection{Bus Mismatches during Load Flows}

The comparison between the alpha-M.Q.S.O.N.R. algorithm and the NewtonRaphson method is illustrated in Figures 4.10 to 4.16 from the point of view of the bus mismatches during load flows. The largest per unit mismatches of the bus active power, reactive power, and square of the voltage magnitude are plotted for each iteration for (1) the Newton-Raphson method, (2) the alpha-M.Q.S.O.N.R. method with alpha equal to zero, and (3) the alpha - M.Q.S.O.N.R. method with alpha equal to one (which is equivalent to 


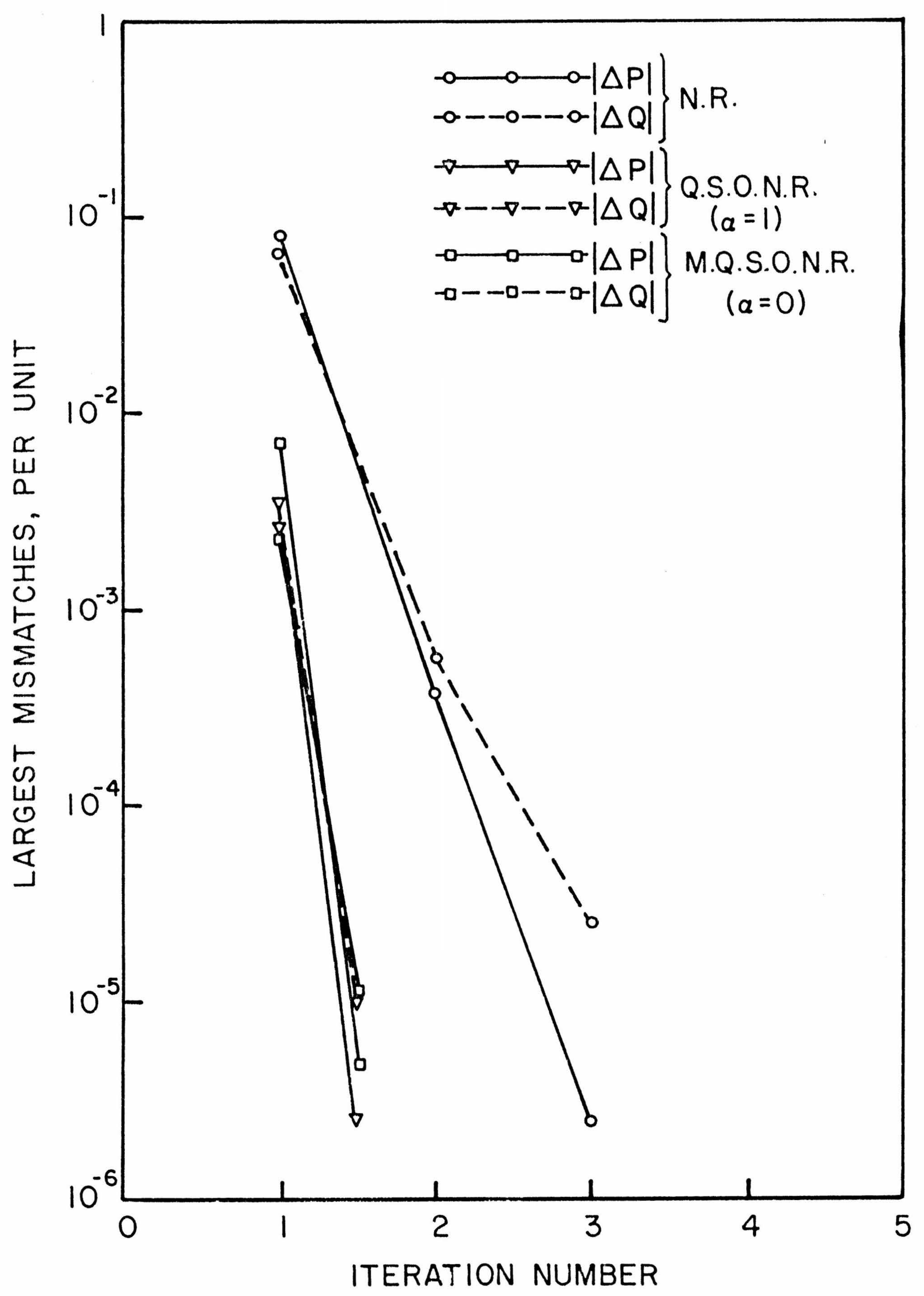

Figure 4.10: Convergence Patterns of Load Flows of the 5-Bus System. 


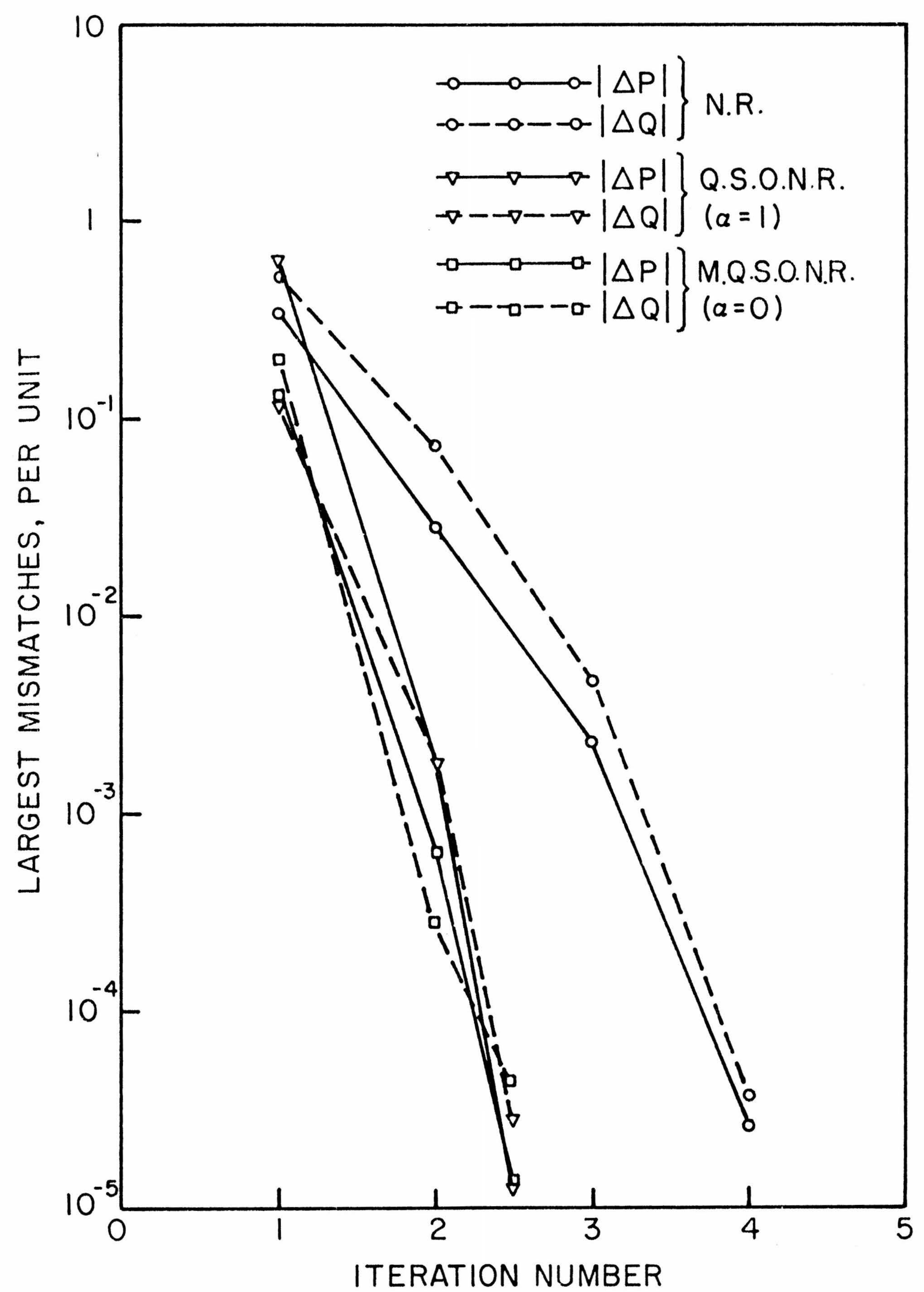

Figure 4.11: Convergence Patterns of Load Flows of the 23-Bus system 


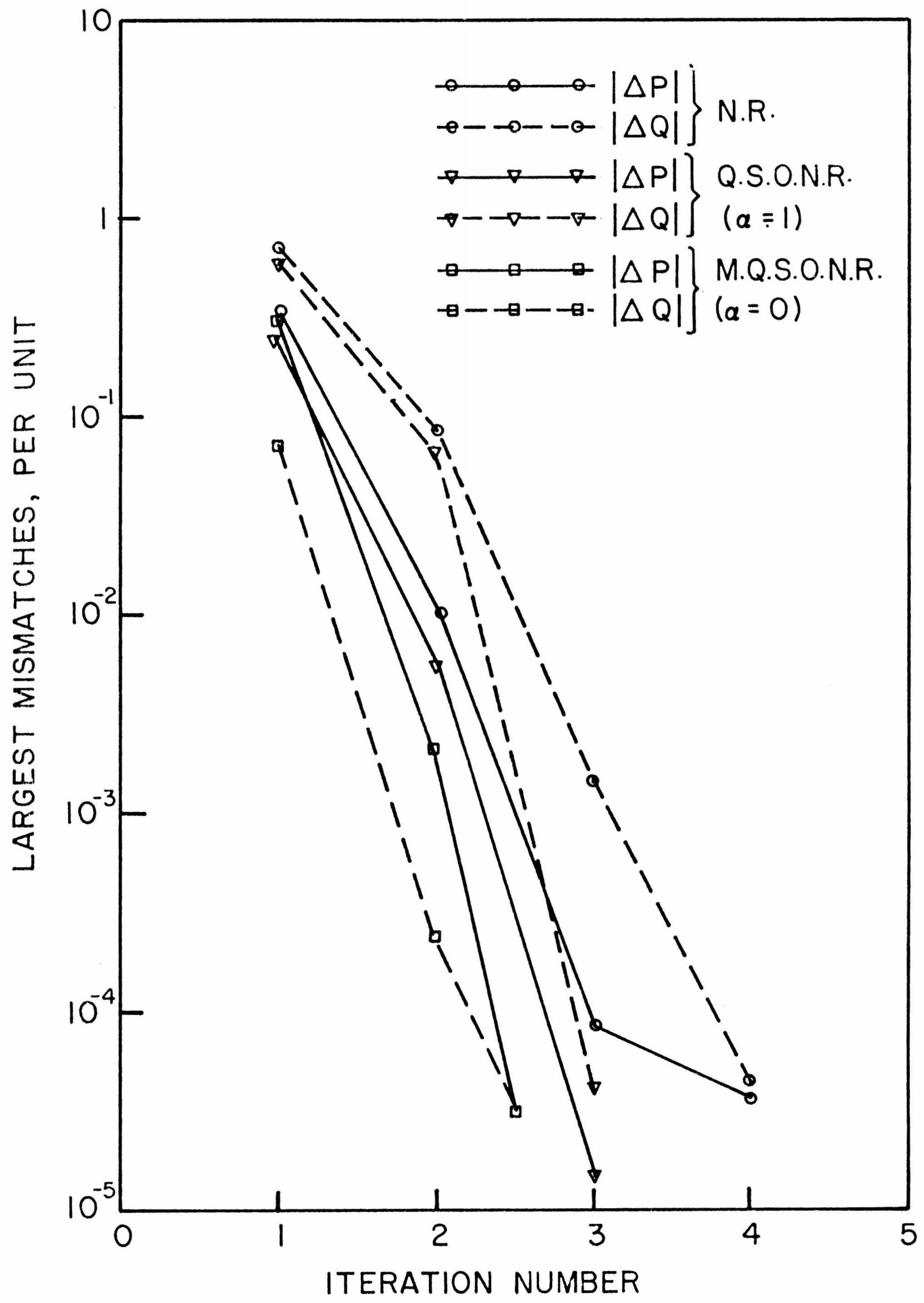

Figure 4.12: Convergence Patterns of Load Flows of the IEEE 57-Bus Test System. 


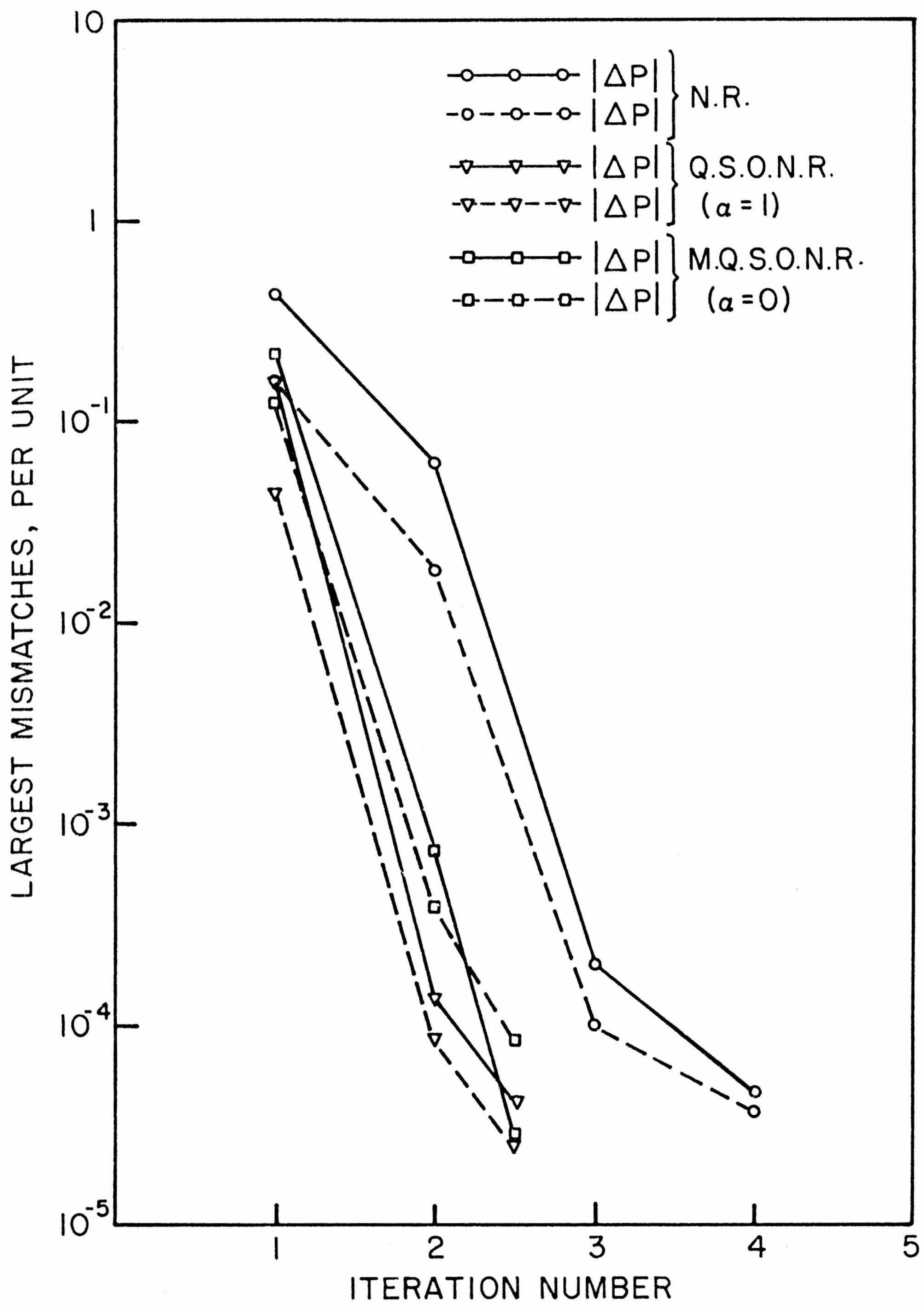

Figure 4.13: Convergence Patterns of Load Flows of the IEEE 118-Bus Test System. 


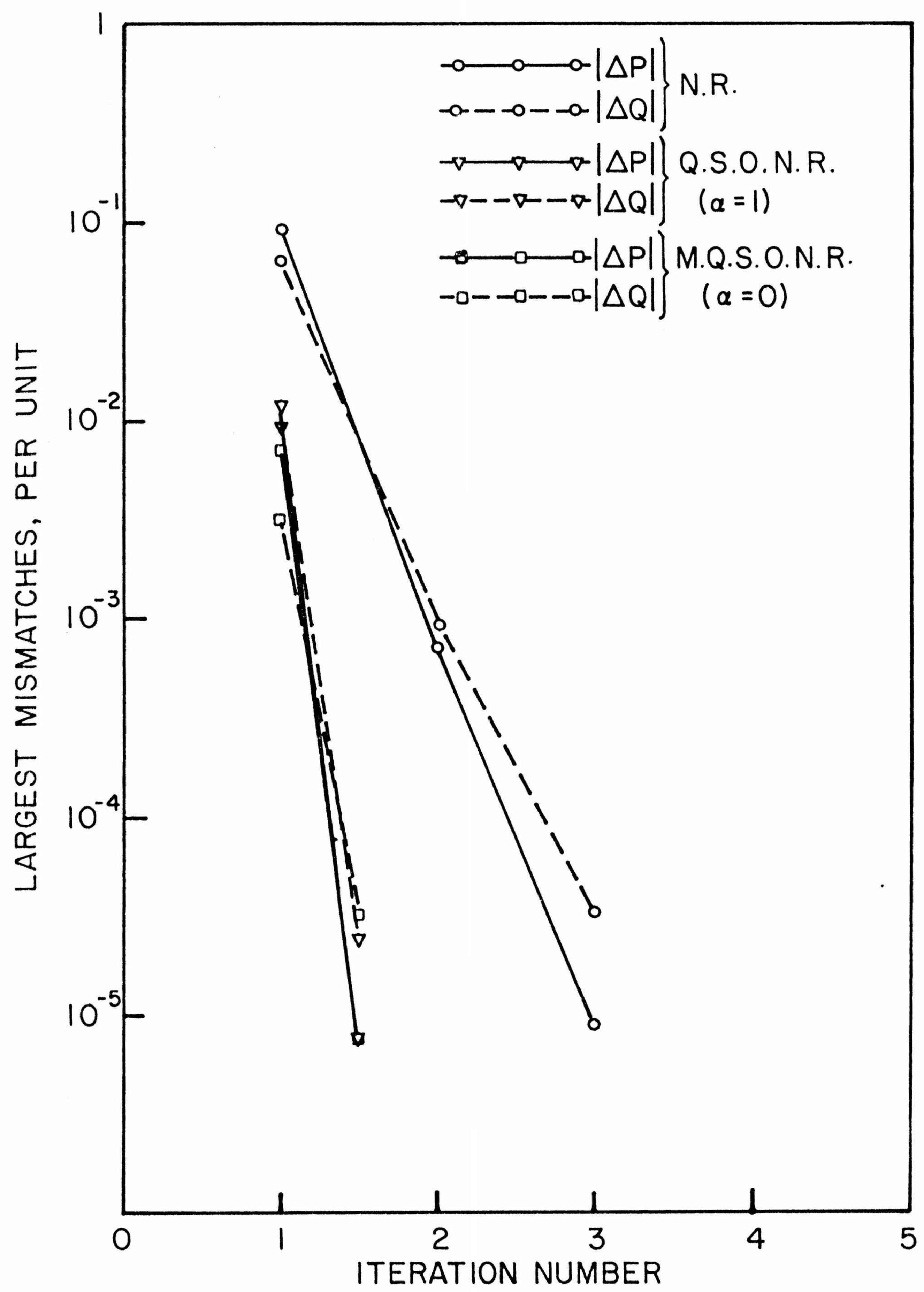

Figure 4.1: Convergence Patterns of Load Flows of the 5-Bus (No Voltage Regulated Buses) System 


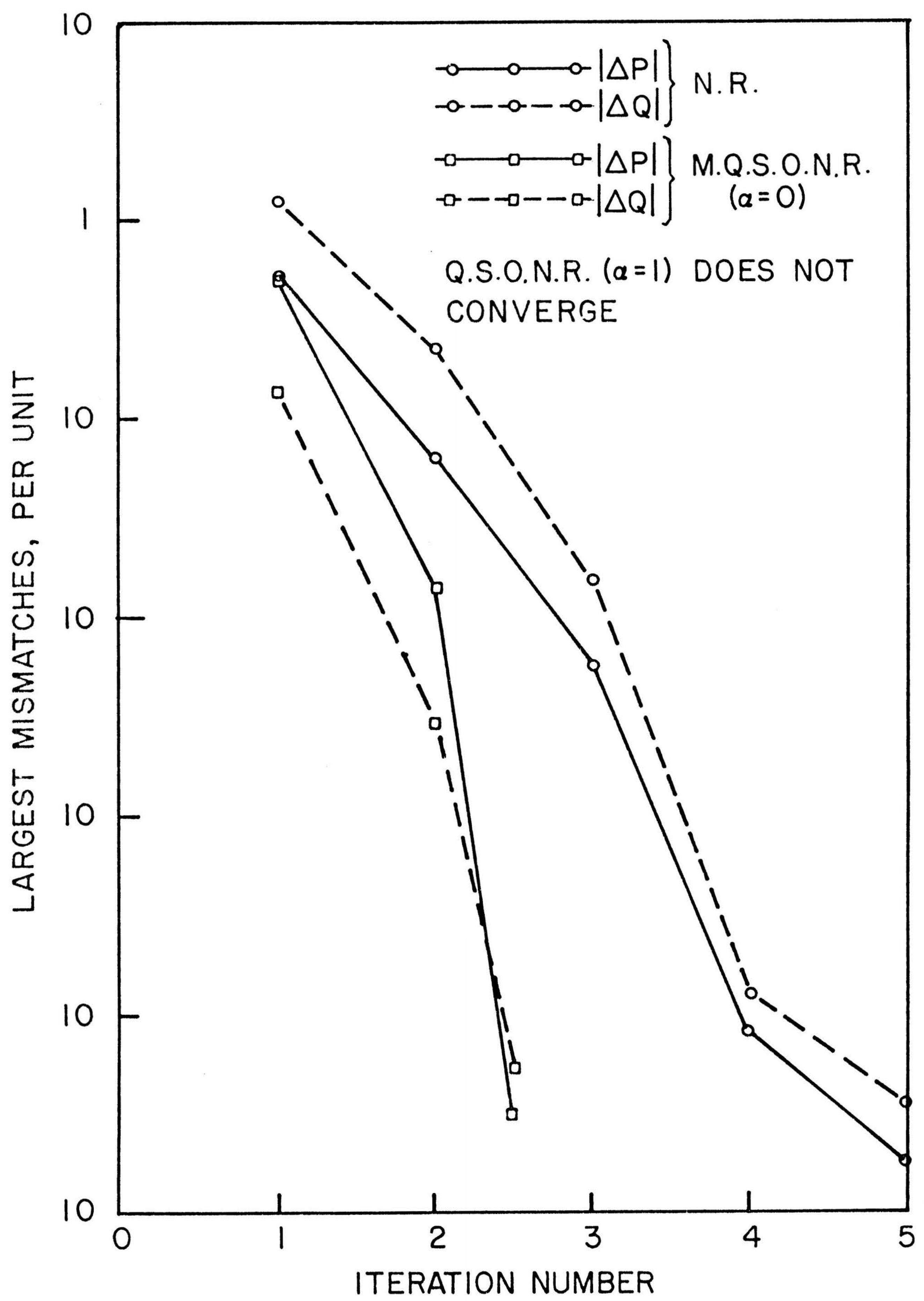

Figure 4.15: Convergence Patterns of Load Flows of the 57-Bus (No Voltage Regulated Buses) System 


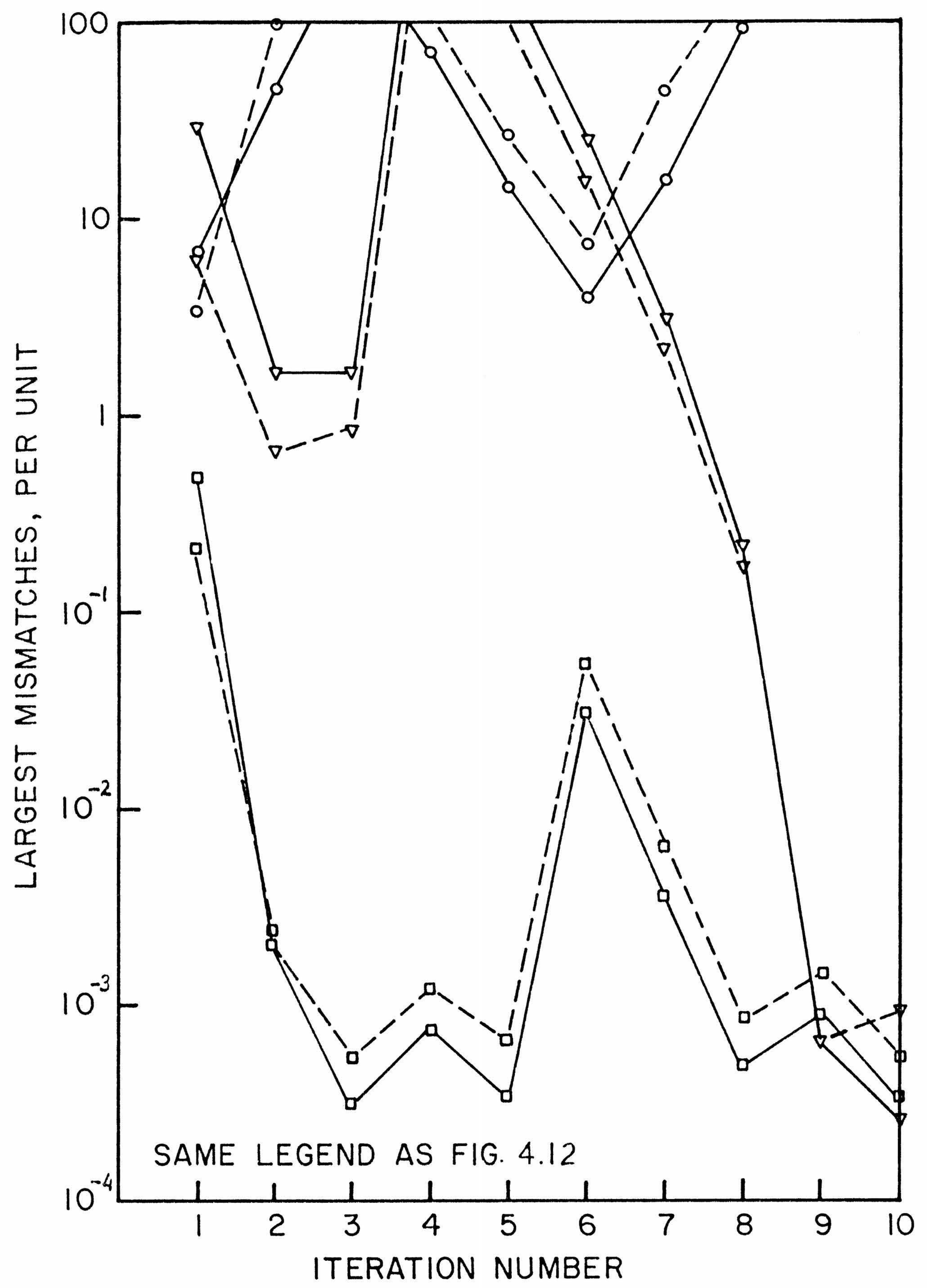

Figure 4.16: Convergence Patterns of Load Flows of the 118-Bus (No Voltage Controlled Buses) System. 
normal Q.S.O.N.R. method). The complete sets of maximum mismatch values for each system and for every alpha value between -2.0 and +2.0 (in 0.1 increments) are tabulated in Appendix G.

On the graphs we can again see how much faster is the rate of convergence with the alpha - M.Q.S.O.N.R. method with alpha equal to zero in comparison with the Newton-Raphson method. Also, in almost every case, the former method converges to a more accurate solution than does the latter.

Comparing the new method with alpha equal to zero and with alpha equal to one shows that in the 5-bus, 23-bus, 118-bus, and the 5-bus (no V.C.B.) systems, the latter converges to a slightly more accurate solution in the same number of iterations as the former. However, with the 118-bus (no V.C.B.) system the method with alpha equal to zero is a great deal better than when alpha equals one. With the 57-bus system it is also much better in that it converges faster. And, with the 57-bus (no V.C.B.) system the method with alpha equal to one does not even converge. Therefore, as an overall result, the alpha-M.Q.S.O.N.R. method with alpha equal to zero is superior to the Q.S.O.N.R. method (which is the alpha-M.Q.S.O.N.R. method with alpha equal to one).

\subsubsection{Importance of the Initial Values for the Bus Voltages}

Using the second order terms in a load flow allows convergence to occur over a larger range of initial guesses of the load bus voltages thian with a first order technique such as Newton-Raphson. However, it was found that only when the bus voltages started from a flat start did the alpha-M.Q.S.O.N.R. method perform at its best. A flat start means that 
the initial voltage magnitudes at all load buses are set to one per unit and the initial voltage angle is set to be the same as that of the slack bus (which serves as the reference bus).

To illustrate this point, the 118-bus system is used. It has a slack bus voltage angle of thirty degrees. Figure 4.5 shows the convergence pattern for a normal flat start with each load bus having an initial voltage magnitude of one per unit and an angle of thirty degrees. Figure 4.16 shows the convergence pattern when the load buses have their initial voltage magnitudes the same, at one per unit, but their initial voltage angles set at zero degrees. The difference between the two graphs is substantial. The first shows the lowest number of iterations to convergence to be two, while the other shows two and one-half as the lowest. The range of alpha values with which convergence occurs is much reduced in the second graph, and the load flow when alpha equals zero is not the best. Also, convergence for the Newton-Raphson method is not as good. So, there is no doubt that a flat start should be employed for the best results. 
TABLE 4.1: Number of Iterations to Convergence for Various Alpha Values and Various Systems.

\begin{tabular}{|c|c|c|c|c|c|c|c|c|c|c|c|}
\hline System & $\begin{array}{c}\text { Tolerance } \\
\text { (p.u.) }\end{array}$ & $\begin{array}{l}\text { Newton } \\
\text {-Raphson }\end{array}$ & -2.0 & -1.9 & -1.8 & $\frac{\text { ALPH }}{-1.7}$ & $\frac{A \text { VALUE }}{-1.6}$ & $\frac{5}{-1.5}$ & -1.4 & -1.3 & -1.2 \\
\hline 5 - Bus & .001 & 2.0 & 1.5 & 1.5 & 1.5 & 1.5 & 1.5 & 1.5 & 1.5 & 1.5 & 1.5 \\
\hline 23 - Bus & .0001 & 4.0 & 4.5 & 4.5 & $>10.0$ & $>10.0$ & 4.5 & $>10.0$ & 3.5 & 3.5 & 3.5 \\
\hline \multirow[t]{2}{*}{57 - Bus } & .0001 & 4.0 & $>10.0$ & $>10.0$ & $>10.0$ & $>10.0$ & $>10.0$ & $>10.0$ & $>10.0$ & $>10.0$ & $>10.0$ \\
\hline & .001 & 4.0 & $>10.0$ & $>10.0$ & $>10.0$ & $>10.0$ & $>10.0$ & $>10.0$ & $>10.0$ & $>10.0$ & $>10.0$ \\
\hline 118 - Bus & .0001 & 4.0 & 3.5 & 5.0 & 3.5 & 4.5 & 5.0 & 4.5 & $>10.0$ & $>10.0$ & $>10.0$ \\
\hline 57 - Bus & .0001 & 5.0 & 6.0 & 4.5 & 4.5 & 4.5 & 4.5 & 5.0 & 7.5 & $>10.0$ & $>10.0$ \\
\hline (No. V.C.B.) & .001 & 4.0 & 5.5 & 4.5 & 4.0 & 4.0 & 4.5 & 4.5 & 7.5 & $>10.0$ & $>10.0$ \\
\hline \multirow[t]{2}{*}{118 - Bus } & .0001 & $>10.0$ & $>10.0$ & $>10.0$ & $>10.0$ & $>10.0$ & $>10.0$ & $>10.0$ & $>10.0$ & $>10.0$ & $>10.0$ \\
\hline & .001 & $>10.0$ & $>10.0$ & $>10.0$ & $>10.0$ & $>10.0$ & $>10.0$ & $>10.0$ & $>10.0$ & $>10.0$ & $>10.0$ \\
\hline
\end{tabular}


TABLE 4.1 (Continued)

\begin{tabular}{|c|c|c|c|c|c|c|c|c|c|c|c|}
\hline \multirow[b]{2}{*}{ SYSTEM } & \multirow{2}{*}{$\begin{array}{c}\text { Tolerance } \\
\left(p \cdot u_{.}\right)\end{array}$} & \multicolumn{10}{|c|}{ ALPHA VALUES } \\
\hline & & -1.1 & -1.0 & -0.9 & -0.8 & -0.7 & -0.6 & -0.5 & -0.4 & -0.3 & -0.2 \\
\hline 5 - Bus & $\begin{array}{l}.0001 \\
.001\end{array}$ & $\begin{array}{l}1.5 \\
1.5\end{array}$ & $\begin{array}{l}1.5 \\
1.5\end{array}$ & $\begin{array}{l}1.5 \\
1.5\end{array}$ & $\begin{array}{l}1.5 \\
1.5\end{array}$ & $\begin{array}{l}1.5 \\
1.5\end{array}$ & $\begin{array}{l}1.5 \\
1.5\end{array}$ & $\begin{array}{l}1.5 \\
1.5\end{array}$ & $\begin{array}{l}1.5 \\
1.5\end{array}$ & $\begin{array}{l}1.5 \\
1.5\end{array}$ & $\begin{array}{l}1.5 \\
1.5\end{array}$ \\
\hline 23 - Bus & $\begin{array}{l}.0001 \\
.001\end{array}$ & $\begin{array}{l}3.0 \\
2.5\end{array}$ & $\begin{array}{l}3.0 \\
2.5\end{array}$ & $\begin{array}{l}2.5 \\
2.5\end{array}$ & $\begin{array}{l}2.5 \\
2.5\end{array}$ & $\begin{array}{l}2.5 \\
2.5\end{array}$ & $\begin{array}{l}2.5 \\
2.5\end{array}$ & $\begin{array}{l}2.5 \\
2.5\end{array}$ & $\begin{array}{l}2.5 \\
2.5\end{array}$ & $\begin{array}{l}2.5 \\
2.5\end{array}$ & $\begin{array}{l}2.5 \\
2.0\end{array}$ \\
\hline 57 - Bus & $\begin{array}{l}.0001 \\
.001\end{array}$ & $\begin{array}{l}>10.0 \\
>10.0\end{array}$ & $\begin{array}{l}4.0 \\
3.5\end{array}$ & $\begin{array}{l}3.5 \\
3.5\end{array}$ & $\begin{array}{l}3.5 \\
3.0\end{array}$ & $\begin{array}{l}3.0 \\
2.5\end{array}$ & $\begin{array}{l}3.0 \\
2.5\end{array}$ & $\begin{array}{l}2.5 \\
2.5\end{array}$ & $\begin{array}{l}2.5 \\
2.5\end{array}$ & $\begin{array}{l}2.5 \\
2.5\end{array}$ & $\begin{array}{l}2.5 \\
2.5\end{array}$ \\
\hline $118-B u s$ & $\begin{array}{l}.0001 \\
.001\end{array}$ & $\begin{array}{l}>10.0 \\
>10.0\end{array}$ & $\begin{array}{l}>10.0 \\
>10.0\end{array}$ & $\begin{array}{l}4.5 \\
4.5\end{array}$ & $\begin{array}{l}4.5 \\
3.5\end{array}$ & $\begin{array}{l}4.0 \\
3.0\end{array}$ & $\begin{array}{l}3.5 \\
2.5\end{array}$ & $\begin{array}{l}3.0 \\
2.5\end{array}$ & $\begin{array}{l}3.0 \\
2.5\end{array}$ & $\begin{array}{l}2.5 \\
2.5\end{array}$ & $\begin{array}{l}3.5 \\
2.5\end{array}$ \\
\hline $\begin{array}{l}5-\text { Bus } \\
(\text { No. V.C.B })\end{array}$ & $\begin{array}{l}.0001 \\
.001\end{array}$ & $\begin{array}{l}1.5 \\
1.5\end{array}$ & $\begin{array}{l}1.5 \\
1.5\end{array}$ & $\begin{array}{l}1.5 \\
1.5\end{array}$ & $\begin{array}{l}1.5 \\
1.5\end{array}$ & $\begin{array}{l}1.5 \\
1.5\end{array}$ & $\begin{array}{l}1.5 \\
1.5\end{array}$ & $\begin{array}{l}1.5 \\
1.5\end{array}$ & $\begin{array}{l}1.5 \\
1.5\end{array}$ & $\begin{array}{l}1.5 \\
1.5\end{array}$ & $\begin{array}{l}1.5 \\
1.5\end{array}$ \\
\hline $\begin{array}{l}57-\text { Bus } \\
(\text { No V.C.B) }\end{array}$ & $\begin{array}{l}.0001 \\
.001\end{array}$ & $\begin{array}{l}>10.0 \\
>10.0\end{array}$ & $\begin{array}{l}7.5 \\
7.0\end{array}$ & $\begin{array}{l}>10.0 \\
>10.0\end{array}$ & $\begin{array}{l}6.0 \\
5.5\end{array}$ & $\begin{array}{l}>10.0 \\
>10.0\end{array}$ & $\begin{array}{l}4.0 \\
4.0\end{array}$ & $\begin{array}{l}3.5 \\
3.5\end{array}$ & $\begin{array}{l}3.5 \\
3.0\end{array}$ & $\begin{array}{l}3.0 \\
3.0\end{array}$ & $\begin{array}{l}3.0 \\
2.5\end{array}$ \\
\hline $\begin{array}{l}115-\text { Bus } \\
\text { (No V.C.B) }\end{array}$ & $\begin{array}{l}.0001 \\
.001\end{array}$ & $\begin{array}{l}>10.0 \\
>10.0\end{array}$ & $\begin{array}{l}>10.0 \\
>10.0\end{array}$ & $\begin{array}{l}>10.0 \\
>10.0\end{array}$ & $\begin{array}{l}>10.0 \\
>10.0\end{array}$ & $\begin{array}{l}>10.0 \\
>10.0\end{array}$ & $\begin{array}{r}>10.0 \\
5.0\end{array}$ & $\begin{array}{r}>10.0 \\
4.5\end{array}$ & $\begin{array}{r}>10.0 \\
3.5\end{array}$ & $\begin{array}{r}>10.0 \\
3.0\end{array}$ & $\begin{array}{r}>10.0 \\
2.5\end{array}$ \\
\hline
\end{tabular}


TABLE 4.1 (Continued)

\begin{tabular}{|c|c|c|c|c|c|c|c|c|c|c|c|}
\hline \multirow[b]{2}{*}{ SYSTEM } & \multirow{2}{*}{$\begin{array}{c}\text { Tolerance } \\
\left(p \cdot u_{.}\right)\end{array}$} & \multicolumn{9}{|c|}{ ALPHA VALUES } & \multirow[b]{2}{*}{0.8} \\
\hline & & -0.1 & 0.0 & 0.1 & 0.2 & 0.3 & 0.4 & 0.5 & 0.6 & 0.7 & \\
\hline $5-$ Bus & $\begin{array}{l}.0001 \\
.001\end{array}$ & $\begin{array}{l}1.5 \\
1.5\end{array}$ & $\begin{array}{l}1.5 \\
1.5\end{array}$ & $\begin{array}{l}1.5 \\
1.5\end{array}$ & $\begin{array}{l}1.5 \\
1.5\end{array}$ & $\begin{array}{l}1.5 \\
1.5\end{array}$ & $\begin{array}{l}1.5 \\
1.5\end{array}$ & $\begin{array}{l}1.5 \\
1.5\end{array}$ & $\begin{array}{l}1.5 \\
1.5\end{array}$ & $\begin{array}{l}1.5 \\
1.5\end{array}$ & $\begin{array}{l}1.5 \\
1.5\end{array}$ \\
\hline 23 - Bus & $\begin{array}{l}.0001 \\
.001\end{array}$ & $\begin{array}{l}2.5 \\
2.0\end{array}$ & $\begin{array}{l}2.5 \\
2.0\end{array}$ & $\begin{array}{l}2.5 \\
2.0\end{array}$ & $\begin{array}{l}2.5 \\
2.0\end{array}$ & $\begin{array}{l}2.5 \\
2.0\end{array}$ & $\begin{array}{l}2.5 \\
2.0\end{array}$ & $\begin{array}{l}2.5 \\
2.0\end{array}$ & $\begin{array}{l}2.5 \\
2.5\end{array}$ & $\begin{array}{l}2.5 \\
2.5\end{array}$ & $\begin{array}{l}2.5 \\
2.5\end{array}$ \\
\hline 57 - Bus & $\begin{array}{l}.0001 \\
.001\end{array}$ & $\begin{array}{l}2.5 \\
2.5\end{array}$ & $\begin{array}{l}2.5 \\
2.5\end{array}$ & $\begin{array}{l}2.5 \\
2.5\end{array}$ & $\begin{array}{l}2.5 \\
2.5\end{array}$ & $\begin{array}{l}2.5 \\
2.5\end{array}$ & $\begin{array}{l}2.5 \\
2.5\end{array}$ & $\begin{array}{l}2.5 \\
2.5\end{array}$ & $\begin{array}{l}2.5 \\
2.5\end{array}$ & $\begin{array}{l}2.5 \\
2.5\end{array}$ & $\begin{array}{l}2.5 \\
2.5\end{array}$ \\
\hline 118 - Bus & $\begin{array}{l}.0001 \\
.001\end{array}$ & $\begin{array}{l}4.0 \\
2.5\end{array}$ & $\begin{array}{l}2.4 \\
2.0\end{array}$ & $\begin{array}{l}3.0 \\
2.0\end{array}$ & $\begin{array}{l}2.5 \\
2.0\end{array}$ & $\begin{array}{l}3.0 \\
2.0\end{array}$ & $\begin{array}{l}3.0 \\
2.0\end{array}$ & $\begin{array}{l}2.0 \\
2.0\end{array}$ & $\begin{array}{l}2.0 \\
2.0\end{array}$ & $\begin{array}{l}2.5 \\
2.0\end{array}$ & $\begin{array}{l}3.0 \\
2.0\end{array}$ \\
\hline $\begin{array}{l}5-\text { Bus } \\
(\text { No V.C.B.) }\end{array}$ & $\begin{array}{l}.0001 \\
.001\end{array}$ & $\begin{array}{l}1.5 \\
1.5\end{array}$ & $\begin{array}{l}1.5 \\
1.5\end{array}$ & $\begin{array}{l}1.5 \\
1.5\end{array}$ & $\begin{array}{l}1.5 \\
1.5\end{array}$ & $\begin{array}{l}1.5 \\
1.5\end{array}$ & $\begin{array}{l}1.5 \\
1.5\end{array}$ & $\begin{array}{l}1.5 \\
1.5\end{array}$ & $\begin{array}{l}1.5 \\
1.5\end{array}$ & $\begin{array}{l}1.5 \\
1.5\end{array}$ & $\begin{array}{l}1.5 \\
1.5\end{array}$ \\
\hline $\begin{array}{l}57-\text { Bus } \\
(\text { No V.C.B.) }\end{array}$ & $\begin{array}{l}.0001 \\
.001\end{array}$ & $\begin{array}{l}3.0 \\
2.5\end{array}$ & $\begin{array}{l}2.5 \\
2.5\end{array}$ & $\begin{array}{l}2.5 \\
2.5\end{array}$ & $\begin{array}{l}2.5 \\
2.5\end{array}$ & $\begin{array}{l}3.0 \\
2.5\end{array}$ & $\begin{array}{l}3.0 \\
3.0\end{array}$ & $\begin{array}{l}3.5 \\
3.0\end{array}$ & $\begin{array}{l}4.5 \\
4.0\end{array}$ & $\begin{array}{l}>10.0 \\
>10.0\end{array}$ & $\begin{array}{l}>10.0 \\
>10.0\end{array}$ \\
\hline $\begin{array}{l}118-\text { Bus } \\
(\text { No V.C.B.) }\end{array}$ & $\begin{array}{l}.0001 \\
.001\end{array}$ & $\begin{array}{r}>10.0 \\
2.5\end{array}$ & $\begin{array}{r}>10.0 \\
2.5\end{array}$ & $\begin{array}{r}>10.0 \\
2.0\end{array}$ & $\begin{array}{r}>10.0 \\
3.5\end{array}$ & $\begin{array}{r}>10.0 \\
3.5\end{array}$ & $\begin{array}{r}>10.0 \\
4.0\end{array}$ & $\begin{array}{r}>10.0 \\
4.5\end{array}$ & $\begin{array}{r}>10.0 \\
4.5\end{array}$ & $\begin{array}{r}>10.0 \\
5.0\end{array}$ & $\begin{array}{r}>10.0 \\
7.5\end{array}$ \\
\hline $\begin{array}{l}118-\text { Bus } \\
\left(V_{\text {start }}=1 / 0^{\circ}\right)\end{array}$ & $\begin{array}{l}.0001 \\
.001\end{array}$ & & & & & & & & & & \\
\hline
\end{tabular}


TABLE 4.1 (Continued)

\begin{tabular}{|c|c|c|c|c|c|c|c|c|c|c|c|c|c|}
\hline \multirow{3}{*}{$\begin{array}{l}\text { SYSTEM } \\
5 \text { - BUS }\end{array}$} & \multirow{2}{*}{$\begin{array}{c}\text { Tolerance } \\
(\text { p.u. })\end{array}$} & \multirow[b]{2}{*}{$\overline{0.9}$} & \multicolumn{11}{|c|}{ ALPHA VALUES } \\
\hline & & & 1.0 & 1.1 & 1.2 & 1.3 & 1.4 & 1.5 & 1.6 & 1.7 & 1.8 & 1.9 & 2.0 \\
\hline & $\begin{array}{l}.0001 \\
.001\end{array}$ & $\begin{array}{l}1.5 \\
1.5\end{array}$ & $\begin{array}{l}1.5 \\
1.5\end{array}$ & $\begin{array}{l}1.5 \\
1.5\end{array}$ & $\begin{array}{l}1.5 \\
1.5\end{array}$ & $\begin{array}{l}1.5 \\
1.5\end{array}$ & $\begin{array}{l}1.5 \\
1.5\end{array}$ & $\begin{array}{l}1.5 \\
1.5\end{array}$ & $\begin{array}{l}1.5 \\
1.5\end{array}$ & $\begin{array}{l}1.5 \\
1.5\end{array}$ & $\begin{array}{l}1.5 \\
1.5\end{array}$ & $\begin{array}{l}1.5 \\
1.5\end{array}$ & $\begin{array}{l}1.5 \\
1.5\end{array}$ \\
\hline 23 - Bus & $\begin{array}{l}.0001 \\
.001\end{array}$ & $\begin{array}{l}2.5 \\
2.5\end{array}$ & $\begin{array}{l}2.5 \\
2.5\end{array}$ & $\begin{array}{l}2.5 \\
2.5\end{array}$ & $\begin{array}{l}2.5 \\
2.5\end{array}$ & $\begin{array}{l}2.5 \\
2.5\end{array}$ & $\begin{array}{l}2.5 \\
2.5\end{array}$ & $\begin{array}{l}2.5 \\
2.5\end{array}$ & $\begin{array}{l}2.5 \\
2.5\end{array}$ & $\begin{array}{l}2.5 \\
2.5\end{array}$ & $\begin{array}{l}2.5 \\
2.5\end{array}$ & $\begin{array}{l}2.5 \\
2.5\end{array}$ & $\begin{array}{l}2.5 \\
2.5\end{array}$ \\
\hline 57 - Bus & $\begin{array}{l}.0001 \\
.001\end{array}$ & $\begin{array}{l}3.0 \\
2.5\end{array}$ & $\begin{array}{l}3.0 \\
2.5\end{array}$ & $\begin{array}{l}3.5 \\
3.0\end{array}$ & $\begin{array}{l}3.5 \\
3.5\end{array}$ & $\begin{array}{l}4.0 \\
4.0\end{array}$ & $\begin{array}{l}8.5 \\
8.5\end{array}$ & $\begin{array}{l}>10.0 \\
>10.0\end{array}$ & $\begin{array}{l}6.0 \\
5.5\end{array}$ & $\begin{array}{l}6.5 \\
6.5\end{array}$ & $\begin{array}{l}7.5 \\
7.0\end{array}$ & $\begin{array}{l}>10.0 \\
>10.0\end{array}$ & $\begin{array}{l}2.5 \\
2.5\end{array}$ \\
\hline 118 - Bus & $\begin{array}{l}.0001 \\
.001\end{array}$ & $\begin{array}{l}3.5 \\
2.0\end{array}$ & $\begin{array}{l}2.5 \\
2.0\end{array}$ & $\begin{array}{l}2.5 \\
2.0\end{array}$ & $\begin{array}{l}4.5 \\
2.0\end{array}$ & $\begin{array}{l}3.0 \\
2.0\end{array}$ & $\begin{array}{l}3.0 \\
2.0\end{array}$ & $\begin{array}{l}2.5 \\
2.0\end{array}$ & $\begin{array}{l}4.0 \\
2.0\end{array}$ & $\begin{array}{l}3.0 \\
2.0\end{array}$ & $\begin{array}{l}2.5 \\
2.0\end{array}$ & $\begin{array}{l}5.0 \\
2.0\end{array}$ & $\begin{array}{l}2.5 \\
2.0\end{array}$ \\
\hline $\begin{array}{l}5-\text { Bus } \\
(\text { No V.C.B) }\end{array}$ & $\begin{array}{l}.0001 \\
.001\end{array}$ & $\begin{array}{l}1.5 \\
1.5\end{array}$ & $\begin{array}{l}1.5 \\
1.5\end{array}$ & $\begin{array}{l}1.5 \\
1.5\end{array}$ & $\begin{array}{l}1.5 \\
1.5\end{array}$ & $\begin{array}{l}1.5 \\
1.5\end{array}$ & $\begin{array}{l}1.5 \\
1.5\end{array}$ & $\begin{array}{l}1.5 \\
1.5\end{array}$ & $\begin{array}{l}1.5 \\
1.5\end{array}$ & $\begin{array}{l}1.5 \\
1.5\end{array}$ & $\begin{array}{l}1.5 \\
1.5\end{array}$ & $\begin{array}{l}1.5 \\
1.5\end{array}$ & $\begin{array}{l}1.5 \\
1.5\end{array}$ \\
\hline $\begin{array}{l}57-\text { Bus } \\
(\text { No V.C.B.) }\end{array}$ & $\begin{array}{l}.0001 \\
.001\end{array}$ & $\begin{array}{l}6.5 \\
6.5\end{array}$ & $\begin{array}{l}>10.0 \\
>10.0\end{array}$ & $\begin{array}{l}>10.0 \\
>10.0\end{array}$ & $\begin{array}{l}>10.0 \\
>10.0\end{array}$ & $\begin{array}{l}>10.0 \\
>10.0\end{array}$ & $\begin{array}{l}>10.0 \\
>10.0\end{array}$ & $\begin{array}{l}>10.0 \\
>10.0\end{array}$ & $\begin{array}{l}>10.0 \\
>10.0\end{array}$ & $\begin{array}{l}6.5 \\
6.5\end{array}$ & $\begin{array}{l}5.5 \\
5.5\end{array}$ & $\begin{array}{l}5 \\
4.5\end{array}$ & $\begin{array}{l}4.5 \\
4.5\end{array}$ \\
\hline $\begin{array}{l}118-\text { Bus } \\
\text { (No V.C.B.) }\end{array}$ & $\begin{array}{l}.0001 \\
.001\end{array}$ & $\begin{array}{l}>10.0 \\
>10.0\end{array}$ & $\begin{array}{r}>10.0 \\
9.0\end{array}$ & $\begin{array}{r}>10.0 \\
9.5\end{array}$ & $\begin{array}{r}>10.0 \\
6.0\end{array}$ & $\begin{array}{r}>10.0 \\
5.5\end{array}$ & $\begin{array}{r}>10.0 \\
5.0\end{array}$ & $\begin{array}{r}>10.0 \\
8.5\end{array}$ & $\begin{array}{l}>10.0 \\
>10.0\end{array}$ & $\begin{array}{l}>10.0 \\
>10.0\end{array}$ & $\begin{array}{r}>10.0 \\
8.5\end{array}$ & $\begin{array}{l}>10.0 \\
>10.0\end{array}$ & $\begin{array}{l}>10.0 \\
>10.0\end{array}$ \\
\hline
\end{tabular}




\section{CHAPTER $\underline{\bar{V}}$ \\ CONCLUDING REMARKS}

\subsection{Conclusions}

Although much time was spent developing and testing the alphamodified quasi-second order Newton-Raphson technique in rectangular coordinates, the results were consistent enough so as to make precise conclusions possible.

First, it was found that, for all systems tested, load flow convergence characteristics are best when alpha is equal to zero. With this value, the method was shown to have a convergence rate about twice as fast as the Newton-Raphson technique. The additional computing effort envolved does not correspond to twice as much per iteration. Therefore, the method is also faster in terms of computer time. Also, there is only a slight increase in storage requirements. Though not discussed previously, it does appear that this new method does have better convergence properties than the second order load flow method in polar coordinates reported by Sachdev and Medicherla [46].

The merit of this method is enhanced by the fact that by simply adding a subroutine, load flow programs presently in use can be extended to include second order terms without any major modifications.

As a final remark, it might be noted that there is an indication that this method would be successful with ill-conditioned systems. However much more testing is required in this area before any conslusions can be stated. 


\subsection{Future Work}

In every test case conducted for this thesis, convergence with the alpha-M.Q.S.O.N.R. (alpha equal to zero) occurs in $1.5,2.0$, or 2.5 iterations. Obviously, it would be very difficult to converge in fewer iterations, no matter how good a technique was applied. In order to better assess the capability of the new method, it should be tested with much larger systems and with difficult networks (including underground transmission). An indication of its power is given by the rapid convergence for the 118-Bus (no V.C.B.) system for which the Newton-Raphson fails to converge. Similar results were obtained for another system not reported here.

There is virtually an unlimited number of things that can be done with the technique presented in this thesis to try and achieve a better load flow method. I will suggest here some ideas to pursue and directions to follow.

First on the agenda would be to perform the modifications necessary to obtain further alpha-modified methods such as those mentioned in Chapter 111 .

As the theory for the alpha-modified methods illustrates, alpha can take on a different value for every bus of a system being tested. Therefore, an effort should be made to develop (and to test the worth of) a procedure to choose the best values of alpha to operate on their corresponding buses.

The present program could be expanded to include the ability to solve systems with D.C. lines and links. Also, additional programming 
could be added to allow optimal load flows to be performed.

In an attempt to generally decrease the number of iterations required for this method (as well as for other load flow methods), it may be worth utilizing a different, equally valid, convergence criterion. Perhaps the average of all the absolute mismatch values, subject to limiting the maximum value that a mismatch could have, could be used. This would eliminate the very common situation where convergence is delayed only because one or two bus mismatches are not quite within the given tolerance. If the average were used, there would probably be substantial savings in computing time.

Another way of reducing storage requirements, computational effort and computing time would be to develop, from the present algorithm, a decoupled load flow method. This would, of course, be based upon exploiting the weak coupling between real power and voltage magnitude, and reactive power and voltage phase angles. There is a good possibility though, that adding second order terms may be of insignificant value in the presence of the major approximations used in decoupling.

A further area of investigation could look into ways of getting better initial estimates of the voltages at load buses, such as a variation of that reported by Stott [58].

This is only a brief list of areas worth pursuing. The number of major and minor modifications that could be applied to the alpha-M.Q.S.O.N.R. method, is limited only by ones imagination.

In closing, the method in its own right should be applied to any practical problem involving nonlinear equations. Examples in the power 
systems area include, but are not limited to, various formulations of the economy operation problem, stability analysis, automatic generation control, and hysteresis motor dynamic performance and optimization evaluation. 


\section{BIBLIOGRAPHY AND REFERENCES}

1. Baumann, "Some New Aspects of Load Flow Calculation", IEEE Trans. on PAS, Vol. 85, pp. 1164-1176, November 1966.

2. Bennett, "Digital Computers and the Load-flow Problem", Proc. of the IEE (London), Vol. 103 B, Supplement 1, p. 16, 1956.

3. Billinton, Bollinger, and Dhar, "A New Modified Newton's Method for Load-Flow Analysis", Conference Paper No. C 72 004-5 for the IEEE Winter Power Meeting, 1972.

4. Boneparte and W.W. Maslin, "Simplified Load Flow", Proc. of the 1967 Power Industry Computer Application Conference, Pittsburgh, PA, pp. 385-394, May 15-17, 1967.

5. Brameller and Denmead, "Some Improved Methods for Digital Network Analysis", Proc. of IEE (London) Vol. 109, Pt. A, pp. 109-116, 1962.

6. Britton, 'Improved Area Interchange Control for Newton's Method Load Flows", IEEE Trans. on PAS, Vol. 88, pp. 1577-1581, October 1969.

7. Britton, "Improved Load Flow Performance Through a More General Equation Form"', IEEE Trans. on PAS, Vol. 90, pp. 109-116, January 1971.

8. Brown, Carter, Happ, and Person, "Power Flow Solution by Matrix Iterative Method", AIEE Trans. of PAS, Vol. 82, Part 111 , pp. 1-10, April 1963.

9. Brown and Tinney, "Digital Solutions for Large Power Networks", AlEE Trans. on PAS, Vol. 76, p. 347, June 1957. 
10. Carré, "Solution of Load-Flow Problems by Partitioning Systems into Trees", IEEE Trnas. on PAS, Vol. 87, pp. 1931-1938, November 1968.

11. Cory, B.J., and P.B. Henser, "Economic Dispatch with Security using Non-l inear Programming, Proceedings"', Fourth Power Systems Computations Conference, Grenoble, France, paper 2.1/5, September 1972 .

12. Conner, D.A., "Representative Bibliography on Load-Flow Analysis and Related Topics", Paper C73-104-7, IEEE P.E.S. Winter Meeting, New York, January, 1973.

13. Cronin, J.H. and M.B. Newman, "Digital Load-Flow Program for 1000 Bus Systems", Trans. IEEE on P.A.S., Vol. 83, pp. 718-720, 1964.

14. Curtis, A.R., and J.K. Reid, "Fortran Subroutines for the Solution of Sparse sets of Linear Equations", Theoretical Physics Division, Atomic Energy Research Establishment, Harwel1, Oxfordshire, 1971.

15. Delson, "The Spurious Solution in Load Flow Calculations", AIEE Conference Paper 62-277, 1962.

16. Despotović, Babić, and Mastilović, "A Rapid and Reliable Method for Solving Load Flow Problems", IEEE Trans. on PAS, Vol. 90, pp. 123-130, January 1971.

17. Domme 1, Hermann, W., "Newton's Method", T-PAS 68, October, pp. 1866-1877.

18. Dommel and Tinney, "Optimal Power Flow Soltuions", IEEE Trans. on PAS, Vol. 87, pp. 1866-1876, October 1968.

19. Dommel, Tinney, and Powell, "Further Developments in Newton's Method for Power System Application'", Confernece Paper No. 70 CP 161 for the IEEE Winter Power Meeting, 1970. 
20. Dopazo, Klitin, Stagg, and Watson, "Optimization Technique for Real and Reactive Power Allocation", Proc. of the IEEE, Vol. 55, pp. 1877-1885, November 1967.

21. Dunstan, "Digital Load Flow Studies", AlEE Trans. on PAS, Vol. 73, Part III-A, p. 825, 1954.

22. Dusonchet, Talukdar, Sinnot, and El-Abaid, "Load Flows Using a Combination of Point Jacobi and Newton's Methods", IEEE Trans. on PAS, Vol. 90, pp. 941-949, May 1971.

23. Dyrkaez and Maginniss, 'A New Automatic Program for Load Flow Studies on the IBM 704"', AIEE Trans. on PAS, Vol. 78, Part III-A, p. 52, 1959.

24. El-Abiad and Jaimes, "A Method for Optimum Scheduling of Power and Voltage Magnitude", IEEE Trans. on PAS, Vol. 88, pp. 413422, April 1969.

25. El-Abiad, Watson, and Stagg, "The Load-flow Problem - Its Formulation and Solution - Part I", AIEE Conference Paper $61-1054,1961$.

26. Elgerd, "Electric Energy Systems Theory: An Introduction", McGrawHill Book Co., pp. 200-265, 1971.

27. El-Hawary, M.E., Discussion of [42], Discussion A 76 491-1, IEEE Summer Power Meeting, Portland, Oregon, 1976.

28. El-Hawary, M.E., O.K. Wellon, and P.R. Hamilton, 'The Modified Qausi-Second Order Newton-Raphson Method for Low Flow Solutions", Paper No. 77015 - A, International Electrical and Electronics Conference and Exposition, Toronto, Sept. 1977. 
29. El-Hawary, M.E., and W.J. Vetter, Discussion [46], IEEE Trans. on Power Apparatus and Systems, Vol. PAS-96, pp. 196, 1977.

30. Freris, L.L., and A.M. Sasson, "Investigations on the Load-Flow Problem", Proc. Inst. Elec. Eng., Vol. 114, pp. 1960, December 1967.

31. Galloway, Taylor, Hogg, and Scott, "New Approach to PowerSystem Load-Flow Analysis in a Digital Computer", Proc. of the IEE (London), Vol. 117, pp. 165-196, January 1970.

32. Glimn, Habermann, Henderson, Kirchmayer, "Digital Calculations of Network Impedances", AIEE Trans. on PAS, Vol. 74, Part III, p. $1285,1955$.

33. Glimm and Stagg, "Automatic Calculation of Load Flows", AlEE Trans. on PAS, Vol. 76, pp. 817-825, october 1957.

34. Gupta and Davis, "Digital Computers in Power System Analysis", Proc. of the IEE (London), Vol. 108 A, pp. 383-398, 1961.

35. Hale and Goodrich, "Digital Computation of Power Flow - Some New Aspects", AlEE Trans. on PAS, Vol. 78 A, p. 919, October 1959.

36. Henderson, "Automatic Digital Computer Solution of Load-Flow Studies", AlEE Trans. on PAS, Vol. 73, Part III, pp. 1696-1702, February 1955.

37. Hurbert and Haynes, "A Rapid Digital Computer Solution for Power System Network Load Flow", IEEE Trans. on PAS, Vol. 90, 934-940, May 1971. 
38. Humpage, "Analytical Formulation of the Load Flow Problem", Proc. of the 1967 Power System Load Flow Analysis Symposium, London, 1967.

39. Jordan, "Rapid Converging Digital Load Flow", AlEE Trans. On PAS, Vol. 76, pp. 1433-1438, February 1957.

40. Laughton and Davis, "Numerical Techniques in Solution of Power System Load-Flow Problems", Proc. of the IEE (London), Vol. 111, p. 1575, September 1964.

41. Marriage, E.A., and J.E.D. Northcote-Green, "Load Flow and Stability Studies for Transmission Planning", Transactions, Engineering and Operating Division, CEA, Vol. 13, 1974.

42. Medicherla, T.K.P., and M.S. Sachdev, "A Second Order Decoupled Load Flow Technique", paper A 76 491-1, IEEE Summer Power Meeting, Portland, Oregon, 1976.

43. Meisel and Barnard, "Application of Fixed-Point Techniques to Load-Flow Studies", IEEE Trans. on PAS, Vol. 89, pp. 136-140, January 1970.

44. Ogbuobiri, E.C., W.F. Tinney, and J.W. Walker, "Sparsity Directed Decomposition from Gaussian Elimination of Matrices, IEEE Trans. Power App. \& Syst., Vol. PAS-89, No. 1, pp. 141, 149, January 1970.

45. Peterson, N.M., and W.S. Meyer, "Automatic Adjustment of Transformer and Phase-shifter Taps in the Newton Power Flow', IEEE Trans. Power App. \& Systems, Vol. PAS-90, pp. 103-1088, January/February 1971. 
46. Sachdev, M.S., and T.K.P. Medicherla, "A Second Order Load Flow Technique", IEEE Trans. on Power Apparatus and Systems, Vol. PAS-96, pp. 189-197, 1977.

47. Sachdev, M.S., T.K.P. Medicherla, and R. Billinton, "Second Order Load Flow Techniques", Transactions, Engineering and Operating Division, CEA, 1977.

48. Sasson, "Combined Use of the Powell and Fletcher-Powell Nonlinear Programming Methods for Optimal Load Flows", IEEE Trans. on PAS, Vol. 88, pp. 1530-1537, October 1969.

49. Sasson and Jaimes, "Digital Methods Applied to Power Flow Studies", IEEE Trans. on PAS, Vol. 86, pp. 860-867, July 1967.

50. Sasson, Trevino, and Aboytes, "Improved Newton's Load Flow

Through a Minimization Technique", IEEE Trans. on PAS, Vol. 90, pp. 1974-1981, September 1971 .

51. Sasson, Viloria, and Aboytes, "Optimal Load Flow Solution Using the Hessian Matrix", Proceedings of the 1971 Power Industry Computer Applications Confernece, pp. 203-209, May 23-26, 1971.

52. Sasson, Viloria, and Aboytes, "Optimal Load Flow Soltuion the Hessian Matrix", Conference Paper No. T 72 198-5 for the IEEE Winter Power Meeting, 1972.

53. Sato and Tinney, "Techniques for Exploiting the Sparsity of the Network Admittance Matrix", IEEE Trans. on PAS, Vol. 82, Part pp. 944-950, December 1963.

54. Sato, N., and W.F. Tinney, "Techniques for Exploiting the Sparsity of the Network Admittance Matrix", IEEE Trans. Power Apparatus and Systems, Vol. 82, pp. 944-950, December 1963. 
55. Stagg, G.W., and A.H. El-Abiad, "Computer Methods in Power System Analysis", McGraw Hill, New York, 1968.

56. St. Clair and Stagg, "Experience in Computation of Load Flow Studies Using High Speed Computer", AIEE Conference Paper 58-1100, 1958.

57. Stott, B., "Decoupled Newton Load Flow", IEEE Trans. PAS, Vol. PAS-91, pp. 1955-1959, September/0ctober, 1972.

58. Stott, B., "Effective Starting Process for N.R. Load Flows", Proc. Inst. Elec. Eng., Vol. 118, pp. 983-987, August 1971.

59. Stott, B., "Review of Load-Flow Calculation Methods", Proceedings of IEEE (Special issue on Computer in the Power Industry), Vol. 62, No. 7, pp. 916-929, July 1974.

60. Stott, B., and 0. Alsac, "Fast Decoupled Load Flow", IEEE Trans. PAS, Vol. 93, pp. 859-869, May/June 1974.

61. Stott, "Decoupled Newton Load Flow", Conference Paper No.

T 72 135-7 for the IEEE Winter Power Meeting, 1972.

62. Taylor and Treece, "Load Flow Analysis by the Gauss-Seidel Method", Proc. of the 1967 Power System Load Flow Analysis Symposium, London, 1967.

63. Tinney, W.F., "Notes on Network Solutions by Optimally Ordered Triangular Factorization", Notes to supplement [Tinney, Walker, November, 1967][65].

64. Tinney and Hart, "Power Flow Solution by Newton's Method", IEEE Trans. on PAS, Vol. 86, pp. 1449-1460, November 1967. 
65. Tinney, W.F., and J.W. Walker, 'Direct Solutions of Sparse Network Equations by Optimally Ordered Triangular Factorization", Proceedings of IEEE, Vol. 55, pp. 1801-1809, November 1967.

66. Tinney, W.F., W.L. Powell, N.M. Peterson, "Sparsity-oriented Network Reduction", IEEE PICA Conference Proceedings, Minneapolis, pp. 384-390, July 1973.

67. Tinney, W.F., and W.S. Meyer, "Solution of Large Sparse Systems by Ordered Triangular Factorization", IEEE Trans. Automatic Control, Vol. Ac-18, No. 4, pp. 333-346, August 1973.

68. Walker, J.W., "Renumbering Subroutine", July, 1967, A computer subroutine implementing theorey of [65].

69. Wallach and Even, "Application of Newton's Method to Load-Flow Calculations", Proc. of the IEE (London), Vol. 114, pp. 372374, March 1967; Discussion Vol. 114, pp. 1163-1164, August 1967.

70. Wallach, Even, and Yavin, "Improved Methods for Load-Flow Calculations", IEEE Trans. on PAS, Vol. 90, pp. 116-122, January 1971.

71. Ward and Hale, "Digital Computer Solution of Power-Flow Problems", AlEE Trans. on PAS, Vol. 75, pp. 398-404, June 1956.

72. Van Ness, "Convergence of Iterative Load Flow Studies", AlEE Trans. on PAS, Vol. 78B, pp. 1590-1597, February 1960.

73. Van Ness, "Iteration Methods for Digital Load-Flow Studies", AlEe Trans. on PAS, Vol. 78A, Part 111, pp. 583-588, August 1959.

74. Van Ness and Griffin, "Elimination Methods for Load-Flow Studies", AlEE Trans. on PAS, Vol. 80, pp. 299-304, June 1961. 
75. Wu, Felix, F., "Theoretical Study of the Convergence of the fast Decoupled Load Flow', IEEE Trans: on Power Apparatus E Systems, Vol. PAS-96, pp. 268-275, January 1977. 
APPENDIX A

JACOB IAN ELEMENTS 
The Jacobian elements are the first order derivatives of the load flows equations, $(2.21),(2.22)$, and (2.23).

The first order partial derivatives of the active bus powers are:

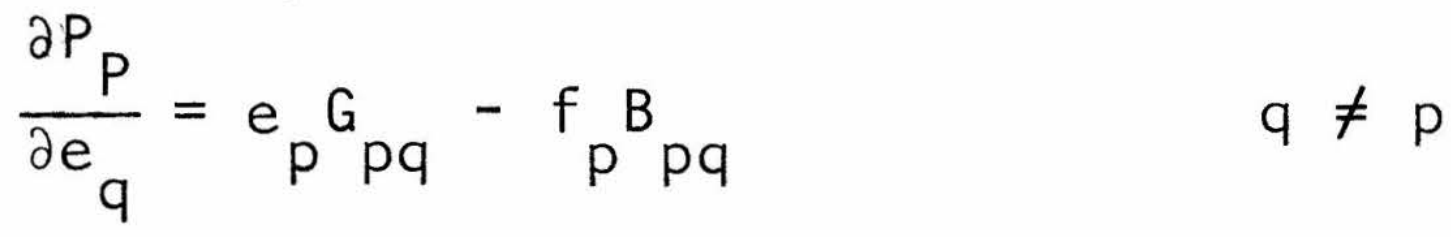

$$
\begin{aligned}
& \frac{\partial P}{\partial e_{p}}=2 e_{p} G_{p p}+\sum_{\substack{q=1 \\
q \neq p}}^{n}\left(e_{q} G_{p q}+f_{q} B_{p q}\right) \\
& \frac{\partial P}{\partial f_{q}}=e_{p} B_{p q}+f_{p} G_{p q} \quad q \neq p \\
& \frac{\partial P}{\partial f_{p}}=2 f_{p} G_{p p}+\sum_{\substack{q=1 \\
q \neq p}}^{n}\left(f_{q} G_{p q}-e_{p} B_{p q}\right)
\end{aligned}
$$

The first order partial derivatives of the reactive bus powers are:

$$
\begin{aligned}
& \frac{\partial Q_{p}}{\partial e_{q}}=e_{p} B p q+f_{p} G_{p q} \quad q \neq p \\
& \frac{\partial Q_{p}}{\partial e_{p}}=2 e_{p p p} B-\sum_{\substack{q=1 \\
q \neq p}}^{n}\left(f_{q} G G_{p q}-e_{q} B_{p q}\right) \\
& \frac{\partial Q_{p}}{\partial f_{q}}=-e_{p} G_{p q}+f_{p} B \text { pq } \quad q \neq p \\
& \frac{\partial Q_{p}}{\partial f_{p}}=2 f_{p} B_{p p}+\sum_{\substack{q=1 \\
q \neq p}}^{n}\left(e_{q} G_{p q}+f_{q} B_{p q}\right)
\end{aligned}
$$


The first order partial derivatives of the square of the bus voltage magnitudes are:

$$
\begin{aligned}
& \frac{\partial\left|v_{p}\right|^{2}}{\partial e_{q}}=0 \\
& \frac{\partial\left|v_{p}\right|^{2}}{\partial e_{p}}=2 e_{p} \\
& \frac{\partial\left|v_{p}\right|^{2}}{\partial f_{q}}=0 \\
& \frac{\partial\left|v_{p}\right|^{2}}{\partial f_{p}}=2 f_{p}
\end{aligned}
$$


APPENDIX B

HESS IAN ELEMENTS 
The Hessian elements are the second order derivatives of the load flow equations, (2.21), (2.22) and (2.23). As such, we may obtain them by simply taking the derivatives of the Jacobian elements found in appendix $A$.

Based on the first order partial derivatives, the second order partial derivaties of the active bus powers are:

$$
\begin{aligned}
& \frac{\partial^{2} P_{p}}{\partial e_{q} \partial e_{p}}=\frac{\partial^{2} P_{p}}{\partial e_{p} \partial e_{q}}=G_{p q} \\
& \frac{\partial^{2} F_{p}}{\partial e_{q}^{2}}=0 \\
& \frac{\partial^{2} p}{\partial e_{p}^{2}}=2 G_{p p} \\
& \frac{\partial^{2} p_{p}}{\partial f_{q} \partial e_{p}}=\frac{\partial^{2} p_{p}}{\partial e_{p} \partial f_{q}}=B_{p q} \\
& \frac{\partial^{2} p}{\partial f_{q}^{2}}=0 \\
& \frac{\partial^{2} P_{p}}{\partial f_{q} \partial f_{p}}=\frac{\partial^{2} P_{p}}{\partial f_{p} \partial f_{q}}=G_{p q} \\
& \frac{\partial^{2} P}{\partial f_{p}^{2}}=2 G_{p p} \\
& \frac{\partial^{2} p_{p}}{\partial f_{p} \partial e_{q}}=\frac{\partial^{2} p_{p}}{\partial e_{q} \partial f_{p}}=-B_{p q}
\end{aligned}
$$




$$
\begin{aligned}
& \frac{\partial^{2} p_{p}}{\partial e_{q} \partial f_{q}}=\frac{\partial^{2} p_{p}}{\partial f_{q} \partial e_{q}}=0 \\
& \frac{\partial^{2} p_{p}}{\partial f_{p} \partial e_{p}}=\frac{\partial^{2} p_{p}}{\partial e_{p} \partial f_{p}}=0 \\
& \frac{\partial^{2} P_{p}}{\partial e_{r} \partial e_{q}}=0 \\
& \frac{\partial^{2} P_{p}}{\partial f_{r}^{\partial f} q}=0 \\
& \frac{\partial^{2} P_{p}}{\partial e_{r} \partial f_{q}}=0 \\
& \frac{\partial^{2} p_{p}}{\partial f_{r} e_{q}}=0
\end{aligned}
$$

The second order partial derivatives for the reactive bus powers are:

$$
\begin{aligned}
& \frac{\partial^{2} Q_{p}}{\partial e_{q} e_{p}}=\frac{\partial^{2} Q_{p}}{\partial e_{p} \partial e_{q}}=B_{p q} \\
& \frac{\partial^{2} Q_{p}}{\partial e_{q}^{2}}=0 \\
& \frac{\partial^{2} Q_{p}}{\partial e_{p}^{2}}=2 B_{p p} \\
& \frac{\partial^{2} Q_{p}}{\partial{ }^{f}{ }^{\partial e_{p}}}=\frac{\partial^{2} Q_{p}}{\partial e_{p}{ }^{2 f} q}=-G_{p q}
\end{aligned}
$$


103

$$
\begin{aligned}
& \frac{\partial^{2} Q_{p}}{\partial f_{q}^{2}}=0 \\
& \frac{\partial^{2} Q_{p}}{\partial f_{q} \partial f_{p}}=\frac{\partial^{2} Q_{p}}{\partial f_{p} \partial f_{q}}=B_{p q} \\
& \frac{\partial^{2} Q_{p}}{\partial f_{p}^{2}}=2 B p \\
& \frac{\partial^{2} Q_{p}}{\partial f_{p} \partial e_{q}}=\frac{\partial^{2} Q_{p}}{\partial e_{q} \partial f_{p}}=G_{p q} \\
& \frac{\partial^{2} Q_{p}}{\partial e_{q} \partial f_{q}}=\frac{\partial^{2} Q_{p}}{\partial f_{q} \partial e_{q}}=0 \\
& \frac{\partial^{2} Q_{p}}{\partial f_{p} \partial e_{p}}=\frac{\partial^{2} p_{p}}{\partial e_{p} \partial f_{p}}=0 \\
& \frac{\partial^{2} Q_{p}}{\partial e_{r} \partial e_{q}}=0 \\
& \frac{\partial^{2} Q_{p}}{\partial f r^{\partial e_{q}}}=0 \\
& \frac{\partial^{2} Q_{p}}{\partial e_{r} \partial f_{q}}=0 \\
& \frac{\partial^{2} Q_{p}}{\partial f r^{\partial e_{q}}}=0
\end{aligned}
$$


The second order partial derivatives for the square of the bus voltage magnitudes are:

$$
\begin{aligned}
& \frac{\partial^{2}\left|v_{p}\right|^{2}}{\partial e_{q} \partial e_{p}}=\frac{\partial^{2}\left|v_{p}\right|^{2}}{\partial e_{p} \partial e_{q}}=0 \\
& \frac{\partial^{2}\left|v_{p}\right|^{2}}{\partial e_{q}^{2}}=0
\end{aligned}
$$$$
\frac{\partial^{2}\left|v_{p}\right| 2}{\partial e_{p}^{2}}=2
$$$$
\frac{\partial^{2}\left|v_{p}\right|^{2}}{\partial f_{q} \partial e_{p}}=\frac{\partial^{2}\left|v_{p}\right|^{2}}{\partial e_{p} \partial f_{q}}=0
$$$$
\frac{\partial^{2}\left|v_{p}\right|^{2}}{\partial f_{q}^{2}}=0
$$$$
\frac{\partial^{2}\left|v_{p}\right|^{2}}{\partial f_{q} \partial f_{p}}=\frac{\partial^{2}\left|v_{p}\right|^{2}}{\partial f_{p} \partial f_{q}}=0
$$$$
\frac{\partial^{2}\left|v_{p}\right|^{2}}{\partial^{2} f_{p}^{2}}=2
$$$$
\frac{\partial^{2}\left|v_{p}\right|^{2}}{\partial f_{p} \partial e_{q}}=\frac{\partial^{2}\left|v_{p}\right|^{2}}{\partial e_{q} \partial f_{p}}=0
$$$$
\frac{\partial^{2}\left|v_{p}\right|^{2}}{\partial e_{q} \partial f_{q}}=\frac{\partial^{2}\left|v_{p}\right|^{2}}{\partial f_{q} \partial e_{q}}=0
$$

$$
\frac{\partial^{2}\left|v_{p}\right|^{2}}{\partial f_{p} \partial e_{p}}=\frac{\partial^{2}\left|v_{p}\right|^{2}}{\partial e_{p} \partial f_{p}}=0
$$


$\frac{\partial^{2}\left|v_{p}\right|^{2}}{\partial e_{r} \partial e_{q}}=0$

$\frac{\partial^{2}\left|v_{p}\right|^{2}}{\partial f_{r} \partial f_{q}}=0$

$\frac{\partial^{2}\left|v_{p}\right|^{2}}{\partial e_{r} \partial f_{q}}=0$

$\frac{\partial^{2}\left|v_{p}\right|^{2}}{\partial f r^{\partial e} q}=0$ 
APPENDIX C

SUBROUTINE SPECIFICATION SHEETS 
In this appendix a description of the sparsity directed programs for solving linear sets of equations is given. These were developed at the U.K. Atomic Energy Establishments' Horwell Laboratories . 


\section{Purpose}

To calculate equilibration factors for the rows and columns of a sparce nxn matrix A, which, if applied before Gaussian elimination with pivoting, will make the choice of pivots more likely to lead to low growth of round-off errors. The scaling factors are integral powers $16 * * \mathrm{R}_{i}$ (for row $\mathrm{i}$ ) and $16 * * \mathrm{c}_{j}$ (for column $\mathrm{j}$ ) of 16 (but this base can easily be changed to suit a computer which uses a different radix for floating-point operations). Thus pivots should be chosen as if the matrix elements had been

$$
b_{i j}=a_{j j} * 16 * *\left(R_{i}+C_{j}\right)
$$

The matrix $A$ is stored in the condensed form used by MA18A. Here the non-zero elements are stored linearly by columns, with row numbers in a parallel INTEGER $* 2$ array and with pointers to the start and finish of each column in a smaller INTEGER*2 array.

\section{Calling sequence and argument list}

CALL MCI2A (A, IRN, IP, N, NP, ISC, WS, ISING)

where

A is a REAL array which contains the non-zero elements of the matrix to be scaled, with all elements of a column consecutive.

IRN is an INTEGER $* 2$ array in which IRN $(K)$ contains i if $A(K)$ holds $a_{i j}$. is an INTEGER $* 2$ array of dimension $(N P, 2)$, where $N P \geq N+1$. IP $(m, 2)$ contains $j$, the column number of the column which is stored mth in sequence, and IP $(j, l)$ contains $k$, where $A(k)$ is the first element of column $j . \quad I P(I P(m+1,2), 1)$ thus points to the first element of $A$ beyond those for column $j$. IP $(N+1,2)$ contains $N+1$, and IP $(N+1,1)$ points to the first unused element of array $A$.

$N \quad$ is the order of $A$.

NP is the first dimension of IP.

ISC is an INTEGER*2 array of dimensions (NP,2) in which integer scaling powers are returned, $R_{i}$ in $\operatorname{ISC}(j, 1)$ and $C_{j}$ in $\operatorname{ISC}(j, 2)$ (see $\S 3$ below).

is a workspace array holding $4 * \mathrm{~N}$ REAL $* 4$ numbers.

ISING (INTEGER $* 4$ ) is set on return to 0 normally, but if row 1 or column $J$ of $A$ is found to consist only of zero elements, ISING is set to 1 or -J respectively. The scaling factors returned for non-zero rows and columns are correct. For several zero rows or columns, only the last one detected is returned in ISING. 
Note: The output and workspace requirements are identical for single and double-precision versions, only array $A$ being declared $R E A L * 8$ in the latter.

\section{Method}

The variables $p_{i}$ and $c_{j}$ are chosen to minimize the function

$$
\phi=\sum_{i, j}\left(f_{i j}-p_{i}-c_{j}\right)^{2}
$$

where -

$$
f_{i j}=\log \left|a_{i j}\right| / \log 16
$$

and the summation is over pairs $i, j$ for which $a_{i j} \neq 0$. This is done to sufficient accuracy in only a few matrix-by vector multiplications. Then $R_{i}$ and $C_{j}$ are obtained by rounding $-p_{i}$ and $-c_{j}$ to integers. See Curtis and Reid (1971) for further information.

Use of this method gives far better results on sparse matrices than scali to equilibrate row and column norms, and MCI2A/AD is called by MAI8A/AD before factorising a matrix.

\section{$\underline{\text { Reference }}$}

Curtis, A.R. and Reid, J.K. "On the automatic scaling of matrices for Gaussian elimination", AERE note TP.444 (1971). 


\section{Purpose}

This subroutine solves a general sparse NXN system of linear equations

$$
\sum_{j=1}^{N} a_{i j} x_{j}=b_{i}, \quad i=1,2, \ldots N
$$

(i.e. find $x=A^{-1} b$ ) or related problems.

There are four entries:

(a) MA18A decomposes A into triangular factors using a pivotal strategy designed to compromise between maintaining sparsity and controlling loss of accuracy through roundoff.

(b) MAISB uses the factors produced by MAI8A (or MAI8C) to find $A^{-1} b,\left(A^{\top}\right)^{-1} b, A b$ or $A^{\top} b$.

(c) MA18C factorises a new matrix $A$ of the same pattern, using the pivotal sequence determined by an earlier entry to MAI8A.

(d) MA18D loads the elements of a new matrix A into a storage array in the sequence required by MAI8C, calling a user-supplied subroutine to obtain each column of $A$ and using indexing information stored by MAI8A.

It is envisaged that MAI8C may be called many times for one call of MA18A, so it is much faster. Also it is expected that MAl8B may be called with many different vectors for the same matrix $A$.

\section{Argument lists}

CALL MAI8A (A, IRN, IP, N, NP, G, U, IA) 
CALL MA I8B (A, IRN, IP, N, NP, W, B, MTYPE)

CALL MAI8C (A, IRN, IP, N, NP, G)

CALL MAI8D (A, IRN, IP, N, NP, W, NAME)

is a REAL*4 (or REAL*8 for the D versions) array of dimension IA holding the non-zero elements of the matrix A on entry to MAI8A or MAI8C and the elements of the triangular factors on exit. Elements are stored by columns. For entry to MA18A, they must be in natural row order within each column and the columns must be in natural order; that is $a_{i j}$ precedes $a_{k \ell}$ if $j<\ell$ or if $j=\ell$ and $i<k$. Thus a typical order might be $a_{11}, a_{31}, a_{12}, a_{23}, a_{53}, a_{54}, a_{45}, a_{55^{\circ}}$ Before entry to MA18C, the elements of $A$ should be set by calling MA18D. A is altered by MAI8A, by MAI8C and by MAI8D.

IRN is an INTEGER $* 2$ array of dimension $1 A * 2$, whose first IA elements are used to hold row numbers and whose remaining elements are used for workspace by MAl8A only. If $a_{i j}$ is held in $A(K)$ then IRN (K) must contain $i$; for the above example IRN would contain $1,3,5,1,4,2,5,5,4,5$, IRN is altered by MA18A. is an INTEGER $* 2$ array of dimensions $(N P, 13)$ where NP $\geq 1$. Before entry to MAI8A the values of $I P(J, 1), J-1, \ldots N$ should be set to the subscript in array $A$ of the first element of column $J$ of the matrix and IP $(\mathrm{N}+1,1)$ should be set to the subscript of the first unused location in $A$; thus in the above example IP would contain 
1,4,6,8,9,11. The contents of IP are altered by MA18A.

$(I, J), \quad I=1, N+1), J=1,5)$ should be left undisturbed between a

MA18A entry and a subsequent entry to $M A 18 B / C / D$, or (for $J=3,4$ )

to MAI8A if the previous scaling factors are to be used (see \$4).

The rest of IP is available as workspace. An equivalence should be used to ensure that IP starts on a 4-byte boundary. MAI8C uses the whole of IP as workspace if it obtains new scaling factors (see $\S 4)$.

$\mathrm{N}$

NP

(REAL*4 or REAL*8 for the $D$ version) is an output parameter used to indicate the possible growth of errors during the elimination. Normally MAI8A and MAI8C scale the rows and columns of the matrix (see §4) so that the comparisons used in choosing each pivot will be reasonable. The maximum difference between the floating-point exponent of any element at any stage of the elimination and the floating-point exponent of the initial largest element in its column is evaluated; $G$ is set to the computer rounding error times 16 to the power of this integer. It is thus an estimate of the relative perturbation on the elements of $A$. It is set to -1 in the event of an error, such as singularity of the matrix or lack of space, preventing successful execution.

(REAL*4 or REAL*8 for the D version) is a number set by the user in the range $0<U \leq 1$ to control the choice of pivots: if $U>1$ 
it is reset to $I$ and if $U \leq 0$ it is reset to the relative floating-point accuracy. When searching a row/column for a pivot any element less than $U$ times the largest element in the row/column is excluded. Thus decreasing $U$ biases the algorithm towards maintaining sparsity at the expense of $G$ and vice-versa. The value 0.25 has been found satisfactory in test examples. (INTEGER*4) indicates the size of arrays $A$ and IRN. The number of elements in the decomposed form of $A$ is limited to IA which may not exceed $(32767-N)$ because of the use of INTEGER $* 2$ indices.

is a REAL*4 (or REAL*8 for the D version) working array of dimension at least $N$. $W(1)$ may be equivalenced with an element of IP beyond IP $(\mathrm{N}+1,5)$ to save space.

is a REAL*4 (or REAL*8 for the D version) array of dimension $N$ used to hold $b$ on entry and $A^{-1} b,\left(A^{\top}\right)^{-1} b, A b$ or $A^{\top} b$ on exit.

MTYPE is an INTEGER $* 4$ variable controlling the action of MAI8B. It should have the value $1,2,3$, or 4 according to whether $A^{-1} b$, $\left(A^{\top}\right)^{-1} b, A b$ or $A^{\top} b$ is required. If $M A 18 B$ is called erroneously, it sets MTYPE $=0$ before return.

NAME is the name of a user supplied subroutine called by MAI8D. It must be declared EXTERNAL by the calling program. It is called by

$$
\text { CALL NAME }(N, W, J)
$$

and should return all the non-zero elements $a_{1 J}$ of column $J$ of the new matrix in $W(1)$, without altering other elements of $W$. MA18D will call NAME $N$ times (with $\mathrm{J}$ values not in sequence), and load the new matrix into array $A$. 


\section{Use of the entries}

Between a call of MA18A and a subsequent call of MA18B, MAI8C or MA18D, the contents of $(\operatorname{IRN}(I), I=1, I A),((I P(I, J), I=1, N+1), J=1,5) N, N P$ should not be altered. $I P(N+1,2)$ is set to $N+1$ on successful completion of MA18A, or to zero if an error has been detected. IP $(\mathrm{N}+1,3)$ is set to zero normally but to 1 if MAI8C detects a zero pivot.

By examining IP $(\mathrm{N}+1,2)$ and for $M A 18 B, I P(N=L, 3)$ subsequent entry points can conclude that MAI8A has not been previously entered, or that it or MAI8C diagnosed an error. This causes an error diagnostic from the new entry. G is set to -1 by MAI8A or MAI8C if an error is found, so that the calling program can test for success by examining the sign of $G$ on return. MA18B detects two types of error: those due to invalid entry as described above, which it signals to the calling program by setting MTYPE=0; or if it finds MTYPE out of range, when it leaves it unaltered.

Execution of MAI8C is much faster than MAI8A, but it is important to check the value of $G$ on successful return from $M A 18 \mathrm{C}$, in case the old pivotal sequence is poor, for the new matrix, from the roundoff point of view. If $G$ is too large to be acceptable as a relative perturbation on $A$, the arrays A, IRN, IP should be reset and MAI8A re-entered. IF there is ample space in arrays $A$ and IRN, it may be worth while to increase the value of $U$. The number of locations used in $A$ or IRN is $(I P(N+1,1)-1)$. G should in any case be monitored to detect error returns.

4. Subroutines called and common block

MA18A (and in some circumstances MAI8C) calls subroutine MC12A to obtain 
row and column scaling factors for the matrix. The application of this scaling is controlled by a parameter in a named common block, which also contains the output stream number for diagnostic messages. The common statement is

\section{COMMON/MA 18E/JP, JSCALE}

and the default values are JP-6, JSCALE $=1$.

By including this statement in his program, the user can, if he wishes, charge the stream number JP or the scaling parameter JSCALE.

NB: This should be done by Fortran instructions, not by BLOCK DATA. The significance of JP is obvious; that of JSCALE is as follows:

JSCALE

$<0$

$=0$

$=1$

$>1$

\section{Scaling action}

Scaling factors determined during an earlier call to MAI8A (or MA18C) are applied to the current matrix. No scaling is done (i.e. all scaling factors are set to 1.0$)$.

MC $12 A$ is called by MAI8A to obtain scaling factors, but the action with MAI8C is as for JSCALE $<0$. MC12A is called both by MAI8A and by MAI8C.

If JSCALE > I, MAI8C will change all 13 columns of array IP, otherwise it will use only the first 5 columns.

The time overhead for calling MC12A is significant on MA18C, but not usually on MAI8A. Moreover, use of scaling factors with MAI8C affects only the value of $G$, not the pivotal sequence as with MAI8A. 


\section{Error diagnostics}

A number of error conditions are diagnosed which prevent successful completion. Most are detected by MA18A, since the other entry points are used only after this one has either succeeded with one set of matrix elements in the prescribed sparsity pattern, or has recorded its failure for them. The following messages may be printed on stream JP by MA18:

(i) ERROR RETURN FROM MAI8A BECAUSE THE ELEMENT HELD IN A $(k)$ IS OUT OF ORDER

This message covers sequence errors in the indexing information supplied in IRN, IP; $k$ gives the location at which the error was detected.

(ii) ERROR RETURN FROM MAIBA BECAUSE THE MATRIX IS SINGULAR. COLUMN (or ROW) j IS DEPENDENT ON THE REST.

This message covers two cases, (a) where the indexing information specifies no non-zero elements in column (or row) j, (b) where after elimination on the column or row all the elements eligible as pivots are zero.

(ii i) ERROR RETURN FROM MAI8A BECAUSE IA IS TOO SMALL. SPACE RAN OUT WHEN ELIMINATING ON PIVOT i.

This message appears when there is insufficient room to store a new non-zero element generated in elimination operations using the $\mathrm{ith}$ pivot. Thus if $\mathrm{i} \ll \mathrm{N}$ much more space will probably be needed, but if $i$ is nearly equal to $N$ just a little more may suffice. 
(iv) ERROR RETURN FROM MAI8B BECAUSE MTYPE $=\mathrm{m}$ WHICH IS OUT OF RANGE. This message needs no comment.

(v) ERROR RETURN FROM MA18B (or MA18C Or MA18D) BECAUSE PREVIOUS ENTRY TO MA18A (or MA18C) GAVE ERROR RETURN.

This message is given with MAIBC in the second position only if MA18B occurs in the first position. In that case, the error detected by MAI8C was a zero pivot, which may not occur on subsequent re-entry to MA18C with a further new matrix.

(vi) ERROR RETURN FROM MA18B(or MA18C or MA18D) BECAUSE NO PREVIOUS ENTRY TO MAI8A.

This message is given if $\operatorname{IP}(\mathrm{N}+1,2)$ is found to have a value which is neither $\mathrm{N}+1$ (after a successful exit from MAl8A) nor 0 (after an error return from MA $18 \mathrm{~A})$.

( $v i i)$ ERROR RETURN FROM MAI8C BECAUSE ZERO PIVOT ( $i j$ ).

This message signifies that $a_{i j}$ was found to be zero when it was due to be used as a pivot by MAI8C.

( $v i \mathrm{i}$ ) ERROR RETURN FROM MAI8C BECAUSE MCI2A HAS GIVEN ERROR RETURN WITH $I S=j$.

This message isgnifies that all the elements of the new matrix in row $i($ if $i>0)$ or in column $(-i)($ if $i<0)$ have been found to be zero.

\section{Method}

The subroutine is described in detail in AERE Report R.6844, which should be consulted for certain coding details if it is planned to transfer the subroutine to a computer other than the System/360. 
- ON INPUT, CONTAINS THE ARRAY TO BE

VSRT0120 SORTED ON OUTPUT, A CONTAINS THE VSRTOI30 SORTED ARRAY VSRT01 40

LA - INPUT VARIABLE CONTAINING THE NUMBER VSRTOI50 OF ELEMENTS IN THE ARRAY TO BE SORTED VSRTOI60 IR(LA) - ON INPUT, IR CONTAINS THE INTEGER VSRTOI70 VALUES $1,2, \ldots$ LA. SEE PROGRAMMING VSRTO180 NOTES. VSRT0190

- ON OUTPUT, IR CONTAINS A RECORD OF THE VSRT0200 PERMUTATIONS MADE ON THE VECTOR A. VSRT0210

C PRECISION 
CALL VSRTPM (A, LA, IR)

CALL VSORTP (A, LA, IR)

\section{Purpose}

VSRTPM sorts any LA consecutive elements of a vector into ascending sequence by absolute value, keeping a record in IR of the permutations to the vector $A$. That is, the elements of IR are moved in the same manner as are the elements in $A$ as $A$ is being sorted.

VSORTP sorts any LA consecutive elements of a vector into ascending sequence by algebraic value, keeping a record in $I R$ of the permutations to the vector $A$. That is, the elements of IR are moved in the same manner as are the elements in $A$ as $A$ is being sorted.

\section{Algorithm}

VSRTPM/VSORTP uses the algorithm declared in IMSL routine VSORTM/VSORTA.

\section{Programming Notes}

1. $\quad I R$ and $A$ must have dimension at least LA.

2. The vector IR must be initialized before entering VSRTPM/VSORTP. Ordinarily, $I R(1)=1, I R(2)=2, \ldots, I R(L A)=L A$. For wider applicability, any integer that is to be associated with $A(1)$ for 1 $=1,2 \ldots$, LA may be entered into $I R(I)$.

3. If entry VSRTPM is used, A is replaced by the sorted absolute values of its elements, on output.

Example

CALL VSORTP (A, LA, IR) 
Input:

$$
\begin{array}{ll}
A=(10 ., 9 ., 8 ., 7 ., 6 ., 5 ., 4 ., 3 ., 2 ., 1 .) & A=(1 ., 2 ., 3 ., 4 ., 5 ., 6 ., 7 ., 8 ., 9 ., 10 .) \\
L A=10 & I R=10,9,8,7,6,5,4,3,2,1) \\
I R=(1,2,3,4,5,6,7,8,9,10) &
\end{array}
$$

\section{Output:}


APPENDIX D

DEFINITIONS AND DIMENSIONS

OF COMPUTER VARIABLE NAMES 
DEFINITIONS OF COMPUTER YARIABLE NAMES

For definitions of the following ten variables, see the sparsity subroutine specification sheets in Appendix $C$ :

$A,(I A+I E X T R A), G, I P, I R N$, MTYPE, $N, N P, U$, and $W$.

The other definitions are:

NAME

DESCRIPTION

AA

Al a vector which holds the row numbers of the non-zero

INPUTED FLAG WHICH TELLS IF TOTAL LINE shunt admittance to ground is inputed $(A A=0)$ or only one-half of total value is inputed $(A A=1)$. elements of the upper (or lower) triangle of the bus admittance matrix.

A2

a vector which tells us how many non-zero upper triangle bus admittance matrix elements that have been at the commencement of a given column.

ALPHA the value determines the portion of the second order correction factor which is used to update the bus mismatches and the portion used to update the diagonal elements of the Jacobian submatrices.

BB inputed flag which indicates whether the transformer inputed information is the tap setting $(B B=1)$ or the turns ratio $(B B=0)$.

CC inputed flag which determines whether a Newton-Raphson load flow is to be solved $(C C=0)$ or one using the alpha M.Q.S.O.N.R. method $(C C=1)$. 
diagonal elements of the bus admittance matrix.

D1, D2, D3, vectors which contain the locations of the diagonal D4

elements of the Jacobian submatrices within the vector of the non-zero elements of the Jacobian, JACOB.

DELK CONTAINS the iteration number for which the corresponding maximum mismatch values are stored.

DELMAX the specified tolerance required in order for convergence to occur.

DELMXP maximum active power mismatch.

DELMXQ maximum reactive power mismatch.

DELMXV maximum voltage squared mismatch.

DELP variable which stores the value which DELMXP has at the end of an iteration.

DELQ variable which stores the value which DELMXQ contains at the end of an iteration.

DELS temporary storage for updated bus mismatches; needed when there is an unsuccessful convergence check at the one-half iteration point.

DELTAP active power bus mismatch.

DELTAQ reactive power bus mismatch.

DELTAS vector which contains all the bus mismatches.

DELTAV voltage squared bus mismatch.

DELV stores the value which DELMXV contains after an iteration.

DESERY, DSHTY, temporary storage for 1 ine data when the 1 ine numbers DSHTYD, DTFMR are being rearranged. real component of bus voltage. 
IEXTRA

JACA 1

JACA 2

JACOB

K

KO

KI

K2

KDEL

KKK

KMAX

KNECT

KTOT

bus number at the receiving end of a line.

temporary storage for EB's when line numbers are being rearranged.

voltage corrections after the first half of an iteration. imaginary component of the bus voltage. the number of non-zero elements in the Jacobian matrix. workspace required for the sparsity subroutine, MAIBA. vector which contains the row numbers of all the non-zero elements of the Jacobian matrix. vector which tells how many non-zero Jacobian matrix elements there are up to the commencement of a given column . non-zero elements of the Jacobian matrix. iteration counter.

the number of voltage regulated buses, not including the slack bus.

the number of load buses.

the number of buses, not including the slack bus. records the number of times that a convergence check is performed.

if one-half an iteration is successful in converging, value is set to 5 . Otherwise its value is 0 . maximum number of iterations allowed. records the number of lines connected to the slack bus. the number of non-zero elements in the bus admittance matrix. 


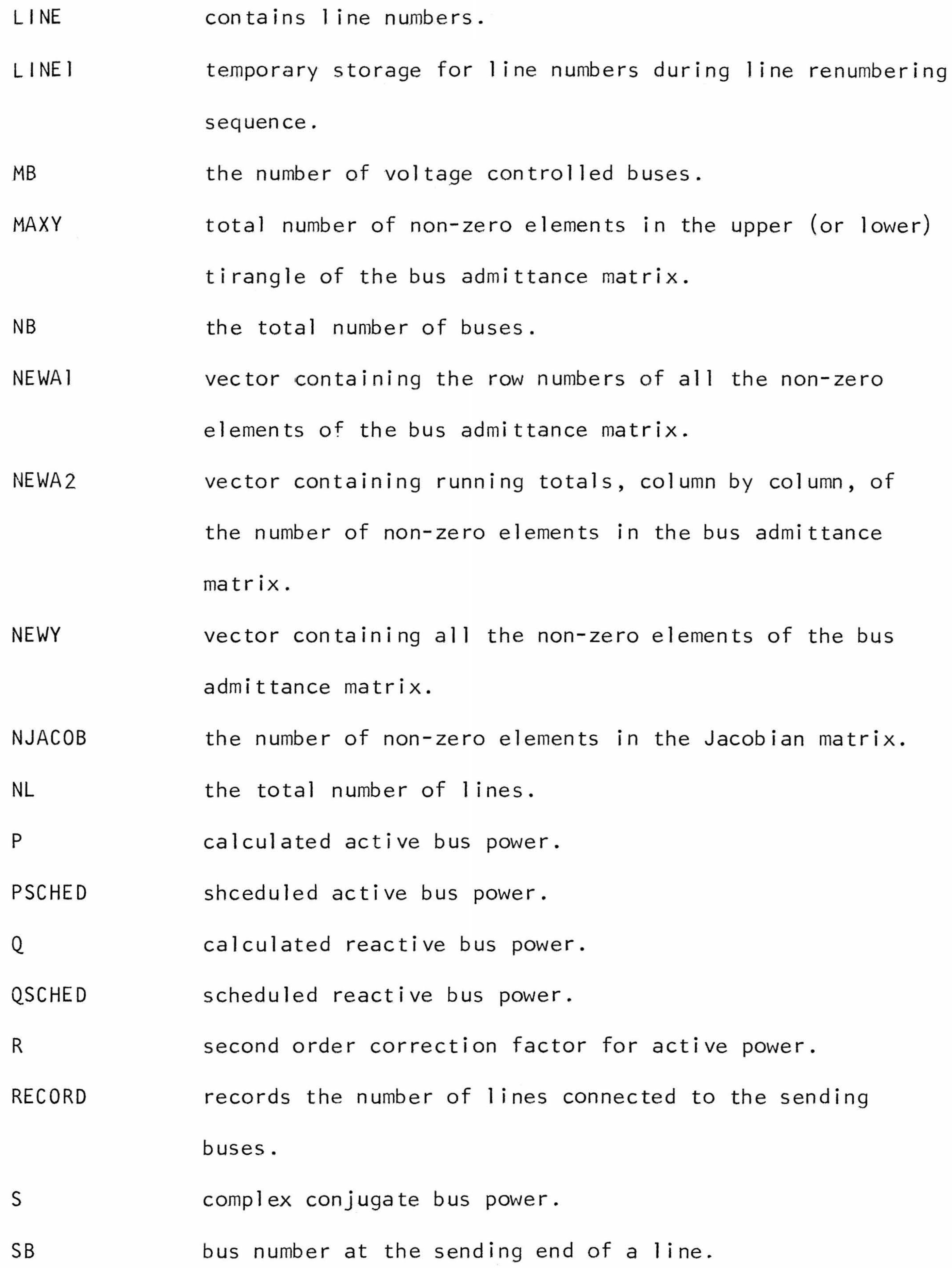


SBCAP

SERY

SERZ

SHTY

SHTYB

SUM1, SUM2

T

TFMR

U2

$$
\text { V }
$$

VSCHED

VV

Y static capacitor or shunt reactor connected to the sending bus of a line.

line series admittance.

line series impedance.

line charging susceptance.

line charging represented by admittance shunted to ground at the received end of a line.

summation portions of the first order mismatch correction factors.

SUM3, SUM4 summation portions of the second order mismatch correction factors.

second order correction factors for reactive power. inputed off-nominal tap setting of a transformer. second order correction feactors for the square of the bus voltage.

complex bus voltage.

sheduled bus voltage magnitude. complex conjugate of the bus voltage. non-diagonal elements of the upper (or lower) triangle of the bus admittance matrix.

If a series of load flows with different alpha values is solved during one computer run, then there are also:

AANT input of the initial alpha value. AINT2, AINT3 $\ldots$ other alpha values. I FLAG counter to determine if a table output may be terminated. 
JFLAG

counts the number of tables printed on one page.

KFLAG

counts the number of tables with less than 2.5 iterations, on a given page.

KKSAVE

indicator as to whether the load flow solution ends in a half iteration.

KSAVE

number of iterations to convergence for a particular alpha value.

LIMIT number of tables desired to be outputed; there are six alphas per table.

SAVEP the maximum active power mismatch is stored for every iteration.

SAVEQ the maximum reactive power mismatch is stored for every iteration.

SAVEV the maximum voltage squared mismatch is stored for every iteration. 
DIMENSIONS OF VARIABLES

We have,

$$
\begin{aligned}
\mathrm{NB} \triangleq & \text { number of buses } \\
\mathrm{NL} \triangleq & \text { number of lines } \\
\mathrm{MB} \triangleq & \text { number of voltage controlled buses, } \\
& \quad \text { including the slack bus. }
\end{aligned}
$$

\section{VAR I ABLE}

A

Al

A2

CRI

CR2

D

DI

D2

D3

D4

DELK

DELP

DELQ

DELS

DELTAS

DELV

DSERY

DSHTY

\section{DIMENS ION}

IEXTRA + (NB - I)

NL

NB

$N B-1$

NB -1

NB

$N B-1$

$N B-1$

NB -1

$N B-1$

$2 *($ KMAX)

$2 *($ KMAX)

$2 *($ KMAX)

$2 *(N B-1)$

$2 *(N B-1)$

$2 *($ KMAX)

$\mathrm{NL}$

NL 


\begin{tabular}{|c|c|}
\hline DTFMR & $N L$ \\
\hline$E$ & NB \\
\hline$E B$ & $\mathrm{NL}$ \\
\hline EB 1 & $\mathrm{NL}$ \\
\hline ERRORI & $2 X(N B-1)$ \\
\hline $\mathrm{F}$ & NB \\
\hline \pm BUS & NB \\
\hline IP & {$[(2 * N B-1), 13]$} \\
\hline IRN & $2 *($ IEXTRA + dimension of JACOB $)$ \\
\hline JACA 1 & $\begin{array}{l}8 * \text { (number of lines not connected to the slack bus })+ \\
4 *(N B-1)\end{array}$ \\
\hline JACA2 & $N B+1$ \\
\hline$J A C O B$ & same as for JACAI \\
\hline LINE & NL \\
\hline LINE I & NL \\
\hline NEWA 1 & $(2 * N L)+N B$ \\
\hline NEWA2 & $N B+1$ \\
\hline NEWY & $(2 X N L)+N B$ \\
\hline$P$ & NB \\
\hline PSCHED & NB \\
\hline Q & NB \\
\hline QSCHED & NB \\
\hline RECORD & NB \\
\hline SB & $N L$ \\
\hline SBCAP & NL \\
\hline SERY & $N L$ \\
\hline
\end{tabular}




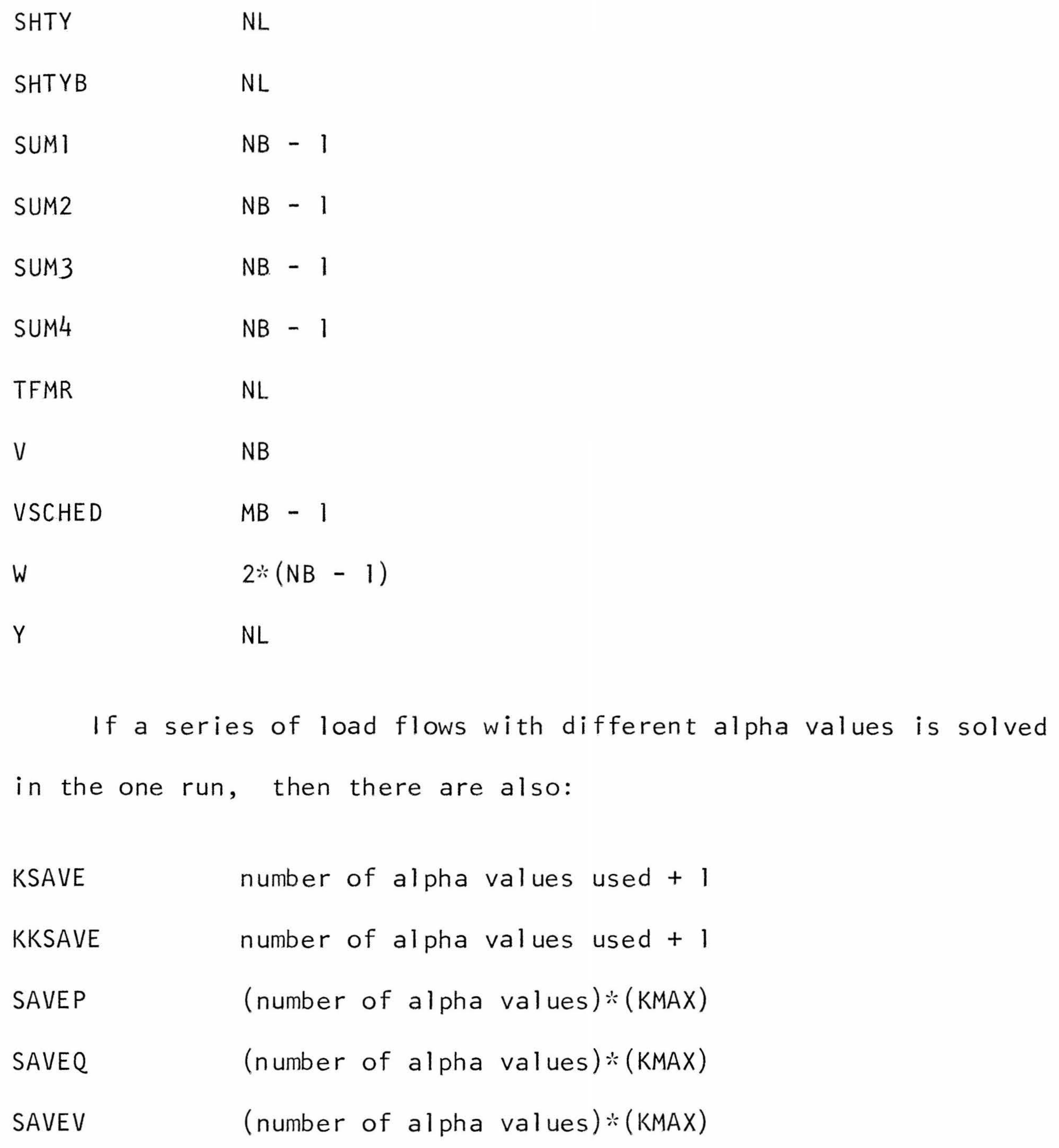


APPENDIX E

PROGRAM LISTING 


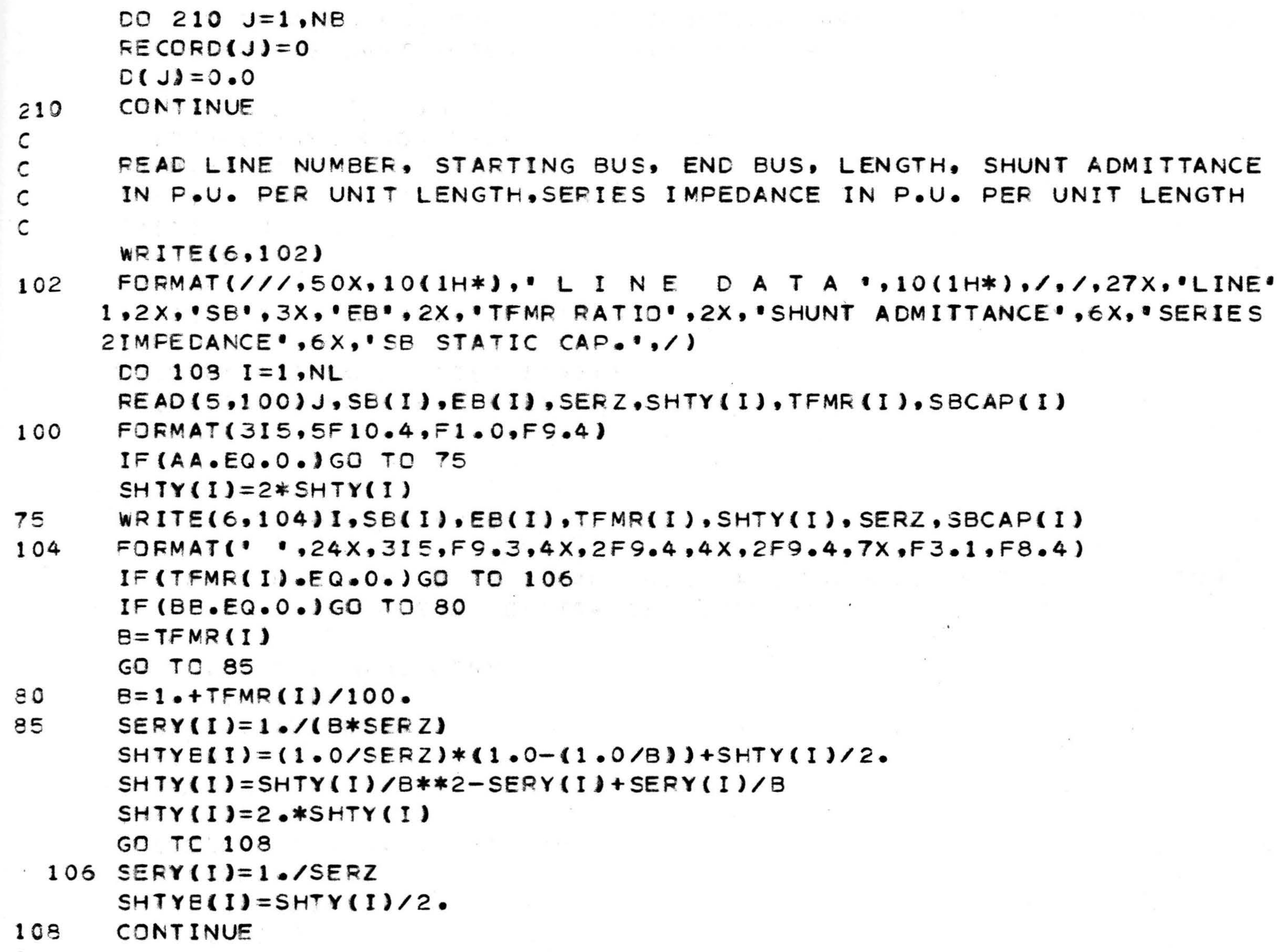

SPARSE STORAGE OF ADNITTANCE MATFIX

(INCLUDES REAFRANGING LINE NUMBERS IF NECESSARY)

\section{ASSEMBLE DIAGONAL SLEMENTS}

CO $119 \quad I=1, N L$

$Y(I)=0.0$

$L=S B(I)$

$N=E B(I)$

$D(L)=D(L)+\operatorname{SERY}(I)+\operatorname{SHTY}(I) / 2 \bullet+\operatorname{SBCAP}(I)$

$D(M)=D(M)+\operatorname{SERY}(I)+S H T Y B(I)$

119 CONTINUE

$C(107)=D(107)+.06$

KNECT $=0$

DO $220 \quad I=1, N L$ 
//E30111CK JOB $(3011,10 K C, 1,02)$, WELLON,CLASS $=C$

$/$ JOBPARM FORMS $=0234$

// EXEC FORTGCLG, REGION. GO $=129 \mathrm{~K}$

IIFOFT.SYSIN DD *

C

CONPLEX Y, V,S,SS, SR, IBUS, SUMS, VV,D, NEWY

COMPLEX SHTY, DSHTY, Z SER, SERY, DSERY, SHTYB, DSHTYB, SBCAP, SERZ

INTEGER DUMMY, OUM1,DUM2, RECORD,EB1, LINE, LINE 1

INTEGER SB,EB,A1, A2,D1,D2,D3,D4, AA, BB,CC

INTEGER*2 JACA 1, JACA2, IP(235,13), IRN(6248)

FEAL JACOB, MAGN

REAL*8 ALPHA

CIMENSION D1 (117), D2(117),D3(117),D4(117), CR 1(117), CR2 (117)

DINENSION E(118),F(118),V(118),P(118),Q(118),D(118),A2(118)

DIMENSION PSCHED ( 118 ), QSCHED ( 118 ), I BUS ( 118$), \operatorname{RECORD~(118)~}$

CINENSION SHTY (186), SHTYB(186), SERY (186), DSHTY(186), DSHTYB(186)

DIMENSION DSERY ( 186$)$, LINE (186), LINE1 (186), EB1(186), Y(186), A1 (179)

DIMENSION TFMR $(186)$, DTFMR $(186), \operatorname{SBCAP}(186)$

DINENSION SB(186), EB(186), W(234), DELTAS(234), ERROR1(234),A(3124)

DIMENSION NEWY (476), NEWA $1(476)$, NEWA2(119), VSCHED (53)

DINENSION JACOB (2124), JACA1 (2124), JACA2(235)

CIMENSION DELK(20), DELP(20), DELQ(20), DELV(20)

DIMENSION SAVEP (500), SAVEQ(500), SAVEV(500), KSAVE(45), KKSAVE (45)

OI MENSION DELS(234)

COMMON /MEMORY/ JACOE, JACA1, JACA 2

EXTERNAL RELOAD

WR ITE $(6,2)$

FORMAT $(/, / /, 5 X, " 118$ BUS TEST SYSTEM $*)$

READ NUMBER OF BUSSES, NUMBEF OF LINES, NUMBER OF VOLTAGE CONTROL EUSSES INCLUDING SLACK BUS, AND FLAGS

READ (5,74) ALPHA

74 FOFMAT (F 10.3$)$

READ $(5,100) A A, B B, C C$

READ $(5,100) \mathrm{NB}, \mathrm{NL}, \mathrm{MB}$

WRITE $(6,76)$ ALPHA, AA, EE, CC, NB, NL, MB

FOFMAT(*, $1 /, 5 X, 1 A L P H A$ AA B B

$11,2 x, 3(5,3 I 7)$

CC NB NL

$M B^{\prime}, /, F 8$.

C

PRINTOUT OF CHANGES MADE IN BUS NUMBERS

WR ITE $(6,151)$

151 FOFMAT $(", / /, 5 X$, "THE FOLLOWING BUS NUMBERS WERE CHANGED TO ALLOW

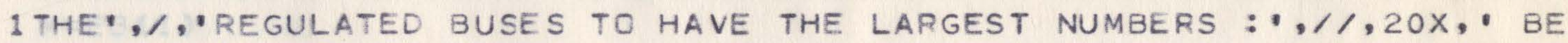
2COMES', / )

DO $155 \quad I=1,10$

READ $(5,153) \mathrm{J} 1, \mathrm{~J} 2, \mathrm{J3}, \mathrm{J4}, \mathrm{J} 5, \mathrm{~J} 6, \mathrm{~J} 7, \mathrm{~J} 8, \mathrm{~J} 9, \mathrm{~J} 10, \mathrm{~J} 11, \mathrm{~J} 12, \mathrm{~J} 13, \mathrm{~J} 14, \mathrm{~J} 15, \mathrm{~J} 16$

153 FOFMAT (16I5)

WRITE $(6,154) \mathrm{J} 1, \mathrm{~J} 2, \mathrm{~J} 3, \mathrm{J4}, \mathrm{J} 5, \mathrm{~J} 6, \mathrm{~J} 7, \mathrm{~J} 8, \mathrm{~J} 9, \mathrm{~J} 10, \mathrm{~J} 11, \mathrm{~J} 12, \mathrm{~J} 13, \mathrm{~J} 14, \mathrm{~J} 15, \mathrm{~J} 16$

154

155

FOFMAT(', $8(14 \mathrm{X}, \mathrm{I} 5, \cdot$

",$(4,1))$

CONTINUE 
THE SENDING AND END BUS DESIGNATIONS ARE REVERSED IF THE S•B. NUMBER IS LARGER THAN THE E.B. NUMBER

IF (SE(I) . LT.EB(I)) GO TO 30

IF (TFMR (I) .NE・0.0) TFMR (I) $=1$. /TFMR (I)

DUMMY $=S B(I)$

$S B(I)=E B(I)$

$E B(I)=D U M M Y$

CONT INUE

RECORD THE NUMBER OF LINES CONNECTED TO EACH SENDING BUS

RECORD (SB (I) ) =RECORD (SB(I)) + 1

IF (EE (I ) •EQ.NB) KNECT $=K N E C T+1$

LINE(I) $=$ I

C

220 CONTINUE

KNEC T $=$ KNEC $T+R E C O R D(N E)$

$C$

C

REARRANGE THE LINES IN AN ORDER ACCEPTABLE FOR THE FORMATION OF THE SPARSE EUS ADMITTANCE VECTOR

C

CALL VSORTP(SB, NL, LINE)

DO 31 I $=1$, NL

$E B 1(I)=E B(L I N E(I))$

DUN $1=0$

DUN2 $=0$

CO $35 \quad I=1$, NB

IF (RECORD (I) •EQ.0)GO TO 35

DUMMY $=$ RECORD (I)

DO $32 \mathrm{E} J=1$, DUMMY

DUM $1=$ DUM $1+1$

$E B 1(J)=E B 1$ (DUM1)

32 LINEI $(J)=\operatorname{LINE}($ DUM 1$)$

CALL VSORTP(EBI, DUMMY, LINEI)

DO $34 \mathrm{~K}=1$, DUMMY

CUN2 $=$ DUM $2+1$

$E B(D \cup M 2)=E B 1(K)$

34 LINE (DUM2) $=$ LINEI $(K)$

35 CONTINUE

C

C

REARRANGE THE LINE DATA TO BE COMPATIBLE WITH THE NEW LINE NUMBERS

$c$

DO $36 \quad I=1$, NL

DTFMR (I) $=$ TFMR (I)

CSHTY (I) $=$ SHTY (I )

DSHTYB (I) $=$ SHTYB (I)

36 CSERY (I) $=$ SERY (I)

CO $37 \quad I=1, N L$

TFNR (I) =DTFMR (LINE(I))

SHTY(I) =DSHTY(LINE(I)) 


\section{SHTYB (I) =DSHTYB (LINE (I ) )}

WRITE $(6,38)$

FOFMAT(///,40X,10(1H*), "RE OR DERE D $2 \cdot, 2 \mathrm{X}$, 'TFMR RATIO',2X,"SHUNT ADMITTANCE", $6 \mathrm{X}$, 'SERIES IMPEDENCE" $6 \mathrm{X},{ }^{\prime}$

3 SB STATIC CAP.', 11

DO $40 \quad I=1$, NL

SERZ $=1$. /SERY (I )

WRITE(6,39) I , LINE(I), SB(I), EB(I), TFMR (I), SHTY (I), SERZ, SBCAP(LINE(I 1))

39 FOFMAT(' , $12 \mathrm{X}, 3 \mathrm{I} 8,2 \mathrm{X}, 13, \mathrm{F9} \cdot 3,3 \mathrm{X}, 2 \mathrm{F9} \cdot 4,4 \mathrm{X}, 2 \mathrm{F9} \cdot 4,7 \mathrm{X}, \mathrm{F} 3 \cdot 1, \mathrm{~F} 8.4)$

C

$\mathrm{J} 1=1$

$L L=0$

$M M=0$

A2 (1) =1

DO $128 \quad I=1, N L$

$L=S B(I)$

$N=E B(I)$

IF (LL.EQ.O) GO TO 122

IF (L.EQ.LL ) GO TO 124

IF $(L \cdot E Q \cdot L L+1) G O$ TO 122

DUN $1=L-2$

DO 120 II I=LL, DUM 1

120

$A 2(I I+1)=J 1$

122

$A 2(L)=J 1$

GO TC 126

$124 \quad I F(M \cdot E Q \cdot M M) \quad J 1=J 1-1$

$126 \quad A 1(J 1)=M$

$Y(J 1)=Y(J 1)-\operatorname{SER} Y(I)$

$J 1=J 1+1$

$L L=L$

$M M=M$

128 CONTINUE

NAXY $=J 1-1$

IF (L.EQ.NB-1) GO TO 134

CUM $1=\mathrm{NB}-1$

CO 132 I =L, DUM!

$132 \quad A 2(I+1)=J 1$

134 CONTINUE

$A 2(N E)=J 1$

$N R L=M A X Y$

WRITE (6,1665) MAXY, AC (NB)

1665 FORMAT ( $, 1 / / /, 5 X, \cdot$ MAXY $=, 14,5 X, \cdot A 2(N B)=1, I 4, / / /)$

WR ITE $(6,1331)(I, D(I), I=1, N B)$

1331 FORMAT(*, $40(3(4 \mathrm{X}, *$ D $(\cdot, 13, \cdot)=\cdot, 2 F 12.4), / 1))$

$K B=0$

$\mathrm{K} 2=\mathrm{NE}-1$

DO $1334 \quad I=1, K 2$ 


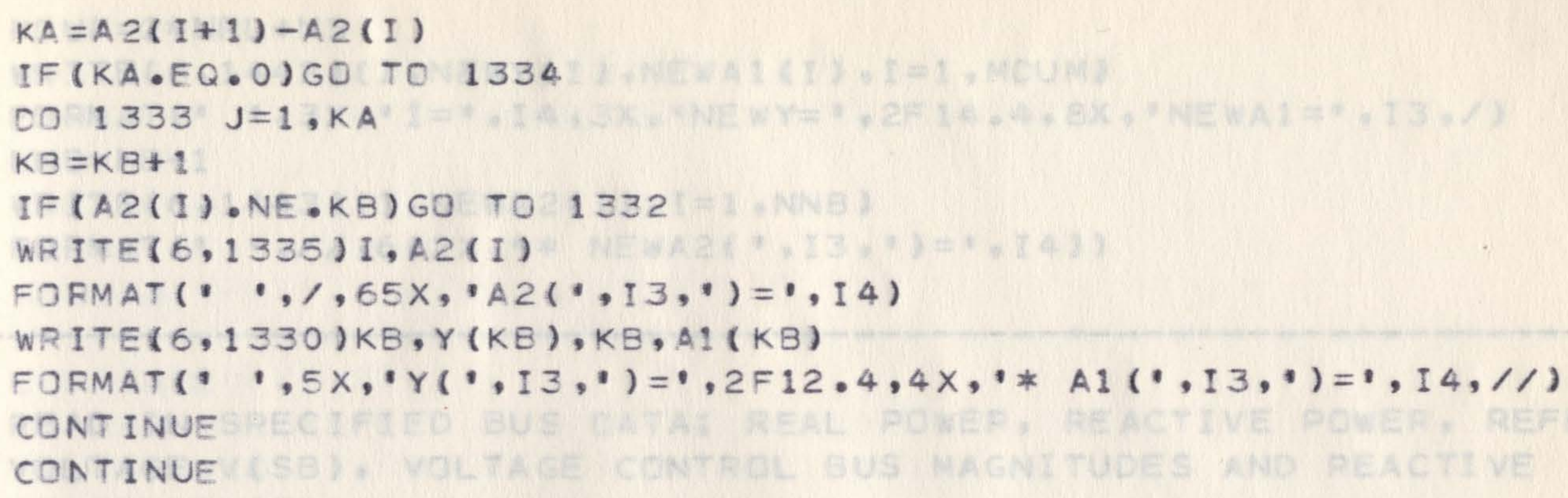

$c$

c

$N E W Y(1)=D(1)$

NEWA $1(1)=1$

NEWAC $(1)=1$

$I A=A 2(2)-A 2(1)$

DO 136 I $1=1$, IA

$K A=11+1$

NEWY $(K A)=Y(I 1)$

136 NEWA1(KA) $=A 1$ (I1)

NE WA2 $(2)=K A+1$

DO $152 \quad I=2$, NB

CUM $1=I-1$

DO 144 I $3=1$, DUMI

IF (A2 I I $) \cdot E Q \cdot A 2(I 3+1))$ GO TO 144

$K B=A 2(13+1)-1$

DUN $2=A 2(I 3)$

DO 142 I $2=D U M 2, K B$

IF (A1 (I2).NE. I ) GO TO 138

$K A=K A+1$

$N E W Y(K A)=Y(I 2)$

NEWA $1(K A)=13$

GO TO 144

138 IF (A1(I2). GT.I ) GO TO 144

142 CONTINUE

144 CONTINUE

$K A=K A+1$

$N E W Y(K A)=D(I)$

NEWA $1(K A)=I$

IF (I.EQ.NB)GO TO 148

$I F(A 2(I) \cdot E Q \cdot A 2(I+1)) \quad G O$ to 148

$K C=A 2(I+1)-1$

DUM $2=A 2(I)$

CO 146 I4 =DUM2, $K C$

$K A=K A+1$

NEWY $(K A)=Y(I 4)$

146 NEWA $1(K A)=A 1(I 4)$ 
NDUM $=2 * N R L+N B$

WRITE $(6,1442)$ (I, NEWY (I), NEWA I (I), I =1, MDUM)

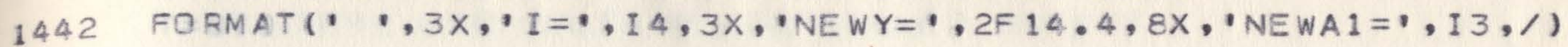

$N N B=N B+1$

WR ITE ( 6,1443 ) (I, NEWA2 (I), I=1, NNB)

1443 FORMAT (",$/ /, 6(2 X, \cdot * \operatorname{NEWA2}(\cdot, I 3, \cdot)=1, I 4))$

$c$

C

$\mathrm{C}$

READ IN SPECIFIED BUS DATA; REAL POWER, REACTIVE POWER, REFERENCE VOLTAGE V(SB), VOLTAGE CONTROL BUS MAGNITUDES AND REACTIVE FOWER LIMITS

$K 1=N B-M B$

$\mathrm{K} 2=\mathrm{NB}-1$

READ $(5,150)$ (PSCHED(I), I=1,K2)

READ $(5,150)(Q S C H E D(I), I=1, K 1)$

READ $(5,150) E(N B), F(N B),(V S C H E D(I), I=1,6)$

IF (KO.GT.6) READ $(5,150)(\operatorname{VSCHED}(I), I=7, K O)$

150 FORMAT $(8 F 10.3)$

WRITE $(6,160)$ (PSCHED ( I ), I=1,K2)

160 FORMAT(IH1,//," P(SCHEDULED) (I) $=0,11 F 10.3, / 1,50(18 \times, 11 \mathrm{~F} 10.3, / 1))$ WRITE $(6,161)(Q S C H E D(I), I=1, K 1)$

161 FOFMAT $(1 \mathrm{HO}, / /, \mathrm{Q}(\mathrm{SCHEDULED})(\mathrm{I})=\cdot, 11 \mathrm{~F} 10.3,1 /, 50(18 \times, 11 \mathrm{~F} 10.3,1 /))$ WR ITE $(6,162) E(N E), F(N B),(V S C H E D(I), I=1, K O)$

162 FOFMAT $(/ /, 10 \mathrm{X}, \cdot \mathrm{V}(\mathrm{SB})=\cdot, 2 \mathrm{~F} 10.3, / / / 6 \mathrm{X}, \cdot \mathrm{VSCHED}(\mathrm{I})=\cdot, 11 \mathrm{~F} 10.3, / /, 50$ $1(18 \times, 11=10.3, / / 1))$

READ $(5,105)$ KMAX, DELMAX

105 FOFMAT (I5, F10.7)

READ $(5,1550)$ IEXTRA

1550 FOFMAT(I10)

WR ITE $(6,1663)$ IEXTRA

1663 FOFMAT(',,$/ / /, 10 X$, IEXTRA $=$, I5, ///)

C - -

$c$

INITIALIZE UNKNOWN VOLTAGES AND REACTIVE POWERS

C

I $\mathrm{J}=0$

I $J K=0$

$001019 \quad I=1,45$

KSAVE (I) $=0$

1019 CONTINUE

101 CONTINUE

DO $250 I=1, K 2$

$E(I)=.866025404$

$F(I)=0.5$

250 CONTINUE

$K 5=K 1+1$

DO $251 \quad I=K 5, K 2$

$251 \quad G(I)=0.0$

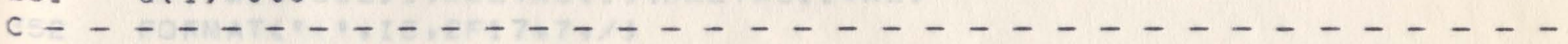


c

$R=0.0$

$T=0.0$

$L=0$

$K=0$

$K K K=0$

$K D E L=0$

COO CONTINUE

DO $255 \quad I=1, K 2$

$C R 1(I)=0.0$

$C R 2(I)=0.0$

255 CONTINUE

SOI CONTINUE

c

c

CALCULATE THE REAL AND REACTIVE POWERS

c

DELMXP $=0.0$

CELMXQ $=0.0$

$D E L M X V=0.0$

$I \mathrm{~B}=0$

DO $261 \mathrm{I}=1, \mathrm{~K} 2$

IA =NEWA $2(I+1)$-NE WA2 (I)

IF (IA.EQ.O) GO TO 261

SUN1 $=0.0$

$\operatorname{SUM} 2=0.0$

CO $262 \mathrm{~J}=1$, IA

$I B=I B+1$

I $C=N E W A I$ ( IB)

SUN $1=S U M 1+E(I C)$ *REAL $(N E W Y(I B))-F(I C)$ AIMAG (NEWY (IB))

SUM2 $=\operatorname{SUM} 2+F($ IC) *REAL (NEWY (IB.)) +E (IC) \#AIMAG (NEWY (IB))

262 CONTINUE

$F(I)=E(I) * S U M 1+F(I) *$ SUM2

$Q(I)=F(I) * S U M 1-E(I) *$ SUM 2

c

CALCULATE MAXIMUM REAL AND REACTIVE POWER ERRORS

c

C

DELTAP=PSCHED (I )-P(I)

CELTAS (I ) = DEL TAP

IF (AES (DELTAP) • GT .DELMXP) DELMXP=ABS (DELTAP)

IF (I.GT.KI)GO TO 261

DELTAQ $=Q S C H E D($ I $)-Q($ I $)$

DEL TAS $(I+K 2)=D E L T A Q$

IF $(A E S(D E L T A Q) \cdot G T \cdot D E L M X Q) D E L M X Q=A B S(D E L T A Q)$

261 CONTINUE

c

WRITE $(6,351)$

351 FORMAT(1HO,15X,5(1H*), POWER ERROR 1 MATRIX $, 5(1 \mathrm{H} *), / /, 15 X, 1 D E L T A$

1 P , $10 X$, 'DELTA $Q \cdot 5 X$, DELTA V-SQUARED , /)

DO $353 \mathrm{I}=1, \mathrm{~K} 1$

WRITE $(6,352)$ I, DELTAS (I), DELTAS(I+K2)

352 FORMAT( , ,I5,2F17.7, /) 


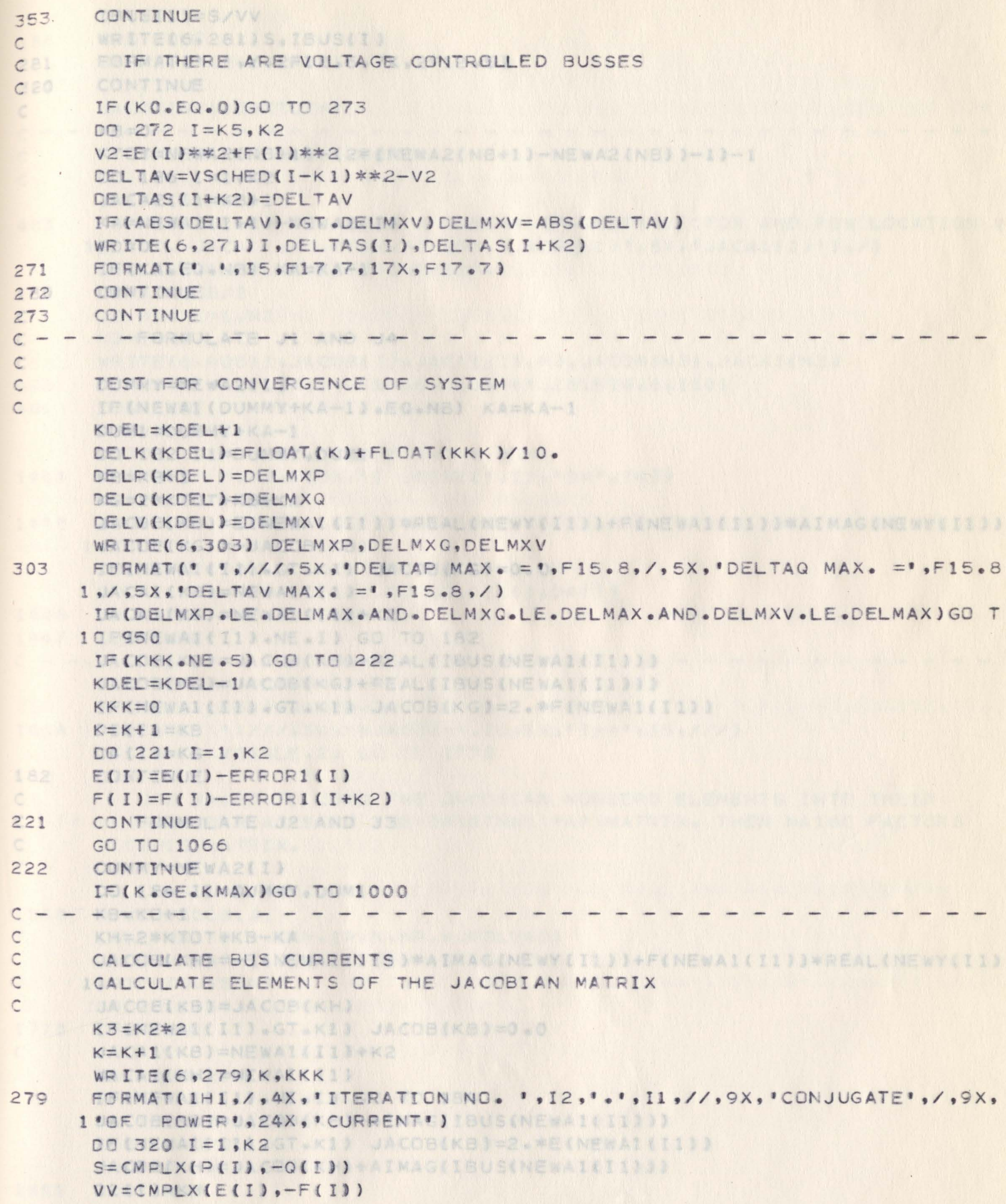

CALCULATE BUS CURRENTS

CALCULATE ELEMENTS OF THE JACOBIAN MATRIX

$k 3=k 2 * 2$

$k=k+1$

WRITE $(6,279) \mathrm{K}, \mathrm{KKK}$

279 FORMAT $(1 H 1, /, 4 \mathrm{X}$, 'ITERATION NO.',I2,'.,11,//,9X, 'CONJUGATE',/,9X, 1.OF POWER',24X,' CURRENT')

DO $320 \quad I=1, K 2$

$S=C M P L X(P(I),-Q(I))$

$V V=C N P L X(E(I),-F(I))$ 
IBUS (I) $=S / V V$

WRITE $(6,281) S$, IBUS(I)

FOFMAT(, , , , 2F12.5, 7X, 2F12.5)

CONTINUE

$K B=0$

$K T O T=N E W A 2(N B+1)-(2 *(N E W A 2(N B+1)-N E W A 2(N B))-1)-1$

DO $186 \quad I=1, K 2$

$J A C A Z(I)=K B+1$

$K A=N E W A 2(I+1)-N E W A 2(I)$

$K D=0$

IF $(K A \cdot E Q \cdot N B) \quad K A=K A-1$

180

CONT INUE

$c$

FORMULATE J1 AND J4

DUMMY =NE WA 2 (I)

IF (NEWAI (DUMMY+KA-1) •EQ.NB) $\quad K A=K A-1$

DUM $1=D U M M Y+K A-1$

DO 182 I 1 =DUMMY, DUM 1

$K B=K E+1$

$K G=2 * K T O T+K B+K A$

JACOE $(K B)=E(N E W A 1(I 1))$ *REAL (NEWY (I 1)) +F(NEWA I (I1)) \#AIMAG $(N E W Y(I 1))$ $J A C O E(K G)=-J A C O B(K B)$

IF (NEWA1 (I 1) . GT •K1) JACOB (KG) $=0.0$

JACA 1 $(K B)=N E W A 1$ (I 1 )

$J A C A 1(K G)=N E W A 1(I 1)+K 2$

IF (NEWAI (II).NE.I) GO TO 182

$J A C O E(K B)=J A C O B(K B)+R E A L(I B U S(N E W A 1(I 1)))$

$J A C O E(K G)=J A C O B(K G)+R E A L(I B U S(N E W A 1(I 1))$ )

IF (NEWAI (II) • GT.KI) JACOB(KG) =2.*F(NEWAI(II) )

$D 1($ I $)=K B$

$C 4($ I $)=K G$

182 CONTINUE

c

FORMULATE J2 AND J3

c

DUMMY $=$ NE WA.2 (I)

DO $1 \& 4$ I 1 = DUMMY, DUM 1

$K B=K B+1$

$K H=2 * K T O T+K B-K A$

JACOB $(K H)=-E(N E W A I(I 1))$ AIMAG (NEWY(I1)) +F(NEWAI (I 1)) *REAL(NEWY(I 1)

1)

$J A C O E(K B)=J A C O B(K H)$

IF (NEWAI (II) . GT.KI) JACOB $(K B)=0 \cdot 0$

$J A C A 1(K B)=N E W A I(I 1)+K 2$

$J A C A 1(K H)=N E W A 1$ (I1)

$I F(N E W A 1(I 1) \cdot N E$. I) GC TO 184

$J A C O B(K B)=J A C O B(K B)-A I M A G(I B U S(N E W A 1(I 1)))$

IF (NEWA1 (I 1). GT.K1) JACOB(KB) =2. *E(NEWAI (I 1))

$J A C O E(K H)=J A C O B(K H)+A I M A G(I B U S(N E W A I(I 1)))$

$\mathrm{D} 2(\mathrm{I})=\mathrm{KH}$ 


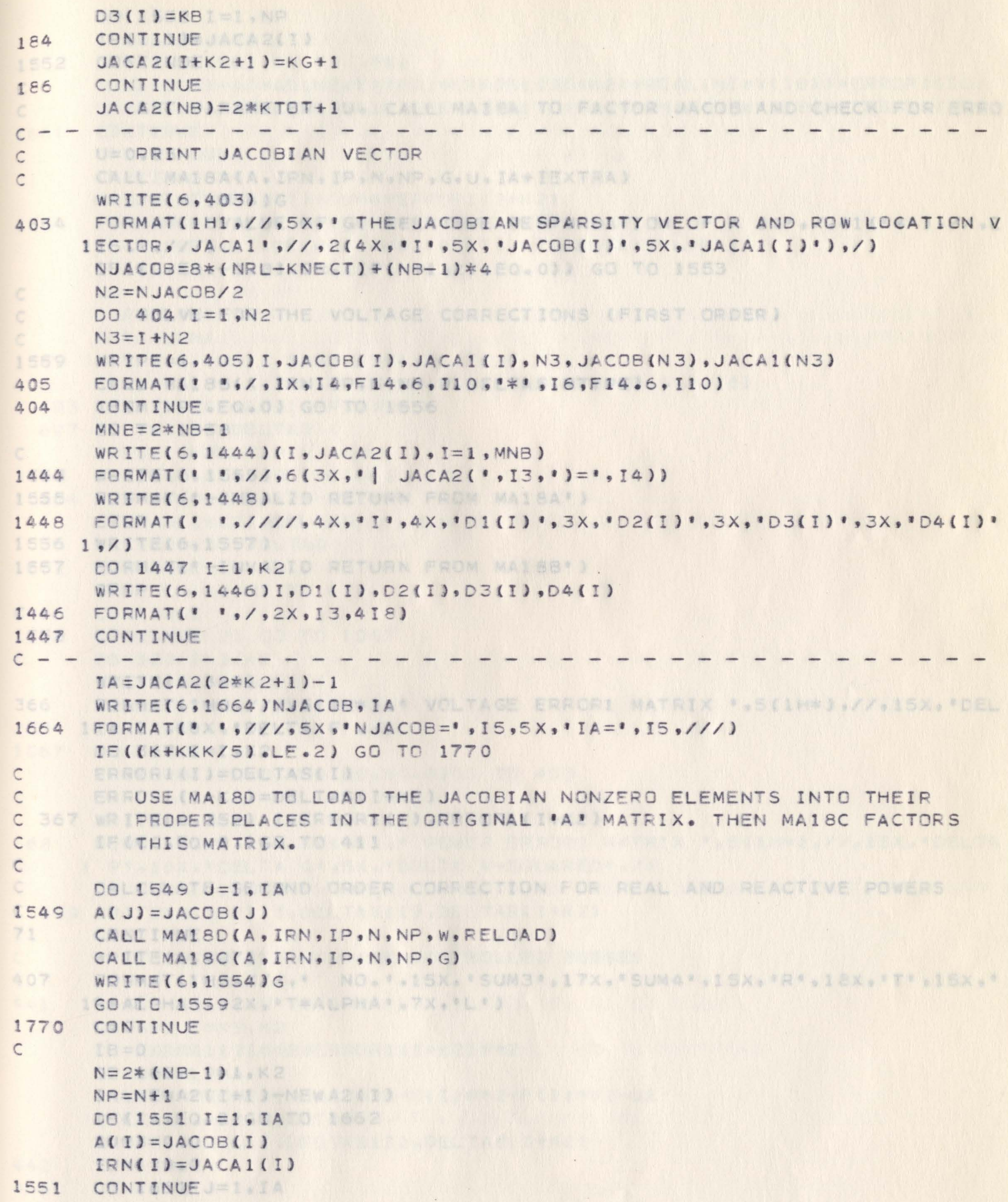




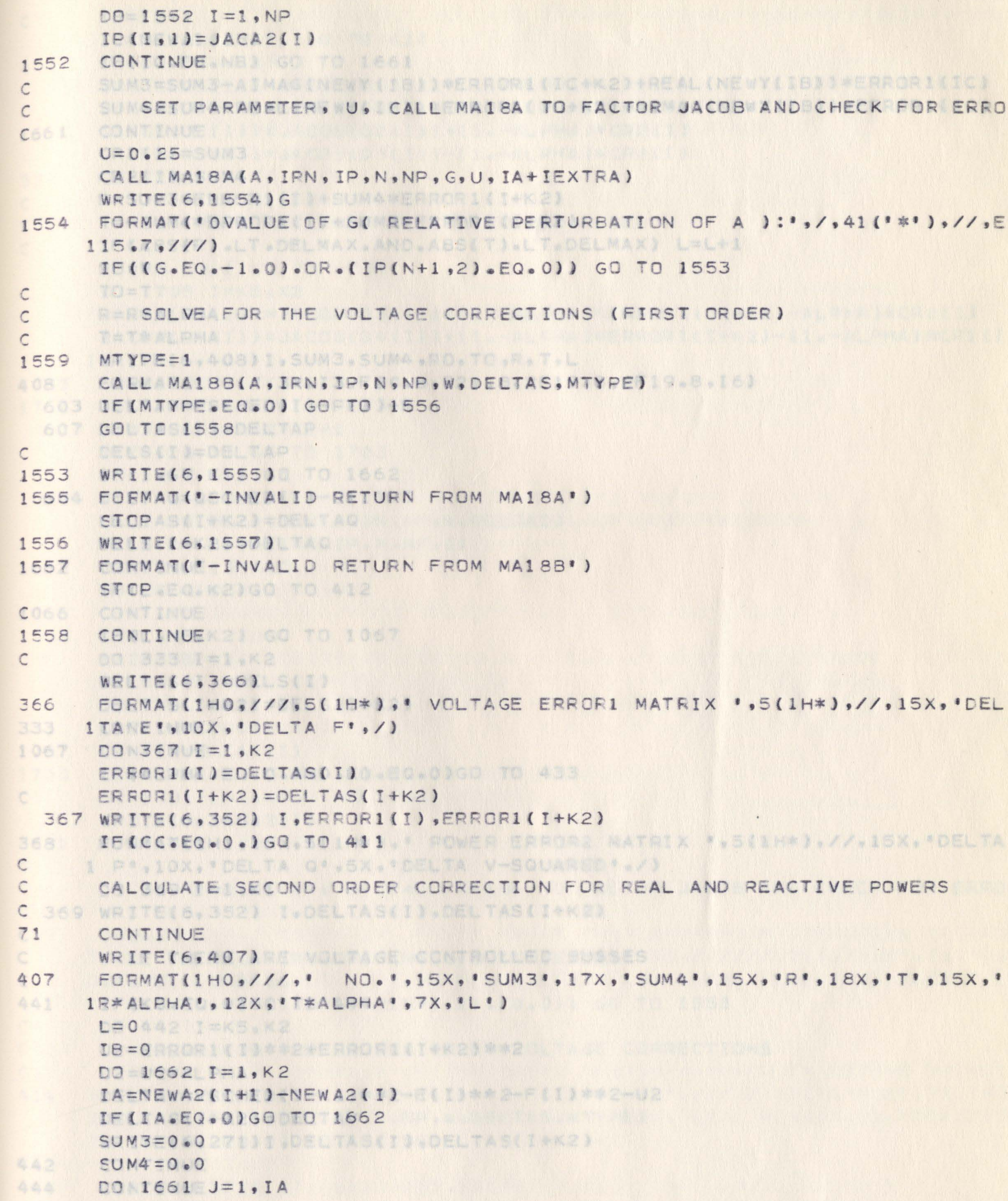


1661

$I B=I E+1$

$I C=N E W A I(I B)$

$I F(I C . E Q . N B)$ GO TO 1661

SUM3 = SUM3-AIMAG (NEWY (IB)) *ERROR 1 (IC+K2) +REAL (NEWY (IB) ) *ERROR 1(IC) SUN4 = SUM4 +REAL $(N E W Y(I B))$ *ERRORI (IC+K2) +AIMAG (NEWY (IB) )*ERROR I (IC)

CONTINUE

$C R 1($ I $)=S U M 3$

$C R 2($ I $)=S U M 4$

$R=S U M 3 * E R R O R 1(I)+S U M 4 * E R R O R 1(I+K 2)$

$T=-$ SUM4*ERROR $1(I)+S U M 3 * E R R O R 1(I+K 2)$

IF $(A B S(R) \cdot L T \cdot D E L M A X \cdot A N D \cdot A B S(T) \cdot L T \cdot D E L M A X) L=L+1$

$\mathrm{FO}=\mathrm{R}$

$T O=T$

$R=R * A L P H A$

$T=T * A L P H A$

WRITE $(6,408)$ I, SUM3, SUM , FO, TO,R, T, L

604 DELTAQ=QSCHED (I) -Q(I) - T

CELTAS $(I+K 2)=D E L T A Q$

DELS $(I+K 2)=D E L T A Q$

1662 CONTINUE

IF (L.EQ.K2)GO TO 412

1066 CONTINUE

IF(L.NE.K2) GO TO 1057

DO $333 \quad I=1, K 2$

CELTAS(I) =DELS(I)

DELTAS $(I+K 2)=D E L S(I+K 2)$

333 CONTINUE

1067 CONTINUE

IF (ALPHA.EQ. O.AND.KO.EQ.O)GO TO 433

C

WRITE $(6,368)$

368 FOFMAT(1H1,15X,5(1H*), POWER ERROR2 MATRIX *,5(1H*), / , 15X, 'DELTA $1 P \cdot, 10 X$, DELTA Q',5X, 'DELTA V-SQUARED', /)

DO $3 \in 9 \quad I=1, K 1$

369 WRITE $(6,352)$ I,DELTAS(I), DELTAS (I+K2)

C

IF THERE ARE VOLTAGE CONTROLLED BUSSES

C

C

441 IF $(K O \cdot E Q \cdot 0) G O$ TO 444

DO $442 \quad I=K 5, K 2$

$U 2=E R R O R 1(I) * 2+E R R O F 1(I+K 2) * * 2$

$U 2=U 2 * A L P H A$

CELTAV $=V S C H E D(I-K 1) * 2-E(I) * 2-F(I) * * 2-U 2$

DELTAS $(I+K 2)=D E L T A V$

WR ITE (6,271) I,DELTAS (I),DELTAS(I+K2)

442 CONTINUE

444 CONTINUE 
$c$

433 DO $33 \quad I=1, K 2$

JACOE $(D 1(I))=J A C O B(D I(I))+(1 \cdot-A L P H A) * C R 1$ (I)

$J A C O E(D 4(I))=J A C O B(D 4$ (I) $)+(1 \cdot-A L P H A) * C R 1$ (I)

$J A C O B(D 2($ I ) ) =JACOE(D2 (I ) ) +(1.-ALPHA )*CR2(I)

$J A C O B(D 3(I))=J A C O B(D 3(I))-(1 \cdot-A L P H A) * C R 2(I)$

33 CONTINUE

c

C

C

\section{IF THERE ARE VOLTAGE CONTROLLED BUSES}

IF (MB.EQ.1)GO TO 1706

$001705 \quad I=K 5, K 2$

$J A C O B(D 3(I))=J A C O B(D 3(I))+(1 \cdot-A L P H A) * E R R O R 1(I)+(1 .-A L P H A) * C R 2(I)$

$J A C O E(D 4(I))=J A C O B(D \&(I))+(1 .-A L P H A) * E R R O R 1(I+K 2)-(1 .-A L P H A) * C R 1(I$ 1)

\section{CONTINUE}

1706 CONTINUE

I $A=J A C A 2(2 * K 2+1)-1$

IF $(K .5 Q \cdot 1)$ GO TO 1703

DO $1649 \quad \mathrm{I}=1$, IA

$1649 \quad A(I)=J A C O B(I)$

CALL MAIBD(A, IRN, IP, N, NP, W, RELOAD)

CALL MAI $8 C(A, I R N, I P, N, N P, G)$

WR ITE $(6,1554) \mathrm{G}$

GO TC 4.14

c

1703 CONTINUE

$N=2 *(N B-1)$

$N P=N+1$

DO $1700 \quad I=1$, IA

$A(I)=J A C O B(I)$

IRN (I) =JACA 1 (I)

1700 CONTINUE

DO $1701 I=1$, NP

$I P(I, 1)=J A C A 2$ (I )

1701 CONTINUE

c

SET PARAMETER, $U$, CALL MAI 1 A TO FACTOR JACOB AND CHECK FOR ERRO

$U=0.25$

CALL MAI $8 A$ (A, IRN, IP, N,NP, G, U, IA+IEXTRA)

WRITE $(6,1554) \mathrm{G}$

$I F((G \cdot E Q \cdot-1 \cdot 0) \cdot O R \cdot(I P(N+1,2) \cdot E Q \cdot 0))$ GO TO 1553

C

C

SOLVE FOR THE SECCND ORDER VOLTAGE CORRECTIONS

$414 \quad$ NTYPE $=1$

CALL MA18B(A, IRN, IP, N, NP, W,DELTAS, MTYPE)

IF (MTYPE.EQ.O) GO TO 1556

C

WR ITE $(6,371)$ 
FORMAT (1HO,///,5(1H*), VOLTAGE ERROR2 MATRIX ",5(1H*),//,15X, DEL 1 TA E',10X, DELTA F,, /)

CO $372 \quad I=1, K 2$

372 WRITE $(6,352)$ I,DELTAS(I), DELTAS(I+K2)

C

C

C

411

420

c

c

c

$c$

C

$c$

c

950

509

510

c

c

c

IF $(C C \cdot E Q \cdot 1 \cdot)$ GO TO 503

WR ITE $(6,502) \mathrm{K}$

502 FOFMAT $(1 H 1, /, 5(1 H *)$,

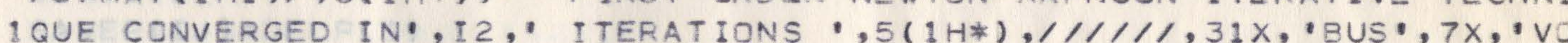

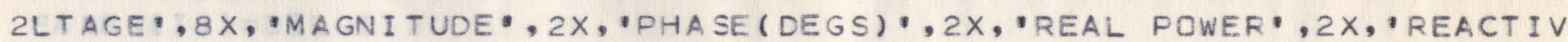
उE FCWER, , /)

GO TO 505

503 WRITE $(6,511) \mathrm{K}, \mathrm{KKK}$

511 FORMAT $(1 \mathrm{H} 1,1,5(1 \mathrm{H}$ *), SECCND CRDER NEWTON-RAPHSON ITERATIVE TECHNI

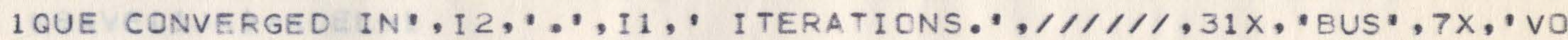
2LTAGE',8X,"MAGNITUDE',2X,"PHASE(CEGS)", 2X, 'REAL POWEF",2X, "REACTIV उE POWER, , /)

$505 \quad$ CO $512 \quad I=1, N B$

PHASE $=A T A N 2(F(I), E(I)) * 57.29578$ 
$M A G N=C A B S(V(I))$

512 WRITE $(6,513)$ I, V(I), MAGN,PHASE,P(I), Q(I)

513

c

FORMAT(, , $26 \mathrm{X}, \mathrm{I} 7,2 \mathrm{X}, 2 \mathrm{~F} 8,4,4 \mathrm{X}, \mathrm{F} 7,4,4 \mathrm{X}, \mathrm{Fg}, 5,6 \mathrm{X}, \mathrm{F} 8,4,4 \mathrm{X}, \mathrm{F} 8,4)$

$c$

CALCULATE AND WRITE OUT LINE FLOWS

C

WRITE $(6,514)$

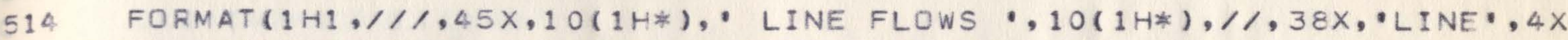
$1, ' S B \cdot, 3 X, '$ 'EB',5X,'REAL POWER',3X,'REACTIVE POWER',/)

DO $515 \quad I=1, N L$

$L=S B(I)$

$N=E B(I)$

$S S=C O N J G(V(L)) *(V(L)-V(M)) * S E R Y(I)+C O N J G(V(L)) * V(L) *(S H T Y(I) / 2.0)$

$S R=C O N J G(V(M)) *(V(M)-V(L)) * S E R Y(I)+C O N J G(V(M)) * V(M) *(S H T Y(I) / 2.0)$

$S S=C O N J G(S S)$

$S R=C C N J G(S R)$

WRITE $(6,516) I, L, M, S S$

515 1WRITE $(6,516) I, M, L, S R$

516 FOFMAT(', $, 37 X, 3 I 5,2 F 13.4)$

GOL TO 1005

1000 WRITE $(6,1001)$ KMAX, DELMAX

1001 FOFMAT $(/, /, /, /, 3 X, 1$ THE MAXIMUM ALLOWED NUMBER OF ITERATIONS HAS BE 1 EN PERFORMED $", \cdot(\cdot, I 2, *) \cdot$, WI THOUT ACHIEVING CONVERGENCE TO THE DE 2 SIRED ACCURACY ', '( , F8.5,')', ', )

1005 CONTINUE

WRITE $(6,1004)$ DELMAX

1004 FORMAT $(1,1,1,1,5 X, 1$ THE REQUIRED ACCURACY WAS, F3.5)

WR ITE $(6,1011)$

1011 FORMAT $/ / /, 5 X$, "THE MAXINUM MISMATCHES AT EACH CONVERGENCE CHECK WE 1 RE : $, /, 3 X, '$ ITERATION',8X, 'DELTA P',12X,'DELTA Q',12X,'DELTA V*\%2'

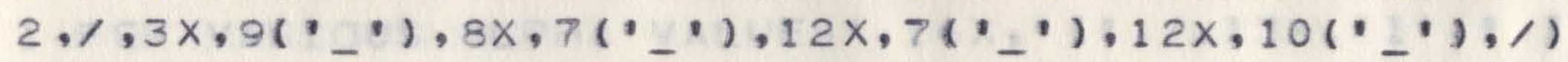

C

$c$

WR ITE $(6,1012)$ DELK (1), DELP(1), DELQ (1), DELV (1)

1012 FORMAT $(6 X, F 3.1,3 X, F 17.8,2 X, F 17.8,2 X, F 17.8,1, \cdot$

c

SAVING MAXIMUM MISMATCH VALUES OF EACH ITERATION

WITH THE PRESENT ALPHA VALUE

DO $1013 I=2, K D E L$

I $J=I J+1$

SAVEF (I J ) =DELP(I)

SA VEG I J ) =DELQ(I)

SAVEV I J ) =DELV (I)

WRITE $(6,1012)$ DELK(I), DELP(I), DELQ(I), DELV(I)

1013 CONTINUE

$I J K=I J K+1$

KSAVE (IJK) $=$ KDEL -1

$K K \subseteq A V E(I J K)=K K K$

IF (CC.NE.1) GO TO 1070

WRITE $(6,1009)$ ALPHA

1009 FOFMAT $(/ / /, 5 X, "$ THE VALUE OF ALPHA WAS , F6. $2, / / /)$ 
IF (ALPHA.GE.2.0) GO TO 1006

$A L P H A=A L P H A+0 \cdot 1 D 0$

GO TO 101

1006

CONTINUE

READ THE INITIAL ALPHA VALUE AND THE NUMBER OF TABLES TO BE PRINTED

READ $(5,1015)$ AANT, LIMIT

c

FOFMAT (F1 0.2 , I5)

DO $1075 \mathrm{JJJ}=1,5$

$A I N T=A A N T$

PRINTING THE MAXIMUM MISMATCH VALUES IN TABLES

WRITE $(6,1014)$

1014 FORMAT $(1 \mathrm{H} 1, /, /, /, /, /, /, 14 \mathrm{X}, 1$ TABLE : MAXIMUM PER UNIT MISMATCHES 1 AFTER EACH ITERATION FOR THE IEEE 118 -BUS SYSTEM, 1$)$

IAA $=1$

$J F L A G=0$

$K F L A G=0$

DO 1061 I=1, LIMIT

IFLAG $=0$

AINT2=AINT+0.1

AINT $3=A I N T+0.2$

AINT $4=A I N T+0.3$

AINT $5=$ AINT+0.4

AINT $6=A$ INT +0.5

WR ITE $(6,1016)$ AINT, AINT2, AINT3, AINT4, A INT5, AINT 6

1016 FORMAT $(14 \mathrm{X}, 85(\cdot-\cdot), /, 13 \mathrm{X}, \cdot 1 \cdot 7 \mathrm{X}, \cdot \mathrm{I} \cdot, 5 \mathrm{X}$, 'I',14X,'MAXIMUM MISMATCHES

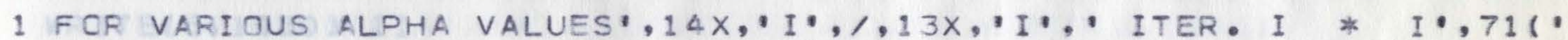
2-' ), 'I', I, 13X,'I ND. I ', 3X, I', 3X,F4.1,5(4X,'I',3X,F4,1), 4X, I $3 \cdot, 1,13 \times, \cdot 1 \cdot, 85(\cdot-\cdot), 1 \cdot)$

WRITE $(6,1036)$

1036 FORMAT(1H+,20X,'I',5X,"I',6(11X,'I'))

IX $=(I-1) \neq 6+1$

DO 1055 II $=1,10$

$c$

$c$

PRINT THE ACTIVE POWER MISMATCHES

C

WR ITE $(6,1017)$

1017 FORMAT $(13 \times, \cdot I,, 7 \times, \cdot I,, 2 X, M$ I $)$

IF (KSAVE (IX).EQ.0) GO TO 1021

IF(I I LE.KSAVE(IX)) WRITE(6,1018)SAVEP(IAA)

1018 FORMAT $(1 \mathrm{H}+, 28 \mathrm{X}, \mathrm{Eg} \cdot 3)$

IF (II.EQ. (KSAVE (IX)+1).AND,KKSAVE(IX),EQ.5) WRITE(6,1031)

1031 FORMAT $(1 \mathrm{H}+, 31 \mathrm{X}, \cdot * * *, 4 \mathrm{X}, \mathrm{I} \cdot \mathrm{\prime})$

IAE $=$ IAA+KSAVE $(I X)$

$I F(K S A V E(I X+1) \cdot E Q \cdot 0)$ GC TO 1021

IF (I I LLE.KSAVE(IX+1)) WRITE( 6,1020$)$ SAVEP (IAB)

1020 FOFMAT $(1 \mathrm{H}+, 40 \mathrm{X}$, E9.3)

IF (I I EQ. (KSAVE(IX+1)+1). AND.KKSAVE $(I X+1) \cdot E Q .5)$ WRITE $(6,1033)$ 
1033 FOFMAT ( $\left.1 \mathrm{Ht}, 43 \mathrm{X}, * \mathrm{k}_{*} *, 4 \mathrm{X}, \mathrm{I}^{\prime} \cdot\right)$

$I A E=I A E+K S A V E(I X+1)$

IF (KSAVE $(I X+2)$.EQ.0) GC TO 1021

IF (II.LE.KSAVE $(I X+2))$ WFITE( 6,1022$)$ SAVEP (IAB)

1022 FORMAT $(1 \mathrm{H}+.52 \times, E 9.3)$

IF (II.EQ. (KSAVE(IX+2)+1). AND.KKSAVE(IX+2).EQ.5) WRITE(6,1035)

1035 FOFMAT $\left(1 \mathrm{H}+, 55 \mathrm{X}, * * * *, 4 \mathrm{X}, \mathrm{I}^{\prime}, \mathrm{\prime}\right)$

$I A E=I A B+K S A V E(I X+2)$

IF (KSAVE $(I X+3) \cdot E Q$. O) GO TO 1021

IF (II . LE.KSAVE (IX+3)) WRITE(6,1024)SAVEF(IAB)

1024 FORMAT $(1 \mathrm{H}+, 64 \mathrm{X}, \mathrm{E9} \cdot 3)$

IF (II.EQ. (KSAVE $(I X+3)+1)$. AND.KKSAVE (IX+3).EQ.5) WRITE(6,1037)

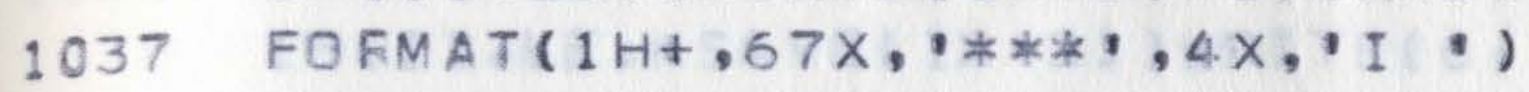

$I A E=I A B+K S A V E(I X+3)$

$I F(K S A V E(I X+4) \cdot E Q .0)$ GC TC 1021

IF (II.LE.KSAVE $(I X+4)$ ) WRITE( 6,1026$)$ SAVEP (IAB)

1026 FOFMAT $(1 \mathrm{H}+, 76 \mathrm{X}, \mathrm{E} 9.3)$

$I F(I I . E Q \cdot(K S A V E(I X+4)+1)$. AND.KKSAVE $(I X+4) \cdot E Q \cdot 5)$ WRITE (6, 1039)

1039 FOFMAT $(1 \mathrm{H}+, 79 \mathrm{X}, * * *, 4 \mathrm{X}, 1 \mathrm{I}, 1)$

IAE $=I A B+K S A V E(I X+4)$

IF (KSAVE $(I X+5) \cdot E Q \cdot 0)$ GO TO 1021

IF (I I.LE.KSAVE $(I X+5))$ WFITE(6,1028)SAVEP(IAB)

1028 FORMAT(1H+,88X,E9.3)

$I F(I I \cdot E Q \cdot(K S A V E(I X+5)+1) \cdot A N D \cdot K K S A V E(I X+5) \cdot E Q \cdot 5)$ WRITE (6,1041)

1041

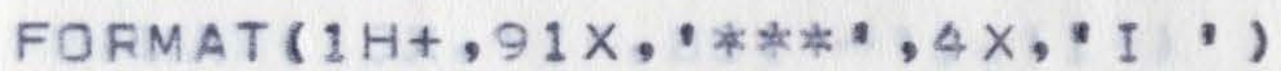

1021 WRITE $(6,1023)$

1023 FOFMAT (1H+,27X,6(11X, I')

c

C

C

\section{FRINT THE REACTIVE POWER MISMATCHES}

WRITE $(6,1030)$ I I

1030 FOFMAT $(13 X$, I', $2 X, I 2,3 X, \cdot I Q \quad I \cdots)$

$I F(K S A V E(I X) \cdot E Q \cdot 0)$ GO TO 1027

IF(II.LE.KSAVE(IX)) WRITE(6,1018) SAVEQ(IAA)

$I F(I I \cdot E Q \cdot K S A V E(I X))$ IFLAG IFLAG+1

$I A E=I A A+K S A V E(I X)$

IF (II.LE.KSAVE(IX+1) ) WFITE(6,1020)SAVEQ (IAB)

$I F(I I \cdot E Q \cdot K S A V E(I X+1))$ IFLAG $=I F L A G+1$

$I A E=I A B+K S A V E(I X+1)$

$I F(I I$. LE.KSAVE(IX+2)) WRITE(6,1022) SAVEQ (IAB)

$I F(I I \cdot E Q \cdot K S A V E(I X+2))$ IFLAG $=I F L A G+1$

$I A E=I A E+K S A V E(I X+2)$

IF (I I.LE.KSAVE(IX+3)) WRITE(6,1024) SAVEQ(IAB)

$I F(I I \cdot E Q \cdot K S A V E(I X+3))$ IFLAG $I F L A G+1$

$I A E=I A B+K S A V E(I X+3)$

IF (II.LE.KSAVE (IX+4) ) WRITE(6,1026) SAVEQ (IAB)

$I F(I I \cdot E Q \cdot K S A V E(I X+4))$ IFLAG $=$ IFLAG+ 1

$I A E=I A E+K S A V E(I X+4)$

IF (II.LE.KSAVE(IX+5)) WRITE(6,1028) SAVEQ(IAB)

1027

IF (II.EQ.KSAVE $(I X+5)$ ) IFLAG I IFLAG+ I

c

WRITE $(6,1023)$ 


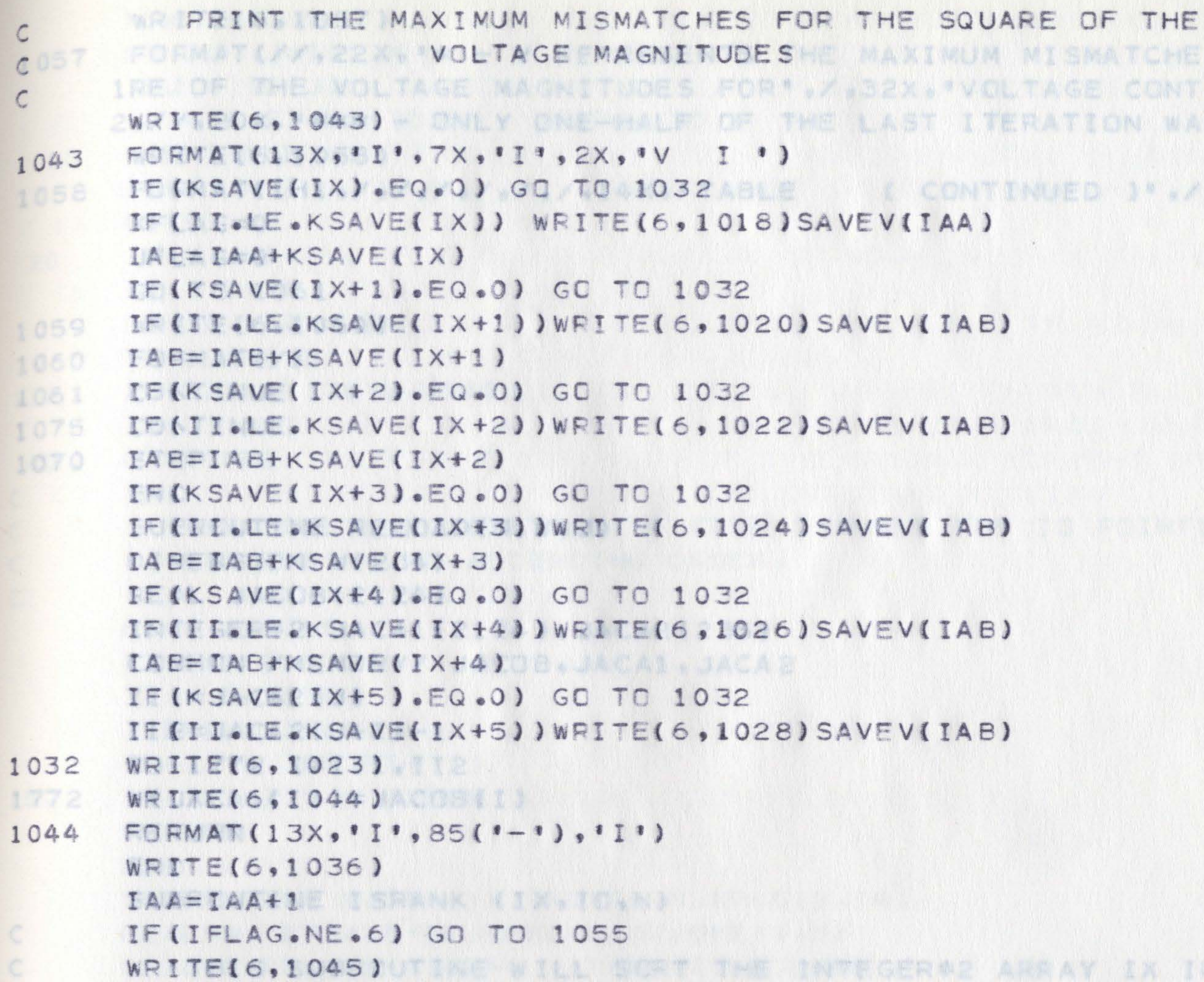

PRINT THE MAXIMUM MISMATCHES FOR THE SQUARE OF THE VOLTAGE MAGNITUDES

1043 FORMAT $(13 \mathrm{X}, \mathrm{I}, 7 \mathrm{X}, \mathrm{I}, 2 \mathrm{X}, \mathrm{V}$ I $)$

IF (KSAVE $(I X) . E Q .0)$ GO TO 1032

IF (II.LE.KSAVE(IX)) WRITE(6,1018) SAVEV(IAA)

$I A E=I A A+K S A V E(I X)$

IF (KSAVE $(I X+1) \cdot E Q .0)$ GC TO 1032

IF (II.LE.KSAVE(IX+1)) WFITE( 6,1020$)$ SAVEV(IAB)

$I A E=I A B+K S A V E(I X+1)$

IF (KSAVE $(I X+2) \cdot E Q \cdot 0)$ GO TO 1032

IF (II.LE.KSAVE(IX+2)) WRITE(6,1022) SAVEV(IAB)

$I A E=I A B+K S A V E(I X+2)$

IF (KSAVE $(I X+3) \cdot E Q .0)$ GO TO 1032

IF (II.LE.KSAVE(IX +3)) WRITE(6,1024) SAVEV(IAB)

$I A E=I A E+K S A V E(I X+3)$

IF (KSAVE $(I X+4) \cdot E Q .0)$ GO TO 1032

IF (II.LE.KSAVE(IX+4)) WRITE(6,1026) SAVEV(IAB)

$I A E=I A B+K S A V E(I X+4)$

$I F(K S A V E(I X+5)$. EQ.0) GO TO 1032

IF (I I.LE.KSAVE(IX+5)) WRITE(6,1028) SAVEV (IAB)

1032

WRITE $(6,1023)$

WRITE $(6,1044)$

1044

FOFMAT $\left(13 \times, I^{\prime}, 85(\cdots), I^{\prime}\right)$

WRITE $(6,1036)$

$I A A=I A A+1$

IF (IFLAG.NE.6) GO TO 1055

WRITE $(6,1045)$

1045 FORMAT $(1 \mathrm{H+}, /)$

IF (II.EQ.KSAVE(IX).AND.KKSAVE(IX).EQ.5) WRITE(6,1046)

$I F(I I . E Q \cdot K S A V E(I X+1)$. AND.KKSAVE $(I X+1)$. EQ.5) WRITE $(6,1047)$

$I=(I I \cdot E Q \cdot K S A V E(I X+2)$. AND.KKSAVE $(I X+2) \cdot E Q \cdot 5)$ WRITE $(6,1048)$

$I F(I I . E Q \cdot K S A V E(I X+3)$. AND.KKSAVE $(I X+3) \cdot E Q .5)$ WRITE $(6,1049)$

IF (II.EQ.KSAVE(IX+4). AND.KKSAVE(IX+4).EQ.5) WRITE (6,1050)

IF (II.EQ.KSAVE $(I X+5)$. AND.KKSAVE $(I X+5)$. EQ.5) WRITE(6,1051)

1046

FORMAT ( $1 \mathrm{H}+, 31 \mathrm{X}, \cdots \neq * \cdots)$

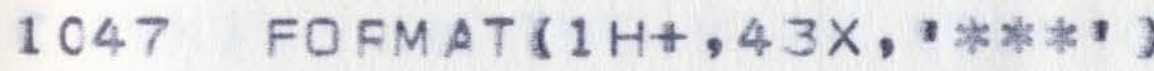

1048 FORMAT $(1 \mathrm{H}+, 55 \mathrm{x}, * * * *)$

1049 FOFMAT ( $1 \mathrm{H}+, 67 \mathrm{X}, \cdots * * * *)$

1050 FOFMAT ( $1 \mathrm{H}+, 79 \mathrm{X}, \cdot * * * 1)$

1051 FOFMAT $(1 \mathrm{H}+, 91 \mathrm{X}, 1 * * * 1)$

$J F L A G=J F L A G+1$

IF (II.LE.2) KFLAG $=K F L A G+1$

GO TO 1056

1055 CONTINUE

1056 CONTINUE

$A I N T=A I N T+0.6$

$I A A=1+K S A V E(I X)+K S A V E(I X+1)+K S A V E(I X+2)+K S A V E(I X+3)+K S A V E(I X+4)+K S$

IAVE $(I X+5)+I A A-I I-1$

IF (II.LE.4.AND.JFLAG.EQ.1) GO TO 1059

IF (II.LE.2.AND.KFLAG.EQ.2.AND.JFLAG.EQ.2) GO TO 1059 
WRITE $(6,1057)$

1057 FOFMAT $/ /, 22 \times, * *$ - $V$ REPRESENTS THE MAXIMUM MISMATCHES OF THE SQUA $1 \mathrm{RE}$ OF THE VOLTAGE MAGNITUDES FOR',/,32X,'VOLTAGE CONTROLLED BUSES' $2,1 /, 20 X, \cdot * * *$ - ONLY ONE-HALF OF THE LAST ITERATION WAS PERFORMED') WRITE $(6,1058)$

1058 FORMAT $(1 \mathrm{H} 1, /, /, /, /, 1,14 \mathrm{X}, 1$ TABLE (CONTINUED $), /$ ) $K F L A G=0$

JFLAG $=0$

GO TC 1061

1059 WRITE $(6,1060)$

1060 FORMAT(/)

1061 CONTINUE

1075 CONTINUE

1070 STCP

ENC

SUERCUTINE RELOAD $(N, W, J)$

DIMENSION W(234)

REAL JACOB (2124)

INTEGER*2 JACA1 (2124), JACA2 (235)

COMMON /MEMORY/ JACOB, JACA1, JACA 2

II $1=J A C A 2(J)$

II $2=J A C A 2(J+1)-1$

DO 1772 I =II 1 , I I 2

$1772 W(J A C A 1(I))=J A C O B(I)$

RE TURN

ENC

SUERCUTINE ISRANK (IX,IO,N)

THIS SUBROUTINE WILL SCRT THE INTEGER*2 ARRAY IX INTO ASCENDING ORDER SUCH THAT IXIO(I))<IX(IOII+1)) FOR $I=1, N$.

THE CODE IS A NEAR COPY OF THE ISRANK ROUTINE OF WATFIV AND IS DESIGNED TO TAKE THE PLACE OF THE HARWELL ROUTINE KEIOAS IN THE SPARSITY ROUTINE MAIBAD.

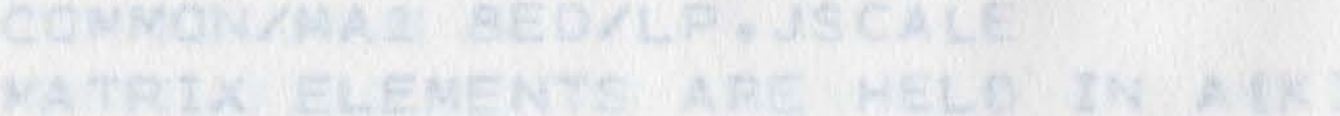

G. SOMERTON

$c$

C

c

IMFLICIT INTEGER*2 (I-M)

DINENSION IX(N), IO(N)

IONE $=1$

ITWO $=2$

ISI = IONE

$I F 1=N$

c

THE FOLLOWING CODE IS ENTIRELY THE WATFIV ROUTINE ISRANK EXCEPT. EVERYTHING IS IN INTEGER* 2 ARITHMETIC.

$I O(I S 1)=I S 1$

IS2 = IS I + IONE

DO $40 \quad I=I S 2$, IF 1

IS $=I X(I)$ 


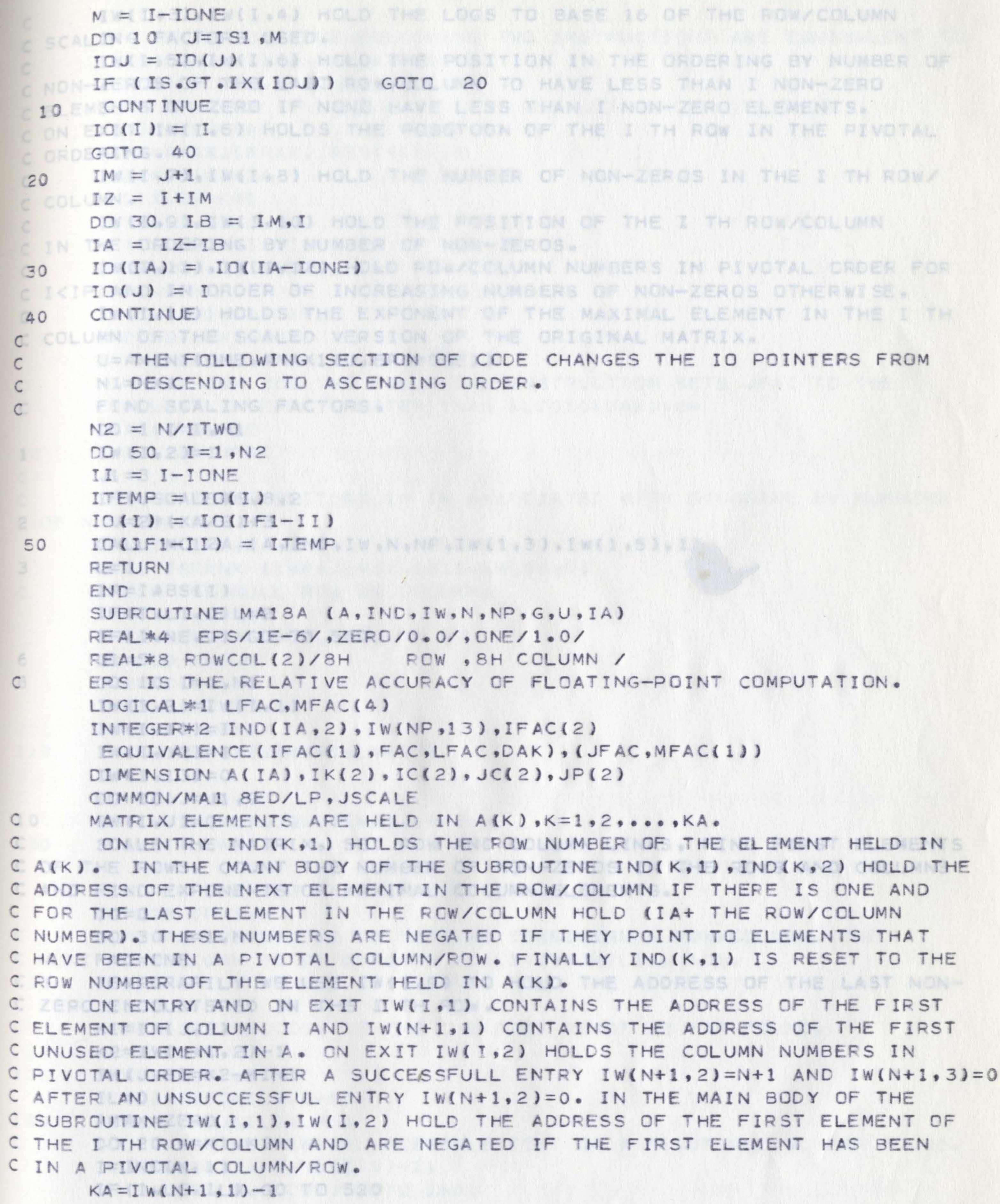

THE FOLLOWING SECTION OF CCDE CHANGES THE IO POINTERS FROM DESCENDING TO ASCENDING ORDER. 
C IW(I,3), IW(I, 4) HOLD THE LOGS TO BASE 16 OF THE ROW/COLUMN C SCALING FACTORS USED.

$c$

IW $(I, 5)$, IW $(I, 6)$ HOLD THE POSITION IN THE ORDERING BY NUMBER OF

C NON-ZEROS OF, THE. LAST ROW/COLUMN TO HAVE LESS THAN I NON-ZERO

C ELEMENTS OR ZERO IF NONE HAVE LESS THAN I NON-ZERO ELEMENTS.

C ON EXIT IW $(I, 5)$ HOLDS THE POSOTOON OF THE I TH ROW IN THE PIVOTAL

C ORDERING.

C c COLUMN.

IW $(I, 7)$, IW(I,8) HOLD THE NUMBER OF NON-ZEROS IN THE I TH ROW/

IW $(I, 9)$, IW(I,10) HOLD THE POSITION OF THE I TH ROW/COLUMN

IN THE ORDERING BY NUMBER OF NON-ZEROS.

IW $(I, 11)$, IW $(I, 12)$ HOLD POW/COLUMN NUMBERS IN PIVOTAL ORDER FOR

I IP AND IN ORDER OF INCREASING NUMBERS OF NON-ZEROS OTHERWISE.

C IW (I, 13) HOLDS THE EXFONENT OF THE MAXIMAL ELEMENT IN THE I TH

C COLUMN OF THE SCALED VERSION CF THE ORIGINAL MATRIX.

$U=A M I N 1(O N E, A M A X 1(U, E P S * O N E))$

$N 1=N+1$

C FIND SCALING FACTORS.

CO 1 ( I $I=1, N 1$

I $W(I, 2)=I$

$\mathrm{J} 1=3$

IF ( JSCALE) $6,8,2$

$20=J=2 *(K A / 2)+3$

CALL MC12A, (A, IND, IW, N, NF, IW $(1,3)$, IW $(1,5)$, I)

$3 \quad L=1$

$I R=I A B S(I)$

$I F(I \cdot L T \cdot O) L=2$

IF (I.NE・O ) GO TO 560

$\mathrm{J} 1=5$

DO $10 \quad \mathrm{I}=1, \mathrm{~N} 1$

$I W(I, 2)=I W(I, 1)$

$I W(I, 11)=I$

$I W(I, 12)=I$

$I W(I, 13)=0$

DO $10 \quad \mathrm{~J}=\mathrm{J} 1,9$

$10 \quad \operatorname{IW}(I, J)=0$

C SO SCALE THE MATRIX, SET ROW AND COLUMN LINKS, FIND FIRST ELEMENTS C OF THE ROWS, COUNT THE NUMBER OF NON-ZEROS IN THE ROWS AND COLUMNS

C AND FIND EXPONENTS OF MAXIMAL COLUMN ELEMENTS.

$I G=0$

DO $30 \mathrm{~J}=1, \mathrm{~N}$

$F A C=C N E$ TENPORARILY WE USE IW $(I, 9)$ TO HOLD THE ADDRESS OF THE LAST NON-
C ZEROIENCCUNTERED IN THE I TH ROW. $K 1=I W(J, 2)$

$K 2=I W(J+1,2)-1$

$I W(J, 8)=K 2-K 1+1$

$I L=0$

$A M A X=Z E R O$

DO $20 \quad K=K 1, K 2$

$I=I N D(K, 1)$

IF (I.LE.IL) GO TO 520 


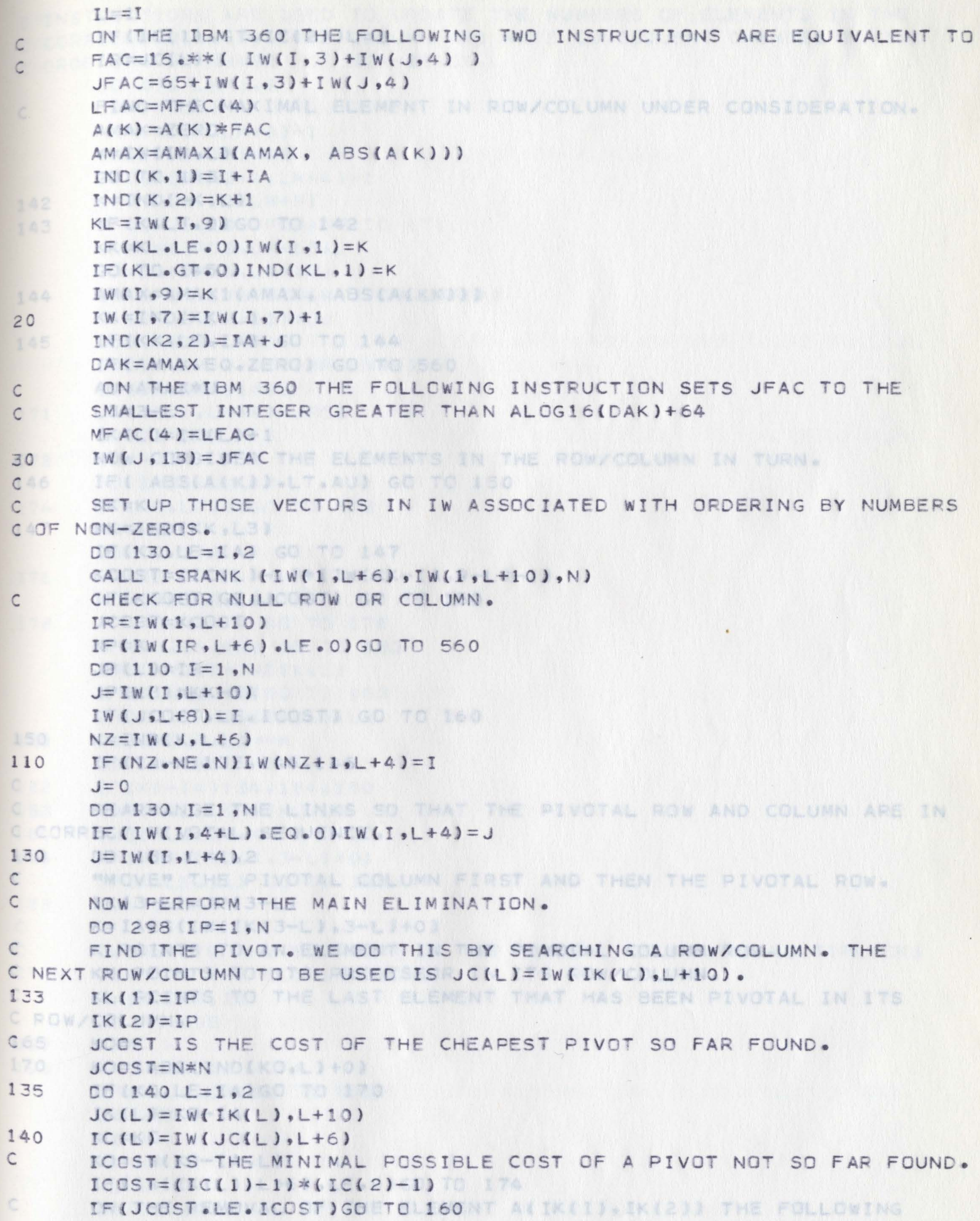




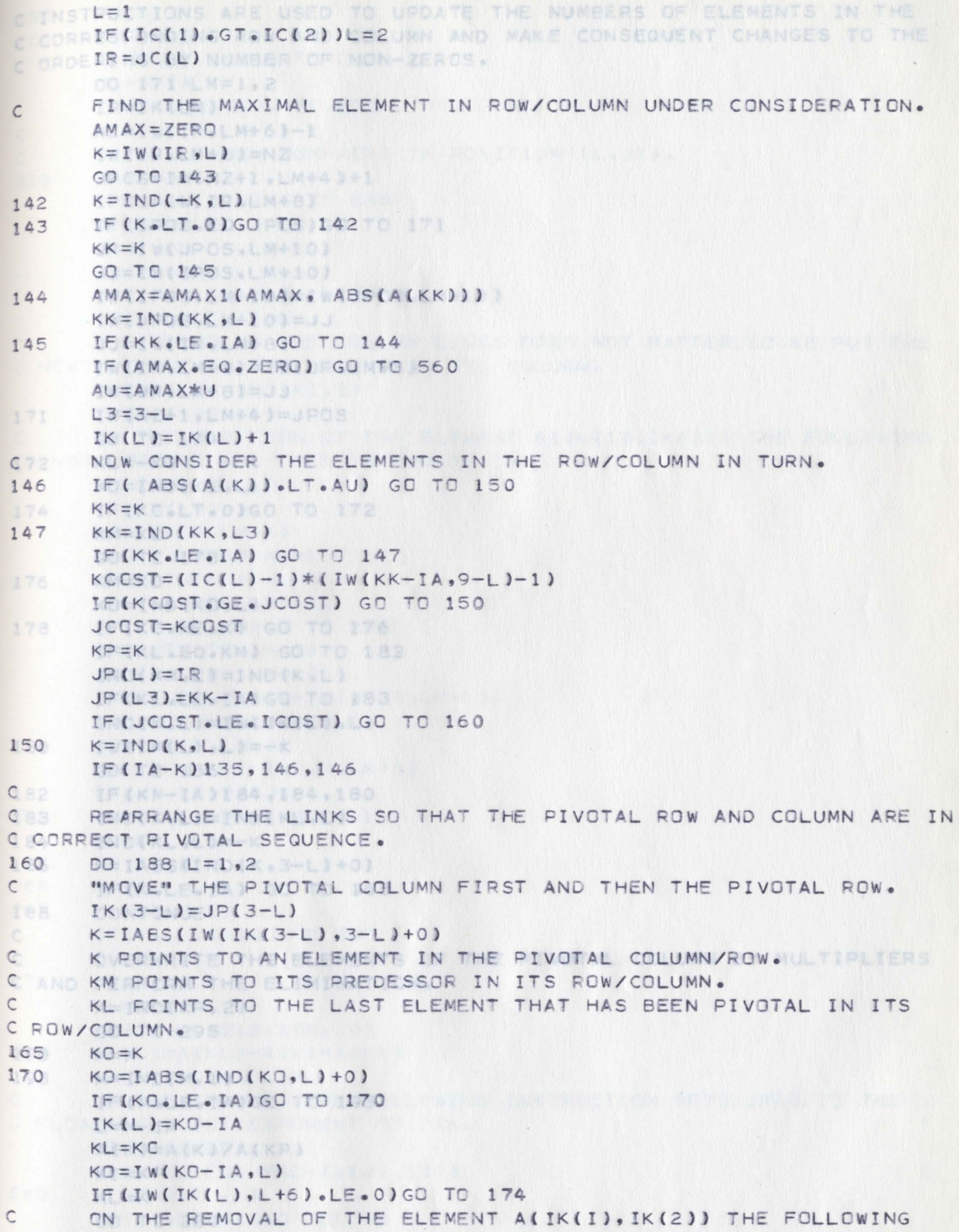




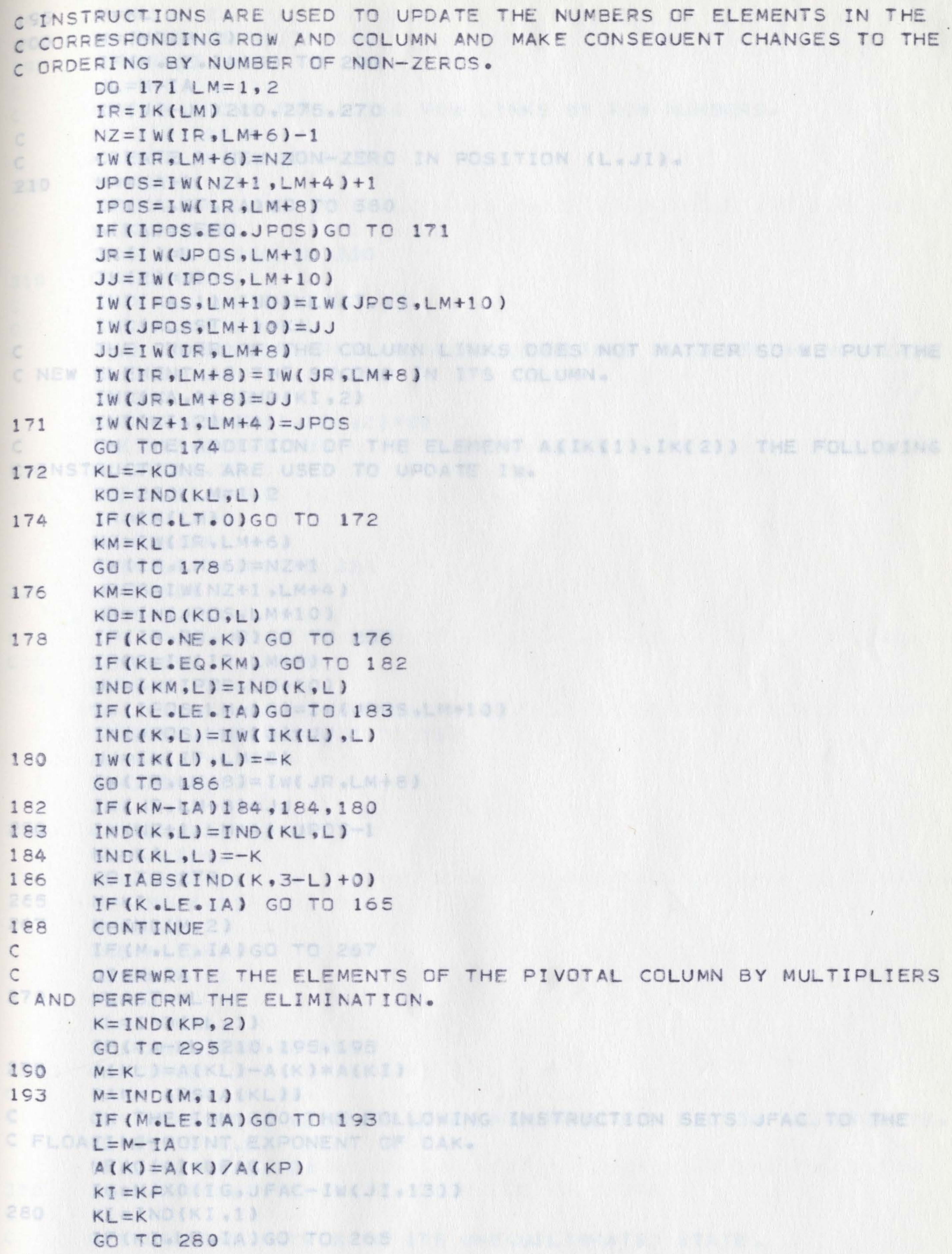




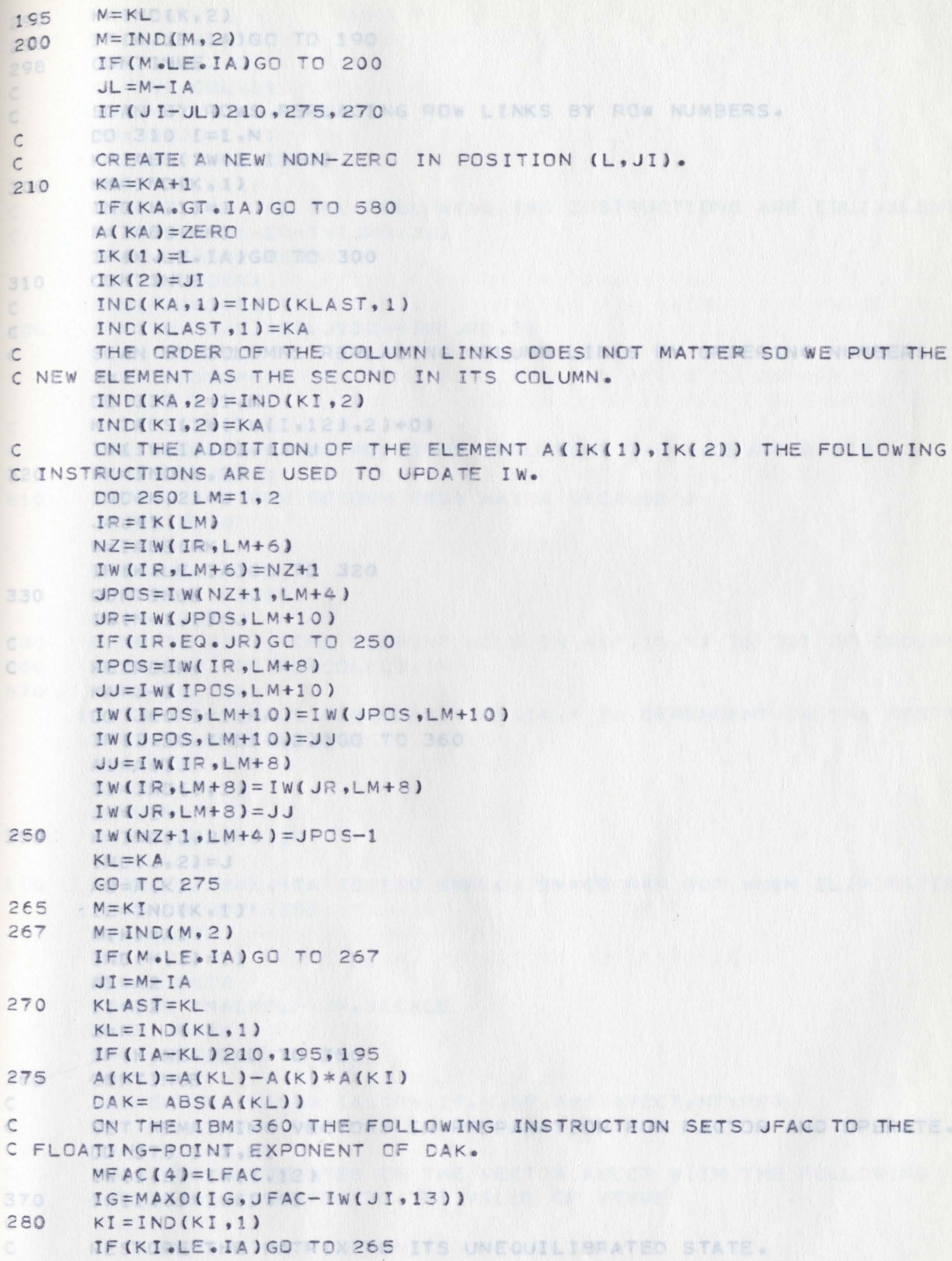




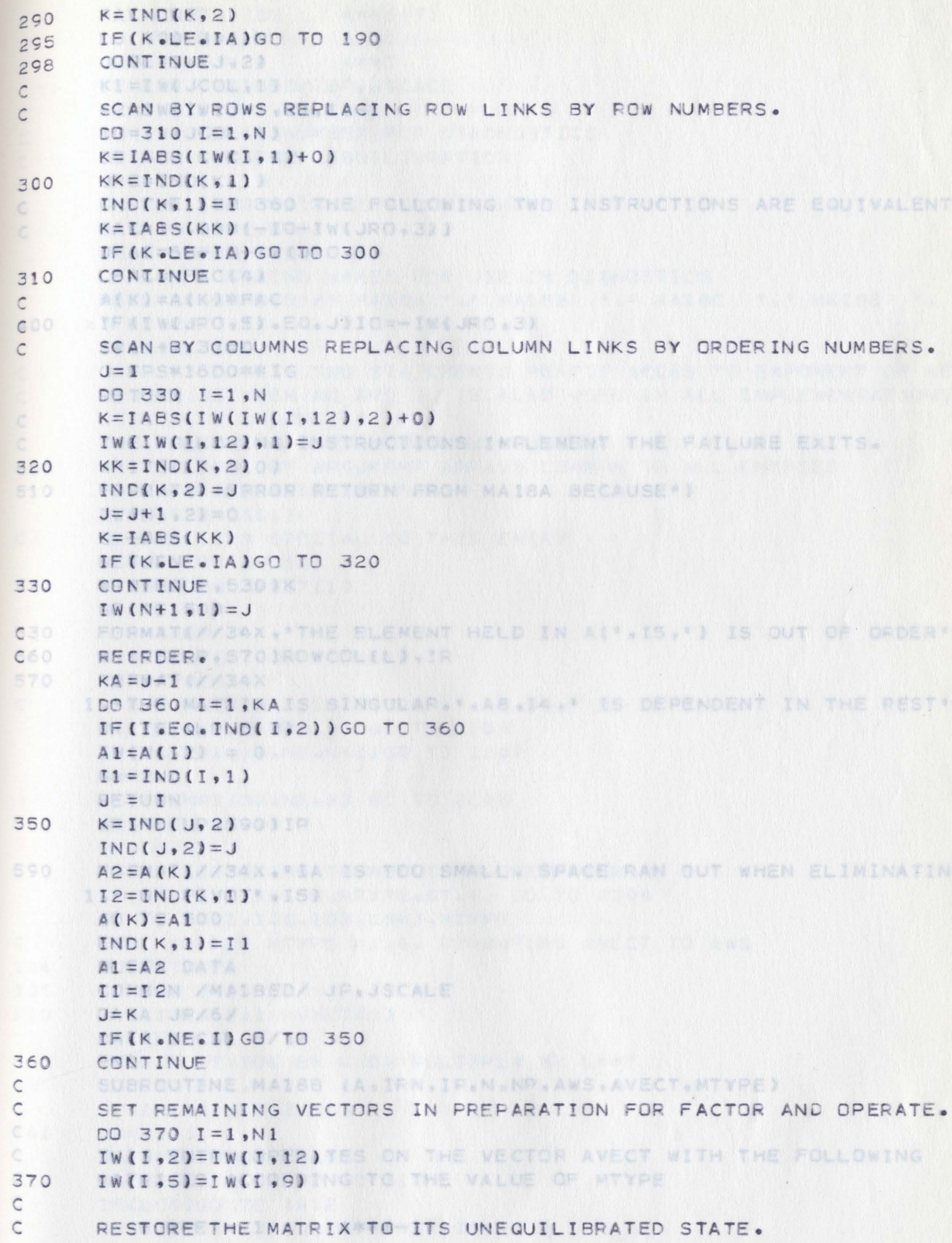




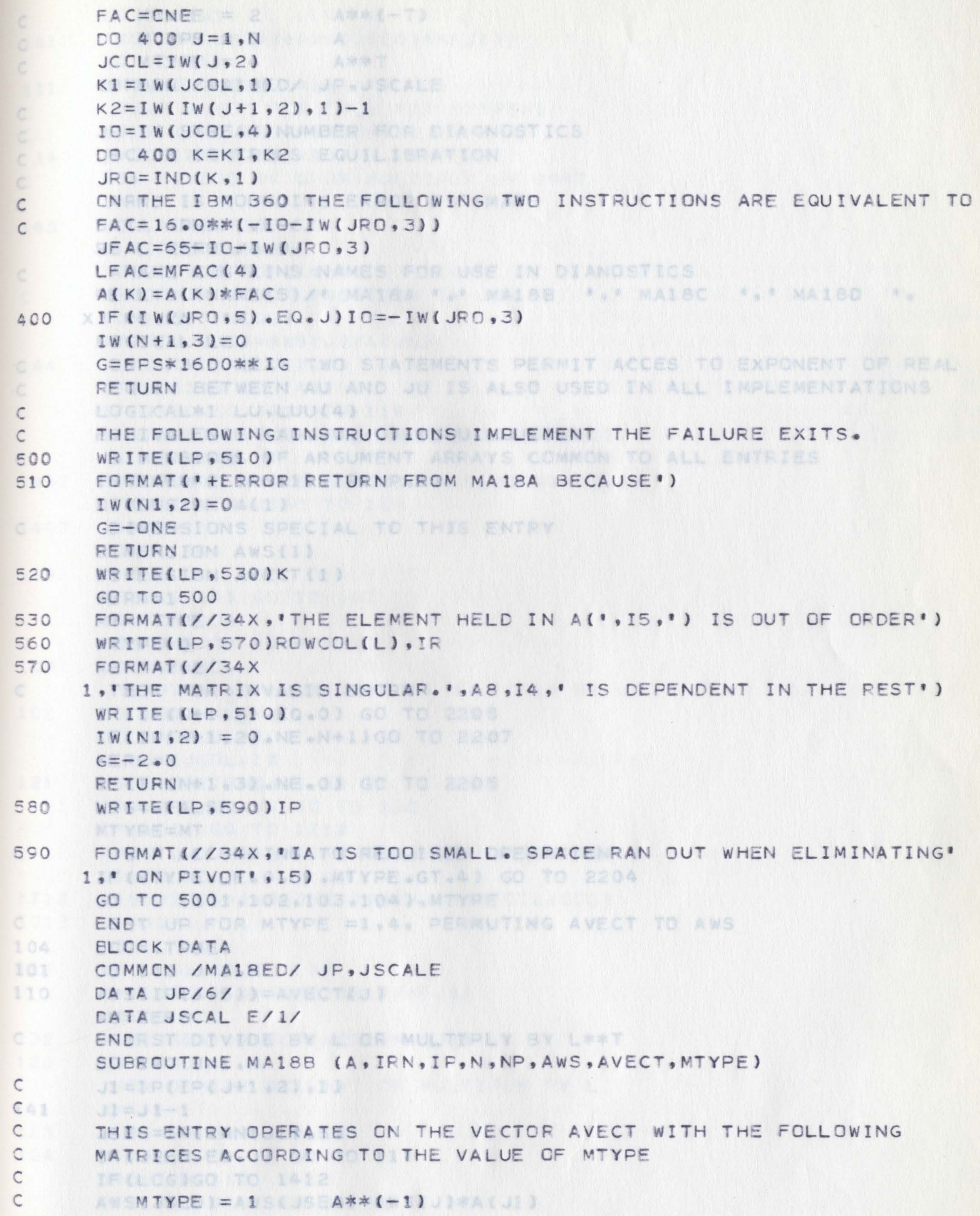

THIS ENTRY OPERATES ON THE VECTOR AVECT WITH THE FOLLOWING MATRICES ACCORDING TO THE VALUE OF MTYPE

$$
\text { MTYPE }=1 \quad A * *(-1)
$$




$$
\begin{array}{ll}
\text { MTYPE }=2 & A * *(-T) \\
\text { MTYPE }=3 & A \\
\text { MTYPE }=4 & A * * T
\end{array}
$$

COMMON /MA18ED/ JP, JSCALE

JP IS STREAM NUMBER FOR DIAGNOSTICS

JSCALE CONTROLS EQUILIBRATION

ARND IS ROUNDING ERROR ESTIMATE

DATA ARND/1.E-6/

REAL ZERO $10.0 /$

C ANAME CONTAINS NAMES FOR USE IN DIANOSTICS

REAL*8 ANAME (5) "MA18A" "MA18B " MA18C " MA18D", $X$. MC 12A $/$

LOGICAL LOG

ON S/360 NEXT TWO STATEMENTS PERMIT ACCES TO EXPONENT OF REAL EQUIV BETWEEN AU AND JU IS ALSO USED IN ALL IMPLEMENTATIONS LOGICAL*I LU, LUU(4)

EQUI VALENCE (AU,JU,LU), (JUU,LUU(1))

DIMENSIONS OF ARGUMENT ARFAYS COMMON TO ALL ENTRIES

INTEGER* 2 IRN(1), IP(NP,5)

OIMENSION $A(1)$

DIMENSIONS SPECIAL TO THIS ENTRY

DIMENSION AWS(1)

DINENSION AVECT(1)

$K E R R=1$

MT $=$ M TYPE

$N T Y P E=0$

KENTFY $=2$

C 


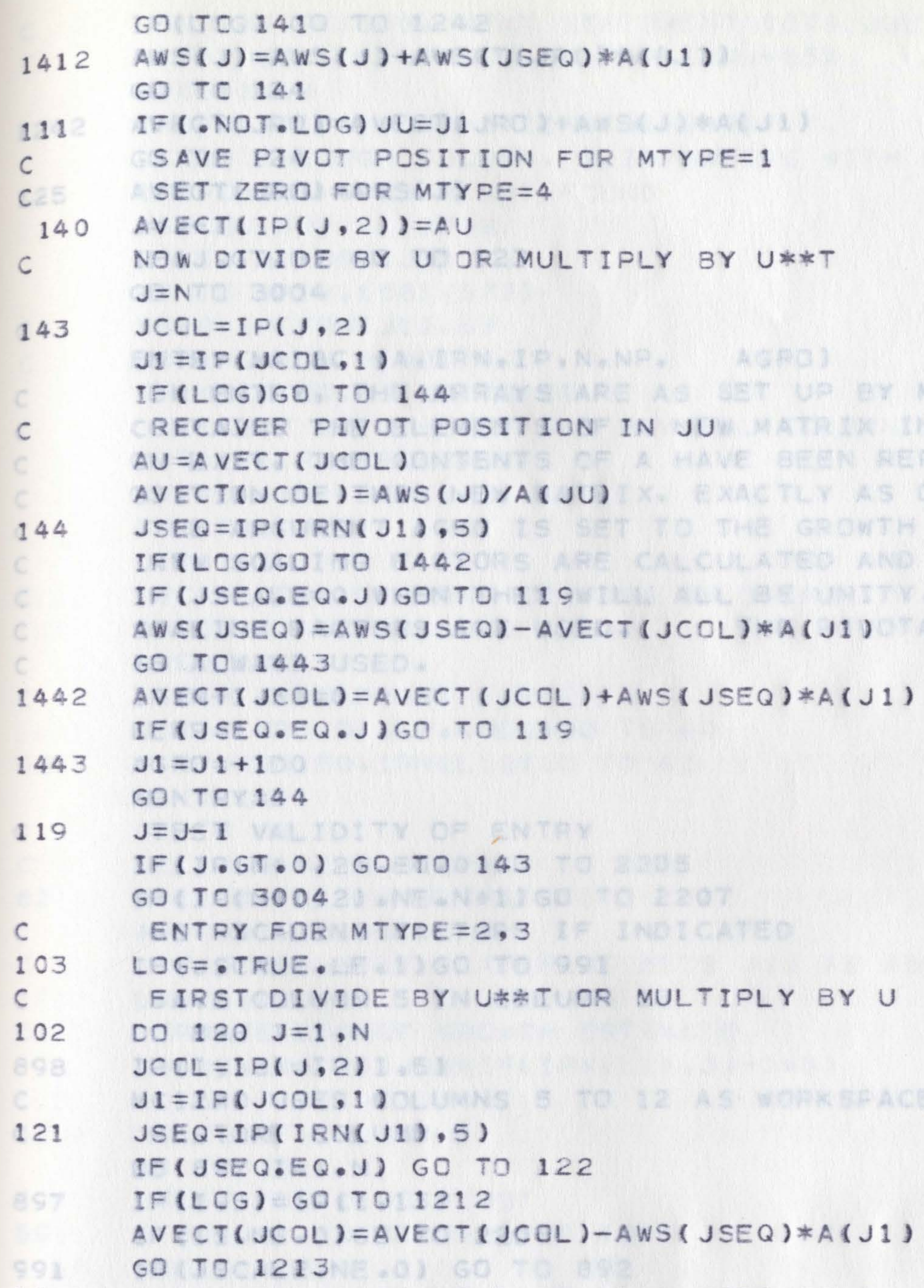


IF (LCG) GO TO 1242

$A W S(J)=A W S(J)-A V E C T(J R O) * A(J 1)$

GO TC 124

1242 AVECT $(J R O)=A$ VECT $(J R O)+A W S(J) * A(J 1)$

GO TO 124

$125 \quad \operatorname{AVECT}(J R O)=A W S(J)$

$\mathrm{J}=\mathrm{J}-1$

IF (J.GT.O) GO TO 123

GO TO 3004

$c$

ENTRY MAIBC (A,IRN,IP, N,NP, AGRO)

ON ENTRY, THE ARRAYS ARE AS SET UP EY MAI 8 AD, EXCEPT THAT A

CONTAINS THE ELEMENTS OF A NEW MATRIX IN UNFACTORISED FORM.

ON EXIT, THE CONTENTS OF A HAVE BEEN REPLACED BY THE LIU DECOMPOSITION OF THIS NEW MATRIX, EXACTLY AS ON EXIT FROM MAISAD.

THE ARGUMENT AGRO IS SET TO THE GROWTH ESTIMATE AS FOR MAISAD.

NEW SCALING FACTORS ARE CALCULATED AND STORED IF JSCAL.GT.1, OR IF JSCALE=O WHEN THEY WILL ALL BE UNITY. OTHERWISE, THE OLD SCALING FACTORS ARE USED. THE PIVOTAL SEQUENCE SET BY MA1SAD IS ALWAYS USED.

$I P(N+1,3)=0$

$K E R R=1$

$A G R O=-1 D O$

KENTRY $=3$

C TEST VALIDITY OF ENTRY

IF (IF $(N+1,2) \cdot E Q \cdot 0) G O$ TO 2205

IF (IP $(N+1,2) \cdot N E \cdot N+1) G O$ TO 2207

C GET SCALING FACTORS IF INDICATED

IF ( JSCALE.LE. I) GO TO 991

C SAVE COLUMN 5 IN COLUMN 13

DO $898 \quad I=1, N$

898 IP $(I, 13)=I P(I, 5)$

C MCIZAD USES COLUMNS 5 TO 12 AS WORKSFACE

C RESTORE COLUMN 5

DO $897 \quad \mathrm{I}=1, \mathrm{~N}$

$897 \quad \operatorname{IP}(I, 5)=I P(I, 13)$

IF (IS.NE. O) GO TO 2208

991 IF (JSCALE.NE.0) GO TO 892

C SET ZERO SCALING POWERS IF JSCALE $=0$

CO $895 \mathrm{~L}=1,2$

CO $895 \mathrm{~K}=1, \mathrm{~N}$

895 IP $(K, L+2)=0$

$892 \quad J U U=0$

I $A G=0$

C OPERATE ON COLUMNS IN SEQUENCE

CO $56 \quad J=1, N$

$J S T=I P(I P(J, 2), 1)$

$J N D=\operatorname{IP}(\operatorname{IP}(J+1,2), 1)-1$

C FIND APPROX LOG OF MAX ELEMENT IN COLUMN

I $A O=0$

DO $57 \mathrm{J1}=\mathrm{JST}, \mathrm{JND}$

$A U=A B S(A(J 1))$ 
C ON SYSTEM/360, NEXT STATEMENT SETS JUU SO THAT

C $16 * *(J U U-64) \cdot G T \cdot A U \cdot G E \cdot 16 * *(J U U-65)$

$\operatorname{LUU}(4)=\mathrm{LU}$

57 IAC $=$ NAXO(IAO, JUU+IP(IRN (J1),3))

c

SCAN THROUGH COLUMN, ELIMINATING WITH ELEMENTS OF U AND ERANCHING WHEN PIVOT FCUND

ASSI GN 581 TO JPIV

DO $5 \& \quad J 1=J S T$, JND

GO TO JPIV, $(581,582)$

$581 K S E Q=\operatorname{IP}(\operatorname{IRN}(J 1), 5)$

C BRANCH ON PIVOT

IF (KSEQ.EQ.J) GO TO 59

C ELEMENT OF U - GET OLD PIVOTAL COLUMN

$K S T=I P(I P(K S E Q, 2), 1)$

$K N D=I P(I P(K S E Q+1,2), 1)-1$

AMULT $=A(J 1)$

$L 1=J 1+1$

C 2 SCAN DOWN COLUMNS KEEFING IN STEP

DO $60 \quad K 1=K S T, K N D$

$K R C=I R N(K 1)$

C SKIP IRRELEVANT ELEMENTS

IF (IP $(K R O, 5)$. LE.KSEQ $)$ GO TO 60

62 IF (KRO.EQ.IRN(LI) $) \in 0$ TO 63

$L 1=L 1+1$

GO TO 62

C. ELININATION STEP

63 $\quad A(L 1)=A(L 1)-A M U L T * A(K 1)$

$A U=A B S(A(L 1))$

C ON $\$ / 360$, NEXT STATEMENT SETS JUU AS ABOVE

LUU (4) $=$ LU

C 7 UPDATE LOG OF GROWTH ESTIMATE

IAG $=$ MAXO(IAG, JUU+IP(IRN(L1), 3)-IAO)

$L 1=L 1+1$

60 CONTINUE

GO TC 58

C TEST FOR ZERO PIVOT

5S IF $(A(J 1) \cdot E Q \cdot Z E R O) G O$ TO 1011

AMULT $=A(J 1)$

ASSIGN 582 TOI JPIV

GO TO 58

C DIVIDE ELEMENTS OF L BY PIVOT

$5 \varepsilon 2 \quad A(J 1)=A(J 1) / A M U L T$

58 CONTINUE

56 CONTINUE

C SET GROWTH ESTIMATE

$A G R O=A R N D * 16 D 0 \%$ IAG

GO TC 3004

ENTRY MA 180 (A, IRN, IF, N, NP, AWS, NAME)

$K E R R=1$

KENTRY $=4$

C TEST VALIDITY OF ENTRY

IF (IF $(N+1,2) \cdot E Q \cdot 0)$ GO TO 2205 


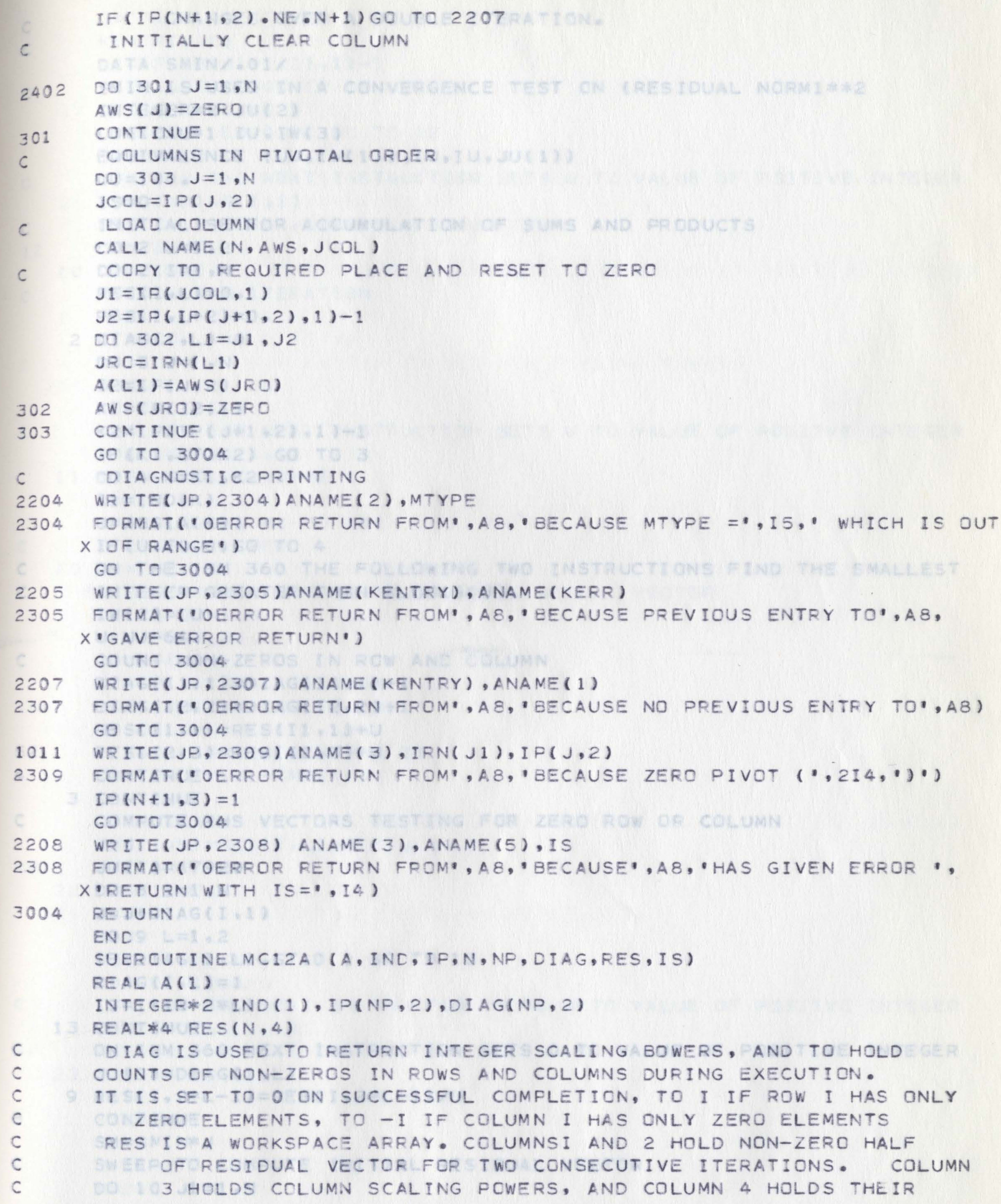

DIAG IS USED TO RETURN INTEGER SCALING BOWERS, AND TO HOLD COUNTS OF NON-ZEROS IN ROWS AND COLUMNS DURING EXECUTION. IT IS SET TO O ON SUCCESSFUL COMPLETION, TO I IF ROW I HAS ONLY ZERO ELEMENTS, TO - I IF COLUMN I HAS ONLY ZERO ELEMENTS RES IS A WORKSPACE ARRAY. COLUMNSI AND 2 HOLD NON-ZERO HALF 54:EF OF RESIDUAL VECTOR FOR TWO CONSECUTIVE ITERATIONS. COLUMN 3 HOLDS COLUMN SCALING POWERS, AND COLUMN 4 HOLDS THEIR 
DATA SMIN/.01/

SMIN IS USED IN A CONVERGENCE TEST ON (RESIDUAL NORMI*\#2

INTEGER* 2 JU ( 2$)$

LOGICAL* I IU, IW(3)

EQUIVALENCE (UU, IW(1)), (U, IU, JU(1))

$U U=100$.

$$
\text { I } S=0
$$

INITIALISE FOR ACCUMULATION OF SUMS AND FRODUCTS

CO $2 \quad L=1,2$

CO 2 I $=1, \mathrm{~N}$

RES $(I, L)=0$.

$\operatorname{RES}(I, L+2)=0$.

2 CIAG $(I, L)=0$

DO $3 \mathrm{~J}=1, \mathrm{~N}$

$I 2=I F(J, 2)$

$K 1=I F(I 2,1)$

$K 2=I F(I P(J+1,2), 1)-1$

$I F(K 1 \cdot G T \cdot K 2)$ GO TO 3

DO $4 K=K 1, K 2$

$I 1=I N D(K)$

$U=A B S(A(K))$

IF $(U \cdot E Q \cdot O) G O$ TO 4

ON THE IBM 360 THE FOLLOWING TWO INSTRUCTIONS FIND THE SMALLEST INTEGER GREATER THAN ALOGIG(U).

I $W(2)=I U$

$\mathrm{U}=\mathrm{UU}-64$.

C COUNT NON-ZEROS IN ROW AND COLUMN

DIAG $(I 1,1)=D I A G(I 1,1)+1$

CIAG $(I 2,2)=D I A G(I 2,2)+1$

RES $(I 1,1)=\operatorname{RES}(I 1,1)+U$

$52 \operatorname{RES}(12,3)=\operatorname{RES}(12,3)+U$

CONTINUE

3 CONTINUE

COMPUTE RHS VECTORS TESTING FOR ZERO ROW OR COLUMN

$\mathrm{J}=\mathrm{O}$

$J \cup(1)=17920$

DO $8 \quad \mathrm{I}=1, \mathrm{~N}$

$J=J+D I A G(I, 1)$

DO $9 L=1,2$

IF (DIAG I,L).GT.O) GO TO 13

DI $A G(I, L)=1$

IS $=I *(3-2 * L)$

13 CONTINUE

ON IEM 360 NEXT INSTRUCTION SETS O TO VALUE OF POSITIVE INTEGER

$J U(2)=D I A G(I, L)$

8

$9 \operatorname{RES}(I, 2 * L-1)=\operatorname{RES}(I, 2 * L-1) / U$

CONTINUE

$S M=S N I N * J$

C SWEEP TO COMPUTE INITIAL RESIDUAL VECTOR

DO $10 \quad J 1=1, N$ 


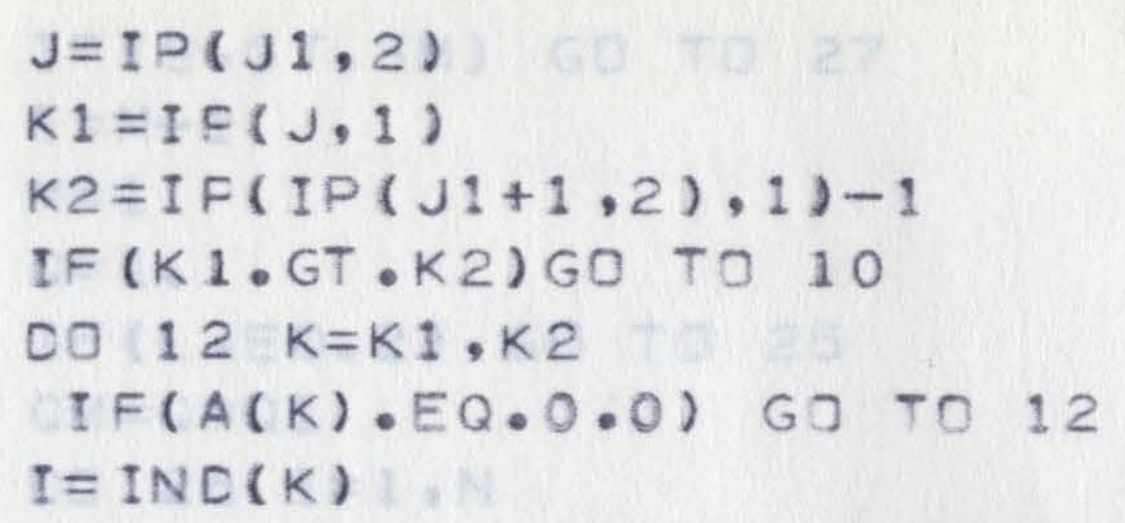

C ON IBM 360 NEXT INSTRUCTION SETS U TO VALUE OF PSITIVE INTEGER $J \cup(2)=D I A G(I, 1)$

$\operatorname{RES}(I, 1)=\operatorname{RES}(I, 1)-\operatorname{RES}(\mathrm{J}, 3) / U$

12 CONTINUE

10 CONTINUE

C INITIALISE ITERATION

$E=0$.

$E 1=0$.

$Q=1$.

$\mathrm{S}=0$.

DO 11 I I $=1, N$

C ON IBM 360 NEXT INSTRUCTION SETS U TO VALUE OF POSITVE INTEGER $J U(2)=D I A G(I, 1)$

$11 S=\subseteq+U * \operatorname{RES}(1,1) * * 2$

$\mathrm{L}=2$

IF (S.LE.SM) GO TO 101

$c$

ITERATION STEP

$20 E M=E * E 1$

C SWEEP THROUGH MATRIX TO UPDATE RESIDUAL VECTOR

DO $22 \quad J 3=1, N$

$\mathrm{J} I=I P(J 3,5)$

$K 1=I F(J 1,1)$

$K 2=I F(I P(J 3+1,2), 1)-1$

IF $(K 1 \cdot G T \cdot K 2)$ GO TO 22

DO $28 K=K 1, K 2$

IF $(A(K) \cdot E Q \cdot 0 \cdot 0)$ GO TO 28

$J 2=(2-L) *(J 1-I N D(K))$

$I=J 1-J 2$

$J=I N D(K)+J 5$

PES $(I, L)=\operatorname{RES}(I, L)+\operatorname{RES}(J, 3-L)$

CONTINUE

22 CONTINUE

$S 1=S$

$\mathrm{S}=0$.

DO $23 \quad \mathrm{I}=1, \mathrm{~N}$

$V=-R E S(I, L) / Q$

C OLEE IBM 360 NEXT INSTRUCTION SETS U TO VALUE OF POSITVE INTEGER JU $(2)=D I A G(I, L)$

RES $(I, L)=V / U$

$23 \subseteq=S+V * R E S(I, L)$

$E 1=E$

$E=G * S / S 1$

$Q 1=Q$

$Q=1 \cdot-E$

$N=3-L$ 


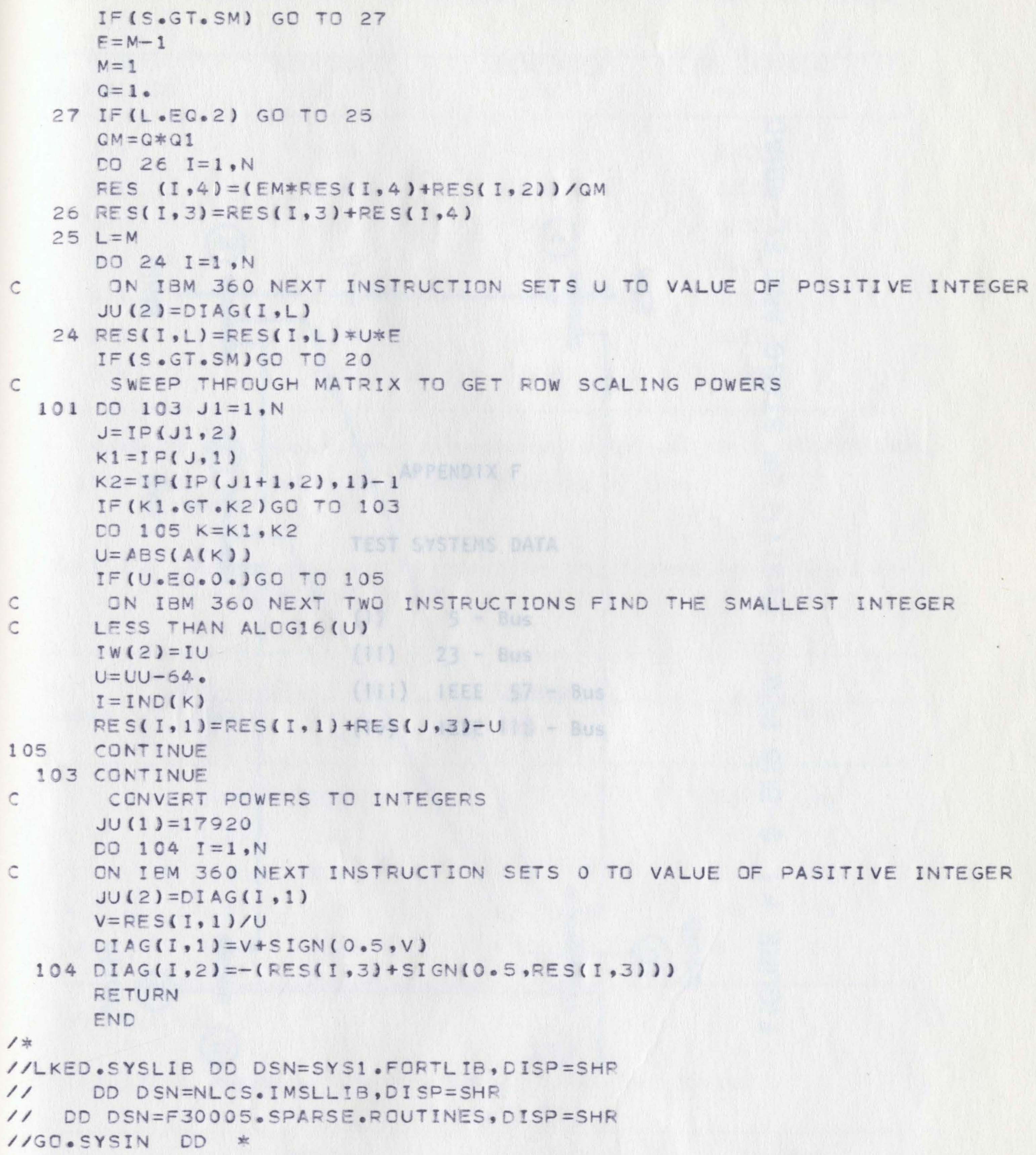




\section{APPENDIX $F$}

TEST SYSTEMS DATA

(i) 5 - Bus

(ii) 23 - Bus

(iii) IEEE $57-$ Bus

(iv) IEEE 118 - Bus 


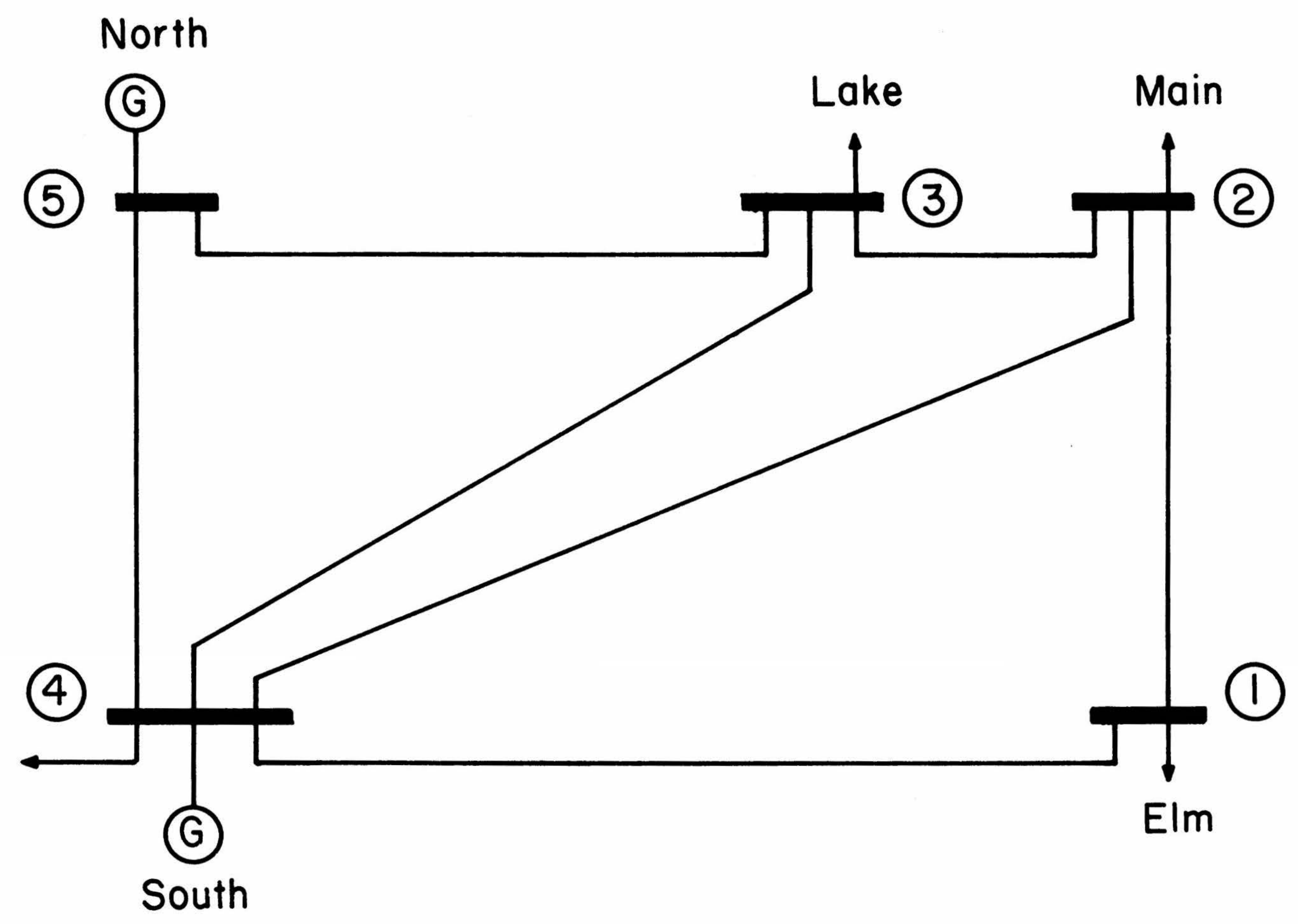

FIGURE F.I 5-BUS POWER SYSTEM OF STAGG AND EL-ABIAD 
TABLE F.1: Impedance and Line-Charging Data for the 5-Bus Test System

\begin{tabular}{cccc}
\hline $\begin{array}{c}\text { LINE } \\
\text { DESIGNATION }\end{array}$ & $\begin{array}{c}\text { RESISTANCE } \\
\text { p.u. }\end{array}$ & $\begin{array}{c}\text { REACTANCE } \\
\text { p.u. }\end{array}$ & $\begin{array}{c}\text { LINE CHARGING } \\
\text { p.u. } *\end{array}$ \\
\hline $2-1$ & 0.08 & 0.24 & 0.025 \\
$3-2$ & 0.01 & 0.03 & 0.010 \\
$4-1$ & 0.04 & 0.12 & 0.015 \\
$4-2$ & 0.06 & 0.18 & 0.020 \\
$4-3$ & 0.06 & 0.18 & 0.020 \\
$5-3$ & 0.08 & 0.24 & 0.025 \\
$5-4$ & 0.02 & 0.06 & 0.030 \\
\hline
\end{tabular}

* Impedance and line charging susceptance in per unit on a 100 MVA base. Line Charging: one-half of total charging of line.

TABLE F.2: Scheduled Loads and Generation and Assumed Bus Voltages for the 5-Bus Test System

\begin{tabular}{|c|c|c|c|c|c|c|}
\hline \multirow{2}{*}{$\begin{array}{l}\text { Bus } \\
\text { Number }\end{array}$} & \multicolumn{2}{|c|}{ Starting Bus Volt } & \multicolumn{2}{|c|}{ Generation } & \multicolumn{2}{|c|}{ Load } \\
\hline & $\begin{array}{l}\text { Mag. } \\
\text { p.u. }\end{array}$ & $\begin{array}{c}\text { Angle } \\
\text { deg. }\end{array}$ & MW & MVAr & MW & MVAr \\
\hline 1 & 1.0 & 0.0 & 0 & 0 & 60 & 10 \\
\hline 2 & 1.0 & 0.0 & 0 & 0 & 40 & 5 \\
\hline 3 & 1.0 & 0.0 & 0 & 0 & 45 & 15 \\
\hline 4 & 1.0 & 0.0 & 40 & 30 & 20 & 10 \\
\hline $5 * *$ & 1.0 & 1.06 & 0 & 0 & 0 & 0 \\
\hline
\end{tabular}

*** Slack Bus

TABLE F.3: Regulated Bus Data for the 5-Bus Test System

\begin{tabular}{cccc}
\hline Bus Number & $\begin{array}{c}\text { Voltage } \\
\text { Magnitude } \\
\text { p.u. }\end{array}$ & $\begin{array}{c}\text { Minimum } \\
\text { MVAr } \\
\text { Capability }\end{array}$ & $\begin{array}{c}\text { Maximum } \\
\text { MVAr } \\
\text { Capability }\end{array}$ \\
\hline 4 & 1.047 & -10 & 50 \\
\hline
\end{tabular}




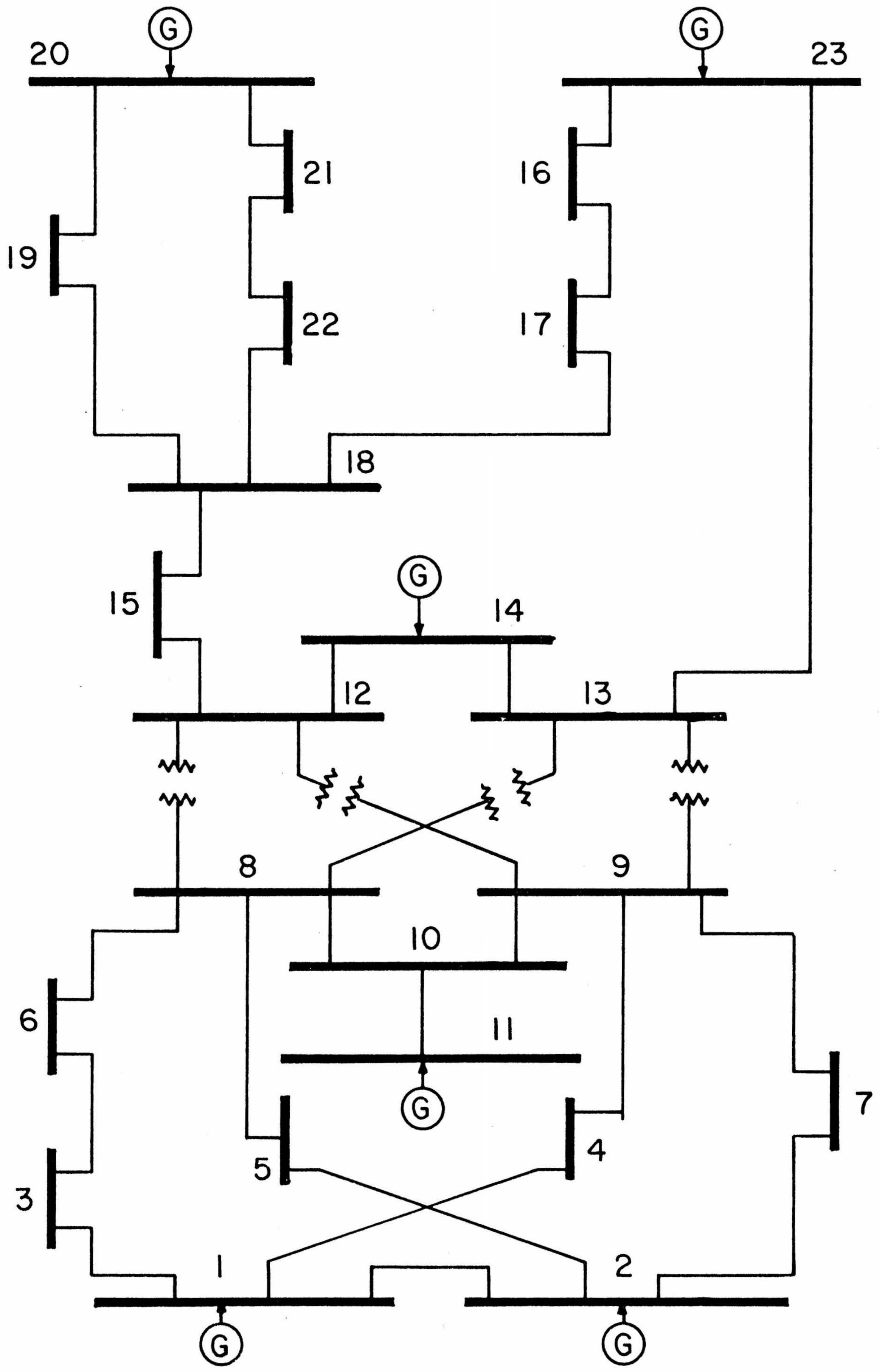

FIGURE F.2 23 - BUS POWER SYSTEM. 
(c)

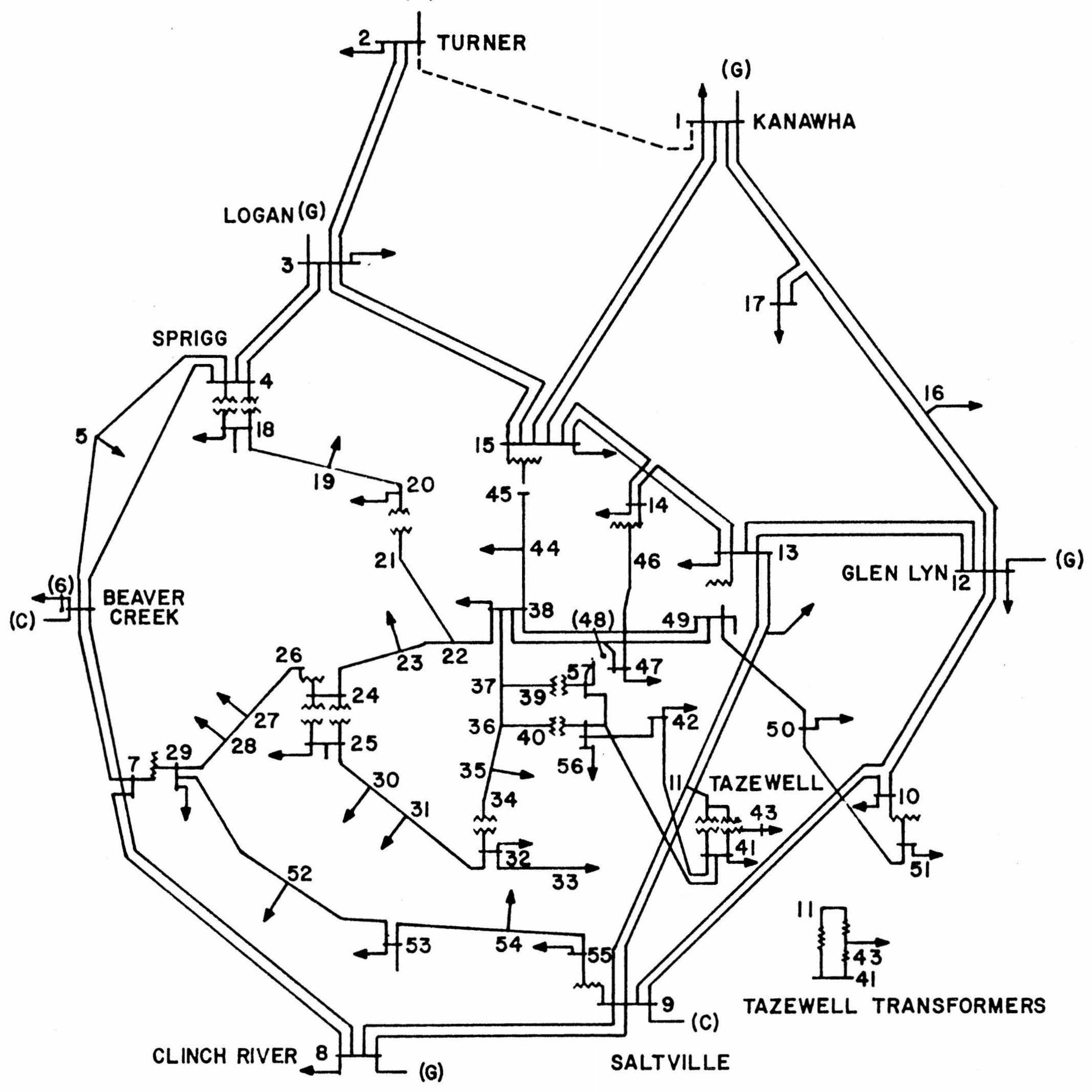

Bus-Code Diagram

(C) Synchronous Compensators

(G) Generators

FIGURE F.3 IEEE 57-BUS POWER SYSTEM 
TABLE F.4: Impedance and Line Charging Data for the 23-Bus Test System

$\begin{array}{cccc}\text { Line } & \text { Resistance } & \text { Reactance } \\ \text { p.u.* } & \text { p.u.* } & \text { Line Charging } \\ \text { p.u.** }\end{array}$

\begin{tabular}{|c|c|c|c|}
\hline $1-3$ & 0.0242 & 0.0540 & 0.0118 \\
\hline $1-4$ & 0.0309 & 0.0693 & 0.0151 \\
\hline $2-5$ & 0.0404 & 0.0888 & 0.0197 \\
\hline $5-8$ & 0.0325 & 0.0709 & 0.0157 \\
\hline $2-7$ & 0.0615 & 0.1620 & 0.0342 \\
\hline $3-6$ & 0.0576 & 0.1520 & 0.0320 \\
\hline $4-9$ & 0.0266 & 0.0700 & 0.0148 \\
\hline $9-7$ & 0.0229 & 0.0504 & 0.0112 \\
\hline $8-6$ & 0.0446 & 0.1003 & 0.0218 \\
\hline $1-10$ & 0.0233 & 0.0514 & 0.0456 \\
\hline $8-10$ & 0.0597 & 0.1315 & 0.0291 \\
\hline $9-10$ & 0.0597 & 0.1315 & 0.0291 \\
\hline $13-14$ & 0.0043 & 0.0351 & 0.2373 \\
\hline $14-12$ & 0.0043 & 0.0351 & 0.2373 \\
\hline $15-12$ & 0.0038 & 0.0307 & 0.2078 \\
\hline $18-15$ & 0.0035 & 0.0288 & 0.1951 \\
\hline $23-13$ & 0.0089 & 0.0720 & 0.4871 \\
\hline $16-17$ & 0.0010 & 0.0080 & 0.0543 \\
\hline $17-18$ & 0.0021 & 0.0167 & 0.1133 \\
\hline $19-18$ & 0.0016 & 0.0127 & 0.0862 \\
\hline $20-19$ & 0.0045 & 0.0362 & 0.2451 \\
\hline $22-18$ & 0.0024 & 0.0192 & 0.1298 \\
\hline $20-21$ & 0.0019 & 0.0156 & 0.1056 \\
\hline $21-22$ & 0.0014 & 0.0114 & 0.0770 \\
\hline $23-16$ & 0.0020 & 0.0164 & 0.1109 \\
\hline $12-8$ & 0.0023 & 0.0839 & 0.0000 \\
\hline $13-8$ & 0.0023 & 0.0839 & 0.0000 \\
\hline $12-9$ & 0.0019 & 0.1300 & 0.0000 \\
\hline $13-9$ & 0.0023 & 0.0839 & 0.0000 \\
\hline $1-2$ & 0.0025 & 0.2000 & 0.0000 \\
\hline
\end{tabular}

* Impedance and line charging susceptance in per unit on a 100 MVA base. Line charging: total charging of line. 
TABLE F.5: Scheduled Loads and Generation and Assumed Bus Voltages for the 23-Bus Test System.

\begin{tabular}{llllll} 
Bus & Starting & Bus Volt. & Generation & Load \\
\cline { 2 - 5 } & $\begin{array}{llll}\text { Mag. } \\
\text { p.u. }\end{array}$ & $\begin{array}{l}\text { Angle } \\
\text { deg. }\end{array}$ & MW MVAr & MW MVAr
\end{tabular}

\begin{tabular}{lllllll}
\hline 1 & 1.0 & 0.0 & 0.663 & 0.143 & 0.0 & 0.0 \\
2 & 1.0 & 0.0 & 0.817 & 0.0 & 0.0 & 0.236 \\
3 & 1.0 & 0.0 & 0.0 & 0.0 & 0.0 & 0.0 \\
4 & 1.0 & 0.0 & 0.0 & 0.0 & 0.470 & 0.120 \\
5 & 1.0 & 0.0 & 0.0 & 0.0 & 0.510 & 0.130 \\
6 & 1.0 & 0.0 & 0.0 & 0.0 & 0.410 & 0.100 \\
7 & 1.0 & 0.0 & 0.0 & 0.0 & 0.480 & 0.120 \\
8 & 1.0 & 0.0 & 0.0 & 0.0 & 0.010 & 0.0 \\
9 & 1.0 & 0.0 & 0.0 & 0.0 & 1.500 & 0.380 \\
10 & 1.0 & 0.0 & 0.0 & 0.0 & 1.770 & 0.440 \\
11 & 1.0 & 0.0 & 1.030 & 0.121 & 0.0 & 0.0 \\
12 & 1.0 & 0.0 & 0.0 & 0.0 & 0.600 & 0.0 \\
13 & 1.0 & 0.0 & 0.400 & 0.0 & 0.0 & 0.0 \\
14 & 1.0 & 0.0 & 0.204 & 0.0 & 0.0 & 0.132 \\
15 & 1.0 & 0.0 & 0.0 & 0.0 & 2.010 & 0.500 \\
16 & 1.0 & 0.0 & 0.0 & 0.0 & 1.320 & 0.330 \\
17 & 1.0 & 0.0 & 0.0 & 0.0 & 3.440 & 0.860 \\
18 & 1.0 & 0.0 & 0.0 & 0.0 & 1.040 & 0.260 \\
19 & 1.0 & 0.0 & 0.0 & 0.0 & 3.760 & 0.940 \\
20 & 1.0 & 0.0 & 8.030 & 0.984 & 0.0 & 0.0 \\
21 & 1.0 & 0.0 & 0.0 & 0.0 & 3.750 & 0.940 \\
22 & 1.0 & 0.0 & 2.100 & 0.520 & 0.0 & 0.0 \\
$23 * *$ & 1.050 & 0.0 & 8.100 & 1.505 & 0.0 & 0.0 \\
& & & & & &
\end{tabular}

*** Slack bus 
TABLE F.6: Impedance and Line-Charging Data for the IEEE 57-Bus Test System.

Line

Designation
Resistance

p.u.*
Reactance

p.u.*
Line Charging

p.u.*

\begin{tabular}{|c|c|c|c|}
\hline $57-2$ & 0.0083 & 0.0280 & 0.0645 \\
\hline $2-3$ & 0.0298 & 0.0850 & 0.0409 \\
\hline $3-4$ & 0.0112 & 0.0366 & 0.0190 \\
\hline $4-5$ & 0.0625 & 0.1320 & 0.0129 \\
\hline $4-6$ & 0.0430 & 0.1480 & 0.0174 \\
\hline $6-7$ & 0.0200 & 0.1020 & 0.0138 \\
\hline $6-8$ & 0.0339 & 0.1730 & 0.0235 \\
\hline $8-9$ & 0.0099 & 0.0505 & 0.0274 \\
\hline $9-10$ & 0.0369 & 0.1679 & 0.0220 \\
\hline $9-11$ & 0.0258 & 0.0848 & 0.0109 \\
\hline $9-12$ & 0.0648 & 0.2950 & 0.0386 \\
\hline $9-13$ & 0.0481 & 0.1580 & 0.0203 \\
\hline $13-14$ & 0.0132 & 0.0434 & 0.0055 \\
\hline $13-15$ & 0.0269 & 0.0869 & 0.0115 \\
\hline $57-15$ & 0.0178 & 0.0910 & 0.0494 \\
\hline $57-16$ & 0.0454 & 0.2060 & 0.0273 \\
\hline $57-17$ & 0.0238 & 0.1080 & 0.0143 \\
\hline $3-15$ & 0.0162 & 0.0530 & 0.0272 \\
\hline $4-18$ & 0 & 0.555 & 0 \\
\hline $4-18$ & 0 & 0.43 & 0 \\
\hline $5-6$ & 0.0302 & 0.0611 & 0.0062 \\
\hline $7-8$ & 0.0139 & 0.0712 & 0.0097 \\
\hline $10-12$ & 0.0277 & 0.1262 & 0.0164 \\
\hline $11-13$ & 0.0223 & 0.0732 & 0.0094 \\
\hline $12-13$ & 0.0178 & 0.0580 & 0.0302 \\
\hline $12-16$ & 0.0180 & 0.0813 & 0.0108 \\
\hline $12-17$ & 0.0397 & 0.1790 & 0.0238 \\
\hline $14-15$ & 0.0171 & 0.0547 & 0.0074 \\
\hline $18-19$ & 0.4610 & 0.6850 & 0 \\
\hline $19-20$ & 0.2830 & 0.4340 & 0 \\
\hline $20-21$ & 0 & 0.7767 & 0 \\
\hline $21-22$ & 0.0736 & 0.1170 & 0 \\
\hline $22-23$ & 0.0099 & 0.0152 & 0 \\
\hline $23-24$ & 0.1660 & 0.2560 & 0.0042 \\
\hline $24-25$ & 0 & 1.182 & 0 \\
\hline $24-25$ & 0 & 1.23 & 0 \\
\hline $24-26$ & 0 & 0.0473 & 0 \\
\hline $26-27$ & 0.1650 & 0.2540 & 0 \\
\hline $27-28$ & 0.0618 & 0.0954 & 0 \\
\hline $28-29$ & 0.0418 & 0.0587 & 0 \\
\hline $7-29$ & 0 & 0.0648 & 0 \\
\hline $25-30$ & 0.1350 & 0.2020 & 0 \\
\hline $30-31$ & 0.3260 & 0.4970 & 0 \\
\hline $31-32$ & 0.5070 & 0.7550 & 0 \\
\hline $32-33$ & 0.0392 & 0.0360 & 0 \\
\hline $32-34$ & 0 & 0.9530 & 0 \\
\hline
\end{tabular}


TABLE F.6: CONT'd

\begin{tabular}{|c|c|c|c|}
\hline $\begin{array}{c}\text { Line } \\
\text { Designation }\end{array}$ & $\begin{array}{c}\text { Resistance } \\
\text { p.u* }\end{array}$ & $\begin{array}{c}\text { Reactance } \\
\text { p.u* }\end{array}$ & $\begin{array}{l}\text { Line Charging } \\
\text { p.u.* }\end{array}$ \\
\hline $34-35$ & 0.0520 & 0.0780 & 0.0016 \\
\hline $35-36$ & 0.0430 & 0.0537 & 0.0008 \\
\hline $36-37$ & 0.0290 & 0.0366 & 0 \\
\hline $37-38$ & 0.0651 & 0.1009 & 0.0010 \\
\hline $37-39$ & 0.0239 & 0.0379 & 0 \\
\hline $36-40$ & 0.0300 & 0.0466 & $n$ \\
\hline $22-38$ & 0.0192 & 0.0295 & 0.0010 \\
\hline $11-41$ & 0 & 0.7490 & 0 \\
\hline $41-42$ & 0.2070 & 0.3520 & 0 \\
\hline $41-43$ & 0 & 0.4120 & 0 \\
\hline $38-44$ & 0.0289 & 0.0585 & 0.0010 \\
\hline $15=45$ & 0 & 0.1042 & 0 \\
\hline $14-46$ & 0 & 0.0735 & 0 \\
\hline $46-47$ & 0.0230 & 0.0680 & 0.0016 \\
\hline $47-48$ & 0.0182 & 0.0233 & 0 \\
\hline $48-49$ & 0.0834 & 0.1290 & 0.0024 \\
\hline $49-50$ & 0.0801 & 0.1280 & 0 \\
\hline $50-51$ & 0.1386 & 0.2200 & 0 \\
\hline $10-51$ & 0 & 0.0712 & 0 \\
\hline $13-49$ & 0 & 0.1910 & 0 \\
\hline $29-52$ & 0.1442 & 0.1870 & 0 \\
\hline $52-53$ & 0.0762 & 0.0984 & 0 \\
\hline $53-54$ & 0.1878 & 0.2320 & 0 \\
\hline $54-55$ & 0.1732 & 0.2265 & 0 \\
\hline $11-43$ & 0 & 0.1530 & 0 \\
\hline $44-45$ & 0.0624 & 0.1242 & 0.0020 \\
\hline $40-56$ & 0 & 1.1950 & 0 \\
\hline $56-41$ & 0.5530 & 0.5490 & 0 \\
\hline $56-42$ & 0.2125 & 0.3540 & 0 \\
\hline $39-1$ & 0 & 1.3550 & 0 \\
\hline $1-56$ & 0.1740 & 0.2600 & 0 \\
\hline $38-49$ & 0.1150 & 0.1770 & 0.0030 \\
\hline $38-48$ & 0.0312 & 0.0482 & 0 \\
\hline $9-55$ & 0 & 0.1205 & 0 \\
\hline
\end{tabular}

* Impedance and line charging susceptance in p.u. on a 100000kVA base Line charging: one-half of total charging of line. 
TABLE F.7: Operating Conditions for the IEEE 57-Bus Test System

\begin{tabular}{ccccc} 
Bus & Starting Bus Volt. & Generation & \multicolumn{2}{c}{ Load } \\
Number $*$ & Mag. & Angle & MW MVAr \\
& p.u. & deg. &
\end{tabular} MW MVAr

\begin{tabular}{|c|c|c|c|c|c|c|}
\hline $57 * *$ & 1.04 & 0 & 0 & 0 & 55.0 & 17.0 \\
\hline 2 & 1.0 & 0 & 0 & 0 & 3.0 & 88.0 \\
\hline 3 & 1.0 & 0 & 40 & 0 & 41.0 & 21.0 \\
\hline 4 & 1.0 & 0 & 0 & 0 & 0 & 0 \\
\hline 5 & 1.0 & 0 & 0 & 0 & 13.0 & 4.0 \\
\hline 6 & 1.0 & 0 & 0 & 0 & 75.0 & 2.0 \\
\hline 7 & 1.0 & 0 & 0 & 0 & 0 & 0 \\
\hline 8 & 1.0 & 0 & 450 & 0 & 150.0 & 22.0 \\
\hline 9 & 1.0 & 0 & 0 & 0 & 121.0 & 26.0 \\
\hline 10 & 1.0 & 0 & 0 & 0 & 5.0 & 2.0 \\
\hline 11 & 1.0 & 0 & 0 & 0 & 0 & 0 \\
\hline 12 & 1.0 & 0 & 310 & 0 & 377.0 & 24.0 \\
\hline 13 & 1.0 & 0 & 0 & 0 & 18.0 & 2.3 \\
\hline 14 & 1.0 & 0 & 0 & 0 & 10.5 & 5.3 \\
\hline 15 & 1.0 & 0 & 0 & 0 & 22.0 & 5.0 \\
\hline 16 & 1.0 & 0 & 0 & 0 & 43.0 & 3.0 \\
\hline 17 & 1.0 & 0 & 0 & 0 & 42.0 & 8.0 \\
\hline 18 & 1.0 & 0 & 0 & 0 & 27.2 & 9.8 \\
\hline 19 & 1.0 & 0 & 0 & 0 & 3.3 & 0.6 \\
\hline 20 & 1.0 & 0 & 0 & 0 & 2.3 & 1.0 \\
\hline 21 & 1.0 & 0 & 0 & 0 & 0 & 0 \\
\hline 22 & 1.0 & 0 & 0 & 0 & 0 & 0 \\
\hline 23 & 1.0 & 0 & 0 & 0 & 6.3 & 2.1 \\
\hline 24 & 1.0 & 0 & 0 & 0 & 0 & 0 \\
\hline 25 & 1.0 & 0 & 0 & 0 & 6.3 & 3.2 \\
\hline 26 & 1.0 & 0 & 0 & 0 & 0 & 0 \\
\hline 27 & 1.0 & 0 & 0 & 0 & 9.3 & 0.5 \\
\hline 28 & 1.0 & 0 & 0 & 0 & 4.6 & 2.3 \\
\hline 29 & 1.0 & 0 & 0 & 0 & 17.0 & 2.6 \\
\hline 30 & 1.0 & 0 & 0 & 0 & 3.6 & 1.8 \\
\hline 31 & 1.0 & 0 & 0 & 0 & 5.8 & 2.9 \\
\hline 32 & 1.0 & 0 & 0 & 0 & 1.6 & 0.8 \\
\hline 33 & 1.0 & 0 & 0 & 0 & 3.8 & 1.9 \\
\hline 34 & 1.0 & 0 & 0 & 0 & 0 & 0 \\
\hline 35 & 1.0 & 0 & 0 & 0 & 6.0 & 3.0 \\
\hline 36 & 1.0 & 0 & 0 & 0 & 0 & 0 \\
\hline 37 & 1.0 & 0 & 0 & 0 & 0 & 0 \\
\hline 38 & 1.0 & 0 & 0 & 0 & 14.0 & 7.0 \\
\hline 39 & 1.0 & 0 & 0 & 0 & 0 & 0 \\
\hline 40 & 1.0 & 0 & 0 & 0 & 0 & 0 \\
\hline 41 & 1.0 & 0 & 0 & 0 & 6.3 & 3.0 \\
\hline 42 & 1.0 & 0 & 0 & 0 & 7.1 & 4.4 \\
\hline 43 & 1.0 & 0 & 0 & 0 & 2.0 & 1.0 \\
\hline 44 & 1.0 & 0 & 0 & 0 & 12.0 & 1.8 \\
\hline 45 & 1.0 & 0 & 0 & 0 & 0 & 0 \\
\hline 46 & 1.0 & 0 & 0 & 0 & 0 & 0 \\
\hline 47 & 1.0 & 0 & 0 & 0 & 29.7 & 11.6 \\
\hline 48 & 1.0 & 0 & 0 & 0 & 0 & 0 \\
\hline 49 & 1.0 & 0 & 0 & 0 & 18.0 & 8.5 \\
\hline
\end{tabular}


TABLE F.7: CONT'D

\begin{tabular}{|c|c|c|c|c|c|c|}
\hline \multirow{2}{*}{$\begin{array}{l}\text { Bus } \\
\text { Number } *\end{array}$} & \multirow{2}{*}{$\begin{array}{l}\text { Starting } \\
\text { Mag. } \\
\text { p.u. }\end{array}$} & \multirow{2}{*}{$\begin{array}{c}\text { Bus Volt. } \\
\text { Angle } \\
\text { deg. }\end{array}$} & \multicolumn{2}{|c|}{ Generation } & \multicolumn{2}{|c|}{ Load } \\
\hline & & & MW & MVAr & MW & MVAr \\
\hline 50 & 1.0 & 0 & 0 & 0 & 21.0 & 10.5 \\
\hline 51 & 1.0 & 0 & 0 & 0 & 18.0 & 5.3 \\
\hline 52 & 1.0 & 0 & 0 & 0 & 4.9 & 2.2 \\
\hline 53 & 1.0 & 0 & 0 & 0 & 200 & 10.0 \\
\hline 54 & 1.0 & 0 & 0 & 0 & 4.1 & 1.4 \\
\hline 55 & 1.0 & 0 & 0 & 0 & 6.8 & 3.4 \\
\hline 56 & 1.0 & 0 & 0 & 0 & 7.6 & 2.2 \\
\hline 1 & 1.0 & 0 & 0 & 0 & 6.7 & 2.0 \\
\hline
\end{tabular}

* This is prior to the Bus Renumbering Necessary to Enable the Regulated Buses to have the higher numbers.

*** Swing Machine 
TABLE F.8: Transformer Data For the IEEE 57-Bus Test System

Transformer

designation

Tap Setting*

$\begin{array}{ll}4-18 & 0.97 \\ 4-18 & 0.978 \\ 7-29 & 0.967\end{array}$

9-55

0.94

10-51

0.93

$11-41$

0.955

11.43

0.958

$13-49$

0.895

$14-46$

0.9

$15-45$

0.955

21-20

1.043

24-25

1.000

24-25

1.000

24-26

1.043

$34-32$

0.975

$39-1$

0.98

40-56

0.958

* Off-nominal turns ratio, as determined by the actual transformer-tap positions and the voltage baiss. In the case of nominal turns ratio, this would equal 1 . 
TABLE F.9: Regulated Bus Data For the IEEE 57-Bus Test System.

\begin{tabular}{cccc}
\hline Bus Number & $\begin{array}{c}\text { Voltage } \\
\text { Magnitude } \\
\text { p.u }\end{array}$ & $\begin{array}{c}\text { Minimum } \\
\text { MVAr } \\
\text { capability }\end{array}$ & $\begin{array}{c}\text { Maximum } \\
\text { MVAr } \\
\text { capability }\end{array}$ \\
\hline 2 & 1.01 & -17 & 50 \\
3 & 0.985 & -10 & 60 \\
6 & 0.98 & -8 & 25 \\
8 & 1.005 & -140 & 200 \\
9 & 0.98 & -3 & 9 \\
12 & 1.015 & -50 & 155 \\
\hline
\end{tabular}

TABLE F.10: Static Capacitor Data For the IEEE 57-Bus Test System

Bus Number Susceptance* p.u.

$\begin{array}{ll}18 & 0.1 \\ 25 & 0.059 \\ 53 & 0.063\end{array}$

* Susceptance in p.u. on a 100000 kVA Base. 


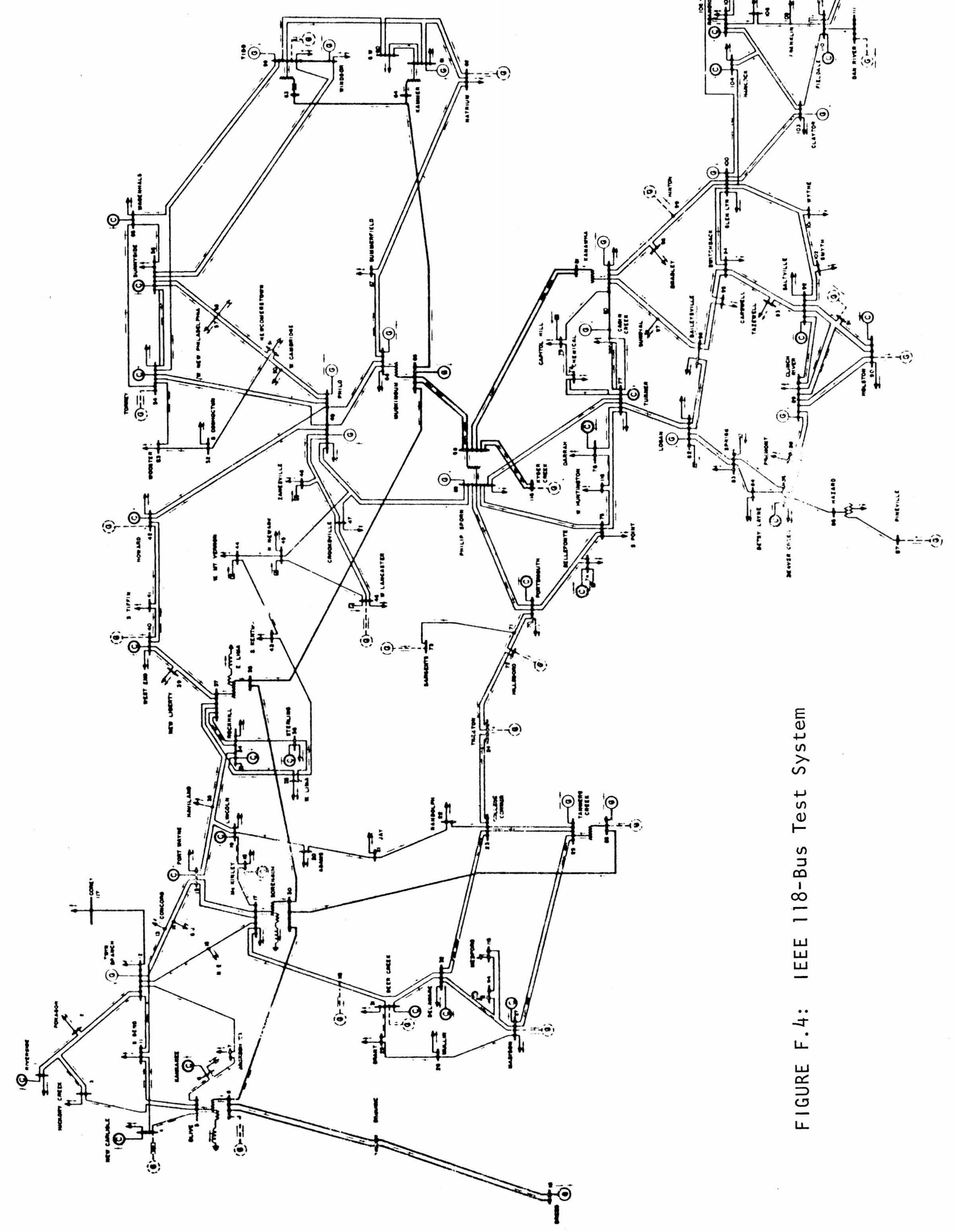


TABLE F.11: CONT'D

\begin{tabular}{|c|c|c|c|}
\hline Line & Resistance & Reactance & Line Charging \\
\hline Designation & Per Unit决 & Per Unit** & Per Unit ** \\
\hline $34-37$ & .00256 & .00940 & .00492 \\
\hline $37-38$ & 0 & .03750 & 0 \\
\hline $37-39$ & .03210 & .10600 & .01350 \\
\hline $37-40$ & .05930 & .16800 & .02100 \\
\hline $30-38$ & $.004 \mathrm{KL}$ & .05400 & .21100 \\
\hline $39-40$ & .018 in & .06050 & .00776 \\
\hline $40-41$ & .01450 & .04870 & .00611 \\
\hline $40-42$ & .05550 & .18300 & .02330 \\
\hline $41-42$ & .04100 & .13500 & .01720 \\
\hline $43-44$ & .06080 & .24540 & .03034 \\
\hline $34-43$ & .04130 & .16810 & .02113 \\
\hline $44-45$ & .02240 & .09010 & .01120 \\
\hline $45-46$ & .04000 & .13560 & .01660 \\
\hline $46-47$ & .03800 & .12700 & .01580 \\
\hline $46-48$ & .06010 & .18900 & .02360 \\
\hline $47-49$ & .01910 & .06250 & .00802 \\
\hline $42-49$ & .07150 & .32300 & .04300 \\
\hline $42-49$ & .07150 & .32300 & .04300 \\
\hline $45-49$ & .06840 & .18600 & .02220 \\
\hline $48-49$ & .01790 & .05050 & .00629 \\
\hline $49-50$ & .02670 & .07520 & .00937 \\
\hline $49-51$ & .04860 & .13700 & .01710 \\
\hline $51-52$ & .02030 & .05880 & .00698 \\
\hline $52-53$ & .04050 & .16350 & .02029 \\
\hline $53-54$ & .02630 & .12200 & .01550 \\
\hline $49-54$ & .07300 & .28900 & .03690 \\
\hline $49-54$ & .08690 & .29100 & .03650 \\
\hline $54-55$ & .01690 & .07070 & .01010 \\
\hline $54-56$ & .00275 & .00955 & .00366 \\
\hline $55-56$ & .00488 & .01510 & .00187 \\
\hline $56-57$ & .03430 & .09660 & .01210 \\
\hline $50-57$ & .04740 & .13400 & .01660 \\
\hline $56-58$ & .03430 & .09660 & .01210 \\
\hline $51-58$ & .02550 & .07190 & .00894 \\
\hline $54-59$ & .05030 & .22930 & .02990 \\
\hline $56-59$ & .08250 & .25100 & .02845 \\
\hline $56-59$ & .08030 & .23900 & .02680 \\
\hline $55-59$ & .04739 & .21580 & .02823 \\
\hline $59-60$ & .03170 & .14500 & .01880 \\
\hline $59-61$ & .03280 & .15000 & .01940 \\
\hline $60-61$ & .00264 & .01350 & .00728 \\
\hline $60-62$ & .01230 & .05610 & .00734 \\
\hline $61-62$ & .00824 & .03760 & .00490 \\
\hline $59-63$ & 0 & .03860 & 0 \\
\hline $63-64$ & .00172 & .02000 & .10800 \\
\hline $61-64$ & 0 & .02680 & 0 \\
\hline $38-65$ & .00901 & .09860 & .52300 \\
\hline $64-65$ & .00269 & .03020 & .19000 \\
\hline $49-66$ & .01800 & .09190 & .01240 \\
\hline $49-66$ & .01800 & .09190 & .01240 \\
\hline $62-66$ & .04820 & .21800 & .02890 \\
\hline $62-67$ & .02580 & . 11700 & .01550 \\
\hline
\end{tabular}


TABLE F.11: Impedance and Line Charging Data for the IEEE 118-Bus Test System.

\begin{tabular}{|c|c|c|c|}
\hline $\begin{array}{c}\text { Line } \\
\text { Designation }\end{array}$ & $\begin{array}{l}\text { Resistance } \\
\text { Per Unit** }\end{array}$ & $\begin{array}{l}\text { Reactance } \\
\text { Per Unit*** }\end{array}$ & $\begin{array}{l}\text { Line Charging } \\
\text { Per Unit ** }\end{array}$ \\
\hline $1-2$ & .03030 & .09990 & .01270 \\
\hline $1-3$ & .01290 & .04240 & .00541 \\
\hline $4-5$ & .00176 & .00798 & .00105 \\
\hline $3-5$ & .02410 & .10800 & .01420 \\
\hline $5-6$ & .01190 & .05400 & .00713 \\
\hline $6-7$ & .00459 & .02080 & .00275 \\
\hline $8-9$ & .00244 & .03050 & .58100 \\
\hline $5-8$ & 0 & .02670 & 0 \\
\hline $9-10$ & .00258 & .03220 & .61500 \\
\hline $4-11$ & .02090 & .06880 & .00874 \\
\hline $5-11$ & .02030 & .06820 & .00869 \\
\hline $11-12$ & .00595 & .01960 & .00251 \\
\hline $2-12$ & .01870 & .06160 & .00786 \\
\hline $3-12$ & .04840 & .16000 & .02030 \\
\hline $7-12$ & .00862 & .03400 & .00437 \\
\hline $11-13$ & .02225 & .07310 & .00938 \\
\hline $12-14$ & .02150 & .07070 & .00908 \\
\hline $13-15$ & .07440 & .24440 & .03134 \\
\hline $14-15$ & .05950 & .19500 & .02510 \\
\hline $12-16$ & .02120 & .08340 & .01070 \\
\hline $15-17$ & .01320 & .04370 & .02220 \\
\hline $16-17$ & .04540 & .18010 & .02330 \\
\hline $17-18$ & .01230 & .05050 & .00649 \\
\hline $18-19$ & & .04930 & .00571 \\
\hline $19-20$ & .02520 & .11700 & .01490 \\
\hline $15-19$ & .01200 & .03940 & .00505 \\
\hline $20-21$ & .01830 & .08490 & .01080 \\
\hline $21-22$ & .02090 & .09700 & .01230 \\
\hline $23-24$ & .01350 & .04920 & .02490 \\
\hline $23-25$ & .01560 & .08000 & .04320 \\
\hline $25-26$ & 0 & .03820 & 0 \\
\hline $25-27$ & .03180 & .16300 & .08820 \\
\hline $27-28$ & .01913 & .08550 & .01080 \\
\hline $28-29$ & .02370 & .09430 & .01190 \\
\hline $17-30$ & 0 & .03880 & 0 \\
\hline $8-30$ & .00431 & .05040 & .25700 \\
\hline $26-30$ & .00799 & .08600 & .45400 \\
\hline $17-31$ & .04740 & .15630 & .01995 \\
\hline $29-31$ & .01080 & .03310 & .00415 \\
\hline $23-32$ & .03170 & .11530 & .05865 \\
\hline $31-32$ & .02980 & .09850 & .01255 \\
\hline $27-32$ & .02290 & .07550 & .00963 \\
\hline $15-33$ & .03800 & .12440 & .01597 \\
\hline $19-34$ & .07520 & .24700 & .03160 \\
\hline $35-36$ & .00224 & .01020 & .00134 \\
\hline $35-37$ & .01100 & .04970 & .00659 \\
\hline $33-37$ & .04150 & .14200 & .01830 \\
\hline $34-36$ & .00871 & .02680 & .00284 \\
\hline $22-23$ & .03420 & .15900 & .02020 \\
\hline
\end{tabular}


TABLE F.II: CONT'D

\begin{tabular}{clll}
\hline Line & Resistance & Reactance & Line Charging \\
Designation & Per Unit** & Per Unit** & Per Unit ***
\end{tabular}

\begin{tabular}{|c|c|c|c|}
\hline $65-66$ & 0 & .03700 & 0 \\
\hline $66-67$ & .02240 & .10150 & .01341 \\
\hline $65-68$ & .00138 & .01600 & .31900 \\
\hline $47-118$ & .08440 & .27780 & .03546 \\
\hline $49-118$ & .09850 & .32400 & .04140 \\
\hline $68-118$ & 0 & .03700 & 0 \\
\hline $118-70$ & .03000 & .12700 & .06100 \\
\hline $24-70$ & .10221 & .41150 & .05099 \\
\hline $70-71$ & .00882 & .03550 & .00439 \\
\hline $24-72$ & .04880 & .19600 & .02440 \\
\hline $71-72$ & .04460 & .18000 & .02222 \\
\hline $71-73$ & .00866 & .04540 & .00589 \\
\hline $70-74$ & .04010 & .13230 & .01684 \\
\hline $70-75$ & .04280 & .14100 & .01800 \\
\hline $118-75$ & .04050 & .12200 & .06200 \\
\hline $74-75$ & .01230 & .04060 & .00517 \\
\hline $76-77$ & .04440 & .14800 & .01840 \\
\hline $118-77$ & .03090 & .10100 & .05190 \\
\hline $75-77$ & .06010 & .19990 & .02489 \\
\hline $77-78$ & .00376 & .01240 & .00632 \\
\hline $78-79$ & .00546 & .02440 & .00324 \\
\hline $77-80$ & .01700 & .04850 & .02360 \\
\hline $77-80$ & .02940 & .10500 & .01140 \\
\hline $79-80$ & .01560 & .07040 & .00935 \\
\hline $68-81$ & .00175 & .02020 & .40400 \\
\hline $80-81$ & 0 & .03700 & 0 \\
\hline $77-82$ & .02980 & .08530 & .04087 \\
\hline $82-83$ & .01120 & .03665 & .01898 \\
\hline $83-84$ & .06250 & .13200 & .01290 \\
\hline $83-85$ & .04300 & .14800 & .01740 \\
\hline $84-85$ & .03020 & .06410 & .00617 \\
\hline $85-86$ & .03500 & .12300 & .01380 \\
\hline $86-87$ & .02828 & .20740 & .02225 \\
\hline $85-88$ & .02000 & .10200 & .01380 \\
\hline $88-89$ & .01390 & .07120 & .00967 \\
\hline $89-90$ & .05180 & .18800 & .02640 \\
\hline $89-90$ & .02380 & .09970 & .05300 \\
\hline $90-91$ & .02540 & .08360 & .01070 \\
\hline $89-92$ & .00990 & .05050 & .02740 \\
\hline $89-92$ & .03930 & .15810 & .02070 \\
\hline $91-92$ & .03870 & .12720 & .01634 \\
\hline $92-93$ & .02580 & .08480 & .01090 \\
\hline $92-94$ & .04810 & .15800 & .02030 \\
\hline $93-94$ & .02230 & .07320 & .00938 \\
\hline $94-95$ & .01320 & .04340 & .00555 \\
\hline $80-96$ & .03560 & .18200 & .02470 \\
\hline $85-89$ & .02390 & .17300 & .02350 \\
\hline
\end{tabular}


TABLE F.II: CONT'D

\begin{tabular}{|c|c|c|c|}
\hline $\begin{array}{c}\text { Line } \\
\text { Designation }\end{array}$ & $\begin{array}{l}\text { Resistance } \\
\text { Per Unit** }\end{array}$ & $\begin{array}{l}\text { Reactance } \\
\text { Per Unit** }\end{array}$ & $\begin{array}{l}\text { Line Charging } \\
\text { Per Unit*** }\end{array}$ \\
\hline $82-96$ & .01620 & .05300 & .02720 \\
\hline $94-96$ & .02690 & .08690 & .01150 \\
\hline $80-97$ & .01830 & .09340 & .01270 \\
\hline $80-98$ & .02380 & .10800 & .01430 \\
\hline $80-99$ & .04540 & .20600 & .02730 \\
\hline $92-100$ & .06480 & .29500 & .03860 \\
\hline $94-100$ & .01780 & .05800 & .03020 \\
\hline $95-96$ & .01710 & .05470 & .00737 \\
\hline $96-97$ & .01730 & .08850 & .01200 \\
\hline $98-100$ & .03970 & .17900 & .02380 \\
\hline $99-100$ & .01800 & .08130 & .01080 \\
\hline $100-101$ & .02770 & .12620 & .01640 \\
\hline $92-102$ & .01230 & .05590 & .00732 \\
\hline $101-102$ & .02460 & .11200 & .01470 \\
\hline $100-103$ & .01600 & .05250 & .02680 \\
\hline $100-104$ & .04510 & .20400 & .02705 \\
\hline $103-104$ & .04660 & .15840 & .02035 \\
\hline $103-105$ & .05350 & .16250 & .02040 \\
\hline $100-106$ & .06050 & .22900 & .03100 \\
\hline $104-105$ & .00994 & .03780 & .00493 \\
\hline $105-106$ & .01400 & .05470 & .00717 \\
\hline $105-107$ & .05300 & .18300 & .02360 \\
\hline $105-108$ & .02610 & .07030 & .00922 \\
\hline $106-107$ & .05300 & .18300 & .02360 \\
\hline $108-109$ & .01050 & .02880 & .00380 \\
\hline $103-110$ & .03906 & .18130 & .02305 \\
\hline $109-110$ & .02780 & .07620 & .01010 \\
\hline $110-11$ & .02200 & .07550 & .01000 \\
\hline $110-112$ & .02470 & .06400 & .03100 \\
\hline $17-113$ & .00913 & .03010 & .00384 \\
\hline $32-113$ & .06150 & .20300 & .02590 \\
\hline $32-114$ & .01350 & .06120 & .00814 \\
\hline $27-115$ & .01640 & .07410 & .00986 \\
\hline $114-115$ & .00230 & .01040 & .00138 \\
\hline $68-116$ & .00034 & .00405 & .08200 \\
\hline $12-117$ & .03290 & .14000 & .01790 \\
\hline $75-69$ & .01450 & .04810 & .00599 \\
\hline $76-69$ & .01640 & .05440 & .00678 \\
\hline
\end{tabular}

* Based on AEP System for Total Loss Formula June 1962.

$* *$ Impedance and line-charging susceptance in per unit on a 100,000 kva base

Line charging one-half of total charging of line 
TABLE F.12: Operating Conditions for the IEEE 118-Bus Test System

\begin{tabular}{|c|c|c|c|c|c|c|}
\hline \multirow{3}{*}{$\begin{array}{l}\text { Bus } \\
\text { Number }\end{array}$} & \multirow{3}{*}{$\begin{array}{l}\text { Starting } \\
\text { Mag. } \\
\text { p.u. }\end{array}$} & \multirow{3}{*}{$\begin{array}{c}\text { Bus Voltage } \\
\text { Angle } \\
\text { Deg. }\end{array}$} & \multicolumn{2}{|c|}{ Generation } & \multicolumn{2}{|c|}{ Load } \\
\hline & & & MW & MVAr & MW & MVAr \\
\hline & & & & & & \\
\hline 1 & 1.0 & 0 & 0 & 0 & 51 & 27 \\
\hline 2 & 1.0 & 0 & 0 & 0 & 20 & 9 \\
\hline 3 & 1.0 & 0 & 0 & 0 & 39 & 10 \\
\hline 4 & 1.0 & 0 & -9 & 0 & 30 & 12 \\
\hline 5 & 1.0 & 0 & 0 & 0 & 0 & 0 \\
\hline 6 & 1.0 & 0 & 0 & 0 & 52 & 22 \\
\hline 7 & 1.0 & 0 & 0 & 0 & 19 & 2 \\
\hline 8 & 1.0 & 0 & -28 & 0 & 0 & 0 \\
\hline 9 & 1.0 & 0 & 0 & 0 & 0 & 0 \\
\hline 10 & 1.0 & 0 & 450 & 0 & 0 & 0 \\
\hline 11 & 1.0 & 0 & 0 & 0 & 70 & 23 \\
\hline 12 & 1.0 & 0 & 85 & 0 & 47 & 10 \\
\hline 13 & 1.0 & 0 & 0 & 0 & 34 & 16 \\
\hline 14 & 1.0 & 0 & 0 & 0 & 14 & 1 \\
\hline 15 & 1.0 & 0 & 0 & 0 & 90 & 30 \\
\hline 16 & 1.0 & 0 & 0 & 0 & 25 & 10 \\
\hline 17 & 1.0 & 0 & 0 & 0 & 11 & 3 \\
\hline 18 & 1.0 & 0 & 0 & 0 & 60 & 34 \\
\hline 19. & 1.0 & 0 & 0 & 0 & 45 & 25 \\
\hline 20 & 1.0 & 0 & 0 & 0 & 18 & 3 \\
\hline 21 & 1.0 & 0 & 0 & 0 & 14 & 8 \\
\hline 22 & 1.0 & 0 & 0 & 0 & 10 & 5 \\
\hline 23 & 1.0 & 0 & 0 & 0 & 7 & 3 \\
\hline 24 & 1.0 & 0 & -13 & 0 & 0 & 0 \\
\hline 25 & 1.0 & 0 & 220 & 0 & 0 & 0 \\
\hline 26 & 1.0 & 0 & 314 & 0 & 0 & 0 \\
\hline 27 & 1.0 & 0 & -9 & 0 & 62 & 13 \\
\hline 28 & 1.0 & 0 & 0 & 0 & 17 & 7 \\
\hline 29 & 1.0 & 0 & 0 & 0 & 24 & 4 \\
\hline 30 & 1.0 & 0 & 0 & 0 & 0 & 0 \\
\hline 31 & 1.0 & 0 & 7 & 0 & 43 & 27 \\
\hline 32 & 1.0 & 0 & 0 & 0 & 59 & 23 \\
\hline 33 & 1.0 & 0 & 0 & 0 & 23 & 9 \\
\hline 34 & 1.0 & 0 & 0 & 0 & 59 & 26 \\
\hline 35 & 1.0 & 0 & 0 & 0 & 33 & 9 \\
\hline 36 & 1.0 & 0 & 0 & 0 & 31 & 17 \\
\hline 37 & 1.0 & 0 & 0 & 0 & 0 & 0 \\
\hline 38 & 1.0 & 0 & 0 & 0 & 0 & 0 \\
\hline 39 & 1.0 & 0 & 0 & 0 & 27 & 11 \\
\hline 40 & 1.0 & 0 & -46 & 0 & 20 & 23 \\
\hline 41 & 1.0 & 0 & 0 & 0 & 37 & 10 \\
\hline 42 & 1.0 & 0 & -59 & 0 & 37 & 23 \\
\hline
\end{tabular}


TABLE F. 12: CONT'D

\begin{tabular}{|c|c|c|c|c|c|c|}
\hline \multirow{2}{*}{$\begin{array}{l}\text { Bus } \\
\text { Number }\end{array}$} & \multirow{2}{*}{$\begin{array}{l}\text { Starting } \\
\text { Mag. } \\
\text { p.u. }\end{array}$} & \multirow{2}{*}{$\begin{array}{c}\text { Bus Voltage } \\
\text { Angle } \\
\text { Deg. } \\
\end{array}$} & \multicolumn{2}{|c|}{ Generation } & \multicolumn{2}{|c|}{ Load } \\
\hline & & & MW & MVAr & MW & MVAr \\
\hline 43 & 1.0 & 0 & 0 & 0 & 18 & 7 \\
\hline 44 & 1.0 & 0 & 0 & 0 & 16 & 8 \\
\hline 45 & 1.0 & 0 & 0 & 0 & 53 & 22 \\
\hline 46 & 1.0 & 0 & 19 & 0 & 28 & 10 \\
\hline 47 & 1.0 & 0 & 0 & 0 & 34 & 0 \\
\hline 48 & 1.0 & 0 & 0 & 0 & 20 & 11 \\
\hline 49 & 1.0 & 0 & 204 & 0 & 87 & 30 \\
\hline 50 & 1.0 & 0 & 0 & 0 & 17 & 1 \\
\hline 51 & 1.0 & 0 & 0 & 0 & 17 & 8 \\
\hline 52 & 1.0 & 0 & 0 & 0 & 18 & 5 \\
\hline 53 & 1.0 & 0 & 0 & 0 & 23 & 11 \\
\hline 54 & 1.0 & 0 & 48 & 0 & 113 & 32 \\
\hline 55 & 1.0 & 0 & 0 & 0 & 63 & 22 \\
\hline 56 & 1.0 & 0 & 0 & 0 & 84 & 18 \\
\hline 57 & 1.0 & 0 & 0 & 0 & 12 & 3 \\
\hline 58 & 1.0 & 0 & 0 & 0 & 12 & 3 \\
\hline 59 & 1.0 & 0 & 155 & 0 & 277 & 113 \\
\hline 60 & 1.0 & 0 & 0 & 0 & 78 & 3 \\
\hline 61 & 1.0 & 0 & 160 & 0 & 0 & 0 \\
\hline 62 & 1.0 & 0 & 0 & 0 & 77 & 14 \\
\hline 63 & 1.0 & 0 & 0 & 0 & 0 & 0 \\
\hline 64 & 1.0 & 0 & 0 & 0 & 0 & 0 \\
\hline 65 & 1.0 & 0 & 391 & 0 & 0 & 0 \\
\hline 66 & 1.0 & 0 & 392 & 0 & 39 & 18 \\
\hline 67 & 1.0 & 0 & 0 & 0 & 28 & 7 \\
\hline 68 & 1.0 & 0 & 0 & 0 & 0 & 0 \\
\hline 118 & 1.035 & 30 & 516.4 & 0 & 0 & 0 \\
\hline 70 & 1.0 & 0 & 0 & 0 & 66 & 20 \\
\hline 71 & 1.0 & 0 & 0 & 0 & 0 & 0 \\
\hline 72 & 1.0 & 0 & -12 & 0 & 0 & 0 \\
\hline 73 & 1.0 & 0 & -6 & 0 & 0 & 0 \\
\hline 74 & 1.0 & 0 & 0 & 0 & 68 & 27 \\
\hline 75 & 1.0 & 0 & 0 & 0 & 47 & 11 \\
\hline 76 & 1.0 & 0 & 0 & 0 & 68 & 36 \\
\hline 77 & 1.0 & 0 & 0 & 0 & 61 & 28 \\
\hline 78 & 1.0 & 0 & 0 & 0 & 71 & 26 \\
\hline 79 & 1.0 & 0 & 0 & 0 & 39 & 32 \\
\hline 80 & 1.0 & 0 & 477 & 0 & 130 & 26 \\
\hline 81 & 1.0 & 0 & 0 & 0 & 0 & 0 \\
\hline 82 & 1.0 & 0 & 0 & 0 & 54 & 27 \\
\hline 83 & 1.0 & 0 & 0 & 0 & 20 & 10 \\
\hline 84 & 1.0 & 0 & 0 & 0 & 11 & 7 \\
\hline 85 & 1.0 & 0 & 0 & 0 & 24 & 15 \\
\hline 86 & 1.0 & 0 & 0 & 0 & 21 & 10 \\
\hline
\end{tabular}


TABLE F. 12: CONT'D

\begin{tabular}{|c|c|c|c|c|c|c|}
\hline \multirow[b]{2}{*}{$\begin{array}{l}\text { Bus } \\
\text { Number }\end{array}$} & \multirow{2}{*}{$\begin{array}{l}\text { Starting } \\
\text { Mag. } \\
\text { p.u. }\end{array}$} & \multirow{2}{*}{$\begin{array}{c}\text { Bus Voltage } \\
\text { Angle } \\
\text { Deg. }\end{array}$} & \multicolumn{2}{|c|}{ Generation } & \multicolumn{2}{|c|}{ Load } \\
\hline & & & MW & Mvar & MW & Mvar \\
\hline 87 & 1.0 & 0 & 4 & 0 & 0 & 0 \\
\hline 88 & 1.0 & 0 & 0 & 0 & 48 & 10 \\
\hline 89 & 1.0 & 0 & 607 & 0 & 0 & 0 \\
\hline 90 & 1.0 & 0 & -85 & 0 & 78 & 42 \\
\hline 91 & 1.0 & 0 & -10 & 0 & 0 & 0 \\
\hline 92 & 1.0 & 0 & 0 & 0 & 65 & 10 \\
\hline 93 & 1.0 & 0 & 0 & 0 & 12 & 7 \\
\hline 94 & 1.0 & 0 & 0 & 0 & 30 & 16 \\
\hline 95 & 1.0 & 0 & 0 & 0 & 42 & 31 \\
\hline 96 & 1.0 & 0 & 0 & 0 & 38 & 15 \\
\hline 97 & 1.0 & 0 & 0 & 0 & 15 & 9 \\
\hline 98 & 1.0 & 0 & 0 & 0 & 34 & 8 \\
\hline 99 & 1.0 & 0 & -42 & 0 & 0 & 0 \\
\hline 100 & 1.0 & 0 & 252 & 0 & 37 & 18 \\
\hline 101 & 1.0 & 0 & 0 & 0 & 22 & 15 \\
\hline 102 & 1.0 & 0 & 0 & 0 & 5 & 3 \\
\hline 103 & 1.0 & 0 & 40 & 0 & 23 & 16 \\
\hline 104 & 1.0 & 0 & 0 & 0 & 38 & 25 \\
\hline 105 & 1.0 & 0 & 0 & 0 & 31 & 26 \\
\hline 106 & 1.0 & 0 & 0 & 0 & 43 & 16 \\
\hline 107 & 1.0 & 0 & -22 & 0 & 28 & 12 \\
\hline 108 & 1.0 & 0 & 0 & 0 & 2 & 1 \\
\hline 109 & 1.0 & 0 & 0 & 0 & 8 & 3 \\
\hline 110 & 1.0 & 0 & 0 & 0 & 39 & 30 \\
\hline 111 & 1.0 & 0 & 36 & 0 & 0 & 0 \\
\hline 112 & 1.0 & 0 & -43 & 0 & 25 & 13 \\
\hline 113 & 1.0 & 0 & -6 & 0 & 0 & 0 \\
\hline 114 & 1.0 & 0 & 0 & 0 & 8 & 3 \\
\hline 115 & 1.0 & 0 & 0 & 0 & 22 & 7 \\
\hline 116 & 1.0 & 0 & -184 & 0 & 0 & 0 \\
\hline 117 & 1.0 & 0 & 0 & 0 & 20 & 8 \\
\hline 69 & 1.0 & 0 & 0 & 0 & 33 & 15 \\
\hline
\end{tabular}

* Swing Machine 
TABLE F.13: Regulated Bus Data For the IEEE 118-Bus Test System

\begin{tabular}{|c|c|c|c|}
\hline $\begin{array}{l}\text { Bux } \\
\text { Number }\end{array}$ & $\begin{array}{c}\text { Voltage Magnitude } \\
\text { Per Unit }\end{array}$ & $\begin{array}{l}\text { Minimum } \\
\text { Mvar Capability }\end{array}$ & $\begin{array}{l}\text { Maximum } \\
\text { Mvar Capability }\end{array}$ \\
\hline 1 & .955 & -5 & 15 \\
\hline 4 & .998 & -300 & 300 \\
\hline 6 & .99 & -13 & 50 \\
\hline 8 & 1.015 & -300 & 300 \\
\hline 10 & 1.05 & -147 & 200 \\
\hline 12 & .99 & -35 & 120 \\
\hline 15 & .97 & -10 & 30 \\
\hline 18 & .973 & -16 & 50 \\
\hline 19 & .962 & -8 & 24 \\
\hline 24 & . 992 & -300 & 300 \\
\hline 25 & 1.05 & -47 & 140 \\
\hline 26 & 1.015 & -1000 & 1000 \\
\hline 27 & .968 & -300 & 300 \\
\hline 31 & .967 & -300 & 300 \\
\hline 32 & .963 & -14 & 42 \\
\hline 34 & .984 & -8 & 24 \\
\hline 36 & .98 & -8 & 24 \\
\hline 40 & .97 & -300 & 300 \\
\hline 42 & .985 & -300 & 300 \\
\hline 46 & 1.005 & -100 & 100 \\
\hline 49 & 1.025 & -85 & 210 \\
\hline 54 & .955 & -300 & 300 \\
\hline 55 & .952 & -8 & 23 \\
\hline 56 & .954 & -8 & 15 \\
\hline 59 & .985 & -60 & 180 \\
\hline 61 & .995 & -100 & 300 \\
\hline 62 & . 998 & -20 & 20 \\
\hline 65 & 1.005 & -67 & 200 \\
\hline 66 & 1.05 & -67 & 200 \\
\hline 70 & .984 & -10 & 32 \\
\hline 72 & .98 & -100 & 100 \\
\hline 73 & .991 & -100 & 100 \\
\hline 74 & .958 & -6 & 9 \\
\hline 76 & .943 & -8 & 23 \\
\hline 77 & 1.006 & -20 & 70 \\
\hline 80 & 1.04 & -165 & 280 \\
\hline 85 & .985 & -8 & 23 \\
\hline 87 & 1.015 & -100 & 1000 \\
\hline 89 & 1.005 & -210 & 300 \\
\hline 90 & .985 & -300 & 300 \\
\hline 91 & .98 & -100 & 100 \\
\hline 92 & .99 & -3 & 9 \\
\hline 99 & 1.01 & -100 & 100 \\
\hline
\end{tabular}


TABLE F. 13: CONT'D

\begin{tabular}{lccc}
\hline $\begin{array}{l}\text { Bus } \\
\text { Number }\end{array}$ & $\begin{array}{c}\text { Voltage Magnitude } \\
\text { Per Unit }\end{array}$ & $\begin{array}{c}\text { Minimum } \\
\text { Mvar Capability }\end{array}$ & $\begin{array}{c}\text { Maximum } \\
\text { Mvar Capability }\end{array}$ \\
\hline 100 & 1.017 & -50 & 155 \\
103 & 1.01 & -15 & 40 \\
104 & .971 & -8 & 23 \\
105 & .965 & -8 & 23 \\
107 & .952 & -200 & 200 \\
110 & .973 & -8 & 23 \\
111 & .98 & -100 & 1000 \\
112 & .975 & -100 & 1000 \\
113 & .993 & -100 & 200 \\
116 & 1.005 & -1000 & 1000 \\
\hline
\end{tabular}


TABLE F.14: Transformer Data for the IEEE 118-Bus

Test System

\begin{tabular}{cc}
\hline TRANSFORMER & \\
DESIGNATION & TAP SETTING* \\
\hline $8-5$ & .985 \\
$26-25$ & .96 \\
$30-17$ & .96 \\
$38-37$ & .935 \\
$63-59$ & .96 \\
$64-61$ & .985 \\
$65-66$ & .935 \\
$68-69$ & .935 \\
$81-80$ & .935 \\
\hline
\end{tabular}

$*$

Off-nominal turns ratio, as determined by the actual transformer tap positions and the voltage bases. In the case of nominal turns ratio, this would equal 1.

TABLE F.15: Static Capacitor Data for the IEEE 118-Bus Test System

\begin{tabular}{cc}
$\begin{array}{c}\text { BUS } \\
\text { NUMBER }\end{array}$ & $\begin{array}{c}\text { SUSCEPTANCE } \\
\text { PER UNIT* }\end{array}$ \\
\cline { 2 - 2 } 17 & -.4 \\
34 & 0 \\
37 & .14 \\
44 & -.25 \\
45 & .1 \\
46 & .1 \\
48 & .1 \\
74 & .15 \\
79 & .12 \\
82 & .2 \\
83 & .2 \\
105 & .1 \\
107 & .2 \\
110 & .06 \\
\hline
\end{tabular}

* Susceptance in per unit on a 100,00-kva base 
APPENDIX G

MAXIMUM MISMATCHES DURING LOAD FLOWS 
TAELE GI: MAXIMUM PEF UNIT MISMATCHES AFTEO EACH ITERATION FOF THE 5-BUS SYSTEM

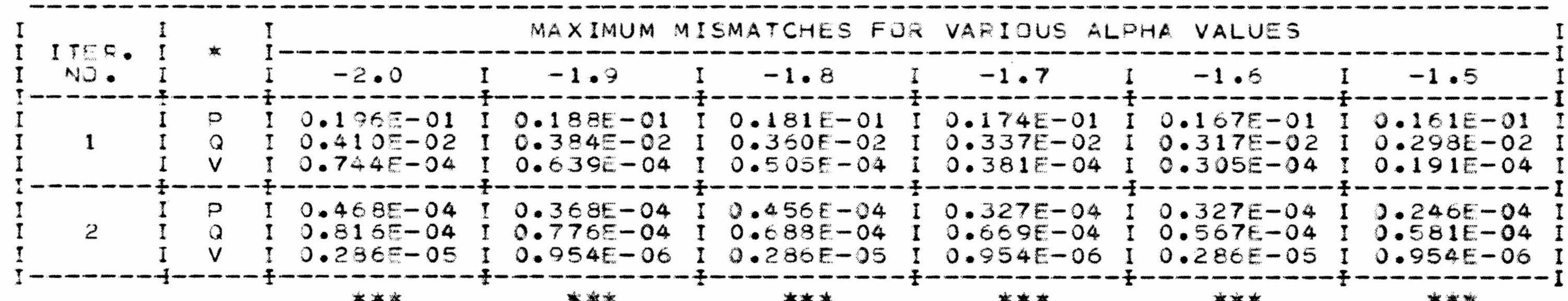

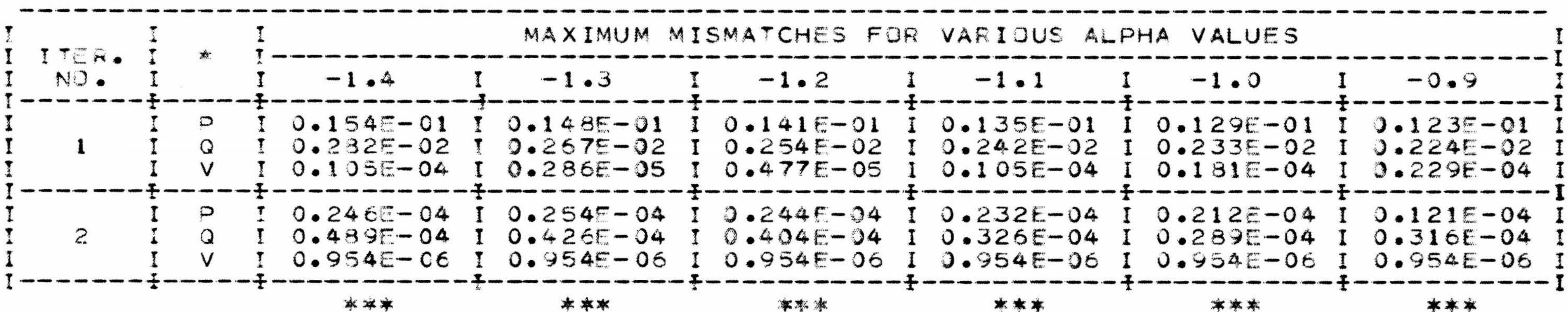

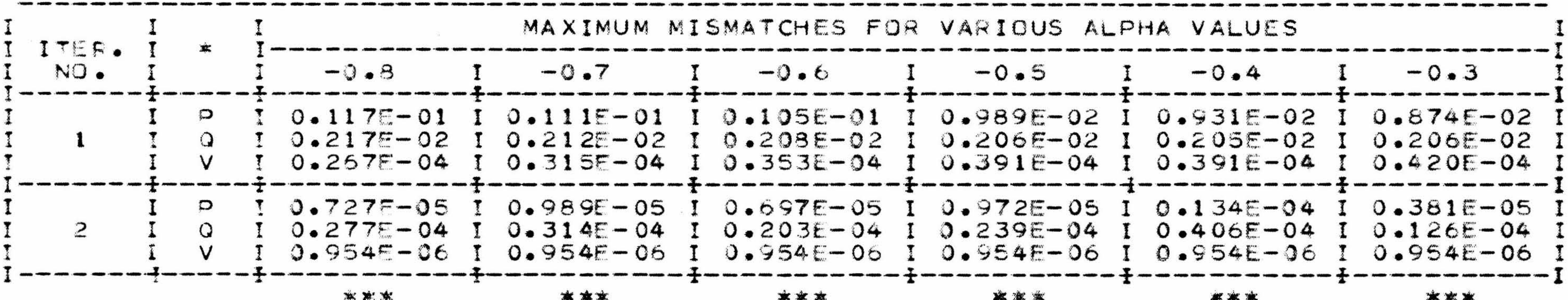




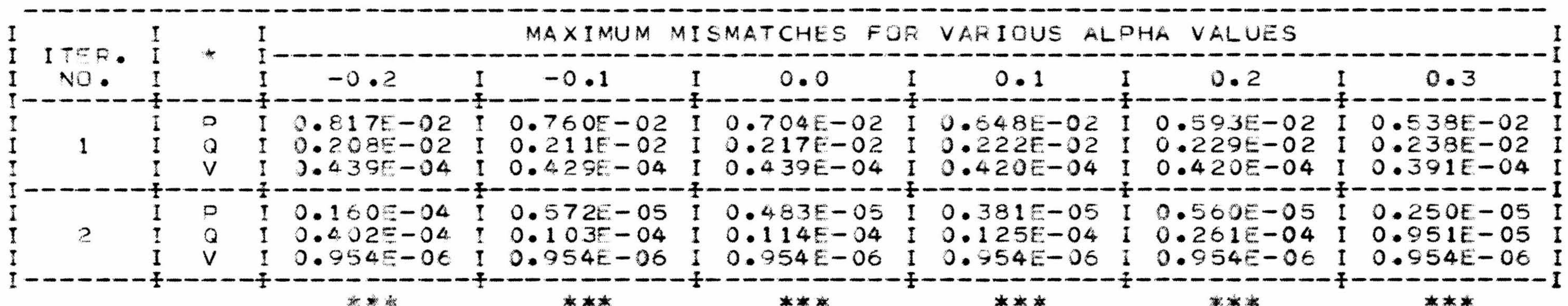

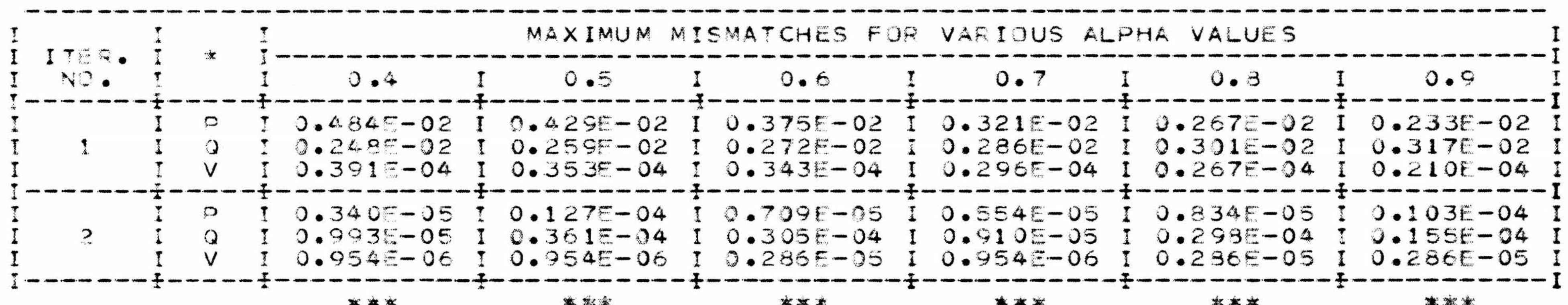

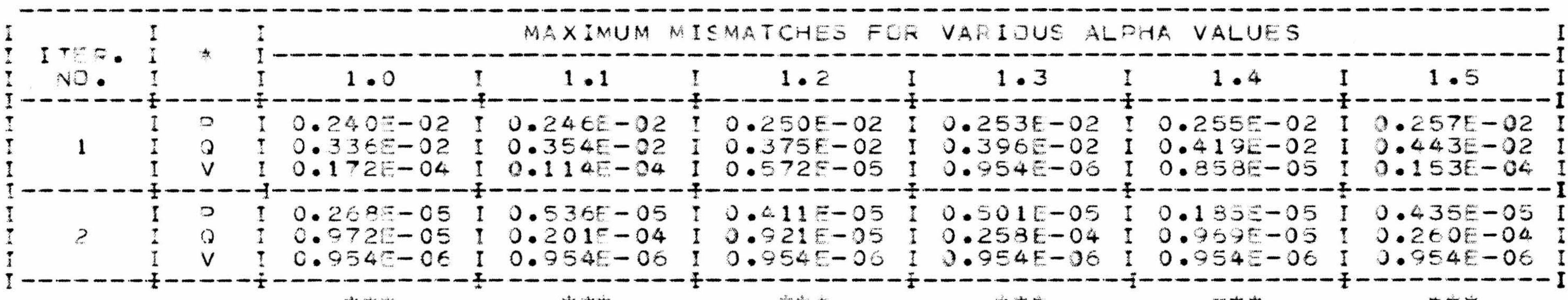




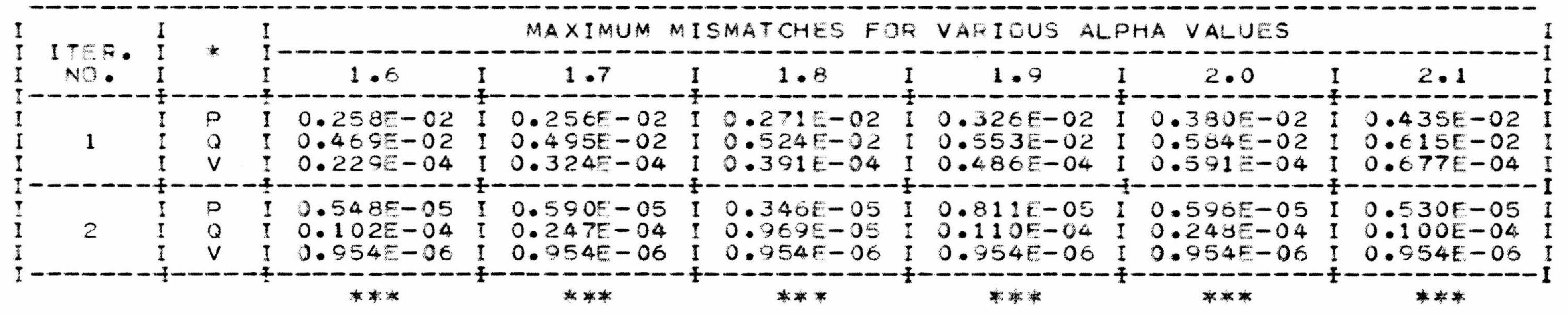


TABLE G2: MAXIMUM PER UNIT MISMATCHES AFTET EACH ITEOATION FOR THE $23-B U S$ SYSTEM

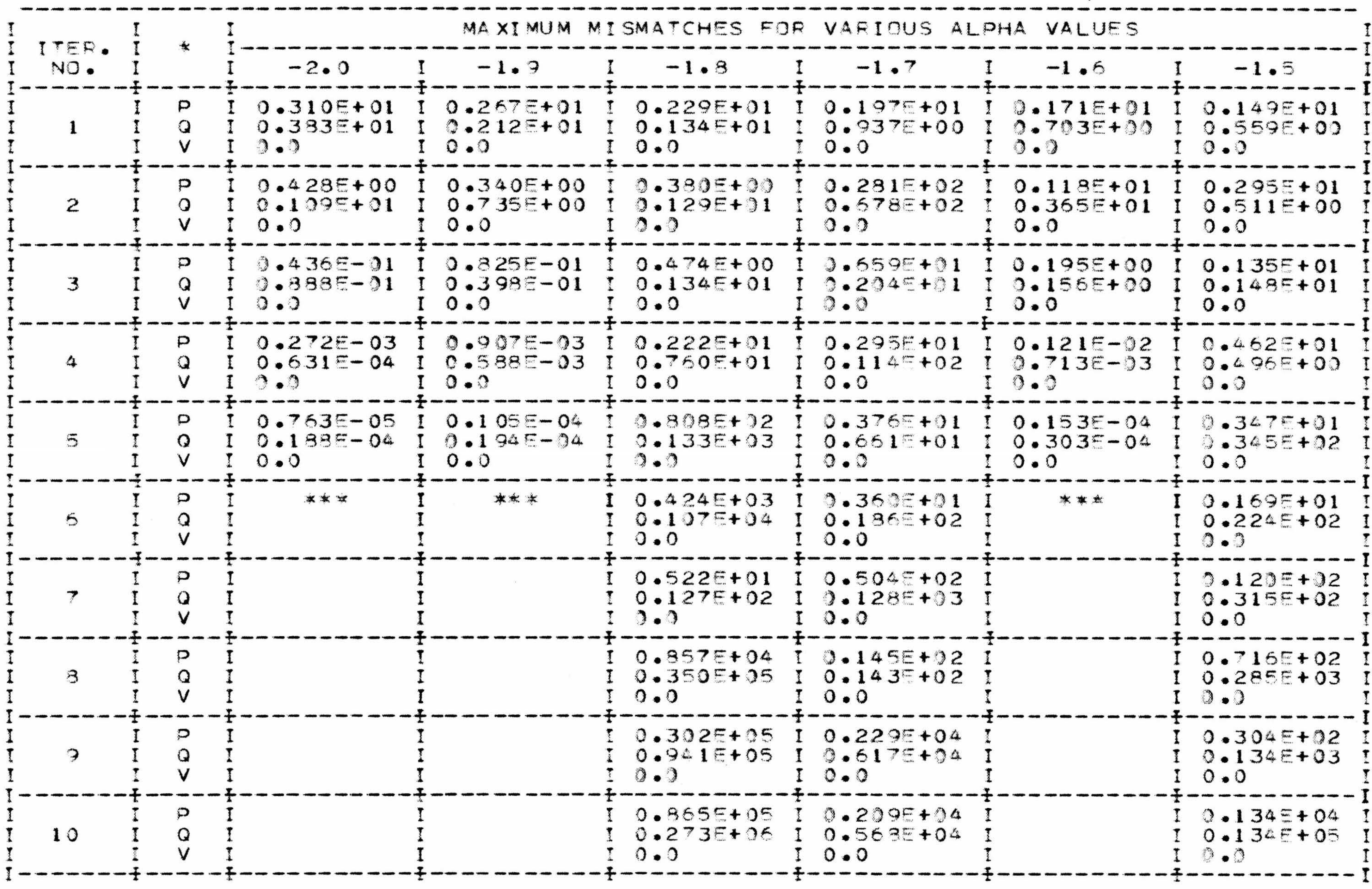



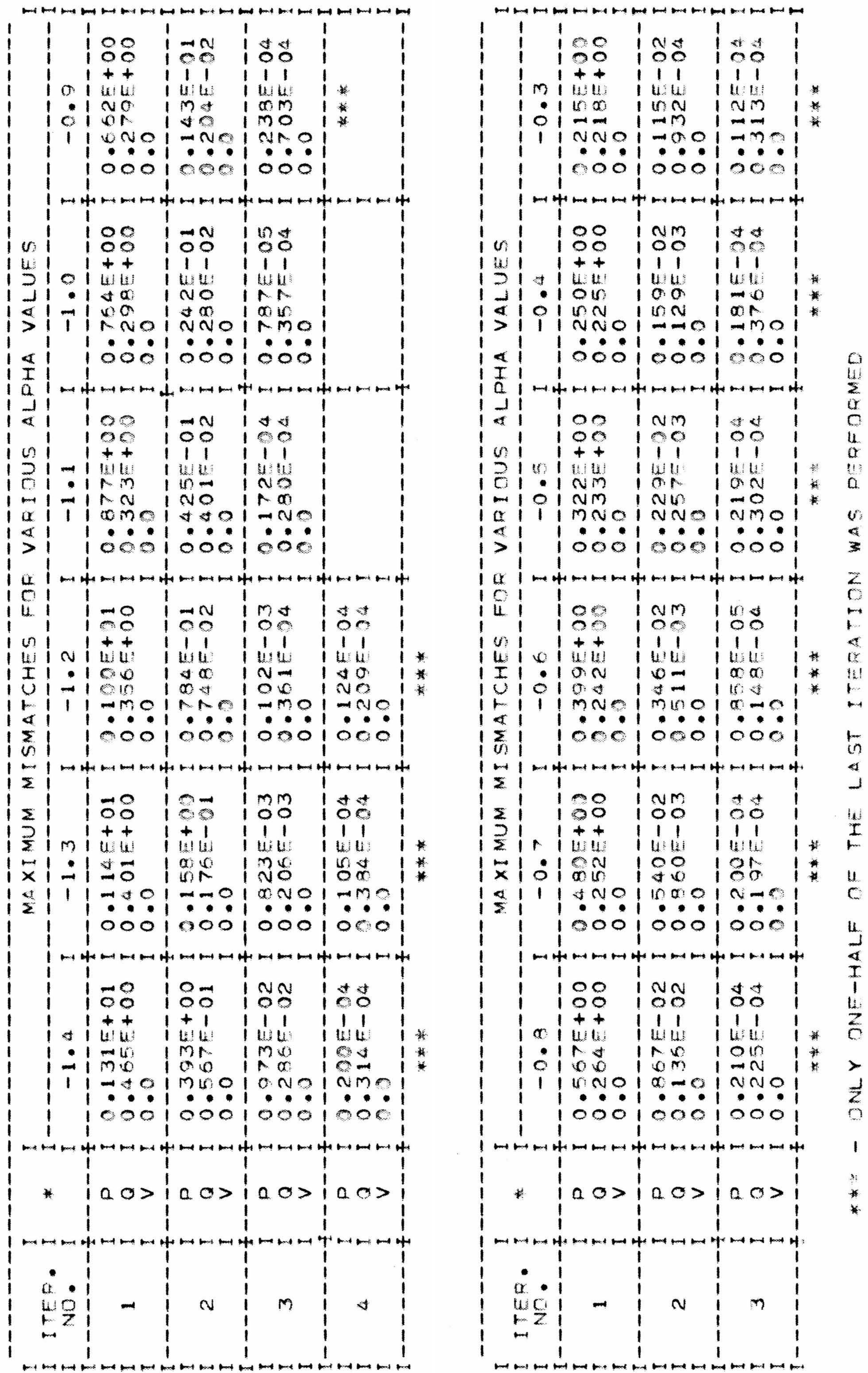


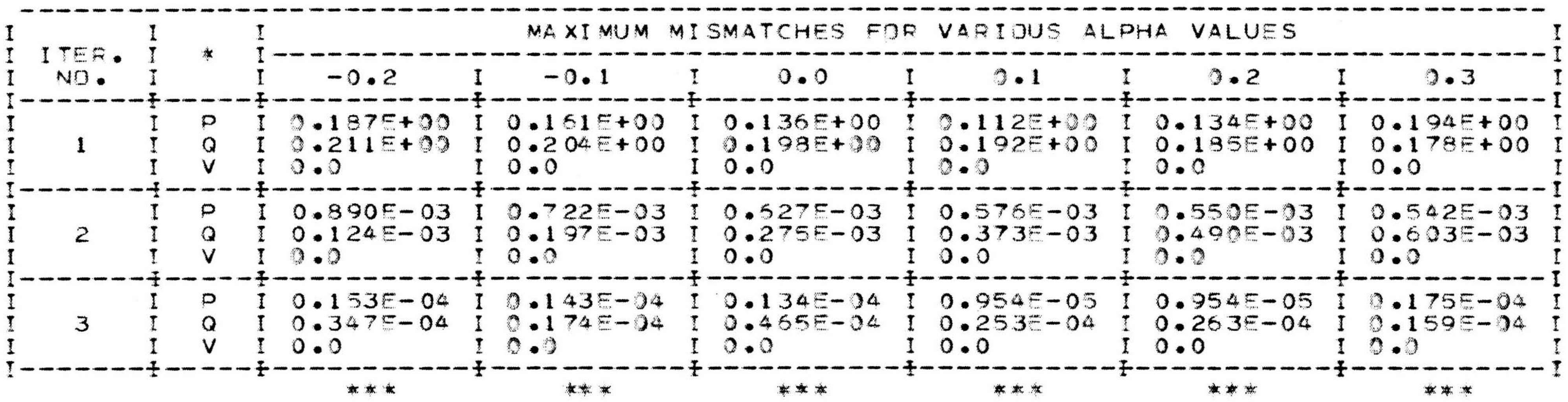

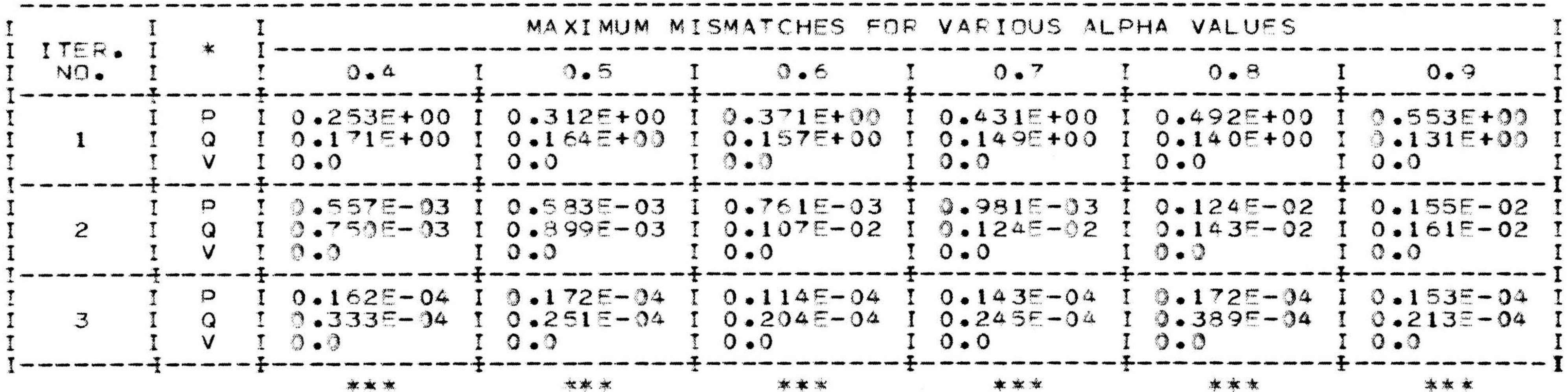

* * only one-half of the last iteration was performed 


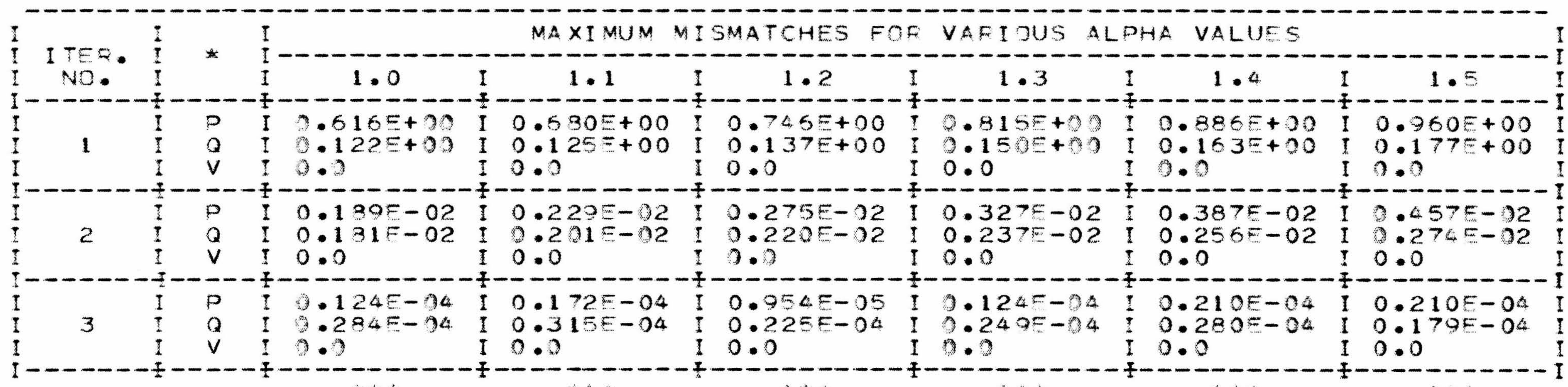

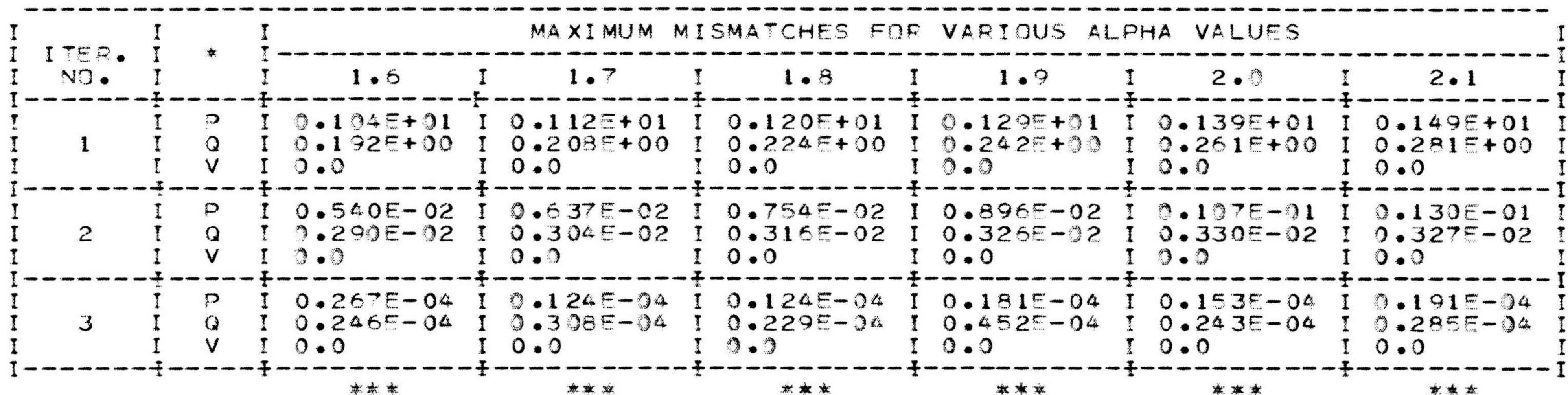

* - ONLY ONE-HALF OF THE LAST ITEOATION WAS PERFOAMED 


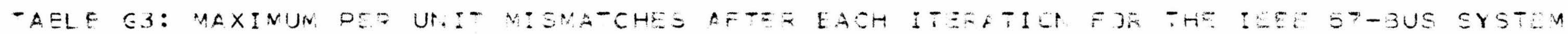

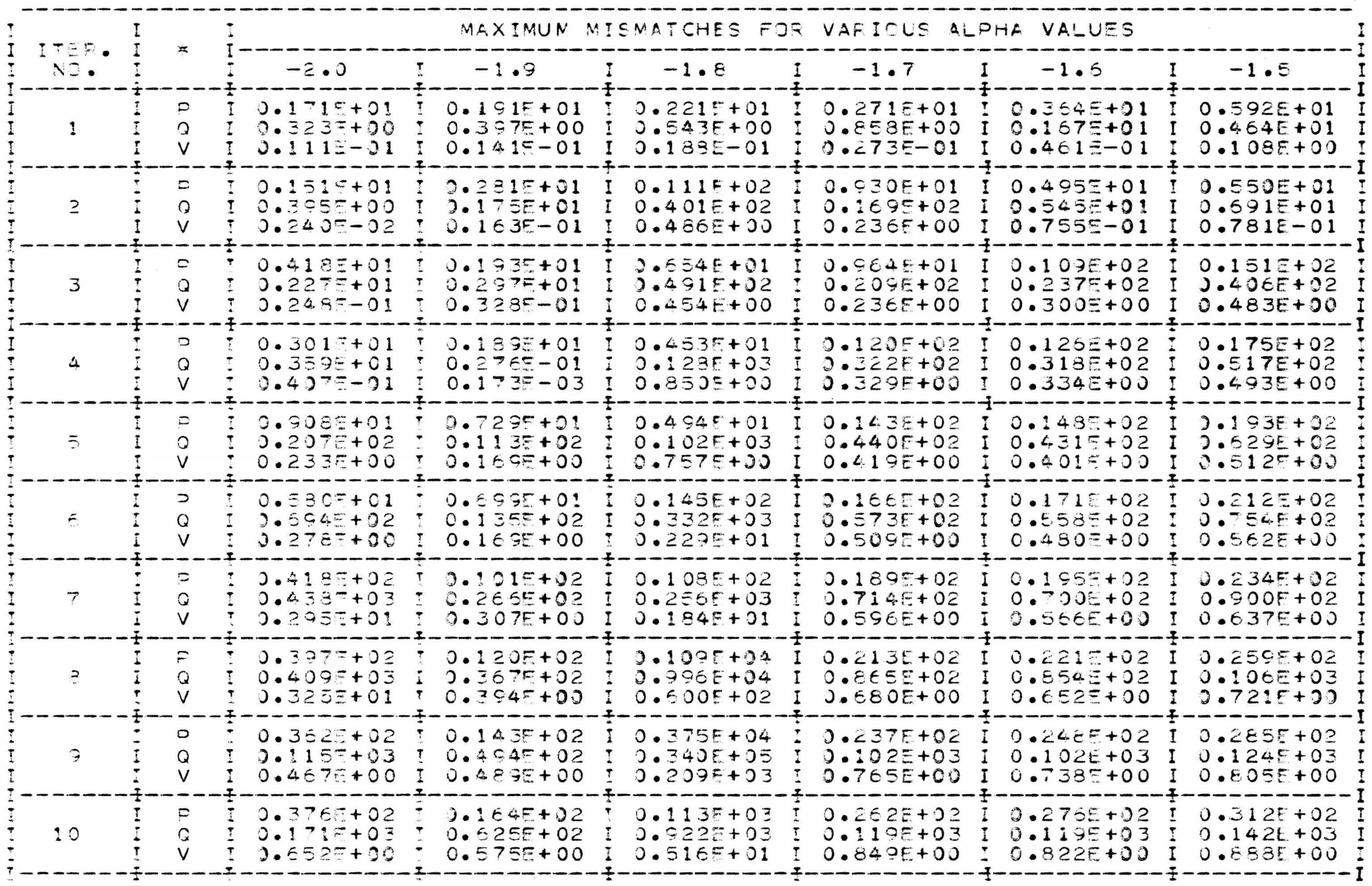




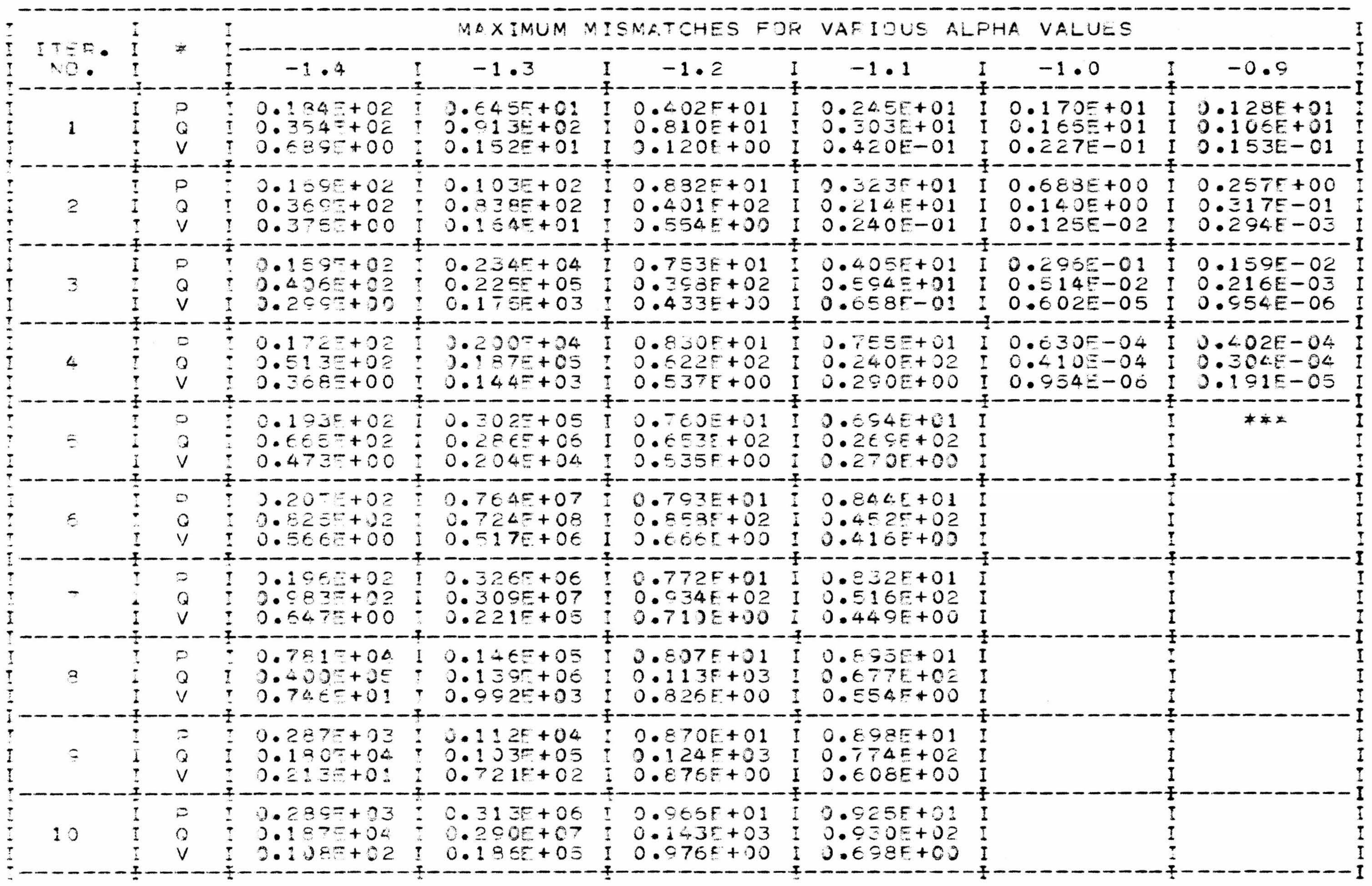




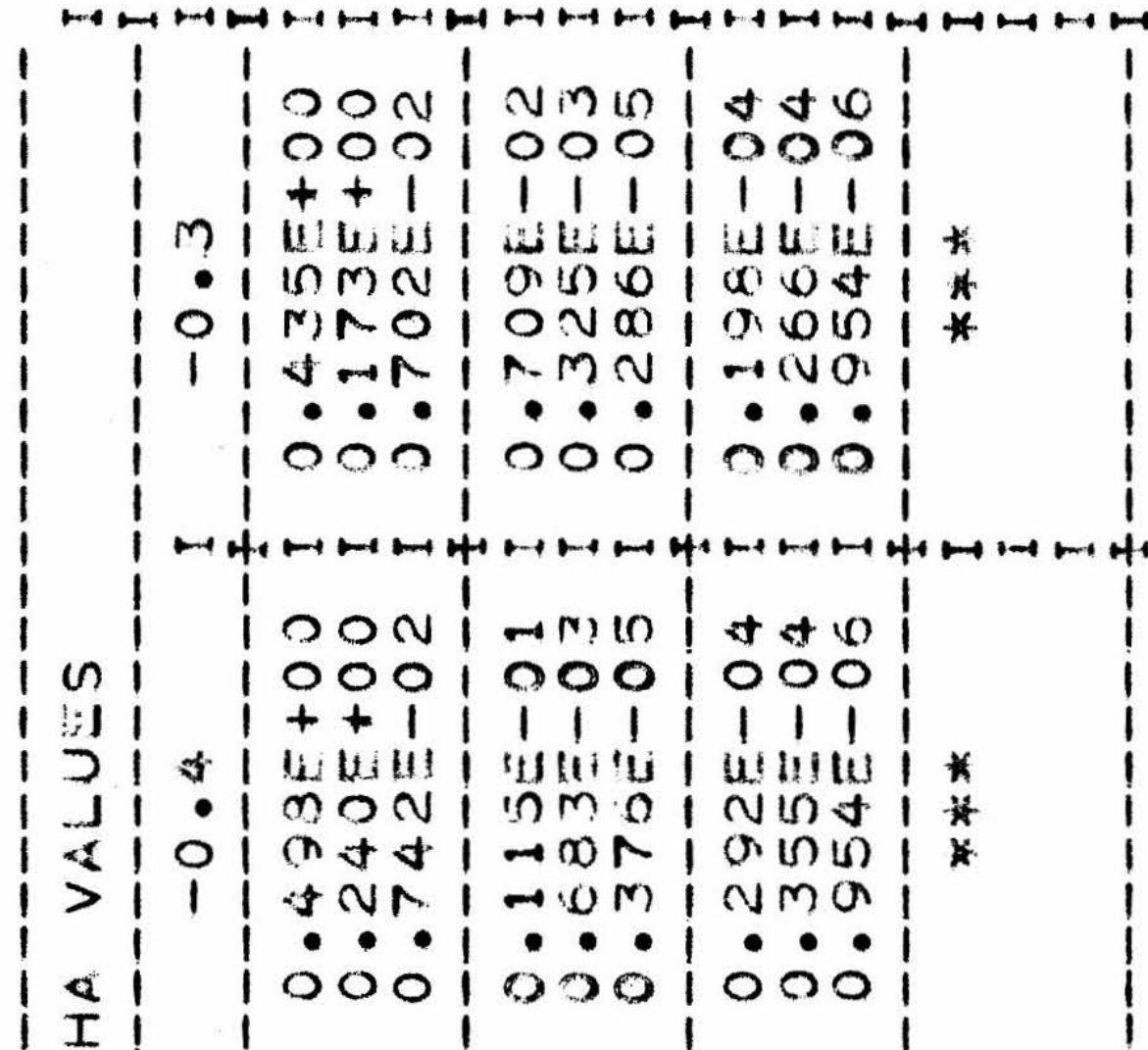

I I thet

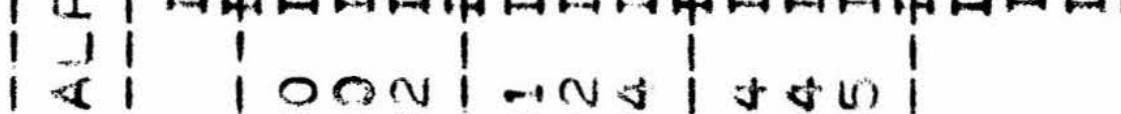

- 1000100010001

(v) $1++\begin{array}{llllllllll}1 & 1 & 1 & 1 & 1 & 1 & 1 & 1 & 1 & 1\end{array}$

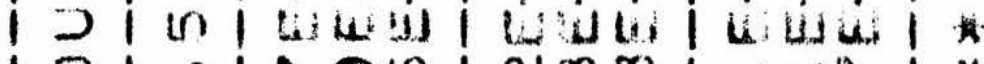

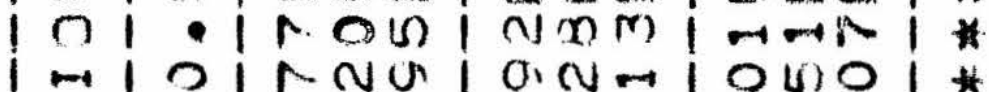

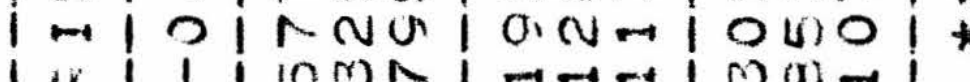

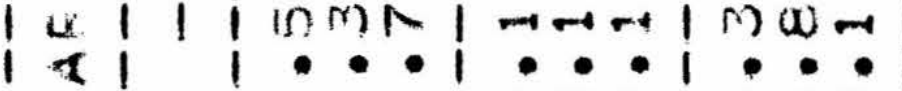

I I |ंक्षी

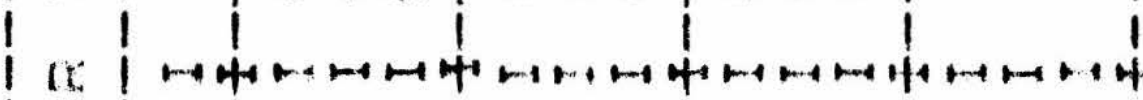

il $10021+2+1+\infty 01$

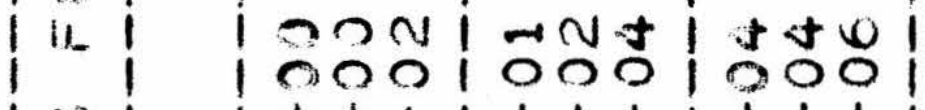

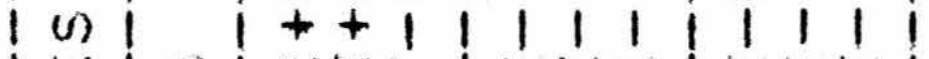

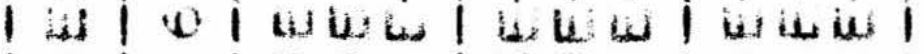

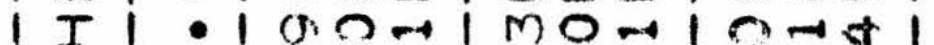

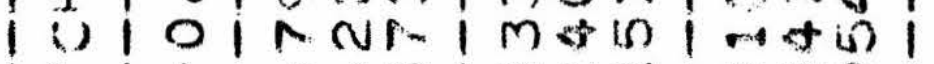

i- 1 |

I isil isi isi

$\sum_{i} \mid$ mo⿰亻

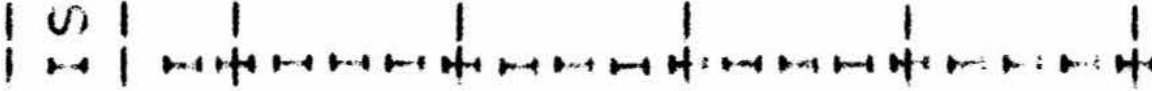

I I

2. 100010001000

$21 \quad \begin{array}{lllllllll}1++1 & 1 & 1 & 1 & 1 & 1 & 1 & 1 & 1\end{array}$

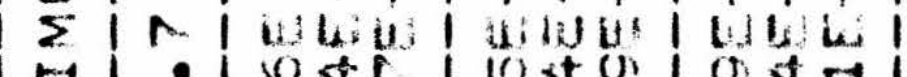

$\times 10|+\operatorname{los}| \tan \mid \rightarrow 00$ ।

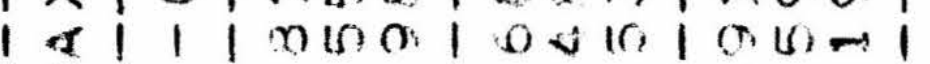

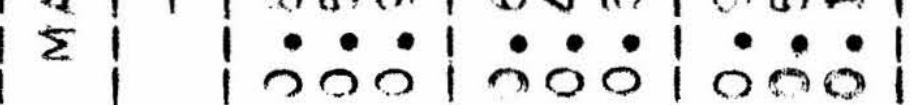

1 l

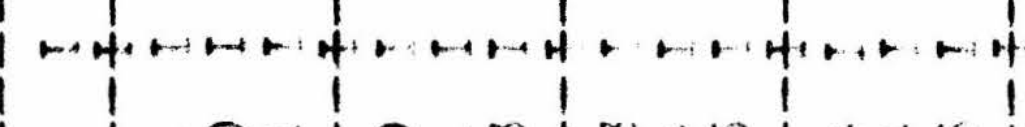

mon|

10001000100010001

$1++11+11111111111$

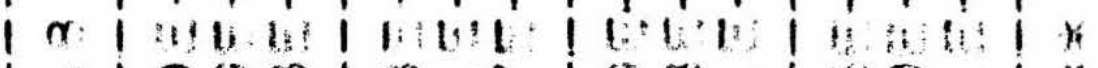

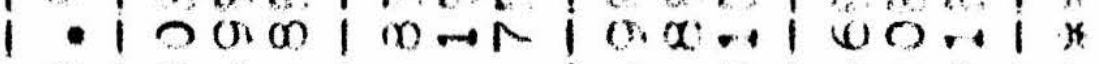

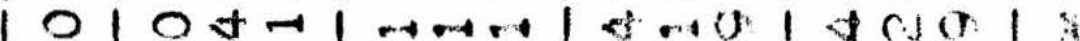

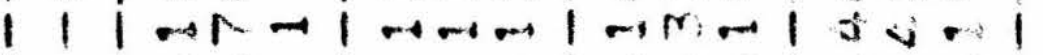
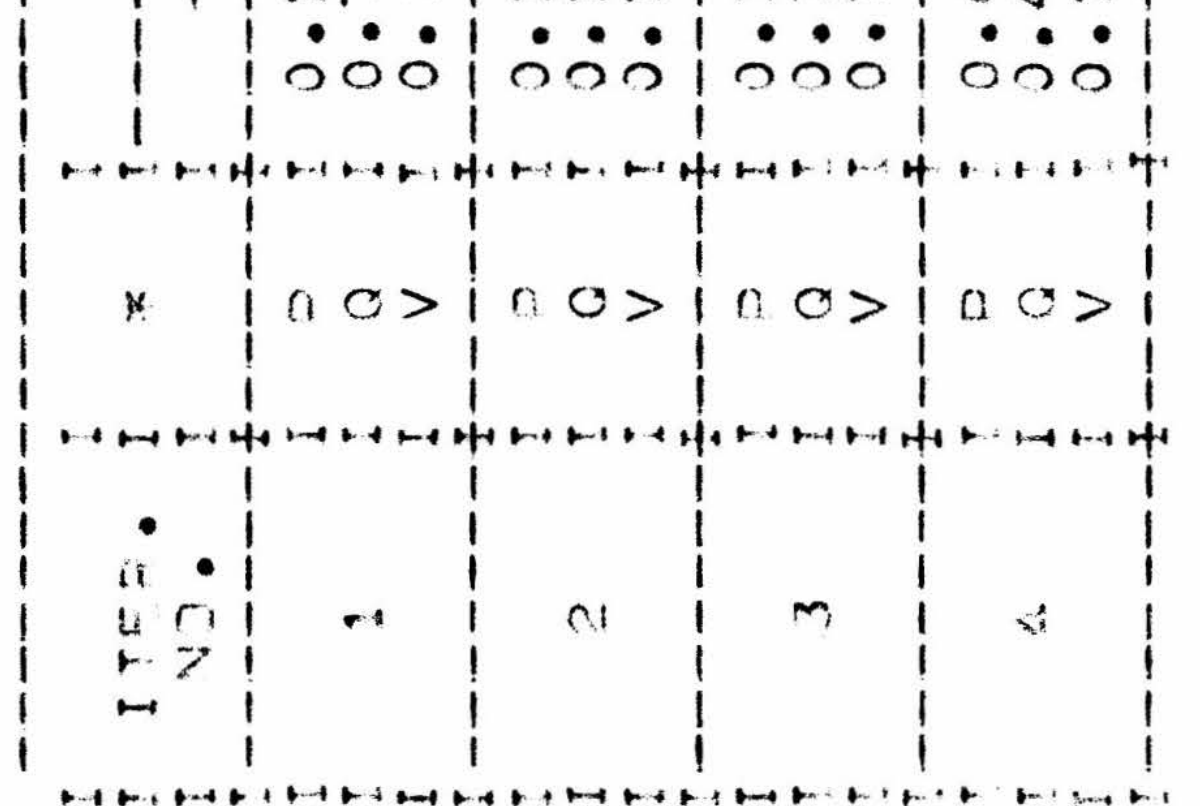

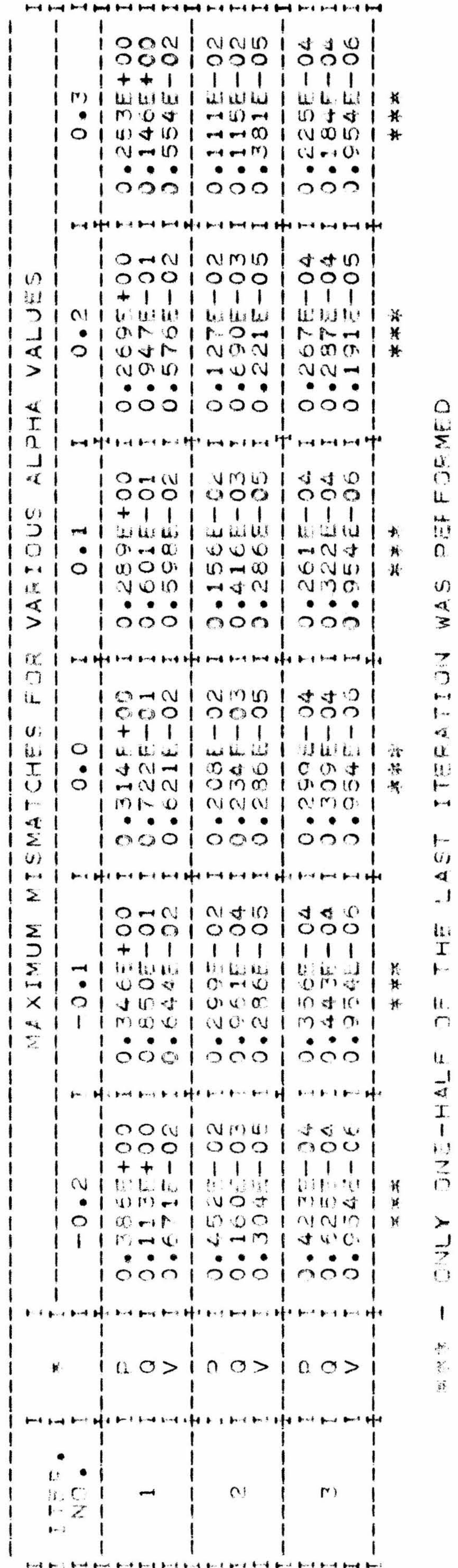




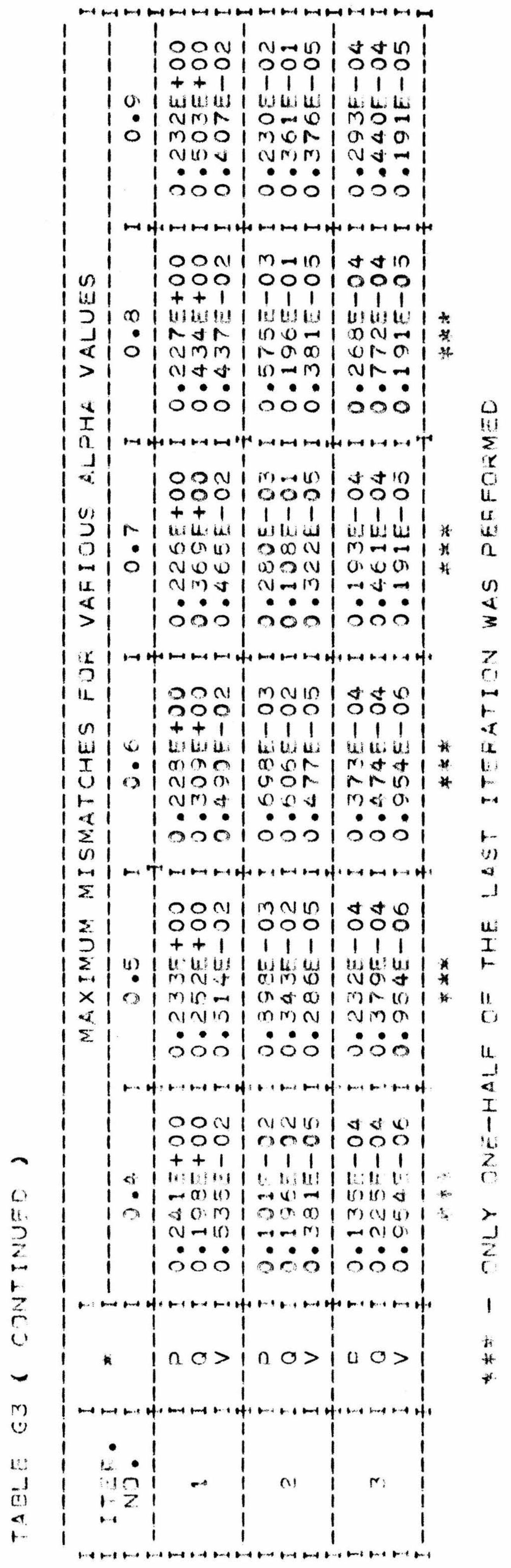


TEELE E ( CONTINUTO)

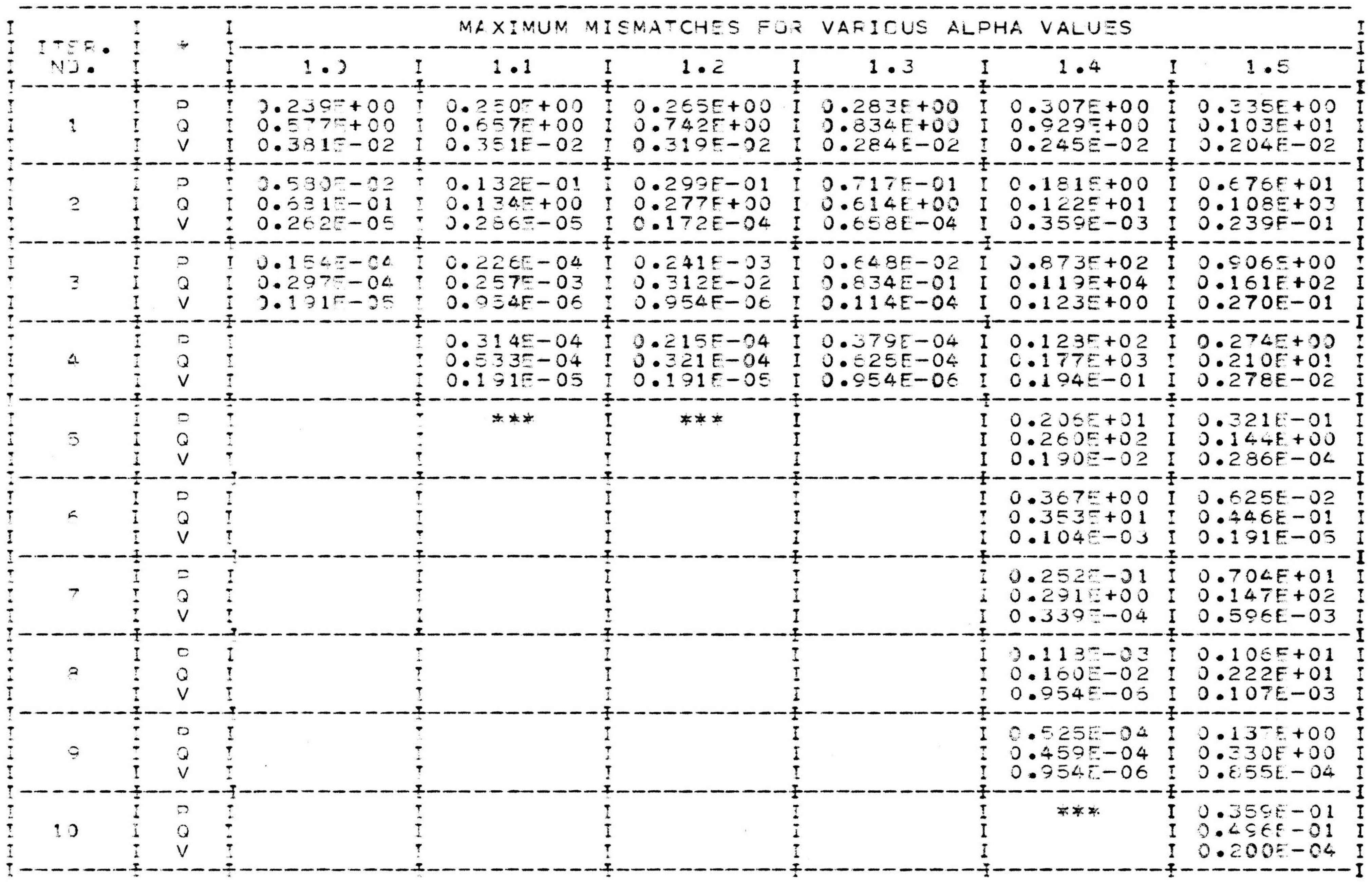




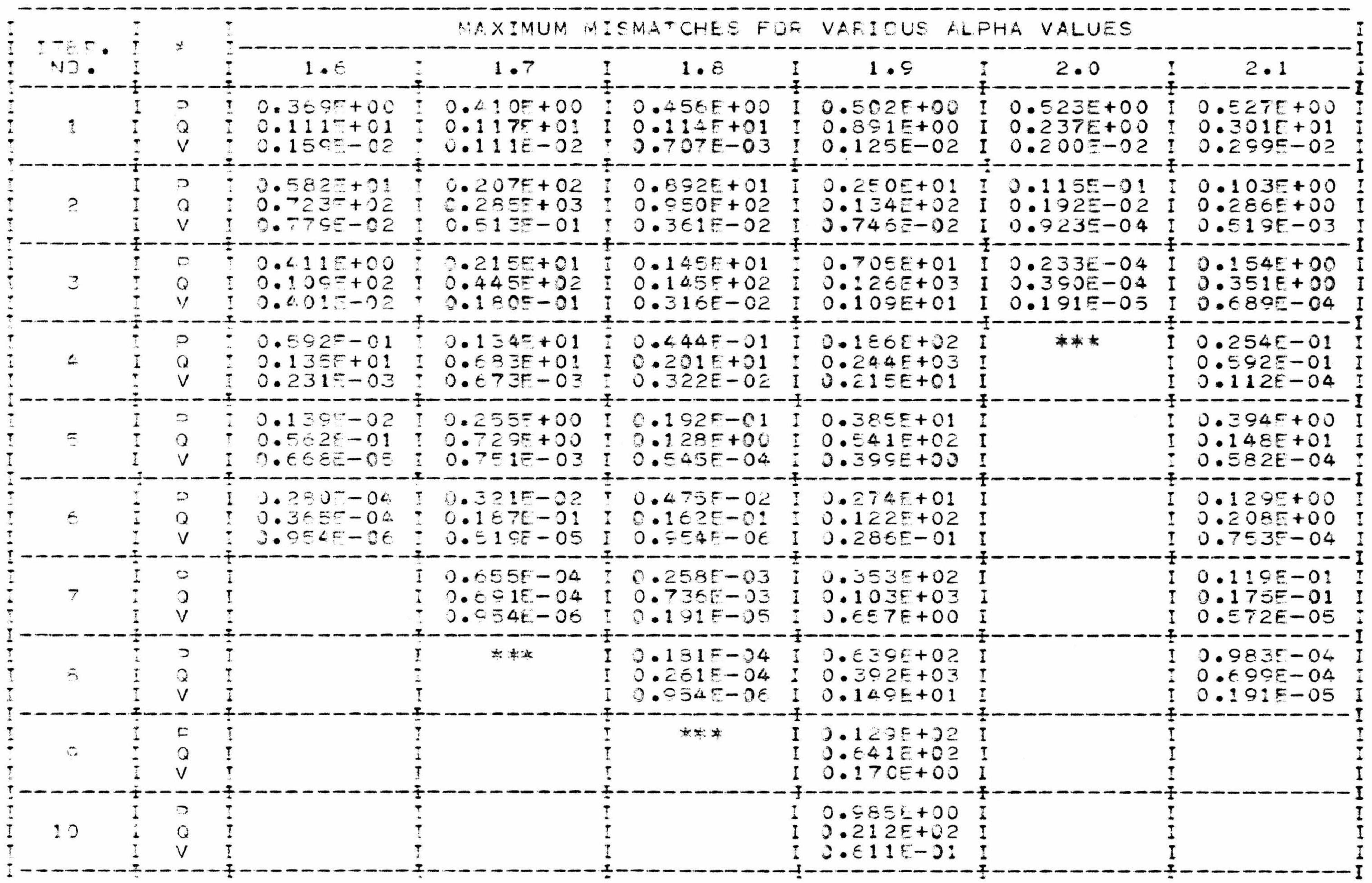




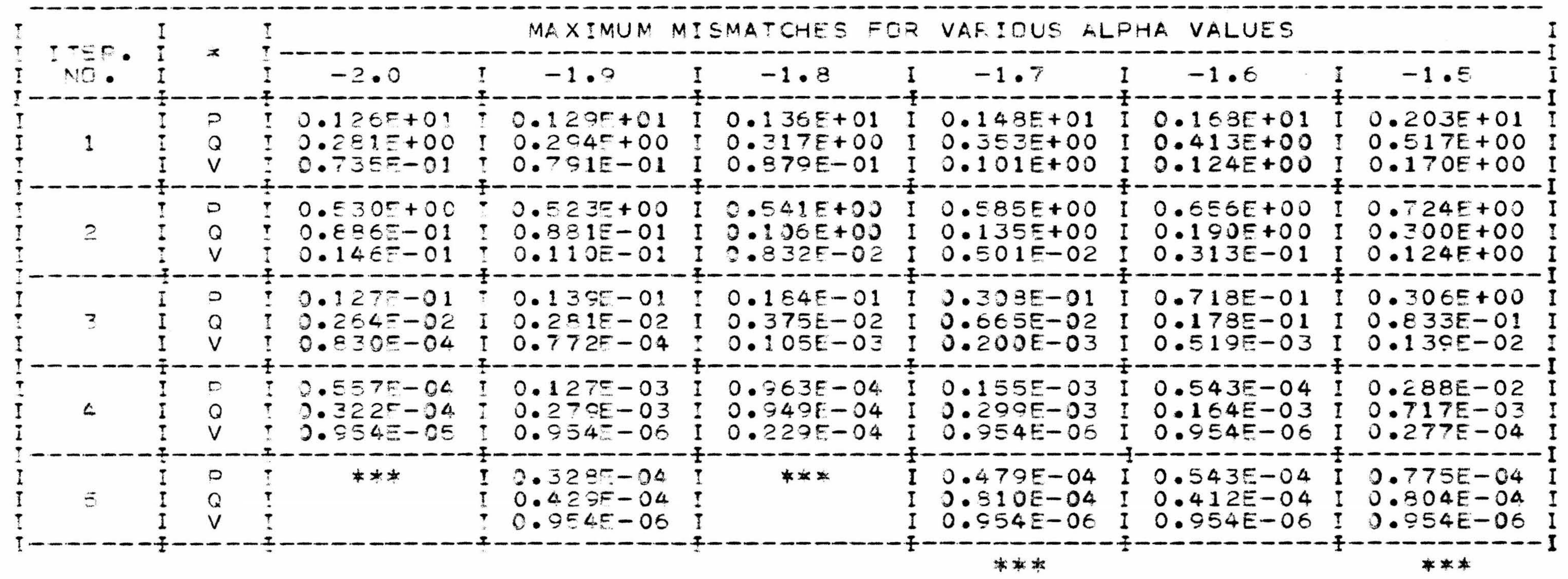

** - JWL ONE-HALF OF THE LACT ITEFATION WAS DEFFOFMEO 


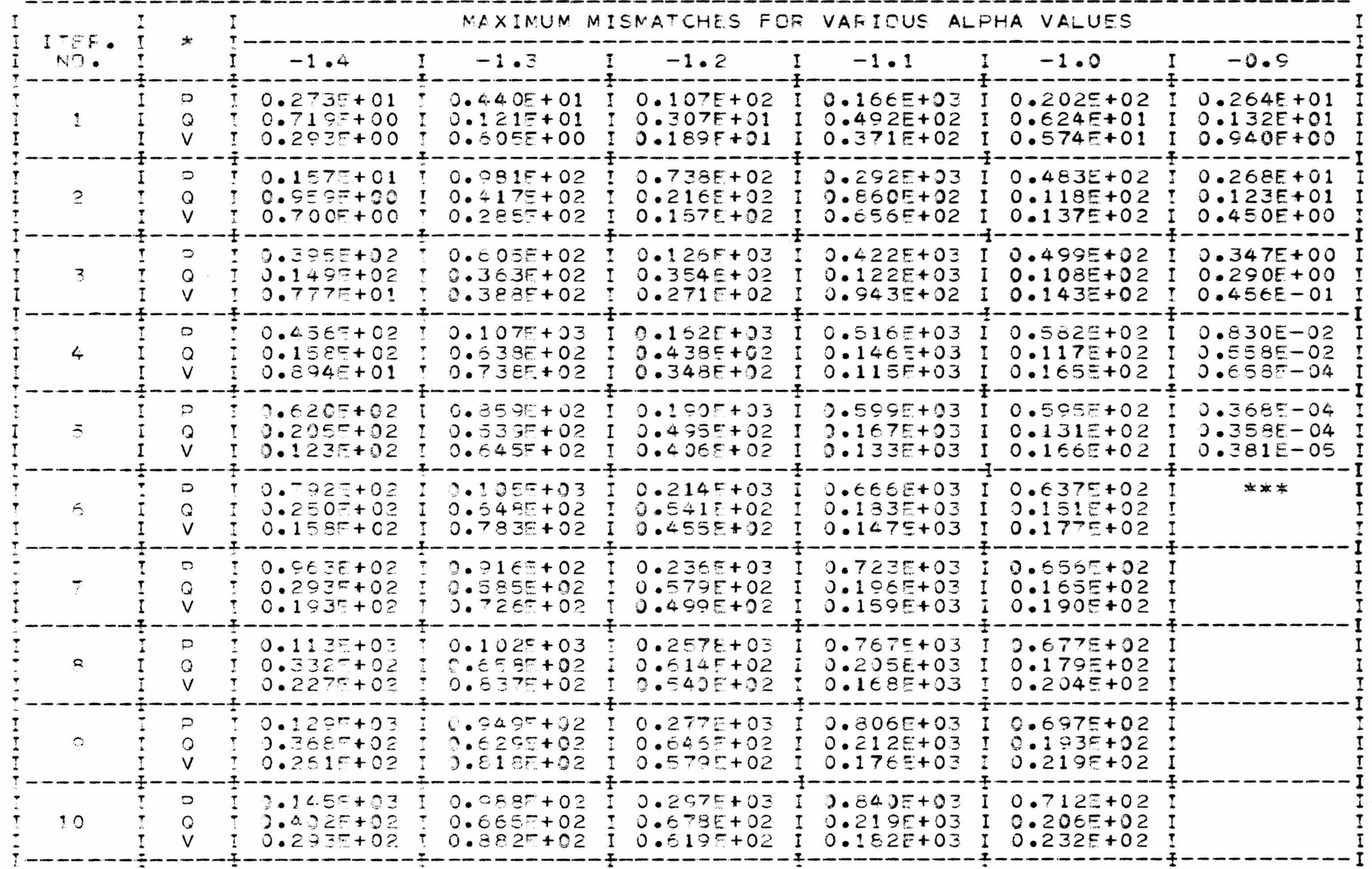


TABLE C4 ( CONTINUEO)

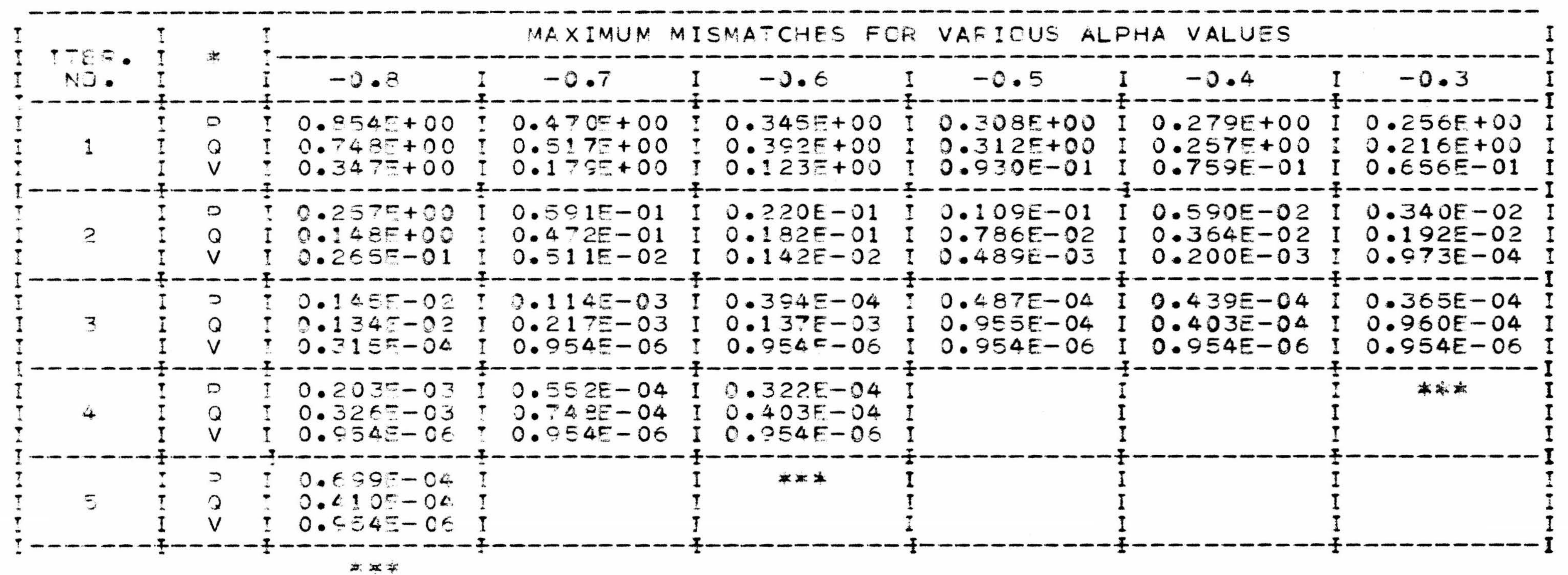

W: - JNLY ONE-HALF GF THE LAST ITERATION WAS FEEFJFMEC 


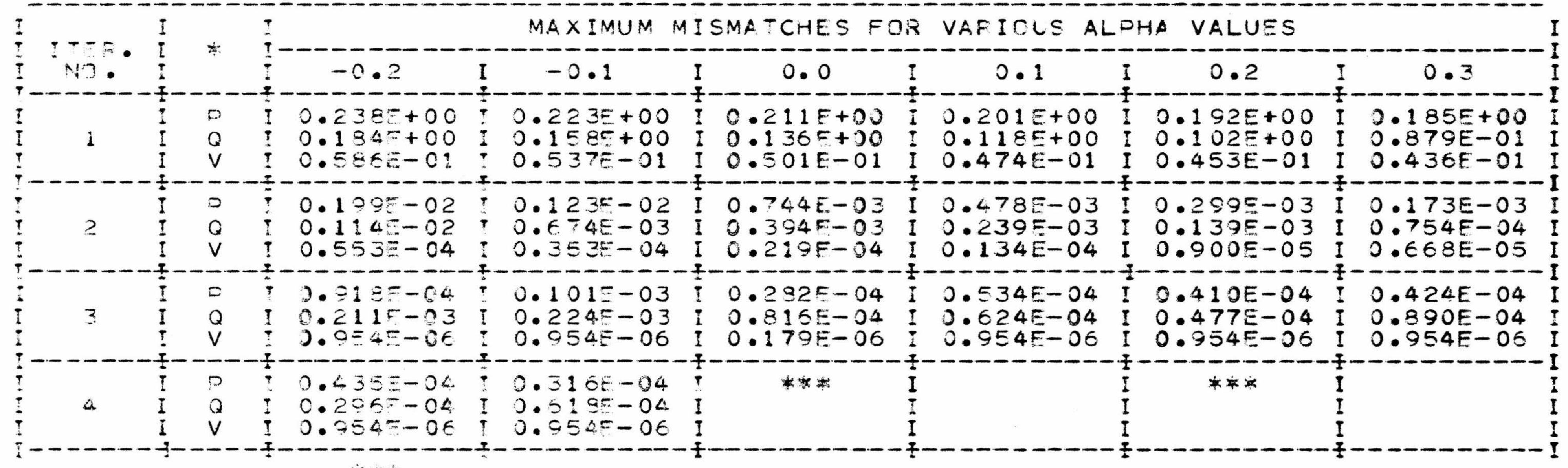
$\div x$

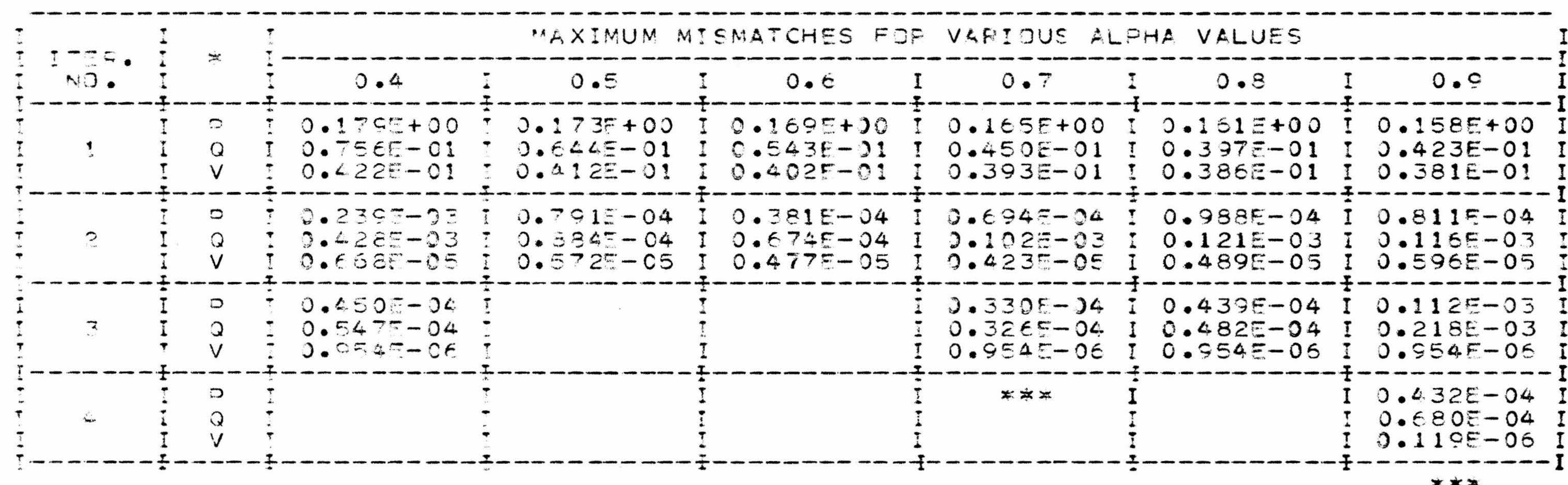




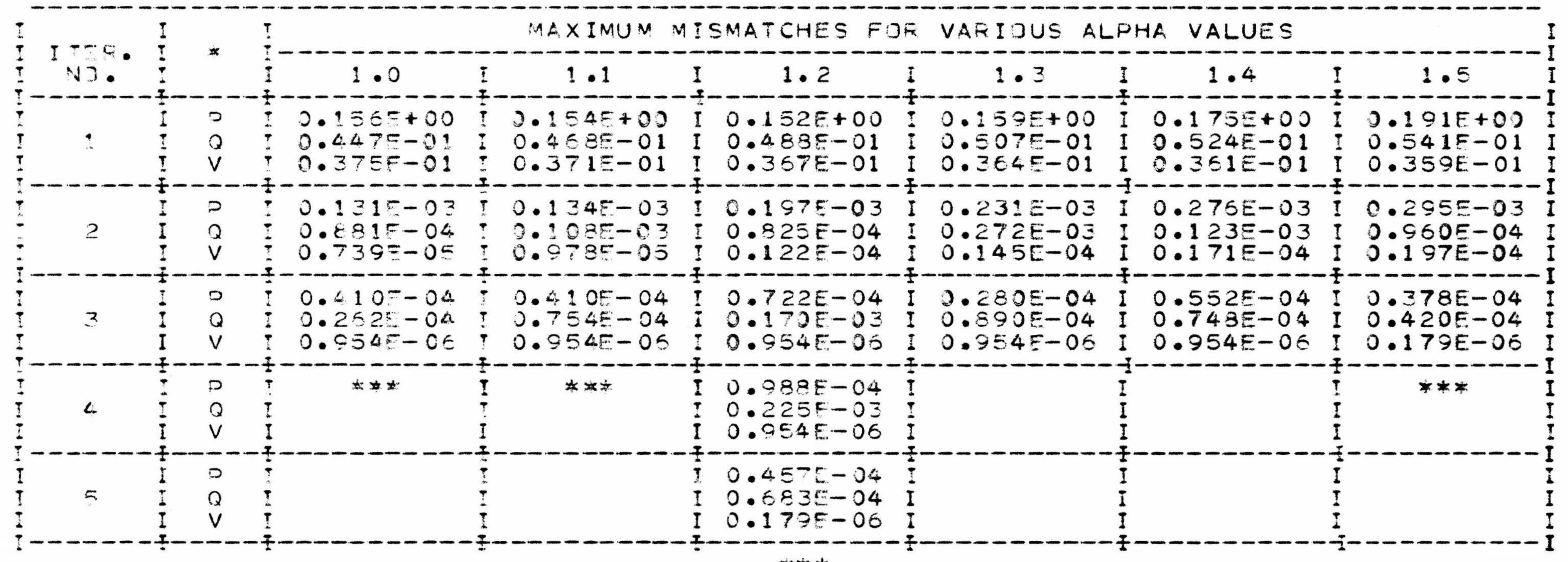

\#*

* * - ONLY ONE-HALF OF THE LAST ITSRATION WAS PEFFOFMED 
APLE GA ( CONTINUEO )

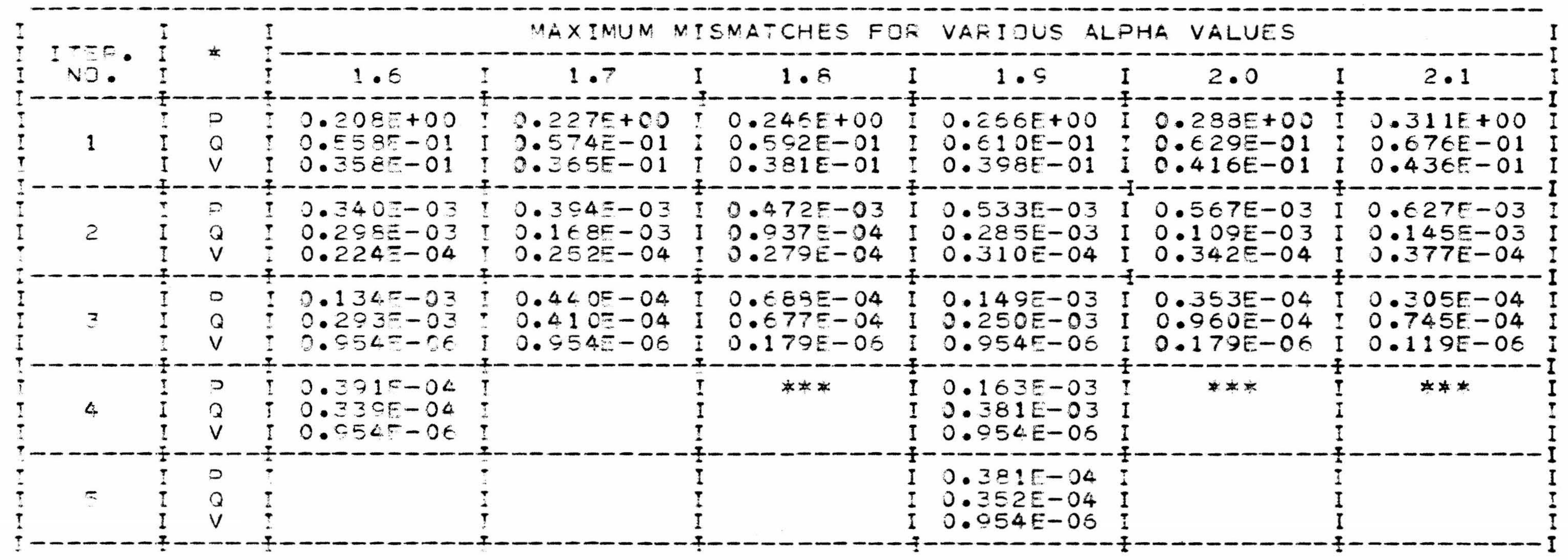

* - ONLY UNF-HALF OF THE LAST ITEFATION WAS PERFOFMED 
TAZLE GS: MAXTMUM PER UNIT MISMATGHES AFTEF EACH ITERATION FJR THE 5-3US (NO VOLTAGE DONTFOLLEL BUSFS) SYSTEM

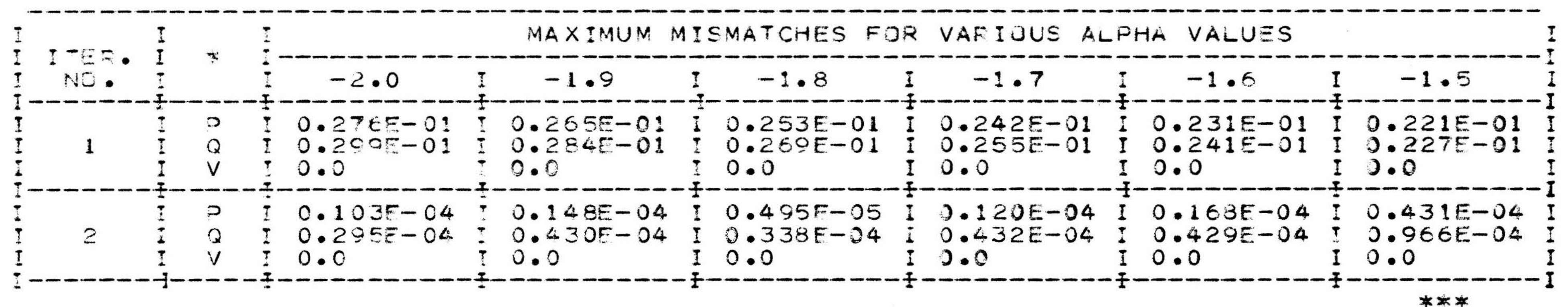

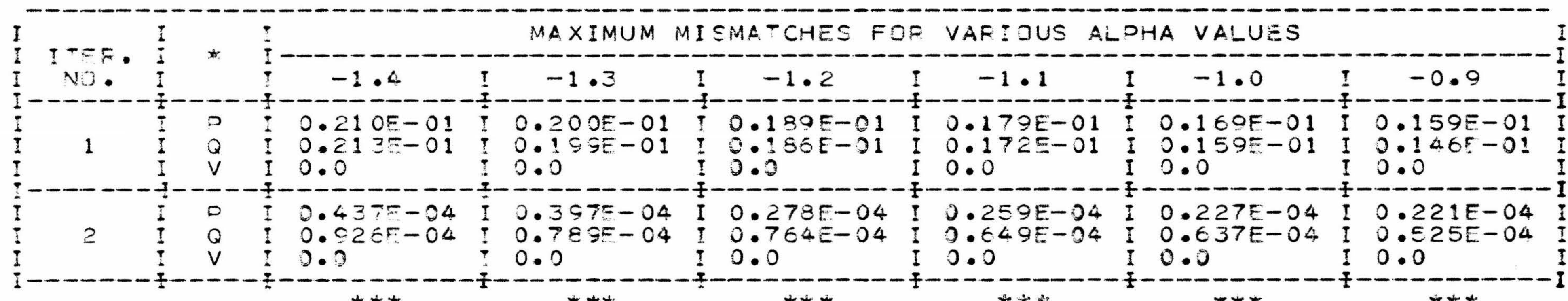

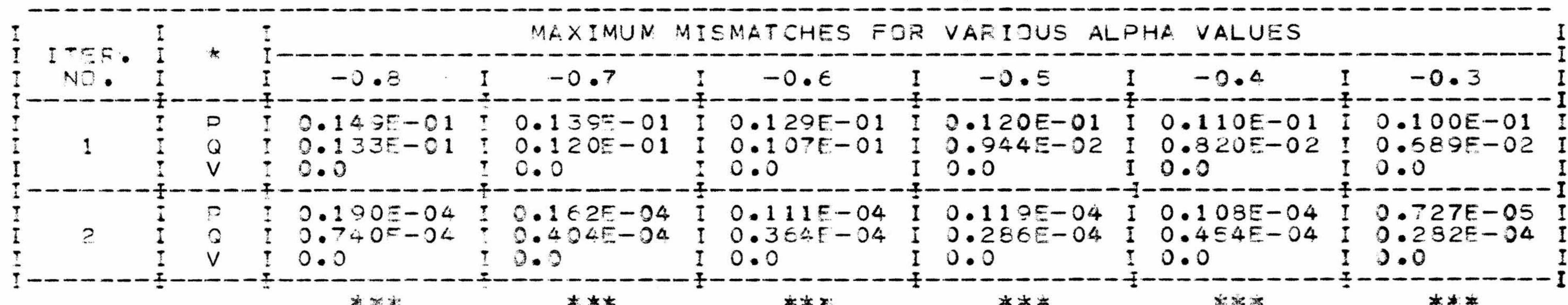




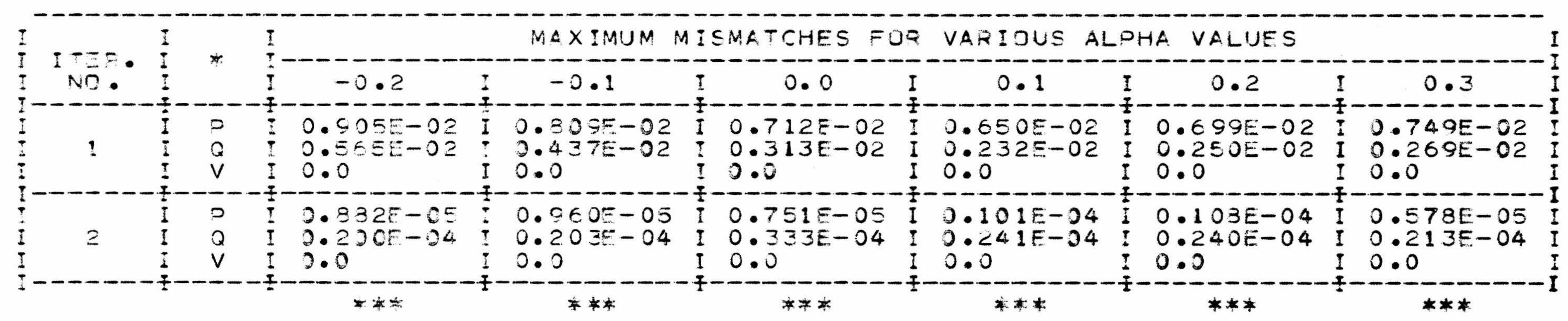

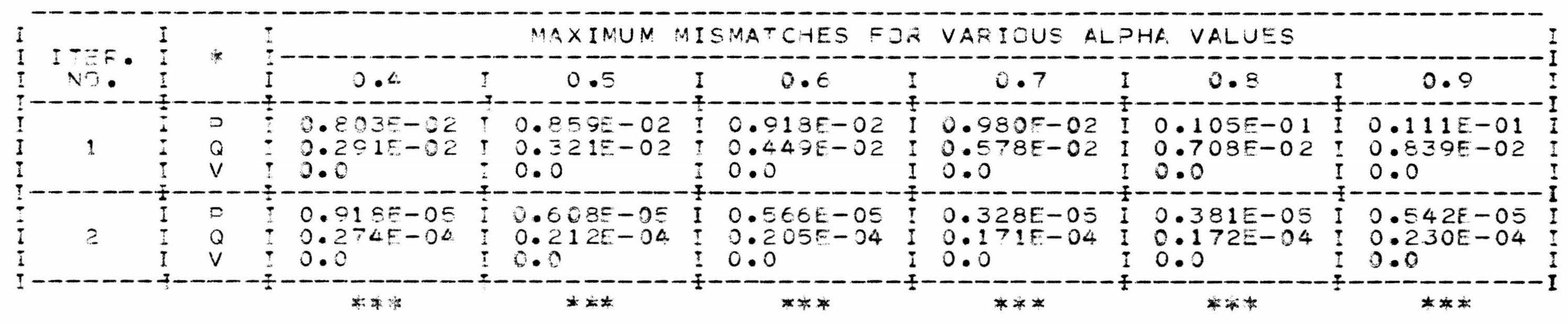

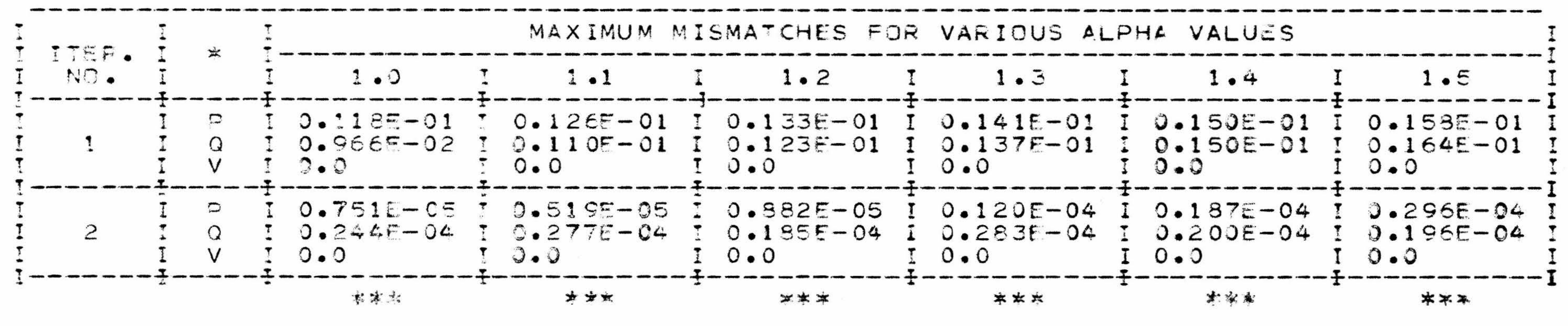


TAELF GS ( CONTINUEC)

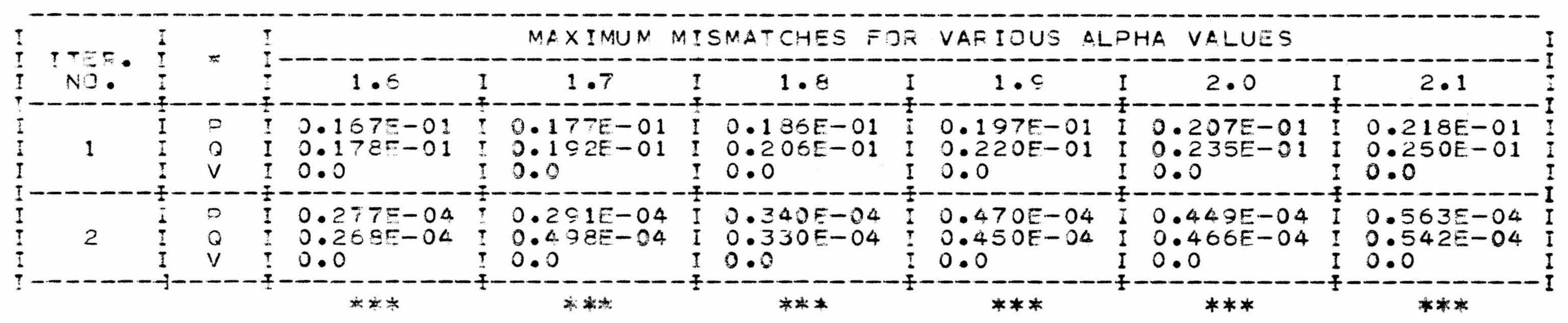


TAELE GS: MEXTMUM PEA UPIT MISMATEHES AF-EA EACH ITEFATION FOF THE 57-BUS INO VOLTAGE

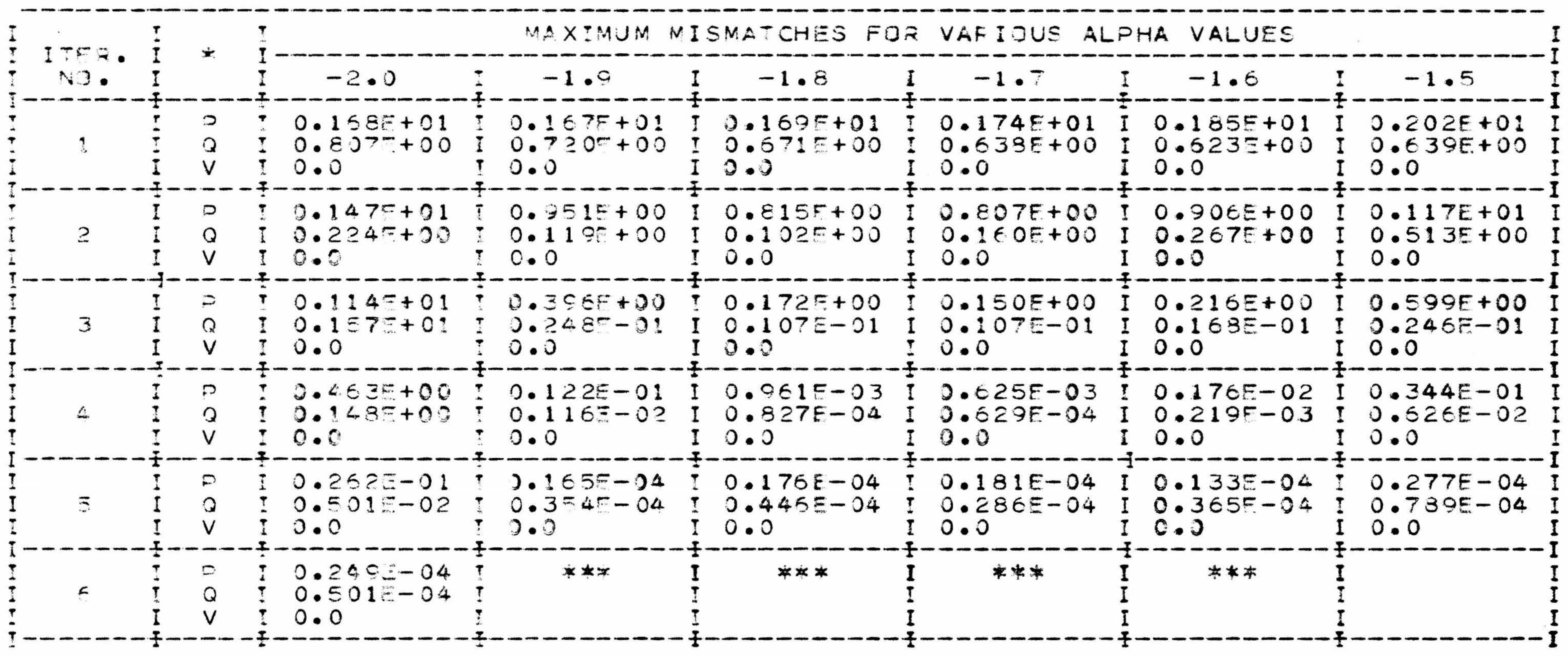

* * - onily one-half ge the last itgation was deffofimed 


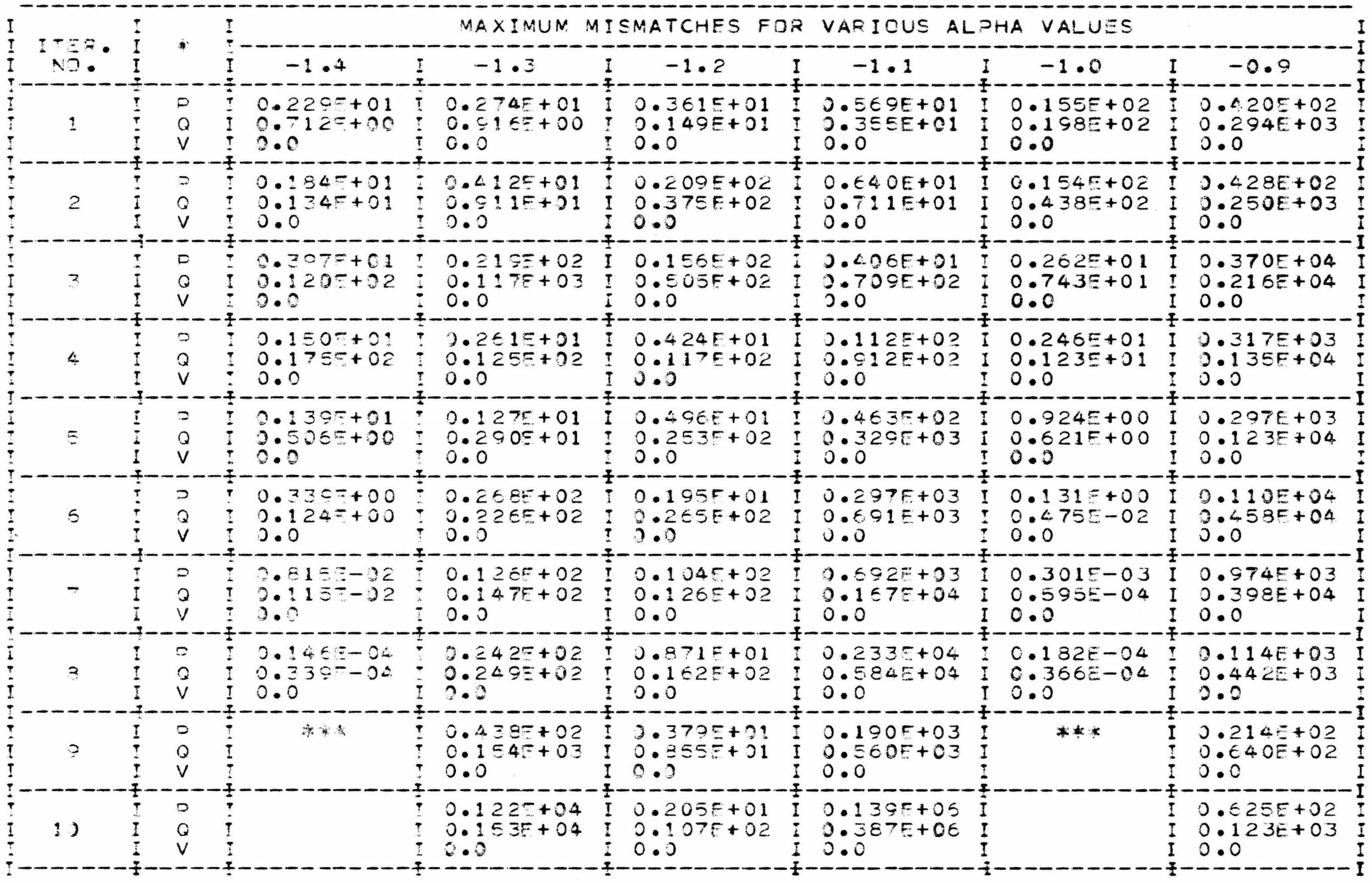




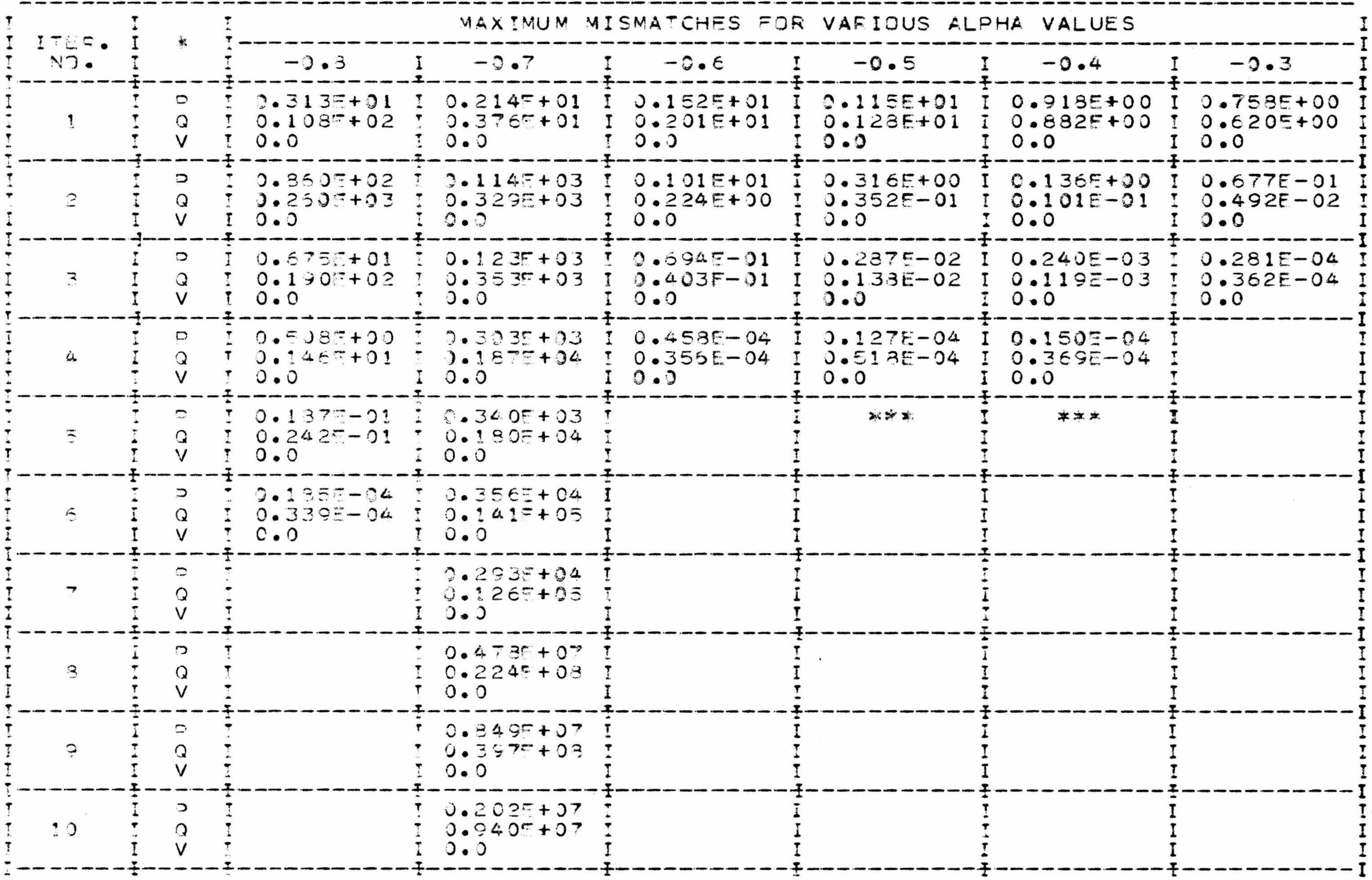


- A.ZLE GS ( CONTINUED)

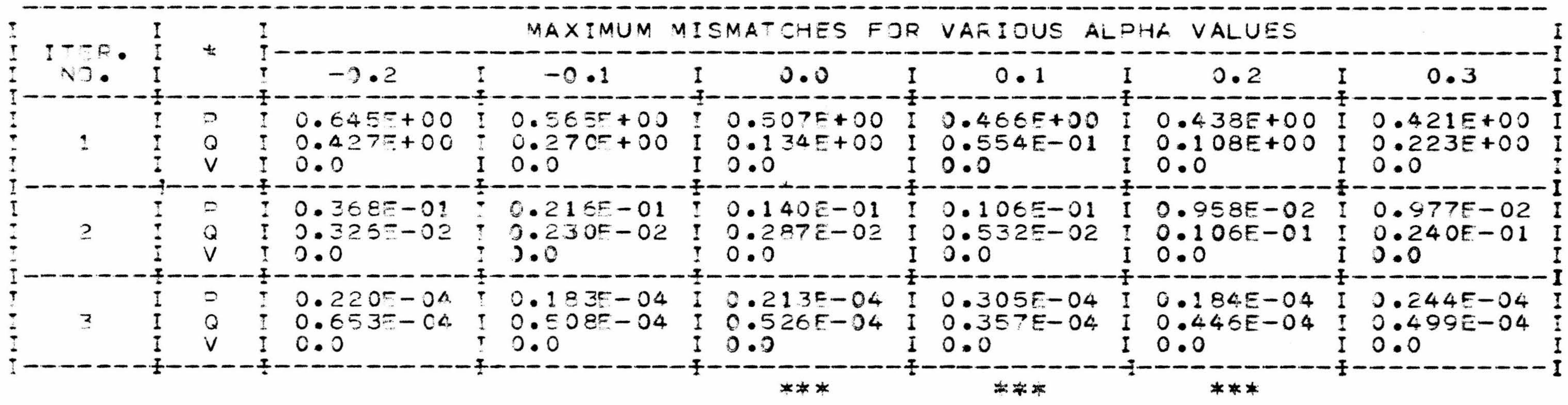

* * - TLY ONE-HALF OF THE LAST ITEFATION WAS PEFFORMEC 


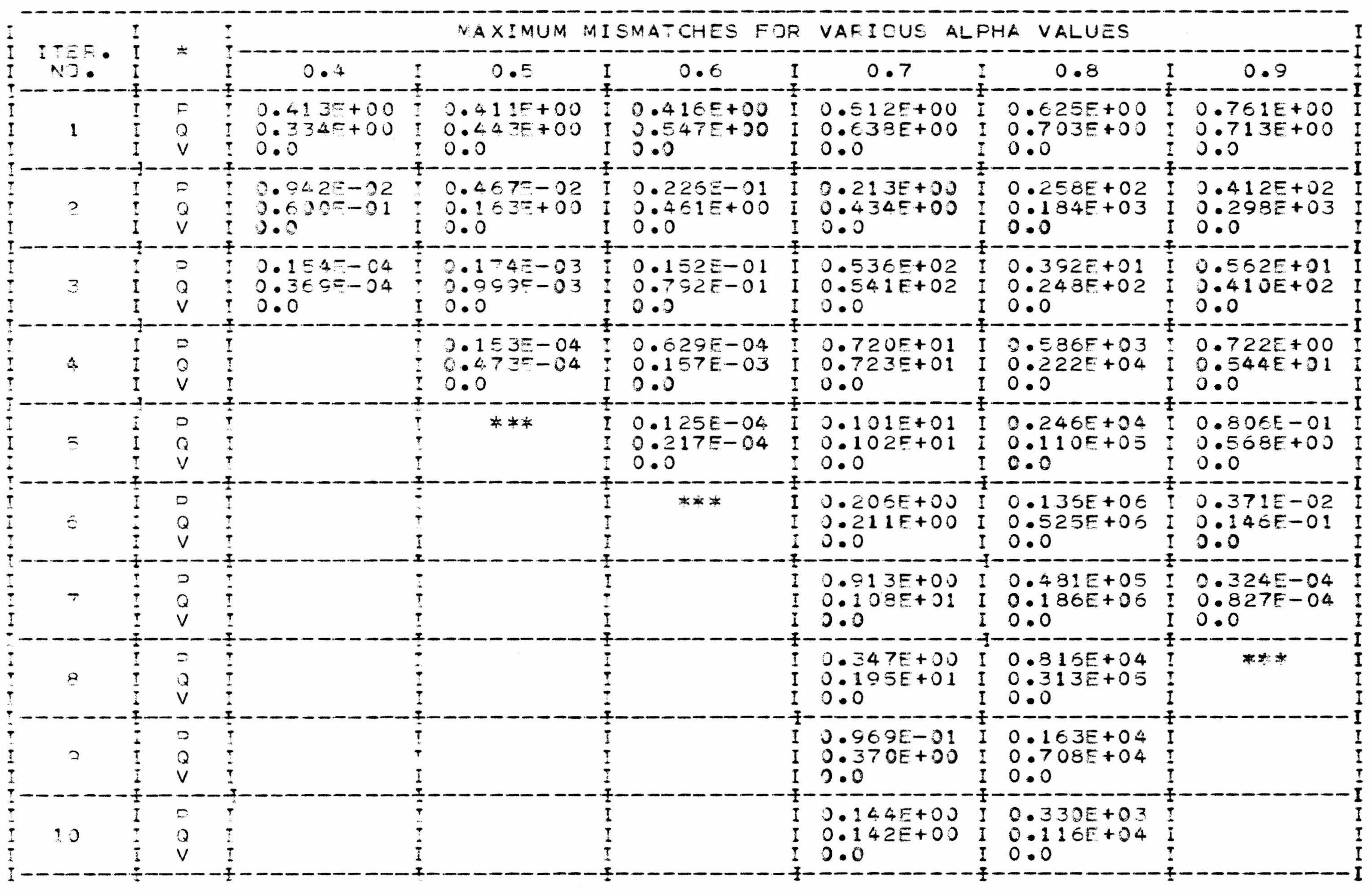




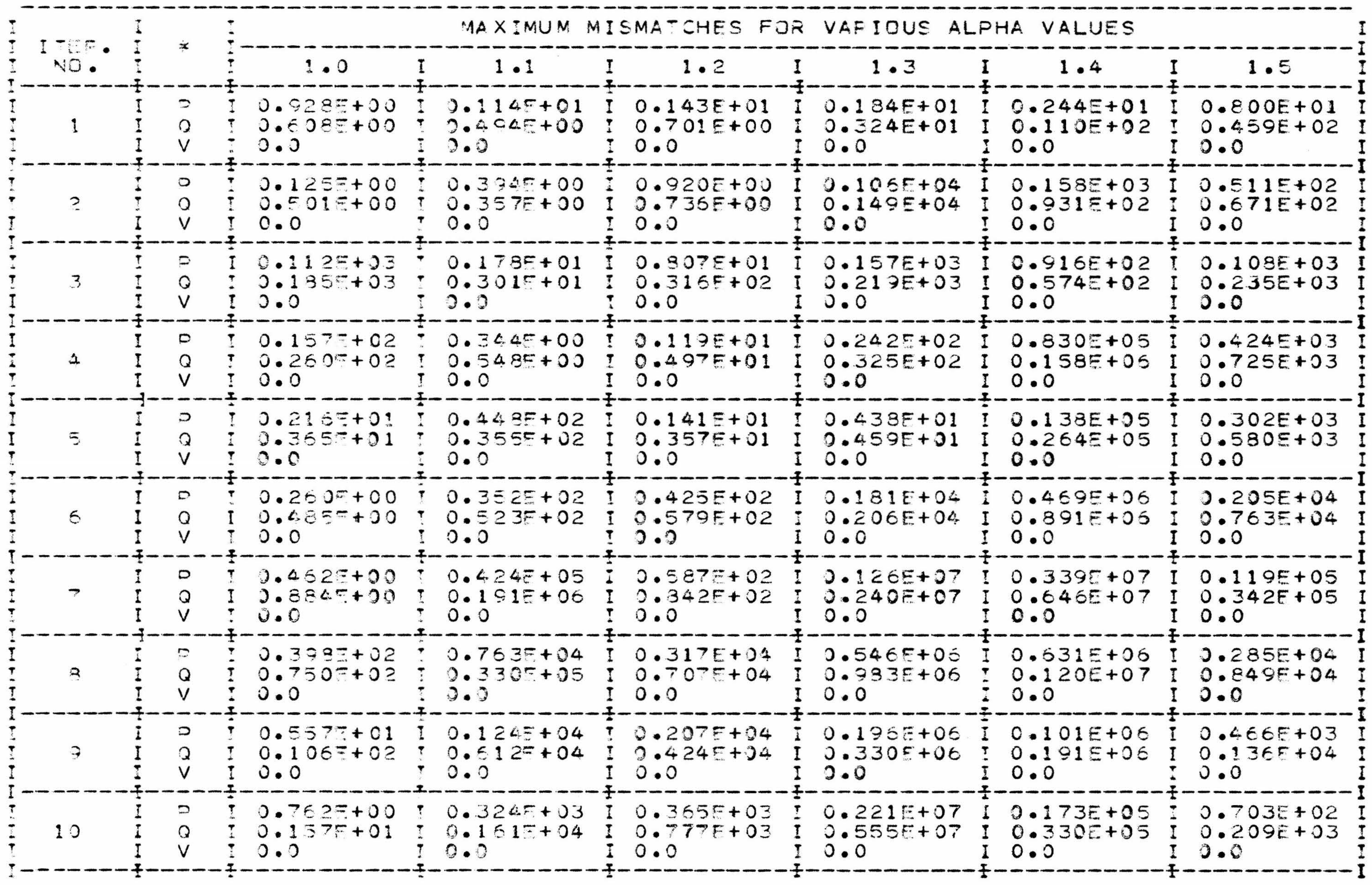


TAELE GE ( CRATTMED)

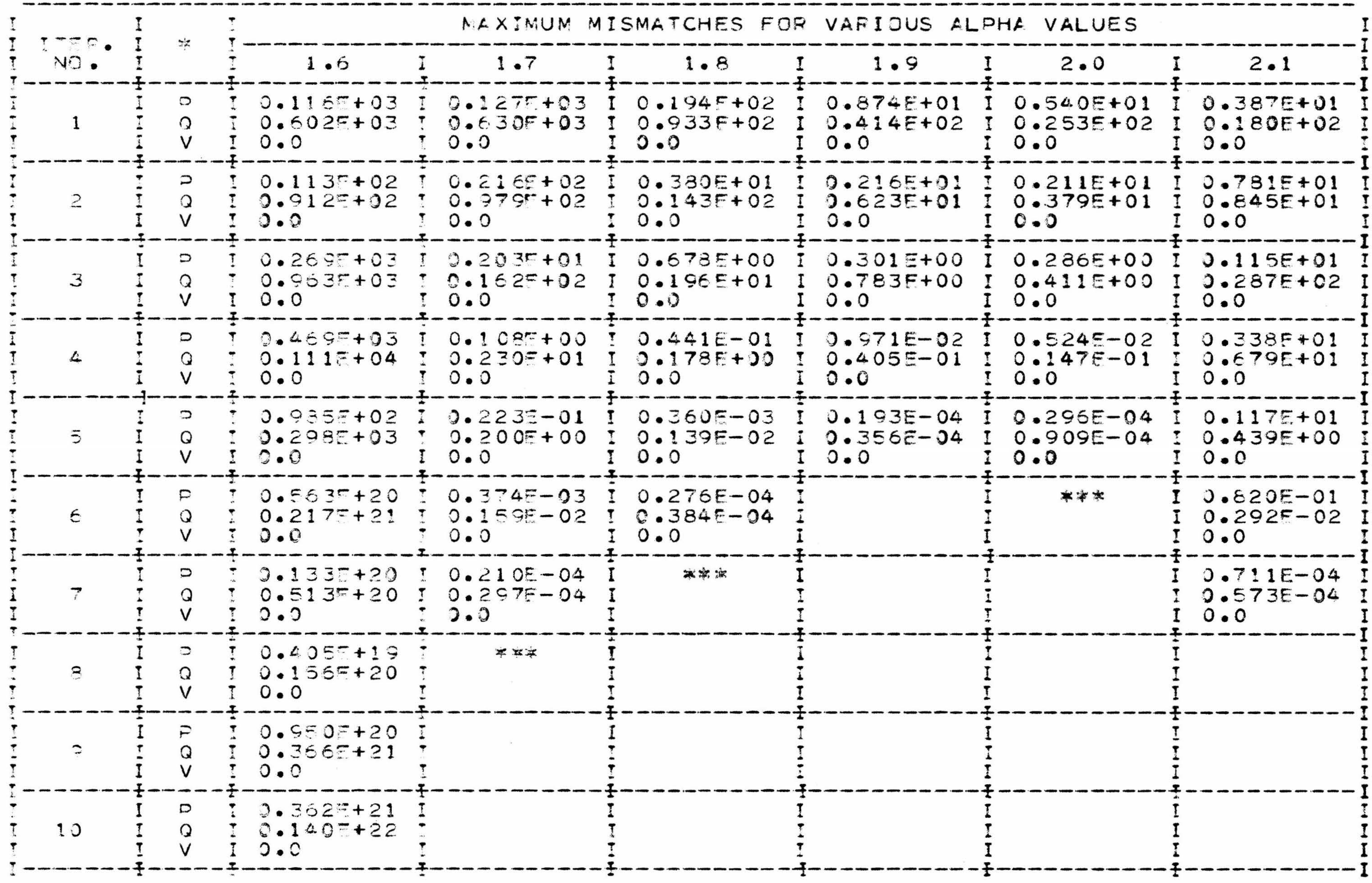


-AELE GT: MAXIMUM PEQ UMIT MISMATCHES LFTFF EACH ITESATICN FOA THE 1IB-BUS INO VOLTAGCONTILLO BUSES) SYSTEM

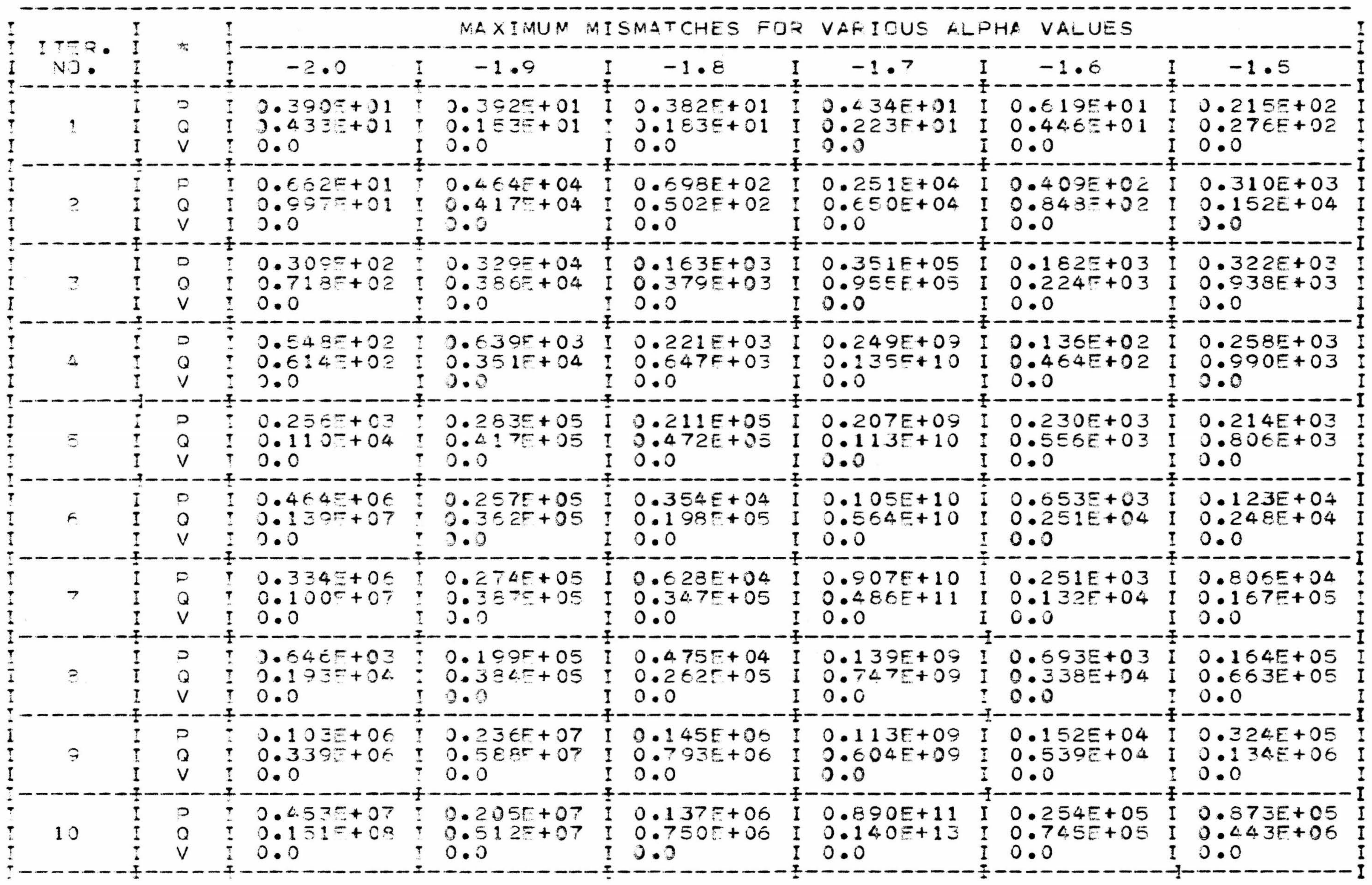


-aEle GT ( GONTtNuedo)

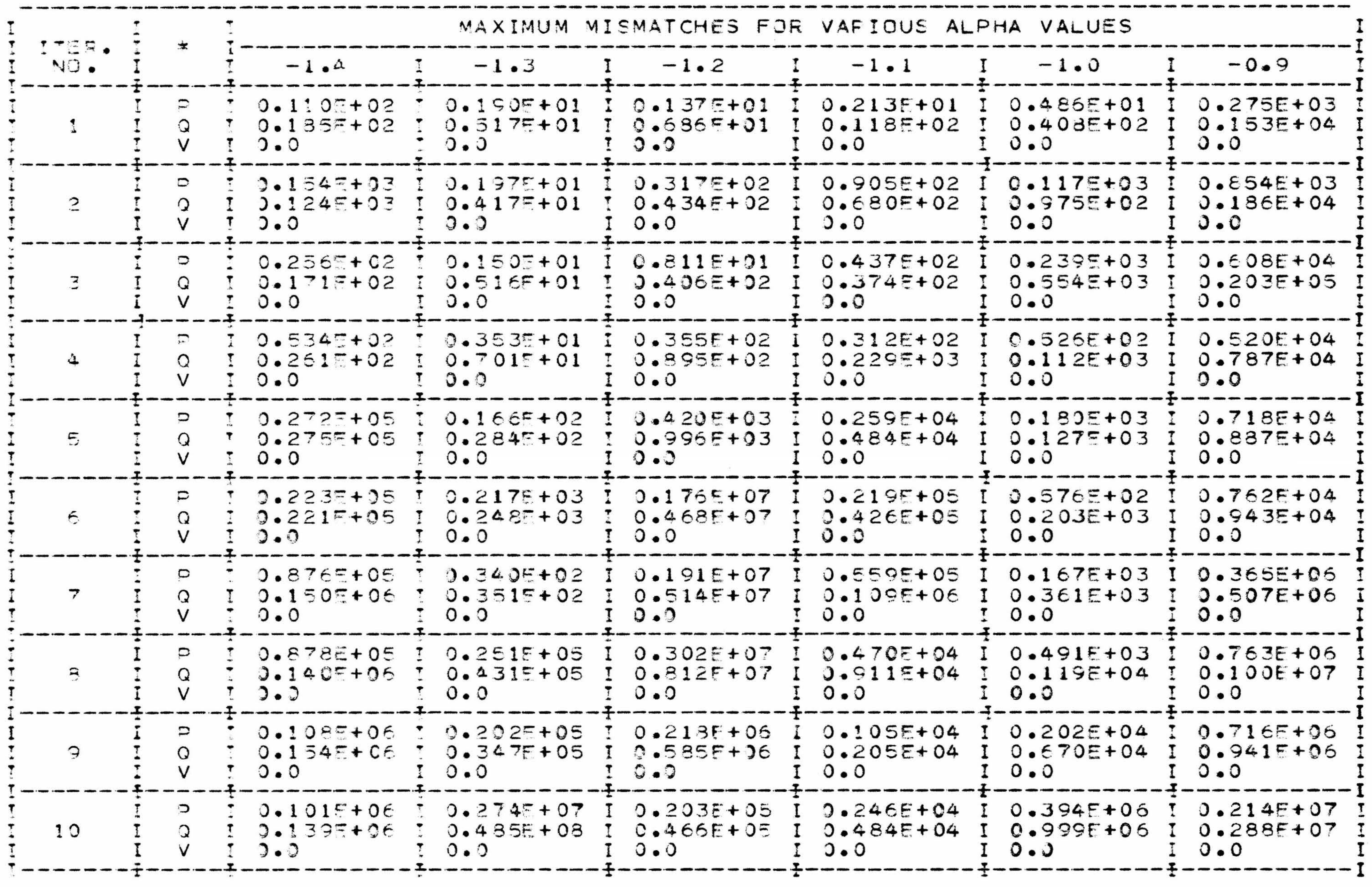




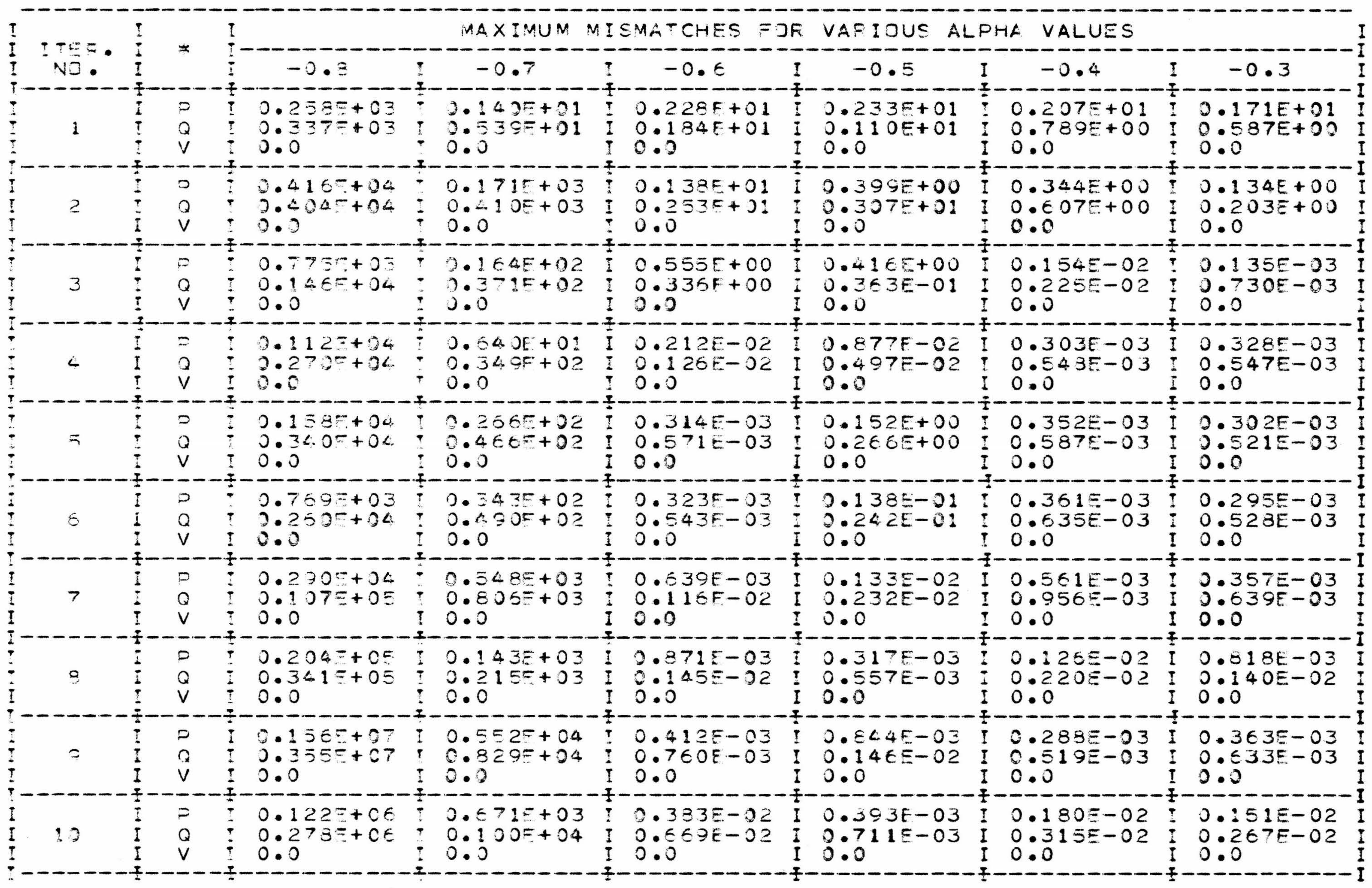




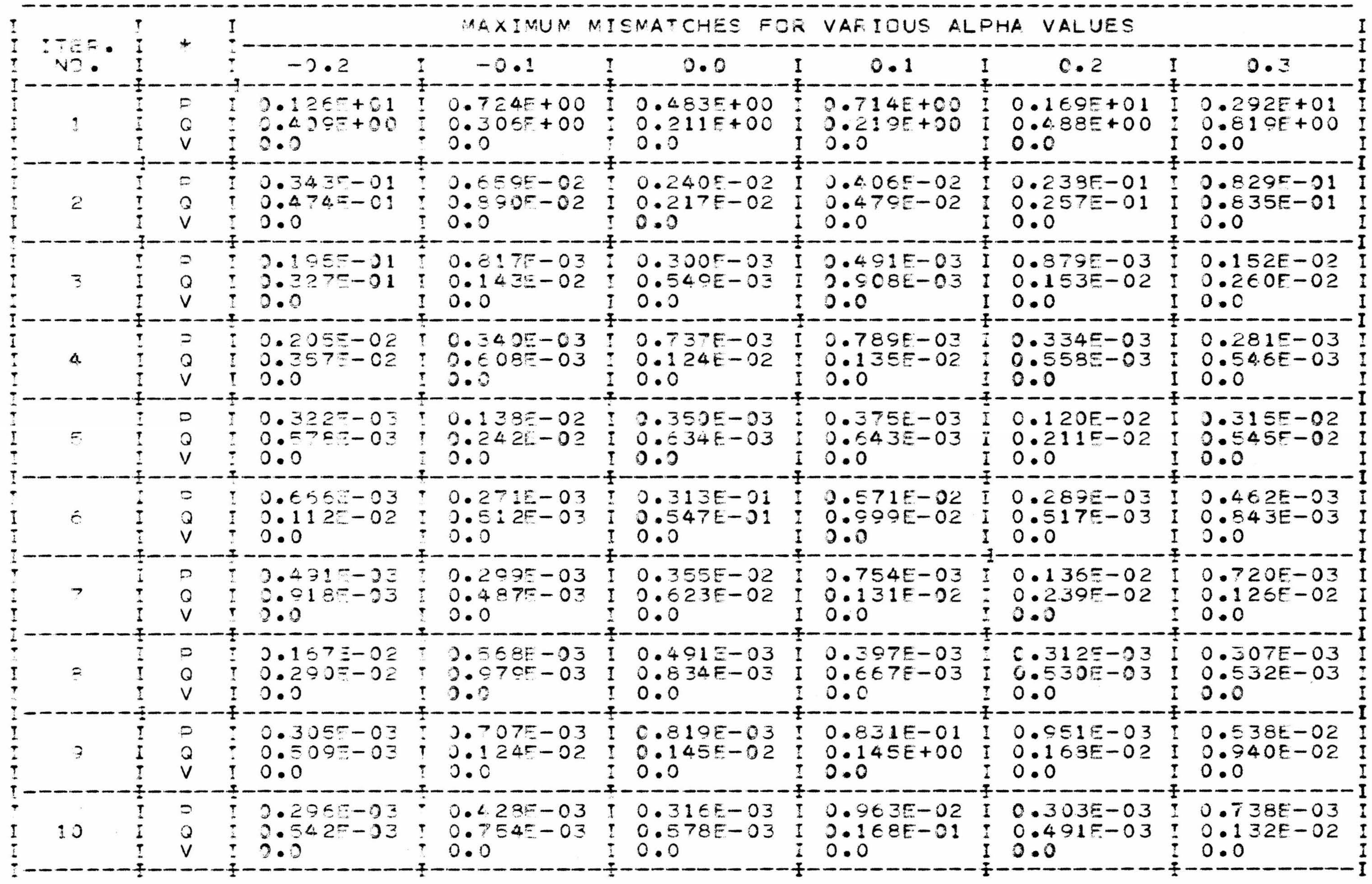




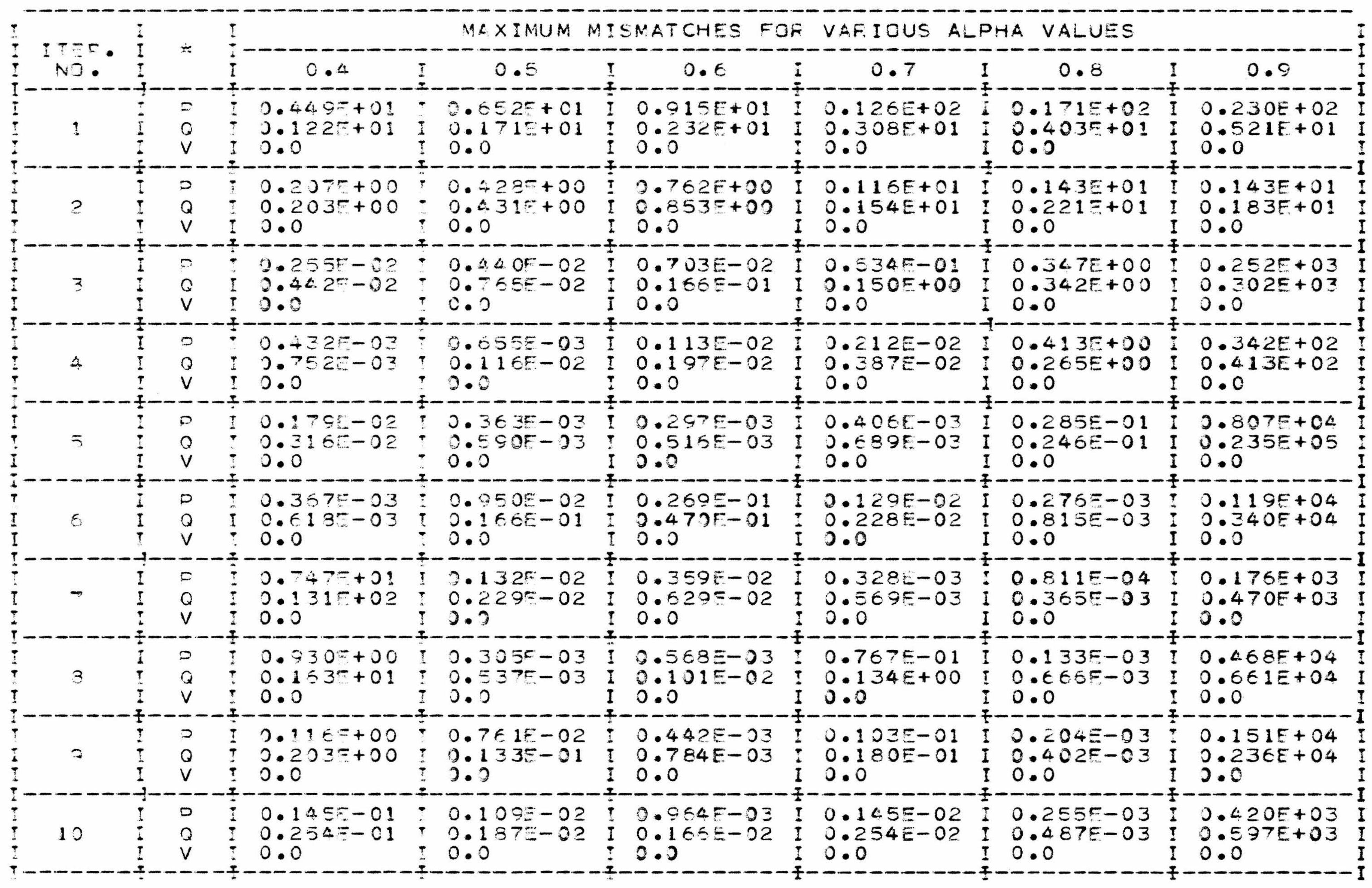




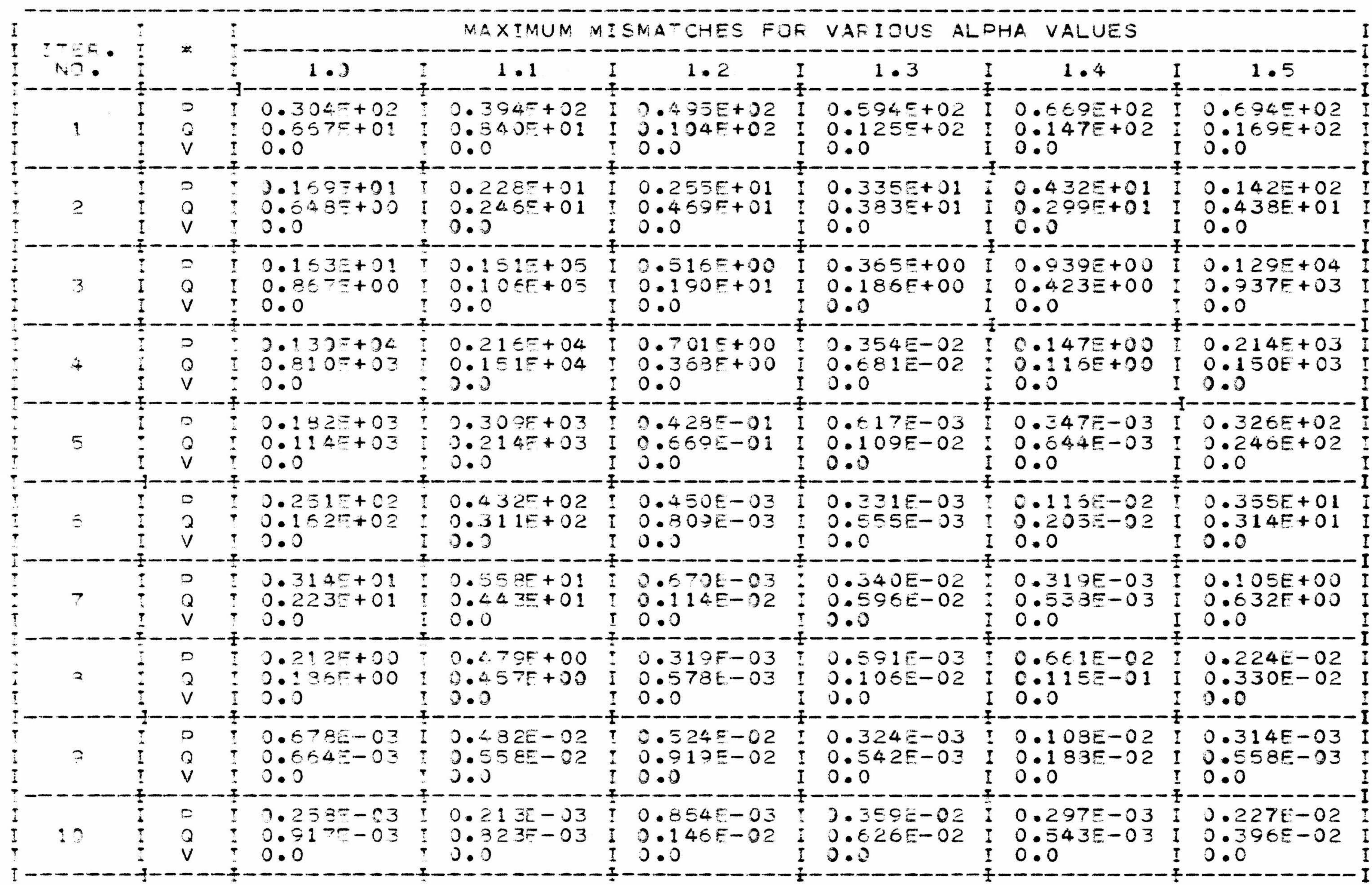




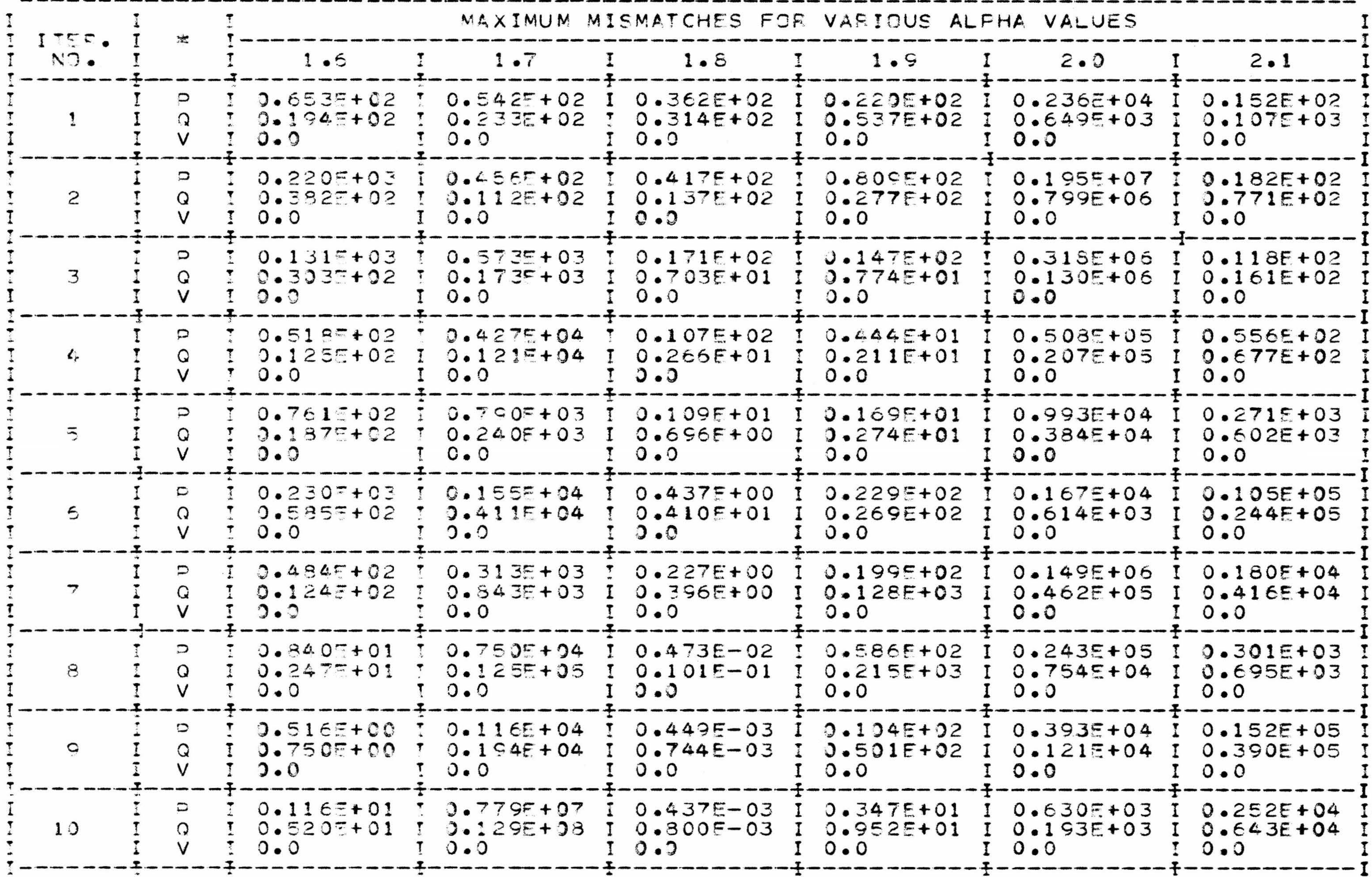




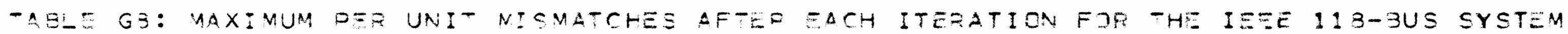

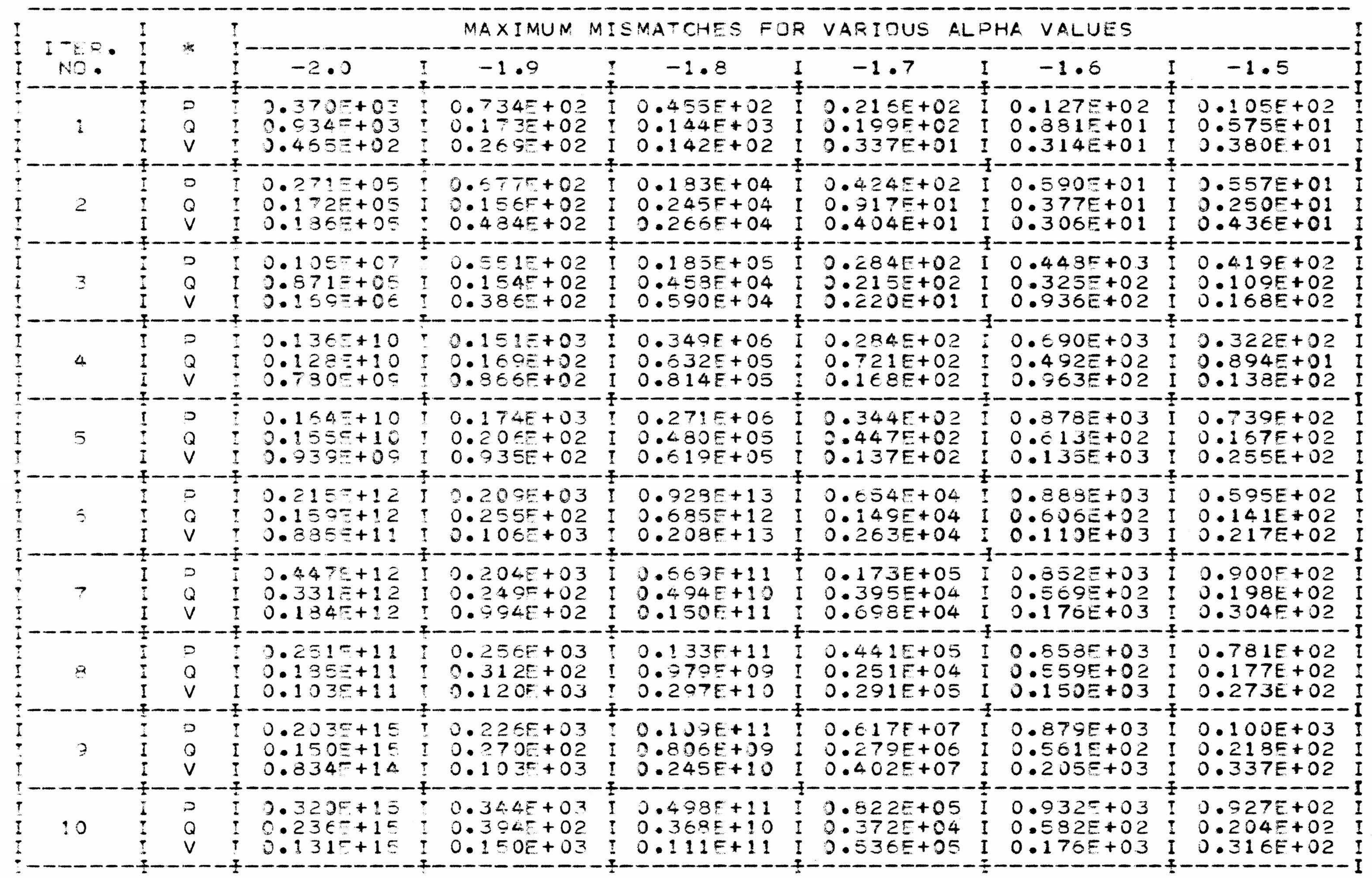

* * ONLY ONE-HQLF TF THE LAST ITERATION WAS PEFFOPMEO 


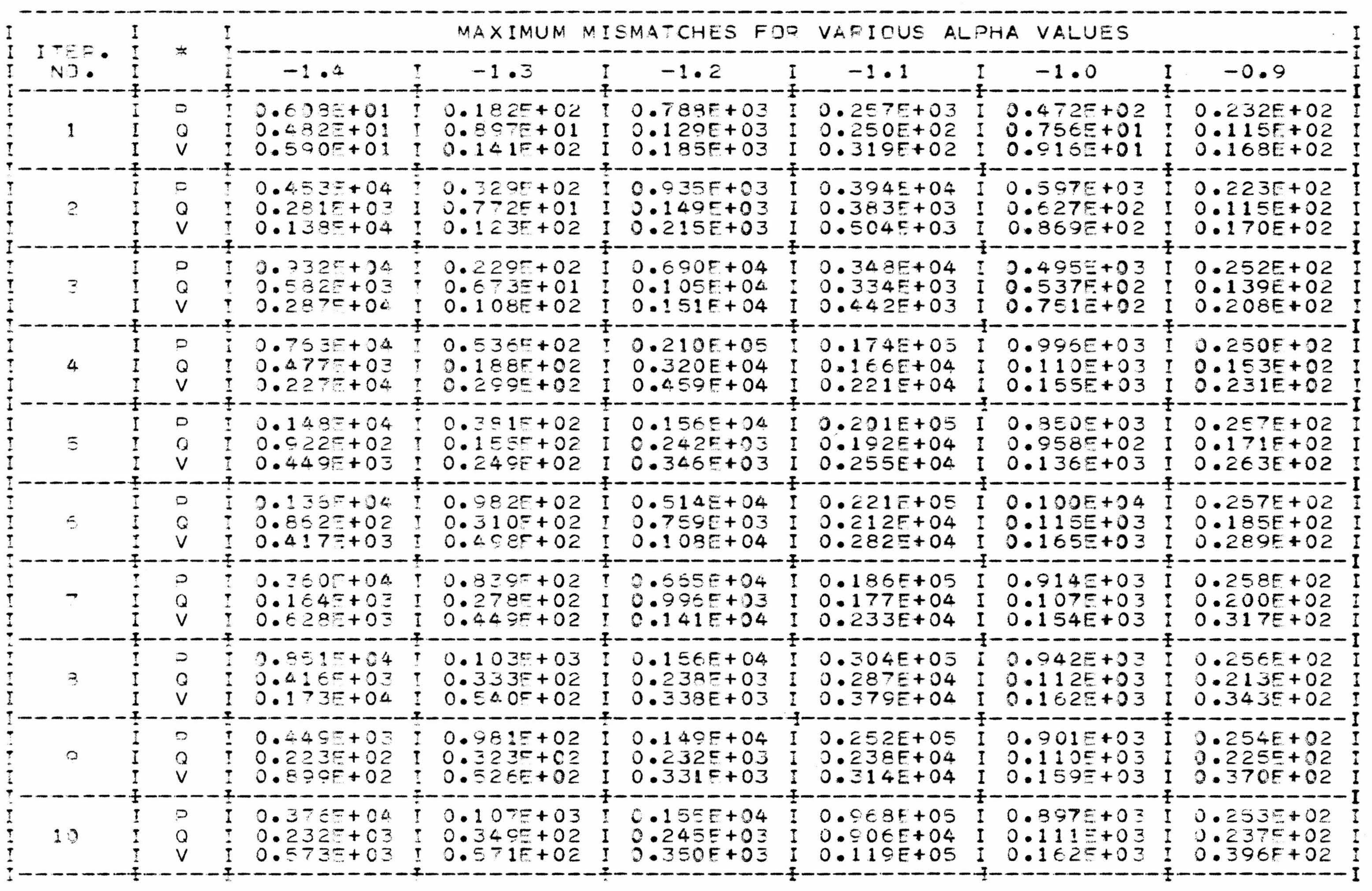




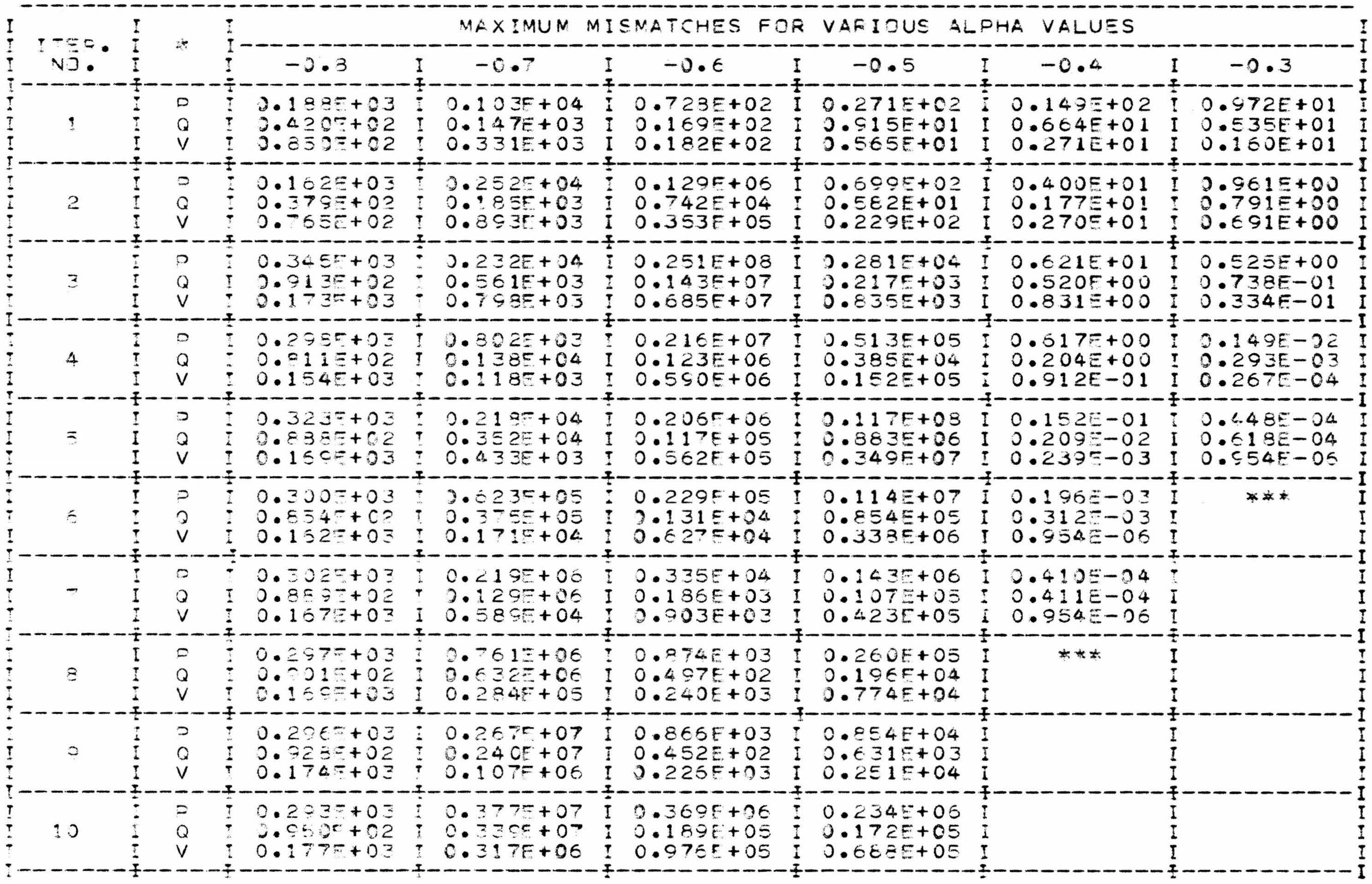




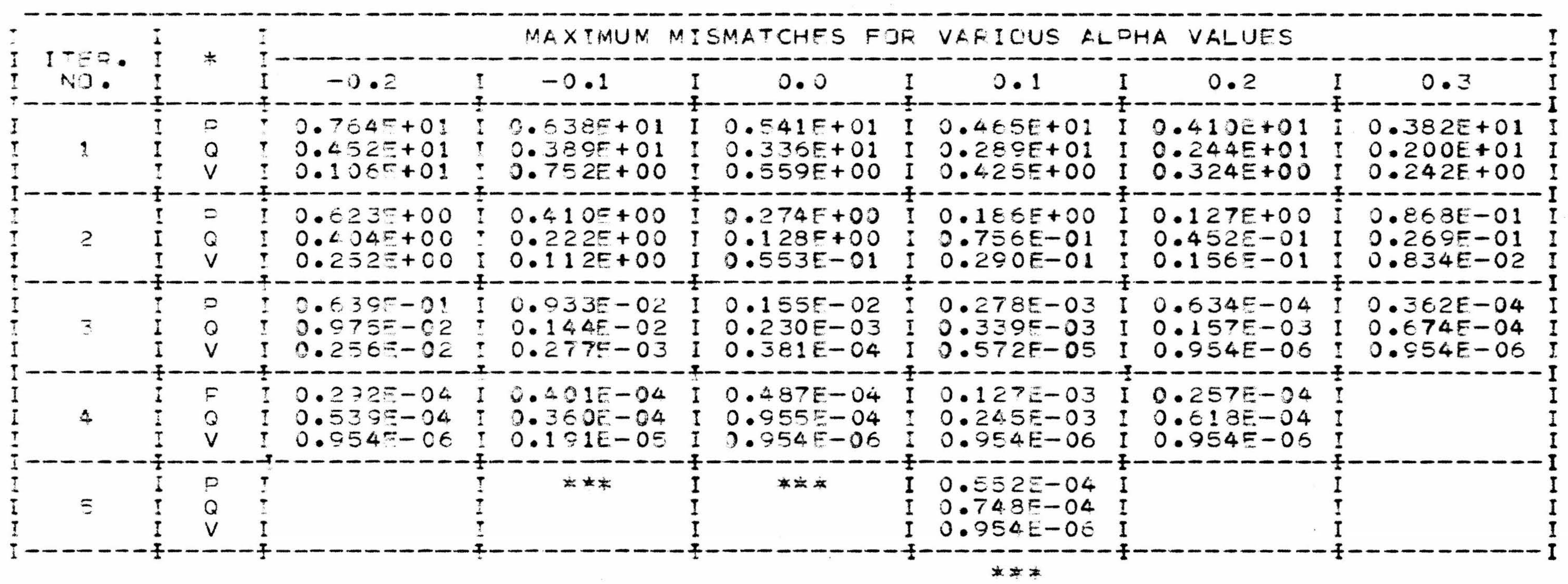

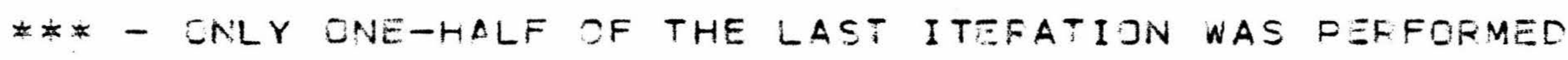




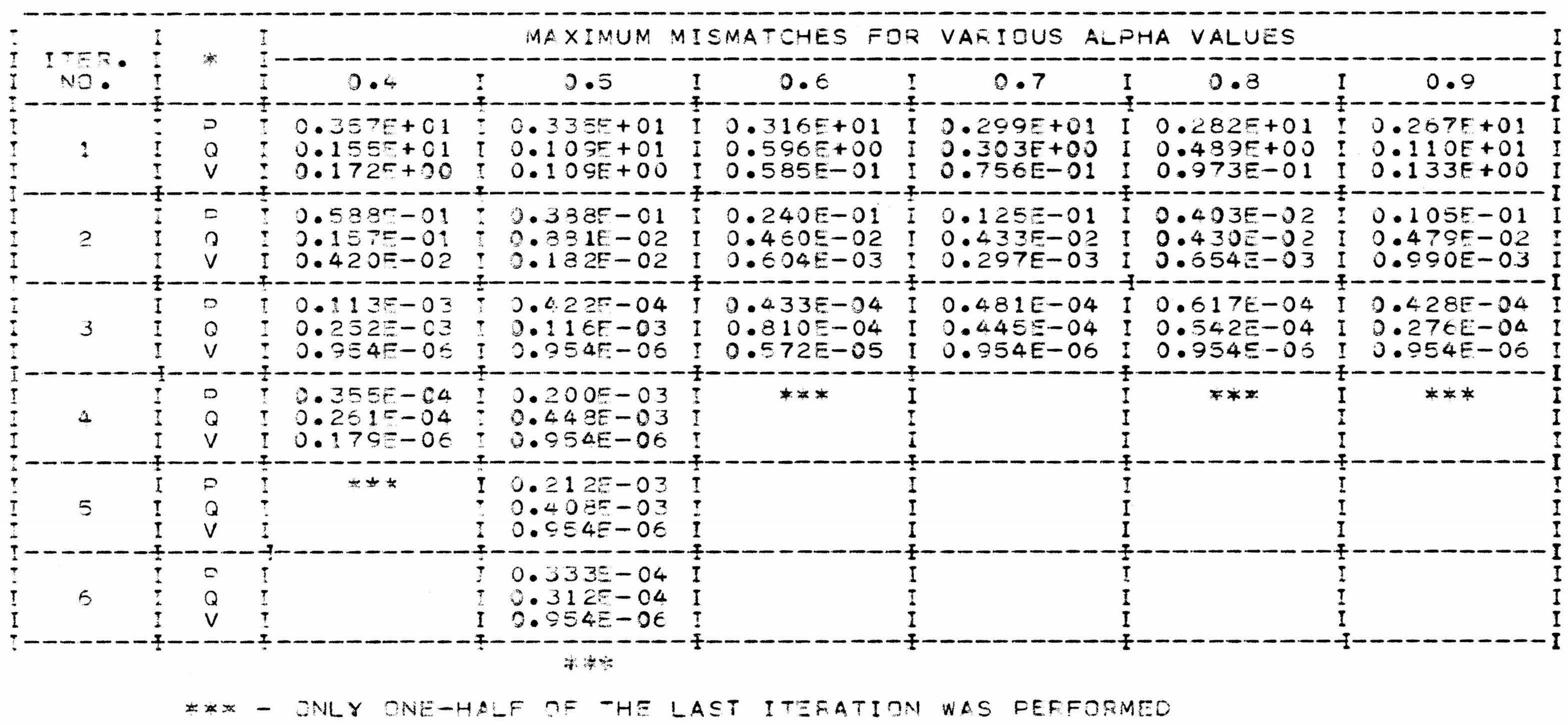




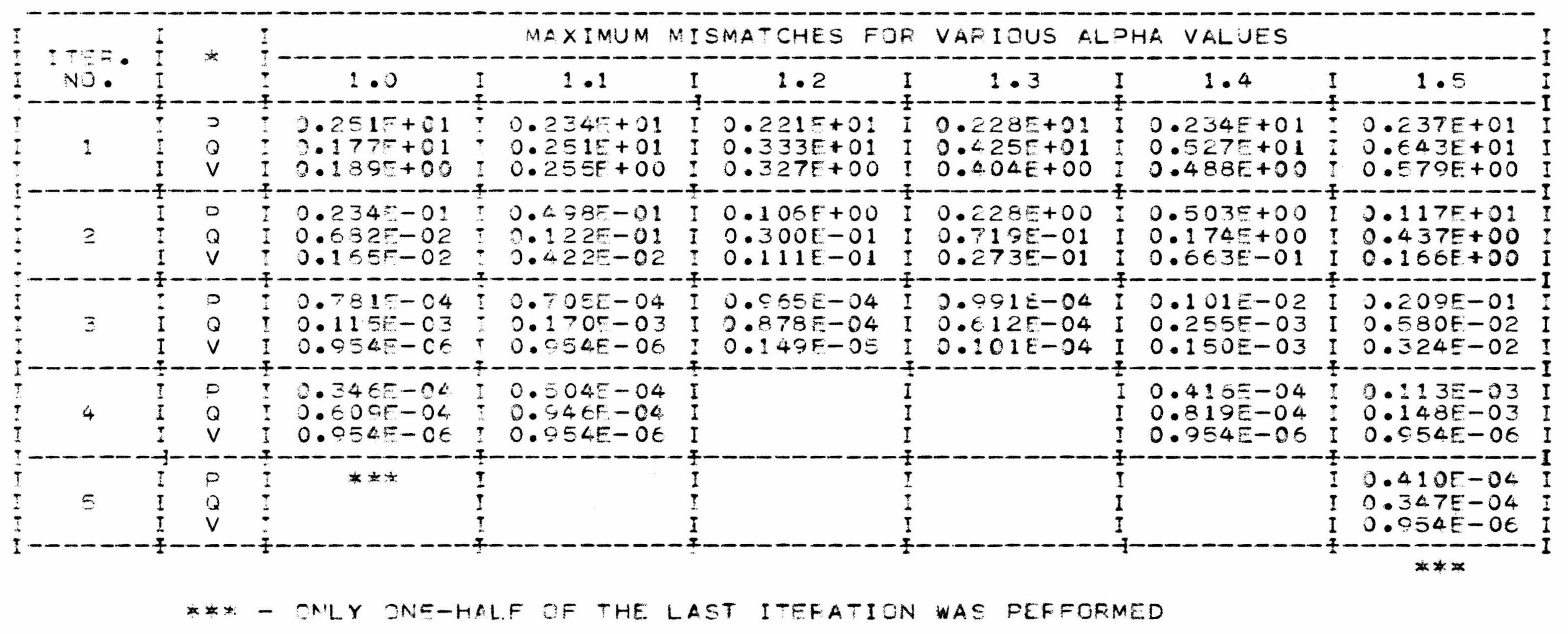




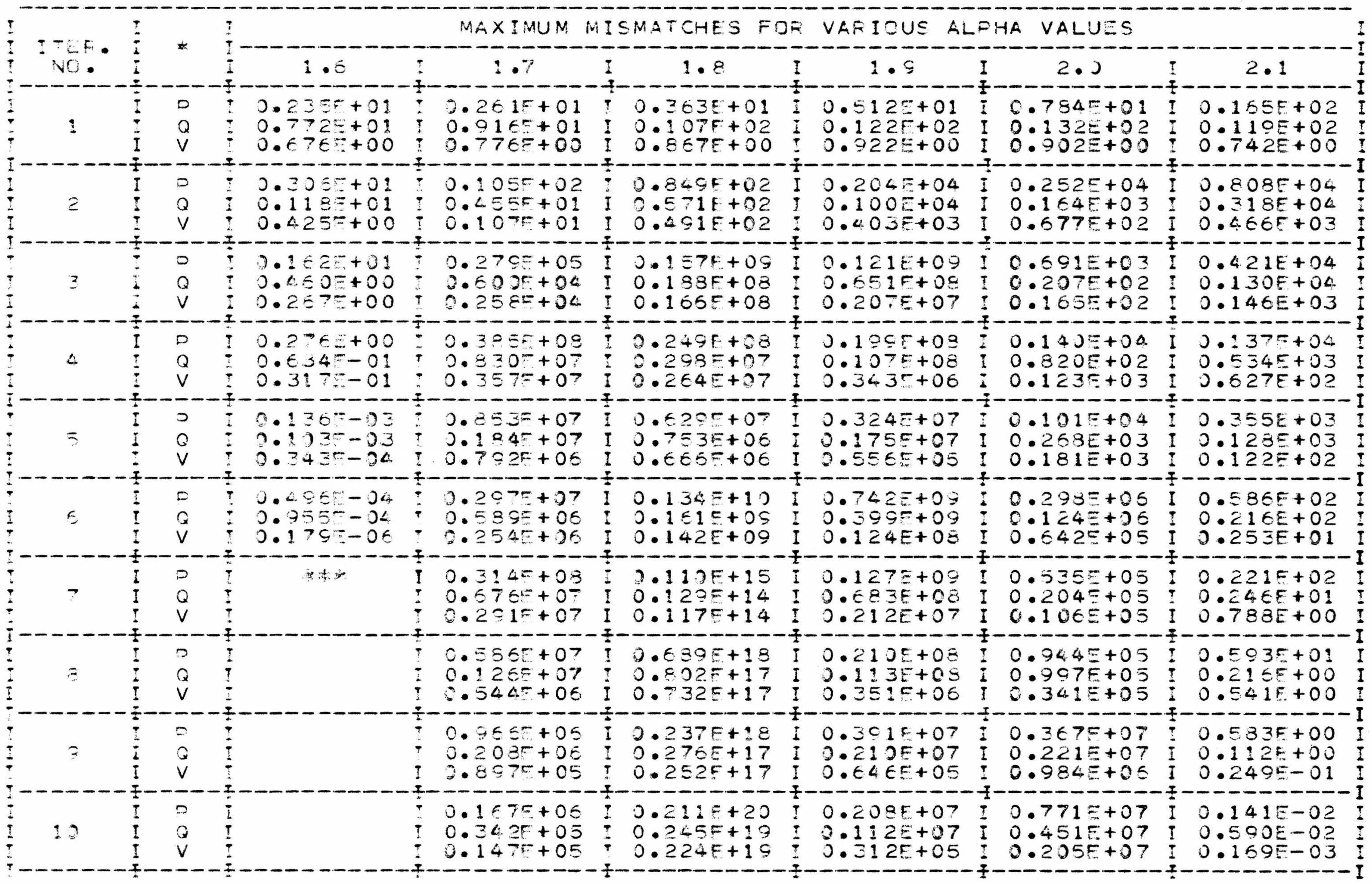







